\title{
Food and fluid related aspects in highly trained athletes
}

Citation for published version (APA):

Brouns, F. J. P. H. (1988). Food and fluid related aspects in highly trained athletes. [Doctoral Thesis, Maastricht University]. De Vrieseborch. https://doi.org/10.26481/dis.19880617fb

Document status and date:

Published: 01/01/1988

DOI:

10.26481/dis. $19880617 \mathrm{fb}$

Document Version:

Publisher's PDF, also known as Version of record

\section{Please check the document version of this publication:}

- A submitted manuscript is the version of the article upon submission and before peer-review. There can be important differences between the submitted version and the official published version of record.

People interested in the research are advised to contact the author for the final version of the publication, or visit the DOI to the publisher's website.

- The final author version and the galley proof are versions of the publication after peer review.

- The final published version features the final layout of the paper including the volume, issue and page numbers.

Link to publication

\footnotetext{
General rights rights.

- You may freely distribute the URL identifying the publication in the public portal. please follow below link for the End User Agreement:

www.umlib.nl/taverne-license

Take down policy

If you believe that this document breaches copyright please contact us at:

repository@maastrichtuniversity.nl

providing details and we will investigate your claim.
}

Copyright and moral rights for the publications made accessible in the public portal are retained by the authors and/or other copyright owners and it is a condition of accessing publications that users recognise and abide by the legal requirements associated with these

- Users may download and print one copy of any publication from the public portal for the purpose of private study or research.

- You may not further distribute the material or use it for any profit-making activity or commercial gain

If the publication is distributed under the terms of Article $25 \mathrm{fa}$ of the Dutch Copyright Act, indicated by the "Taverne" license above, 


\section{Sportwetenschappelijke Onderzoekingen 15}

Food and fluid related aspects in highly trained athletes 


\section{Food and fluid related aspects in highly trained athletes}

\section{PROEFSCHRIFT}

ter verkrijging van de graad van doctor

aan de Rijksuniversiteit Limburg te Maastricht, op gezag van de Rector Magnificus Prof. Dr. F.I.M. Bonke, volgens het besluit van het College van Dekanen, in het openbaar te verdedigen op vrijdag 17 juni 1988 om 14.00 uur

door

Fredericus Johannes Petrus Henricus Brouns geboren te Amsterdam in 1950

Uitgeverij De Vrieseborch - Haarlem 
Promotores:

Prof. Dr. F. ten Hoor

Prof. Dr. Ir. W.H.M. Saris

Leden van de beoordelingscommissie:

Prof. Dr. M. Hebbelinck, Brussel

Prof. Dr. E.A. Newsholme, Oxford

Prof. Dr. C. Williams, Loughborough

Prof. Dr. F. Bosman

Prof. Dr. Ir. R.J.J. Hermus

Prof. Dr. R.S. Reneman

The work presented in this study was done at the nutrition research center of the State University of Limburg, within the framework of the project nutrition, section energy exchange and body composition and was supported by a research grant from Wander Itd Berne, Switzerland. 


\section{To my parents}

In memory of Lars Hermansen 
CIP-GEGEVENS KONINKLIJKE B】BLIOTHEEK, DEN HAAG

Brouns, Fredericus Johannes Petrus Henricus

Food and fluid related aspects in highly trained athletes

/ Fredericus Johannes Petrus Henricus Brouns. - Haarlem :

De Vrieseborch. - III. - (Sportwetenschappelijke

onderzoekingen ; 15)

Proefschrift Maastricht. - Met lit. opg.

ISBN 90-6076-291-6

SISO 617.3 UDC $[613.2 ; 796](043.3)$ NUGI 468

Trefw.: sport en voeding.

(c) 1988 Fred Brouns

Opmak en fotografie Fred Brouns

No part of this book may be reproduced in any form, by print, photoprint, microfilm or any other means, without written permission from B.V. Uitgeverij De Vrieseborch

Jacobijmestratat 5

2011 TG Haarlem

the Netherlands

ISBN 9060762916 
CONTENT

Introduction

Chapter I Dietary problems in the case of strenuous exertion.

Part 1: A literature review

Part 2: The top athletes menu, nutrient dense enough?

Chapter II Eating, drinking and cycling, a controlled Tour de France simulation study, part 1.

Chapter III Eating, drinking and cycling, a controlled Tour de France simulation study.

Part 2: the effect of diet manipulation.

Chapter IV The effect of diet manipulation and repeated sustained exercise on nitrogen balance, a controlled Tour de France simulation study, part 3 .

Chapter V Metabolic changes induced by repeated sustained exhaustive cycling and diet manipulation.

Chapter VI The effect of carbohydrate intake during warming-up on the regulation of blood glucose during exercise.

Chapter VII Abdominal complaints and gastro-intestinal function during long-lasting exercise.

Chapter VIII General discussion and final conclusions.

Algemene discussie en konklusies.

Nawoord

Parts of the present work have already been published.

Chapter I : J. Sports Med. 26, 306-318; 1986.

Chapter VII: Int. J. Sports Med. 8, 175-189; 1987. 


\section{ABBREVIATIONS}

Aceto $\mathrm{A}$ aceto acetate.

ACTH adrenocorticotropic hormone

AM morning

AMP adenosine monophosphate

ATP adenosine triphosphate

BHBA beta hydroxibutyric acid

BW body weight

CCK cholecystokinine

$\mathrm{CHO}$ carbohydrate

$\Delta E$ difference between energy intake and energy expenditure

EB energy balance

EE energy expenditure

El energy intake

en $\% \quad \%$ of total energy

FFA free fatty acids

FM normal diet composed of carbohydrate rich foodstuffs and supplemented with a beverage containing $50 \%$ of fructose and $50 \%$ of maltodextrin

g gram

$\mathrm{mg} \quad$ milligram $\left(10^{-3} \mathrm{gram}\right)$

ng nanogram $\left(10^{-9} \mathrm{gram}\right)$

$\mathrm{pg} \quad$ picogram $\left(10^{-12} \mathrm{gram}\right)$

$\mu \mathrm{g}$ microgram ( $10^{-6}$ gram) (mcg)

GE gastric emplying

GI gastro intestinall

GIP gastro intestinal peptide

${ }^{3} \mathrm{H}_{2} \mathrm{O}$ water labeled with Tritium

HPLC high pressure liquid chromatography

. $\mathrm{kg}^{-1}$ perkilogram

kcal killocalorie.

$\mathrm{kJ} \quad$ kilojoule

I liter

.$^{-1} \quad$ per liter

Max maximal
Mf nomal diet composed of carbodrate rich foodstuffs and supplement with a beverage containing a high fraction of maltodextrin and a low fraction of fructose

min minute

MJ megajoule

$\mathrm{ml} \quad$ milliliter ( $10^{-3}$ liter)

$\mathrm{mmol}$ millimole $\left(10^{-3} \mathrm{~mol}\right)$

$\mathrm{nmol}$ nanomole $\left(10^{-9} \mathrm{~mol}\right)$

pmol picomole $\left(10^{-12} \mathrm{~mol}\right)$

umol micromole $\left(10^{-6} \mathrm{~mol}\right)$

mosm milliosmole

$\mathrm{N}$ normal diet composed of carbohydrate rich foodstuffs

n number

NADH reduced nicotine adenine dinucleotide

$\mathrm{NH}_{3}$ ammonia

Nu urinary nitrogen

PM afternoon

R respiratory quotient

RDA recommended daily allowance

RIA radio immuno assay

SEM standard error of the mean

$t 1 / 2$ hall lime

TG Triacylglycerol

IU international units

$\mathrm{mU}$ milli units

uv ultra violet

$\mathrm{VCO}_{2}$ carbondioxide production (volumertime)

VIP vaso intestinal peptide

$\mathrm{VO}_{2}$ oxygen uptake (volume/time)

vol volume

W Watt

Wmax maximal achieved performance capacity expressed in Watt 


\section{INTRODUCTION}

Nutrition as one of the factors influencing performance has received attention from athletes and their coaches since the classical athletic competitions in Olympia. However, it is only since the last 50 years that scientific studies have been focussed more specifically on the role of nutrients in human performance and physical fitness.

In 1939 Christensen and Hansen observed that a change in the proportions of carbohydrate $(\mathrm{CHO})$ and fat in the daily diet influenced the respiratory quotient. They concluded that food intake was one of the determinants of substrate selection for oxidation. It was also observed that physical activity raised the value of the respiratory quotient $(R)$ and the conclusion was that $\mathrm{CHO}$ metabolism is enhanced as a result of physical activity.

More recently it has been suggested that fat is the dominant substrate for energy exchange in resting conditions and that $\mathrm{CHO}$ plays a role as immediate energy source, whenever energy exchange from fat is too slow to meet the requirements (Newsholme, 1976). Based on this suggestion it can be explained that $\mathrm{CHO}$ degradation, which leads to a larger energy flow per second than fat degradation (McGilvery, 1973), is enhanced at the onset of exercise when aerobic metabolism still has to be increased. It may also explain that increased fatty acid availability, in the course of exercise caused by neural and hormonal adaptations, reduces $\mathrm{CHO}$ oxidation so that endogenous CHO stores can be spared (Newsholme, 1976, Jansson, 1984). Since the studies of Bergström and Hultman $(1967,1967 \mathrm{a})$ it is known that local CHO stores play a limiting role for the ability to perform exercise of a high intensity. This may explain the adaptation of the body to increase fat metabolism and to spare $\mathrm{CHO}$ for emergency actions. The same authors also observed that increasing the amount of $\mathrm{CHO}$ in the daily diet results in increased glycogen stores and that this increase in glycogen availability is related to longer exercise times before exhaustion is reached. The general advice thereafter was that athletes should consume more $\mathrm{CHO}$.

With respect to the observations of Christensen and Hansen (1939a, 1939b) this may sound conflicting. Increasing the amount of $\mathrm{CHO}$ in the diet stimulates $\mathrm{CHO}$ oxidation and inhibits fat metabolism, whereas the natural adaptations of the body lead to the opposite.

Meanwhile a large number of studies with respect to nutritional factors and exercise have been performed and extensively reviewed (Christensen, 1939b; Åstrand, 1977; Bergström. 1967, 1972; Blom, 1984; Costill, 1978, 1980, 1981; Hermansen, 1967, 1979; Lamb, 1986; Saltin, 1967; Sherman, 1981; Brotherhood, 1984). However, only very few studies have been done with highly trained athletes whereas practically no information is available on the effect of highly intensive long lasting exercise performed on sequential 
days. Particularly this type of exercise may have its impact on nutritionall parameters and related energy exchange as well as the occurence of gastrointestinal problems often observed in endurance events. Based on the available data advice is given to athletes and in general this advice is the same for the moderately active jogger as for the elite athlete. In a large number of situations however, theory and praxis fall wide apart. On the one hand studies in which moderately trained athletes are tested may lead to false conclusions with respect to the counseling of highly trained athletes and vice versa. On the other hand nutritionists often claim that a normal composed diet will always be adequate in any situation. These statements are often made without substantial analysis of what is happening in praxis. Therefore it was decided to analyze nutritional problems in elite athletes in the field. More specifically, the question was raised whether or not as a result of daily exhausting exercise athletes differ from a normally active population with respect to eating patterns, food selection and nutritional requirements (Chapter I).

In a second step it was decided to perform a controlled experiment in which highly trained cyclists performed until exhaustion on sequential days and in which the effect of a conventional $\mathrm{CHO}$ rich diet on nutritional and metabolic parameters was compared to the effect of the same diet supplemented with a $\mathrm{CHO}$ beverage. The idea behind this experiment was to examine the efficacy of diet intervention with respect to meeting the nutritional needs during days of exhausting longlasting physical exercise. Secondly, to study the rational for nutritional supplementation under these circumstances. Such a rational could be obtained from the analysis of the changes in nutritional and biochemical parameters as well as performance capacity (Chapter II, III, IV).

A third step was to study the effect of $\mathrm{CHO}$ intake during warming-up on the regulation of the blood glucose concentration during exercise. In contrast to the available studies, which have been performed after an overnight fast and in which $\mathrm{CHO}$ intake took place in resting conditions, this study was pertormed under praxis like circumstances, i.e. after a standardized breakfast and a warming-up procedure (Chapter $V$ ).

Finally, in order to give input to a field which until now has been largely ignored by exercise physiologists (Fogoros, 1980; Sullivan, 1981, 1984), it was decided to analyze the available literature in the field of gastro-intestinal physiology and regulation at rest and during exercise. The latter should serve as a reference for future research (Chapter VI). 


\section{REFERENCES}

1. Astrand. P.O.

Nutrition and physical performance, in: Young D.R. (ed):Physical performance and diet.

Springfield III. Charles C. Thomas Publisher, pp 59-79, 1977.

2. Bergstrom, J., and E. Hultman.

Nutrition for maximal sports pertormance.

JAMA 221: 999-1006, 1972.

3. Bergström, J., and E. Hultman.

A study of the glycogen metabolism during exercise in man.

Scand. J. Clin. Lab. Invest. 19: 218-228, 1967.

4. Bergström, J., L. Hermansen and E. Hultman.

Diet, muscle glycogen and physical performance.

Acta Physiol. Scand. 71: 140-150, 1967.

5. Blom, P.C.S., N.K. Vøllestad, and L. Hermansen.

In: P. Marconnet, J. Poortmans, L. Hermansen.

Physiological Chemistry of training and detraining.

Med. Sport Sci. 17: 148-160, 1984.

5a. Brotherhood, J.R.

Nutrition and sporis performance

Sports Med. 1: 350-389, 1984.

6. Christensen, E.H., and O. Hansen.

Untersuchungen über die Verbrennungsvorgănge bei langdauernder, schwerer Muskelarbeit.

Scan. Arch. Physiol. 81: 152-159, 1939.

7. Christensen, E.H., and O. Hansen.

Respiratorischer Quotient und $\mathrm{O}_{2}$-Aufnahme.

Scan. Arch. Physiol. 81: 180-189, 1939a.

8. Christensen, E. $H_{2}$, and $O$. Hansen

Arbeitstähigkeit und Ernährung.

Scan. Arch. Physiol. 81: 160-171, 1939b.

9. Costill, D.L., W.M. Sherman, W.J. Fink, C. Maresh, et al.

The role of dietary carbohydrates in muscle glycogen resynthesis after strenuous running.

Am. J. Clin. Nutr. 34: 1831-1836, 1981.

10. Costill, D.L., and J.M. Miller -

Nutrition for endurance sport; carbohydrate and fluid balance.

Int. J. Sports Med. 1: 2-14, 1980.

11. Costill, D.L.

Nutritional requirements tor endurance athletics.

Med. Sport 12: 105-110, 1978. 
12. Fogoros, R.N.

Runner"s trots. Gastro-intestinal disturbances in runners.

JAMA 243: 1743-1744, 1980.

13. Hermansen, L., E. Hultman, E. Kayser, B. Saltin, et al.

Muscle fuel for competition: A Round Table.

Phys. Sportsmed. 7: 49-58, 1979.

14. Hermansen, L., E. Hultman, and B. Saltin.

Muscle glycogen during prolanged severe exercise.

Acta Physiol. Scand. 71: 129-139, 1967.

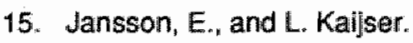

Leg citrate metabolism at rest and during exercise in relation to diet and substrate utilization in man.

Acta Physiol. Scand. 122: 145-153, 1984.

16. Lamb, D.R., and G.R Brodowicz.

Optimal use of fluids of varying formulations to minimize exercise induced disturbances in homeostasis.

Sports Medicine 3: 247-274, 1986.

17. MoGilvery, R.W.

The use of fuels for muscular work.

In: Metabolic adaptation to prolonged physical exercise Howald, H. J.R. and J.R.

Poortmans (eds).

Birkhäuser Verlag Basel, pp 12-20, 1973.

18. Newsholme, E.A.

Carbohydrate metabolism in vivo: regulation of the blood glucose lewel.

Clin. Endocrinoll. Metab, 5: 543-578, 1976.

19. Saltin, B., and L. Hermansen.

Glycogen stores and prolonged severe exercise. In: Blix, G. (ed):

Nutrition and physical activity.

Swedish Nutrition Foundation, 1967, pp 32-46.

20. Sherman, W.M., D.L. Costill, W.J. Fink, and J.M. Miller..

Effect of exercise-diet manipulation on muscle glycogen and its subsequent utilization during pertormance.

Int. J. Sports Med. 2: 114-118, 1981.

21. Sullivan, S.N.

The gastro-intestinal symptoms of running.

N. Eng. J. Med. 304: 915, 1981.

22. Sullivan, S.N. M.C. Champion, N.D. Christofides, et al.

Gastrointestinal regullatory peptide responses in long-distance runners.

Phys. Sportsmed. 12: 77-82, 1984. 


\title{
CHAPTER I DIETARY PROBLEMS IN THE CASE OF STRENUOUS EXERTION
}

\author{
F.J.P.H. Brouns, W.M.M. Saris and F. ten Hoor
}

\section{Part I: A literature review.}

\section{Physical exertion and energy regutrement.}

At is generally known that any form of activity is based on the usage of energy. The more intensive the activity and the longer il lasts the larger the total energy expenditure. This applies particulatly to physical exertion. It is generally assumed that the human body has limited stores of energy. The most important of these are carbohydrates (in the form of glucose and glycogen) and fat.

Since increasing intensity is accompanied by increasing combustion of carbohydrates and decreasing combustion of fat, the quantity of glycogen stored in the body is an important pertormance-limiting factor (Hermansen. 1967). Without adequate substrate avaitability the body is unable to adapt to the required rate of ATP synthesis so that the muscle contractions are hampered. Because the store of glycogen is limited, the athlete who has to perform intensively over a longish period will fall off in pertormance as soon as very low glycogen levels are reached. "Hiting the wall in this manner is a well-known phenomenon in sport. Meanwhile, a number of investigations have shown that this occurance coincides with the low level of muscle glycogen content at that moment (For review see Blom, 1984). Since muscle glycogen is formed principally from the glucose carried by the blood and obtained from the food that the athlete has ingested, it is obvious that proper attention must be paid to food-intake in order to maintain normal muscle glycogen stores. Because a number of enzymes play a key role in substrate combustion and storage, it is reasonable to suggest that the availability of coenzymes such as vitamins, is also of importance. It can be supposed that small deficiencies can lower performance. Although a number of other factors affect the final result, these aspects should not be overlooked now that the difference between winning and losing often can be measured in tenths or even hundredths of second. Because in a number of sports the performance level has become so high that the differences between individuals are only small, endeavors to make further progress have pushed training effort to the limits of mechanical load-ability and energetic power. The latter aspect in particular has led to extremely high energy expenditures in some sports. Whereas for the ordinary active person an energy expenditure of approximately $2.000-2.500 \mathrm{kcal} /$ day $(8.3-10.4 \mathrm{MJ})$ is considered as normal, 
endurance athletes under intensive training may have much higher expenditures. Strauzenberg (1978) reports energy intakes ranging from 5.200 to $6.800 \mathrm{kcal}(21.7-28.4 \mathrm{MJ})$ in various kinds of sport. For long-distance runners he reports an average caloric intake of $4.887 \mathrm{kcal} /$ day $(20.4 \mathrm{MJ})$, measured over ten consecutive days, the intake figure for the least intensive day being $3.620 \mathrm{kcal}(15.1 \mathrm{MJ})$ and for the most intensive day $6.000 \mathrm{kcal}$ (25.1 MJ). These values agree with those from other publications ((eg. Mellerowicz and Meller, 1975; Donath and Strauzenberg, 1975; Haralambie, 1987; Kirsch and von Ameln, 1981; Weicker ${ }_{n}$ 1976). Sometimes for extreme conditions even higher energy consumption figures are recorded. For instance, Biener as cited from Strauss (1979) reports for alpine sports such as climbing an expenditure of 7.000-8.000 kcal (29.3-33.4 MJ) per day. To complete the Wasalöp, a long distance ski-race over $85 \mathrm{~km}$, it has been calculated that an energy expenditure of $9.000 \mathrm{kcal}(37.6 \mathrm{MJ})$ is required. Very recently Saris et al. (1986) calculated a mean expenditure of $6.500 \mathrm{kcal}$ per day in professional cyclists in the Tour the France. The expenditure on the most intensive day was approximately $9.000 \mathrm{kcal}(37.6 \mathrm{MJ})$. In the case of top athletes training intensively high energy expenditures happen not occasionally but one day after another.

Therefore in summary as it can be said that, depending on type of sport and duration of event or training, athletes may have an energy requirement two to five times greater than the normal daily consumption of someone who does not go in for sport.

Therefore it is important that the body's stores of glycogen be replenished in time so that optimal initial glycogen levels will be assured.

\section{Physical effort and appetite.}

It is generally known that light to moderate physical exercise has a stimulating effect on appetite. Everyone knows the effect of a good walk in the country.

However for an athlete involved in strenuous physical exercise the reverse is often the case.

For example it is reported by Karvonen et al. (1978) that with intensive physical activity, carried out repeatedly every hour, the appetite of the person tested decreased sharply so that the next meal was postponed until late evening. Only a few athletes tolerated solid food. Though normal at first, the desire to drink decreased or was suppressed as exhaustion set in. These findings can be related to the negative effect of raised body core temperature and catecholamine levels on appetite (changes that take place during intensive physical exercise). Voelkers (1977) reports from practical observation that after an exhausting day's training American football players sometimes take liquid food because the are just too tired to think of eating anything solid. Donath and Strauzenberg (1975) suggest that an inverse relation between energy consumption and food intake may exist. On days of intensive physical 
activity most athletes appeared to have insufficient appetite to compensate for the high energy expenditure. However on days of reduced intensity this energy was again made up, the intake being then greater than the requirement at that moment. Also Astrand and Rodahl (1977) write: It is a common experience that athletes in active training often are unable to maintain regular meal-schedules and may incur detrimental effects.

\section{The effect of mental stress.}

Besides physical stress it appears that psychological stress can also adversely affect appetite and hence influence the intake of food. According to Canham and Consolazio (1966) athletes about to take part in an important competitive event often react in the same way as soldiers about to go into battle, namely with anorexia, nausea and sometimes vomiting.

Rose and Fuenning (1960), state that there is objective evidence that functional changes (e.g. in motility) take place in the gastrointestinal system immediately before and during an important sport event. Upjohn (1953) reports that it takes about 3-4 hours for the stomach to empty after a normal meal but that this time increases to about 6 hours due to the psychological stress that precedes a competitive event. If this situation occurs frequently it may have harmful consequences for the athlete if the right measures are not taken.

In summary it can thus be said that physical and psychological stress have an adverse influence on appetite. This loss of appetite occurs chiefly before, during and after the competitive event. As a result of this, when there is strenuous physical effort on successive days or at short intervals, inadequate carbohydrate intakes may occur.

\section{Sport and frequency of meals.}

As the energy expenditure of athletes increases, it appears that the normal feeding pattern suffers more and more. This is in fact a logical result of the fact that an increased energy expenditure is the direct corollary of a lengthened physical working time. Thus, if training is done for a great many hours per day, this will mean that the time for preparing and digesting well composed and varied meals is limited (Wilmore and Freund, 1984; Brouns, 1984). We know from practical experience that many people find it does not suit them to indulge in sport on a full stomach. This naturally has its repercussions on the feeding pattern of an athlete under intensive training who necessarily worries about it. In some sports a full stomach may even be a 'contraindication', e.g. boxing, karate and jumping, owing to the risk of possible stomach injuries. But here too there is a real problem in that the athlete must try to cater for his high energy requirement. Therefore a direct relation between dally physical activity and food intake can be assumed. In a normal situation one can say that the 
problem can usually be solved by eating more. In practise however this is often difficult for an athlete. This is also recognized by Mathews, and Fox (1979) who write that it is perfectly possible to divide a 5,000 kcal diet over 5 meals, but that this sort of eating creates a problem for the athlete faced with long periods of consecutive physical exertion. E.g. in the case of the decathlon or tennis championships when singles and doubles have to played on the same day, and also in tournaments. In such a situation there may be a time limitation combined with a decreased appetite and a bad tolerance for sporting on a full stomach.

Haralambie (1978) states that a consumption of $5,000-6,000 \mathrm{kcal}(20.9-25 \mathrm{MJ}$ ) will probably force an athlete to resort to high energy foad. From cycle racing. Tour de France etc., we know that cyclists have been taking liquid baby food on competition days for the past decade, as this is fairly easily digested. This is not generally appreciated by the athletes, however, the alternative may be not eating at all.

In view of the advice often given by dieticians to the effect that a normal composed menu always suffices and that the athlete needs no adaption of his dietary regimen at all must be considered as illogicall. There is a nutritional advice, generally advanced, that no food should be eaten within 3-5 hours before a strenuous physical exercise (competitive event) or at any case only a very small quantity of easily digested food may be taken (Mathews and Fox, 1979; Smith, 1979; Lamb, 1980; American Dietetic Association, 1980, a.o). Top athletes say that the training effort is probably on a par with or even greater that the required for competition. On that basis this advice would thus hold good for any training session. This would leave a top athlete training twice a day with about 7 hours in which to consume the greatly increased volume of food spread over several meals. But practical experience shows this to be impossible. In consequence one falls into a continuous eating pattern, consuming snack food to a large extent and food with a high energy content. At the same time frequent use is made of sugar and sugar solutions. The continuous eating pattern (lots of snacks spread over the day) is supported by a study by Kirsch and von Ameln (1981). The authors studied a group of long-distance runners with a moderately elevated energy expenditure averaging $3,316 \mathrm{kcal}(13.8 \mathrm{MJ})$ per day and a group of racing cyclists with a drastically raised energy expenditure averaging about 6,280 kcal per day (26.2 MJ). They found that the food intake frequency was governed by the total energy expenditure. The runners took 4-7 meals a day but this fragmented pattern was far more pronounced in the case of the cyclists with 6-8 meals a day. They concluded that the cyclists were more or less continuously eating and drinking; in $57 \%$ of cases they ate and drank at intervals of less than 1,5 hours. In $90 \%$ of cases the interval was less than 3 hours. In these circumstances athletes must have access to food and drink throughout the whole day since they tend to eat anything that is easy to 
prepare or ready for use, tasty and with a high energy content (preference for sweet foods). This often results in frequent consumption of cream cakes, chocolate and sweets. In addition a lot of sweetened soft drinks are drunk and, in some sports also beer (Saris, 1980).

As regards the situation in Holland, this has been confirmed in a study of De Wijn and Van Erp-Baart (1980), who found that in the case of competition rowers some $35 \%$ or more of the total daily energy input is obtained from "bites of food in between", such as snacks, sandwiches, biscuits, etc. As these foodstuffs mostly have a high energy content but little protein and vitamins. Such a nutritional pattern leads to a lowering of the nutrient density. (The presence of micro nutrients related to macro nutrients).

\section{In summary it can be stated that:}

1. Athletes with a high energy consumption often get into a continuous eating pattern consisting of many small 'meals' at short intervals.

2 Increased training time is attended by increased energy expenditure so that a greater volume of food must be assimilated but with less and less , time for eating.

3 Intensive sports activity is inadvisable on a full stomach.

4. To cover the energy (carbohydrate) requirement on days of very strenuous training or competition, it is recommended to take liquid food with a high carbohydrate content in addition to the 'normal meals'.

5. The advice that athletes can at all times manage with a normal composed (solid) diet is in fact erronous and based on insufficient know how of sports practice.

\section{Liquid food concentrates.}

From the foregoing it is clear that an adequate energy supply for athletes is actually at its most important in periods when the feeding pattern is most exposed to disturbing factors. Should this be inadequate, then premature depletion of glycogen stores may have a very decisive effect on the end result. Athletes with a high glycogen content perform longer (for review see Blom 1984) and when a low value is reached (about $3 \mathrm{~g} / \mathrm{kg}$ muscle weight) the athlete is forced to discontinue his activity (Karlsson and Saltin, 1971).

For the same reason the supply of carbohydrates shortly before, during and directly after regular prolonged intensive physical effort is an important measure if one wants to stay in the race (Sherman and Costill, 1984). In this case only liquid food may be tolerated optimally.

From studies in which solid food was replaced by liquid food before a competition it transpires that nausea, vomiting and stomach cramps were eliminated and dryness of the mouth did not occur so much (Rose et al., 1961; 
Cooper et al., 1962). At the same time it is possible by this means to better maintain the blood glucose level, whereby a glycogen sparing effect can be achieved (Pirnay et al., 1977), and exhaustion of energy averted. Just how important it is for an intensively training athlete frequently exposed to strenuous physical exertion -as for instance a racing cyclist- to secure a large carbohydrate intake, is apparent from recent studies. It is known that the resynthesis of muscle and liver glycogen after prolonged exhausting effort can take 2-3 days with a normal diet (solid food with a composition of about 50 en\% carbohydrates 35 en\% fat and about 15 en\% protein) (Costill, 1979). (energy percent is the proportion in the energy intake, e.g. intake $2000 \mathrm{kcal}$, carbohydrate 100 gram $=100 \times 4 \mathrm{kcal}=20 \mathrm{en} \%$ ).

This means that if exercise is repeated within this period, the athlete will cope with a decreased endurance capacity due to reduced muscle glycogen stores. By ensuring an ellevated carbohydrate content in the food and a supply of food starting immediately after the sports effort, the time needed for glycogen resynthesis can be reduced substantially (Costill, 1979). This is an essential prerequisite. Otherwise, competitive events lasting several days like the Tour de France would be hard to perform. The carbohydrate content should then be at least $60 \mathrm{en} \%$ (Schneider, 1980; Costill, 1980). One favorable point is that the activity of the enzyme glycogensynthetase varies in inverse proportion to the decrease of glycogen content. This enzyme activity appears most pronounced in the first few hours following effort. It is precisely in this period that the athlete has to contend with a suppressed appetite so that a liquid carbohydrate solution may offer the best alternative (Schneider, 1980; Brooke, 1974; Stucke et al., 1976). As in the case of orally administered food in intensive care, attention must be equally paid in competitive athletics and first-class sport to ensure that the gastro-intestinal tract needs to make as little effort as possible to digest and absorb the food administered.

It is known that liquid food has a quicker absorption so that the food taken is made available sooner to the recovery processes. X-ray examination of the gastro-intestinal motility has shown that liquid pre-game food passes out of the stomach within 2 hours and is completely digested and absorbed within 4 hours after intake. On the other hand, after a pregame meal of solid food, the food was still in the gastro-intestinal tract 4-6 hours afterwards because of the slower rate at which the stomach emptied in these conditions (RoseFuenning, 1960).

The consequences of such dietary measures before and after competition become evident in practice. Athletes have less gastro-intestinal problems. Those who take high-energy (carbohydrate) liquid food immediately after the cessation of sports effort say that they recover sooner and are able to settle down to a good meal earlier.

This is also confirmed by the recent findings of lonescu (1982) and Dragan et al. (1982). 
In summary it can be concluded that:

1. In periods when carbohydrate intake plays tricks on the athlete most (shortly before, during and directly after prolonged exertion) it is at its most urgent.

2 Solid food is badly tolerated just before, during and directly after strenuous exercise.

3. For adequately quick glycogen resynthesis a high carbohydrate content i in the food (60 en\%) is important.

4. Liquid food concentrates offer athletes the readiest option in periods when eating is difficult or impossible or can also be used as an energy supplement.

5. Athletes should be advised about their feeding habits and the composition of their food especially with regard to days of intensive training and com-petition.

\section{REFERENCES}

1. American Dietetic Association.

Nutrition and Physical fitness.

J American Dietetic Association 76: 5, 1980.

2. Astrand, P.O. and K. Rohdahll.

Textbook of workphysiology.

Nutrition and Physical performance, 483-521.

McGraw Hill Book Company, 1977.

3. Biener, $K$.

Sport und Ernăhrung in training und Wettkampf.

Habeggerverlag Derendingen, 1976.

4. Blom, P.C.S., N.K. Vollestad and L. Hermansen.

Diet and recovery proces.

Med. Sci. Sports 17: 148-60, 1984.

5. Brooke, J.O. and L.F. Green.

The effect of a high carbohydrate diet on human recovery following prolonged work to exhaustion.

Ergonomics 17: 489-97, 1974.

6. Brouns, $F$.

Voedingspreparaten in de sport - zin of anzin?

Ned. Tijdschrift voor Dietisten 39 (2): 42-7, 1984.

7. Canham, U.E. and C.F. Consolazio.

Nutrition and stress.

JAMA : 64:70, 1966. 
8. Cooper, D.L., B. Bird and J. Blair.

Use of a liquid meal in a football training programm.

J. of Oklahoma State Med. Assoc. 48: 484-6, 1962.

9. Costill, D.L. al.

Nutrition for endurance sport, carbohydrate and flutd balance.

Int. J. Sports Med. 1 (1): 2-14, 1980.

10. Costill, D.L.

Regime alimentaire el exercises repétes.

In "Place de lalimentation dans la preparation biologique a la competition". J.R. Lacour (ed).

UER de Medicine, Saint Etienne, 1979.

11. Donath, $R$. and S.E. Strauzenberg.

Beitrag zu Fragen der Ernährung der Sportler.

Medizin und Sport 15 (5): 144, 1975.

12. Dragan, li. et all.

Researches concerning the effects of "Powerback" upon working capacity in top athletes.

Priviliged Communication, 1982 .

13. Goodhart, R.S. and M.E. Shills.

Modern nutrition in health and disease.

Lea and Febiger, Philadellphia, 1980.

14. Haralambie, $\mathrm{G}$.

Elekirolythaushalt und körperliche belastung. 1. Kalium und magnesium.

Sport Aktiv 2 (1): 5-8, 1978.

15. lonescu, C. et al.

Researches concerning the effects of "Mineral Plus 6" upon working capacity and elektro-

Iytes recovery in top athletes.

Priviliged Communication, 1982.

16. Karlisson, $\mathrm{J}$, and B., Saltin.

Diet, muscle glycogen and endurance performance.

J. Appi. Physiol. 31: (2): 203-6, 1971.

17. Karvonen, J., J. Saarela and E. Uotila.

The effect of repeated exercise on appetite in a 24-hours relay race.

In: "Nutrition dietetics and spont", 139-45. G. Ricci, A. Venerando (eds).

Edizioni Minerva Medica, Rome, 1978.

18. Kirsch, $K_{.} A_{4}$ and H. won Ameln.

Feeding patterns of endurance athletes.

Europ J. Appl. Physiol. 47 (2): 179-208, 1981.

19. Lamb, D.R.

Physiology of exercise: responses and adlaptations. Chapter 5.

In: Nutrition and athiletic performance: $61-75,1980$. 
20. Mathews, O.K. and E.L. Fox.

The physiological basis of physical education and athletics.

Nutrition, athletic performance and obesity, 391-410.

W.B. Saunders Company, Philadelphia, 1979.

21. Mayer, J.

Physiology of thunger and satiety.

In: "Modern nutrition in health and disease", 560-77.

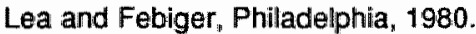

22. Mellerowicz, H. and W. Meller.

Training. Exogene Faktoren, Ernăhnung, 63-69.

Springer Verlag, Berlin, 1975.

23. Pirnay, F., M. Lacroix, F. Mosora A. Luyckx and $P_{\text {. Lefebre. }}$

Glucose oxidation during prolonged exercise evaluated with naturally labeled $\left({ }^{13} \mathrm{C}\right)$ glucose.

J. Appl. Physiol: Respiralt, Environ, Exercise Physiol. 43 (2):258-61, 1977.

24. Rose, K.D. and S.I. Fuemning.

Pre-game emotional tension, gastrointestinal motility and the feeding of athletes.

Nebraska Med. J. Dec. 45:575-9, 1960.

25. Rose, K.D., P.J. Schneider and G.F. Sullivan.

A liquid pre-game meal for athletes.

JAMA 178: 30-3, 1961.

26. Saris ${ }_{1} W_{*,} M$. von Erp-Baart and $F$. Brouns.

Nutritional problems in professional cyclists.

In preparation, 1986.

27. Saris, $\mathbf{W}$.

Topsport en gevulde koeken.

Voeding 41: 399, 1980.

28. Schneider F. et al.

Kohlenhydrate in der Ernahrung des Sportlers und ihre Wirkung auf die Leistungsarbeit.

Med. und Sport 20 (9): 257-63, 1980.

29. Sherman, W. and D.L. Costill.

The marathon. Dietary manipulation to optimize performance.

The American J. of Sportsmedicine 12 (1):44-51, 1984.

30. Smith, N.J.

Nutrition and the athlete, 271-81.

In: "Sports medicine and physiology".

R.H. Strauss (ed).

W.B. Saunders Company, Philadelphila, 1979. 
31. Strauzenberg, S.E.

Food intake in the different sports activities.

In: "Nutrition dietelics and sport" ${ }^{*}$ 171-8.

G. Ricci, A. Venerando (eds).

Edizioni Minerva Medica, Rome, 1978.

32. Stucke, $K_{\text {, }}$ C. Kori-Lindner, B. Grundler, G. Osterman et al.

Wirkungen einer vollbilanzierten synthetischen Diaet auf die Körperliche Leistungsfahigkeit.

Münch. Med. Wschr, Münch.118 (34):1029-34, 1976.

33. Upjohn, HL al.

Nutritrion of athletes.

JAMA 151: 818-9, 1953.

34. Volickers, $F$.

Food for fitness and sports.

Richard Rosenpress, New York, 1977.

35. Weicker, $H$.

Kapittel 10: Ernährung, 85-91.

In: K.D. Húllemann (ed). "Leilstungsmedizin".

Sportmedizin. George Thieme Verlag, Stuttgart, 1976.

36. Wilmore, J.H. and B.J. Freund.

Nutritional enchancement of athletic performance.

Nutrition abstracts and reviews 54 (1): 1-16, 1984.

37. Wijn de, J.F. and M. van Erp-Baart.

Foodpattern, body composition and physical condition of heavy weight competition rowers.

Voeding $41(1): 13-8,1980$. 


\section{CHAPTER I: PART II: THE TOP ATHLETES MENU, NUTRIENT DENSE ENOUGH ?}

In a recent thesis by W.H.M. Saris (1982) we find the following statement: 'Healthy foods do not exist'. The question is how one should interpret this for people who go in for strenuous sport, have a high energy expenditure and need a high carbohydrate proportion in their diet. Since all nutrients are interrelatted one might argue that too much or too little of one particular nutrient will influence the other nutrients e.g. their absorption, utilization etc. It would in general be fair to state that meeting the daily requirement of all nutrients (in so far as this is known) comes nearest to satisfying the definition of a "healthy diet". It would be nice to know this exact daily requirement for every individual but unfortunately we do not know. Most recommendations are based on a survey of large groups of people in which differentiation is made between young, old, male, female, gentle activity, heavy physical work, etc. However, a drawback to this is that feeding habits vary from country to country and that at the same time what is generally applicable for the large group will certainly not always necessarily apply to a specific target-group. Some target-groups have their own specific nutrient recommendations, such as old people, infants and pregnant women.

However, for the group of top athletes there are only very few data available. Opinions vary widely and little research has yet been done. Nevertheless, certain tendencies can be signalized which make it possible to advice athletes and their coaches based on the current status of knowledge. One of these tendencies is that deficiencies, however small they may be, can have adverse effects on the bodily functions in certain circumstances. In fact, deficiencies can result in a lowered performance, especially in periods of stress such as illness or strenuous physical exertion. That is why certain nutrient deficiencies of which it is known that they may have a drastic effect on bodily function, such as vitamins, proteins and carbohydrates, are in fact of such great importance to athletes and their coaches.

\section{Vitamins and sport.}

In almost every recent textbook on the subject of sports physiology and training theory one can find a chapter on food and particularly vitamins. The question generally considered is whether there is a need to give the athlete extra vitamins, i.e. whether intensive sports activity leads to an increased vitamin utilization or requirement. Conflicting views based upon limited evidence may confuse many readers, e.g. Nöcker (1978) states that vitamin supplementation will only bring about improved performance if the athlete has a vitamin deficiency. Well-fed athletes will have no benefit at all, an opinion shared by Vitousek (1980). However, advised intakes are often much 
higher than the normal recommended daily intakes. Fox (1979), Huse-Nelson (1977) and Mashford (1973) are of the opinion that there is no real point in discussing vitamins and that the daily requirements can be amply covered by the normal diet:

Williams (1976) concluded after his extensive study of the literature that the administration of a vitamin in general has no effect upon performance. This conclusion is, however, only valid when there are no deficiencies. He goes on to say that more research is necessary on the effects of vit. B-complex, vit. $C$ and vit. $E$ in as much as the results and opinions obtained (up to 1976) are often contradictory.

McArdlle, Katch and Katch (1981) suggest that vitamins can be used repeatedly in metabolic reactions, i.e. they are not lost, so that the requirements of athletes are no higher than those of people not in training. However this statement is in conflict with the view that the vitamin B1 requirement is directly linked to the carbohydrate proportion in the diet (National Research Council, 1980).

The conflicting opinions raise three important questions:

1. Whether or not athletes have a higher vitamin utilization, and consequently a higher vitamin requirement, than non-athletes.

2. Whether the feeding pattern, and thus the vitamin intake of athletes is indeed such as to be considered adequate.

3. Whether or not administration of a very high vitamin dosage will have an ergogenic effect.

\section{Evidence of an increased nutrient requirement.}

Many sports physicians express the opinion that the overall vitamin requirement of athletes is raised so that extra supplementation is indicated. For instance, Strauzenberg (1978) reports that the vitamin intake of top athletes in East Germany is too low to meet the requirements (Table 1). According to Strauzenberg the increased requirement is most pronounced in the case of endurance athletes.

Cureton (1969) states that intensive training leads to a loss of vit. B and vit. C from the body. Buskirk and Haymes (1972) suggest that training brings about an increase in the number of mitochondria and enzymes, functional proteins that play an important part in the energy metabolism. For this reason extra vitamins (cofactors) would be needed to make the enzymatic reactions possible. Prokop 1978 also supposes this. 
Table 1. Vitamin requirements and intakes of East German top athletes (Strauzenberg, 1978).

\begin{tabular}{lrrrr}
\hline Vitamin & \multicolumn{2}{c}{$\begin{array}{c}\text { Estimated } \\
\text { requirement }\end{array}$} & \multicolumn{2}{c}{$\begin{array}{c}\text { Daily } \\
\text { intake }\end{array}$} \\
\hline A & 13.300 & $\mathrm{IU}$ & 13.700 & $\mathrm{IU}$ \\
B1 & $4-8$ & $\mathrm{mg}$ & 1.9 & $\mathrm{mg}$ \\
B2 & 4 & $\mathrm{mg}$ & 2.9 & $\mathrm{mg}$ \\
Niacin & 30 & $\mathrm{mg}$ & 18 & $\mathrm{mg}$ \\
C & 500 & $\mathrm{mg}$ & 244 & $\mathrm{mg}$
\end{tabular}

Table 2. Estimated vitamin requirements for athletes (CreffBérard, 1976).

$\begin{array}{lll}\text { Vitamin } & \begin{array}{l}\text { Untrained } \\ \text { persons }\end{array} & \text { Athletes }\end{array}$

\begin{tabular}{|c|c|c|c|c|}
\hline B1 & 1.5 & $\mathrm{mg}$ & $5-10$ & $\mathrm{mg}$ \\
\hline $\mathrm{B} 6$ & 4 & $\mathrm{mg}$ & $15-30$ & $\mathrm{mg}$ \\
\hline $\mathrm{B} 12$ & $2-$ & $\mathrm{mcg}$ & $10-20$ & $\mathrm{mcg}$ \\
\hline C & $75-100$ & $\mathrm{mg}$ & $150-300$ & $\mathrm{mg}$ \\
\hline $\mathrm{B} 2$ & 2.5 & $\mathrm{mg}$ & 10- 15 & $\mathrm{mg}$ \\
\hline Nicotinic acid (PP) & 20 & $\mathrm{mg}$ & $30-50$ & $\mathrm{mg}$ \\
\hline Pantothenic acid & 10 & $\mathrm{mg}$ & $10-20$ & $\mathrm{mg}$ \\
\hline Biotin & 5 & $\mathrm{mg}$ & $10-20$ & $\mathrm{mg}$ \\
\hline Folic acid & $10-20$ & $\mathrm{mg}$ & $15-40$ & $\mathrm{mg}$ \\
\hline$P$ & $10-20$ & $\mathrm{mg}$ & $20-40$ & $\mathrm{mg}$ \\
\hline A & $2000-6000$ & $\mathrm{mg}$ & 50000 & $\mathbb{I U}$ \\
\hline D & 400 & IU & 400 & $\mathbb{N U}$ \\
\hline E & $10-30$ & $\mathrm{mg}$ & $30-50$ & $\mathrm{mg}$ \\
\hline
\end{tabular}


Mashford (1973) links the increased vitamin requirement to the greater substrate utilization, and so too does Troll (1978). Creff Bérard (1976, 1980), Kindermann (1977), Schneider (1979) and Jakowlew (1975) suggest an increase of $200 \%$ of all vitamins except vit. $\mathrm{B}$ and $\mathrm{C}$ for which the figure is $500 \%$ (Table 2).

However, it has to be underlined that all these figures are still unsupported by solid research. In this connection it is also essential to know how one defines the term 'extra vitamin requirement":

(a) extra vitamin requirement above normal RDA, on the basis of an increased energy expenditure (if energy expenditure is doubled, the vitamin requirement is doubled too):

(b) an extra requirement over and above the adjustment mentioned in (a), e.g.; energy expenditure is doubled but vitamin requirement is 5 -told).

We will consider extra vitamin requirements as described under (a).

In other publications the existence of an increased demand is denied although it is stated that, as a safety measure, a small vitamin supplement can do no harm (Ardle, Katch and Katch, 1981). Nevertheless, these authors also state that excess should be avoided as a matter of course: "It is a great concern, however "that some athletes resort to taking megadosis or doses of at least tenfold the recommended daily allowances in the hope of improving performance'. The afore mentioned safety measures play a very important part in sport since nobody can guarantee the accuracy of the normal current requirements and nobody is in a position to state the requirement of every individual athlete.Schreurs (1981) also considers this problem when stating in connection with the vitamin recommendation of the Netherlands Food Council: "However, it seems premature and even wrong to conclude from these facts (indicated requirement and average daily intake) that every individual or the majority of Holland's population has an optimal vitamin supply'. At the same time Schreurs states that absorption disturbances and Inadequate food intake are not the only reasons for vitamin deficiencies, but that these can also be caused by increased requirements arising inter alia in connection with physical exertion, periods of accelerated growth, excessive losses, etc. A reason often put forward is that athletes can have an increased vitamin loss. It has been suggested that the losses of vitamins via the sweat and urine (particularly vit. $\mathrm{C}$ ) is increased during prolonged activity (Senger and Israel, 1975; Nöcker, 1978; Mathews and Fox, 1979.). These suggestions are taken to heart by trainers and athletes and are fundamental for the swallowing of what are often large quantities of vitamins for fear of deficiencies and lowered performance due to loss of vitamins. However one would assume that normally such increased losses could be compensated by the larger food intake of the athlete (at least if the quality is excellent). 
But is this the case?

\section{Evidence of insufficient intake.}

The suggestion that an inadequate feeding pattern and/or poor quality food will have a bad effect on the nutrient supply is of course nothing new. But whether this applies to the hard training athlete is a matter upon which opinions differ. The following data however indicate that this may well be true. Recent studies have brought to light the existence of biochemical vitamin deficiencies among athletes, in particular of the B complex vitamins (Kindermann, 1977; Haralambie et al., 1975; Howald and Segesser, 1975).(marginal levels of the fat soluble vitamins have until now never been found in athletes). In such situations supplementation with a vitamin mineral preparation indeed led to an increase in performance. With optimal nutrient intake this would not have been possible.

Keul et al. (1979) reported a performance improvement of $4.3 \%$, reflected in an improved running performance and speed. The pulse rate was significantly slower and the incidence of muscle cramps was also less after supplementation. Haralambie et al. (1975) registered an improved performance chiefly in the last stage of a long lasting exercise trial. Van Dam and Waterloh (1979) registered a better resistance to fatigue, shorter reaction times and a better movement efficiency in fencers. In a comprehensive study on physical education students by Van der Beek et al. (1981) a few biochemical deficiencies were also found but disappeared after vitamin supplementation.

These authors found no improvement in performance after supplementation. However, in a very recent follow-up study, in which a diet with a too low vitamin content (vit. B1-B2-B6 and C) was taken for several months, they found a significant decrease in performance. This like-wise vanished after supplementation (Van der Beek et al., 1984).

Bamji et al. (1982) found a large number of biochemical deficiencies (vit. B2B6) among rural schoolchildren. After supplementation they found a significant improvement of a psychomotor test. Although the group which they studied was not representative for our European population, and certainly not for top athletes, their final conclusion is of interest to us:

'These data also suggest that a functional impact of vitamin supplements may be seen even in the absence of clearcut clinical impact as judged by established nutritional deficiency signs'.

In other words, small shortages manifested as biochemical deficiencies (without clinical deficiency symptoms) can well affect physical performance, all the more so when one reflects on the often large intake of food between meals such as cream cakes, chocolate, etc., as mentioned by De Wijn and Van Erp-Baart (1980). These foods, high in energy but low in vitamins, minerals and protein, accounted for more than $35 \mathrm{en} \%$ in the total energy intake of the group of oarsmen studied. A Marginal vitamin intake may then 
be expected. The best advice must then be to avoid these 'empty calories' and make use of good quality between-meal foods such as muesli, dark bread, almonds and raisins etc.

However, even doing so, in the case of very strenuous sports 'deficiencies' can still arise. To quote Van Dam (1978) and Van Dam and Waterloh (1979): 'Even dietetically composed nutrition is not always sufficient to cover the vitamin needs which can increase a great deal in active athletes'.

This agrees with the findings of Saris et al. (1986) who observed during the Tour de France (23 days cycling competition) that the vitamin B1 intake, expressed as nutrient density (the presence of nutrients in food in relation to the energy intake; example: RDA of vit. $\mathrm{C}=50 \mathrm{mg} /$ day.

Average energy intake $=2000 \mathrm{kcal}(8.4 \mathrm{MJ})$. Nutrient density of vit. $\mathrm{C}$ is than $50=0.025$.

2000

When energy intake is doubled and vit. $C$ intake remains the same, the then nutrient density decreases to

$$
\frac{50}{4000}=0.013 \text {. }
$$

The intake of vitamin B1 was too low on successive days of the competition $(0.26 \mathrm{mg} / 1000 \mathrm{kcal}$ as against $0.43 \mathrm{mg} / 1000 \mathrm{kcal}$ on days of rest) (the recommended daily allowance (RDA) American National Research Council Recommendations) is $0.5 \mathrm{mg} / 1000 \mathrm{kcal}$ ). This was caused by the high energy intake from liquid and solid carbohydrate-rich meals with a too low content of B-complex vitamins due to the refinement of the foodstuffs used. The normal meals on these competition days were of good quality so that extra supplementation appeared to be the only solution to maintain an optimal nutrient density. This in fact may justify the extra care that many trainers take in practice to ensure a "good" vitamin intake by advising vitamin preparations.

From the foregoing it may be concluded that: (a) there are indications that vitamin requirements in athletes may be increased as a result of their increased energy turnover; (b) that vitamins may be lost from the body as a result of intensive long-lasting physical exercise; (c) that even eating 3 meals of high quality per day will not per se guarantee an optimal vitamin status and; (d) that frequent use of energy snacks high in carbohydrate but low in vitamin content may also contribute to this.

\section{Ergogenic effects of overdoses of vitamins.}

The question now arises as to whether megadoses vitamins stimulate performance or do not. The answer to this question is a short sharp no!

Vitamin preparations only have an optimizing effect on performance when intakes are too low. There is not a single investigation up till now that can offer evidence in support of performance boosting effects when intake is 
sufficient c.q. when no biochemical deficiencies can be found.

Latelly, vitamin $E$ has aroused strong interest among coaches since it was suggested that this vitamin would increase the oxygen utilization in the muscle cell so that less lactate would need to be produced (Weiner and Rothschild, 1980). However, carefully controlled trials have failed to show any effect (Lawrence et al., 1975; Sharman, 1976; Talbot and Jamieson, 1977; Bell and Johnson, 1976). For overview see Shephard (1983).

Another important aspect is that a megadose of a single nutrient will always interact in some way with other nutrients. These interactions can be highly undesired. The application of simple vitamins, e.g. B12 injections, shots of vit. $C$, etc., as often happens in sports practice, must be advised against because of possible undesirable interactions. The point is that the lack or excess of one nutrient may often affect the requirements for other nutrients. Wise (1980) and Levander and Chang (1980) report a large number of such interactions. It is known for instance that vit. C promotes the iron absorption in the gastrointestinal tract which may be important especially for endurance athletes. This is a positive interaction. One-sided interpretation however may create problems because high doses of vitamin $\mathrm{C}$ give rise to an inadequate absorption of vitamin B12 (Herbert et al., 1977; Newmark et al., 1976), which in its turn adversely affects the absorption of vit. B6 and B2 (Wise, 1980).

\section{How to solve the problem?}

Since even dietetically well composed meals may lead to biochemical deficiencies in periods of regular intensive training and on the other hand possible negative interactions should be avoided, two questions in the matter of measures to be taken to bridge the possible gap now appear to be relevant:

1. Which vitamins?

2. In what quantities:

If we start by dividing vitamins into two categories: (a) fat soluble and (b) water soluble, then it is fair to say that as regards the former there is so far not a single indication that a supplementation is needed for athletes involved in strenuous sport. Athletes should be advised to take sufficient green vegetables and milk in their daily diet to ensure a sufficient content of vitamins $A$ and $D$. There is no need for vit. $E$ and $K$ supplementation. Because of its interaction with coagulation of the blood, vitamin $K$ may even be harmful. For water soluble vitarnins the situation is rather different. Because of marginal intakes on the one hand and increased losses on the other, supplementation may not be out of place for the active athlete as far as competition and/or periods of intensive training are concerned.

Primarily the intakes should be met by the choice of high quality foods. But as has been described before, this seems not always to be adequate enough.

This applies particularly to the following vitamins: B1, B2 (because of their 
intervention in the energy metabolism), vit. B6 (in connection with protein metabolism).

From this it can be concluded that:

(a)There are no arguments to support increased needs for the fat soluble vitamins $A, D, E$ and $K$ even if daily energy turnover is very high.

(b)Intake of high doses of water soluble vitamins is not, as always assumed, entirely without undesirable side-effects.

(c)Megadoses of vitamins are not of benefit to athletes by means of improving performance.

\section{Nutrient density.}

Since 'how much is enough', 'how much is too much', 'how much is minimal' are all questions very difficult to be answered for each individual it may be important to search for an alternative which can be used safely. We have the opinion that the principle of nutrient density might be an adequate alternative, in so far as water soluble vitamin supplementation is desired (vitamin intake related to energy intake). By this means overdosing and underdosing can always be avoided and undesirable interactions precluded.

The nutrient density for vit. B1 is $0.5 \mathrm{mg} / 1000 \mathrm{kcal}$ (American National Research Council, recommendations 1980). An athlete who expends 6000 $\mathrm{kcal}$ in one day would therefore have to have a vit. B1 intake of $6 \times 0.5=3 \mathrm{mg}$. If he gets $11 / 2 \mathrm{mg}$ from his normal meals he will need to have a $11 / 2 \mathrm{mg}$ from his energy-rich in-between-meals. If following this principle an athlete procures an energy concentrate that has to be taken say while cycling, then the vitamin content in that concentrate should be at least in accordance with the desired nutrient density. For instance, an energy concentrate containing $500 \mathrm{kcal}$ should contain a minimum of $1 / 2 \times 0.5 \mathrm{mg}, i . e .0 .25 \mathrm{mg}$ vit. B1.Seen from this standpoint, liquid foods ought always to be vitaminized at least following this principle in order to be of real nutritive value to the athlete. By this means an adequate nutritional intake would be possible from the normal solid meals and the food concentrates taken before and during competition. The swallowing of unnecessary large quantities of vitamin pills, to be on the safe side, would thus become superfluous. This finally leads us to the following conclusion:

The nutrient density concept gives a basis for the minimal enrichment of daily nutrition with vitamins, if necessary, in such a way that athletes using such products will never be exposed to excessive vitamin intakes, while at the same time being assured that their minimal requirement may be adequately met. The nutrient density concept is a safe guideline for vitamin supplementation, is easily understandable and can be valuable for the 
guidance of athletes and coaches.

\section{Summary}

Athletes involved in strenuous exercise of long duration tend to change their dietary habits depending on the daily quantitative energy expenditure. These changes may be positive, such as increased meal frequency or negative as far as composition of the diet is concerned.

This article reviews aspects of energy expenditure and its relation to dietary habits, quantitative and qualitative intake of macro- and micro-nutrients. The influence of sports activities on possibly increased requirements for vitamins is discussed and an attempt is made to relate micro-nutrient intake to daily energy needs. This results in the proposal of a (minimal) mutrient density concept for athletes involved in heavy training.

\section{REFERENCES}

1. Ardle Mc., W.D., F. Katch and V.L. Katch.

Nutritional aspects of human physical and athletic performance.

Charles C. Thomas. Springtield, 1981.

2. Bamili M.S. et al.

Impact of long term, low dose B-complex vitamin supplements on vitamin status and psychomotor performance of rural school boys.

Nutrition Research 2: 147-53, 1982 .

3. Beek, E.J. van der, L.O. van Dokkum and J. Schrijver.

Marginal vitamin intake and physical periormance in man: possible implications for military personnel.

Ned. Militair Geneesk. Tijdschrft 37: 47-53, April 1984.

4. Beek, E.J. van der et al.

Onderzoek naar de vitamine B1-vitamine B2 - stallus en het effect van suppletie met een gecombineerd vitamine- en ijzerpreparaat op de fysiologisch meetbare prestaties.

TNO rapport no. V 81.467/180204, 1981.

5. Bell, R.D. and G. Johnson.

Der Einfluss won Vitamin-E. Verablolgung wathrend eines Trainings auf die Arbeitsreaktionen mänlicher und weiblicher Leistungssportler.

Sportartzt u. Sportmed. 27 (8):178-81, 1976.

6. Buskirk, $E_{\text {. and }} E_{\text {. Haymes. }}$

Nutritional requirements for women in sport.

Women and sport: A national research conference.

University Park, Penn State University, 1972. 
7. Creff, A.F. and L. Berard.

Dietétique Sportive.

Masson, Paris, 1976.

8. Creff, A.F. and L. Bérard.

Manual pratique de l'alimentation de sportif.

Masson, Paris, 1980.

g. Cureton, $T$.

The diet of schoolboy athletes can be improved.

Athietic J. Sept. 50:71, 1969.

10. Dam, B. van.

Vitamins and sport.

Brit. J. Sports Med. 12 (2): 74-9, 1978.

11. Dam, B. van and E.Waterioh.

Die Wirkung eines Multivitamin-Elektrolyt-Prăparates auf einige biochemische Variabelen sowie auf leistungsbeeinflüssende Faktoren im Fechten.

Leistungssport $9(2): 110-5,1979$.

12. Darden, $E$.

Nutrition and athletic performance. Chapter 6, page 94-100.

The athletic Press; , Pasadena, 1977.

13. Fox, E.L.

Sports Physiology, p. 260.

W.B. Saunders Company, Philadeliphia, 1979.

14. Haralambie, G., J. Keul, A. Baumgartner and K.H. Winker et al.

Die Wirkung eines Multivitamin-Elektrolytgranulats auf Elektrodermalreflex und neuro-

muskuläre Erregbarkeit bei lang währender Körperarbeit.

Schweizerische Zeitschrift für Sportmedizin $23(3): 113-28,1975$.

15. Haymes, E.M.

The use of vitamin and mineral supplements by athletes.

Journal of Drugs Issues 3:361-70, 1980 .

16. Herbent, V. el al.

Destruction of vitamin $\mathrm{B}$ by viltamin $\mathrm{C}$.

Am. J. Clim. Nutr. 30:297, 1977.

17. Hollman, W. and Th. Hettinger.

Sportmedizin - Arbeits _ und Trainingsgrundlagen.

F.K. Schattauer Verlag, Stuttgart, 1976.

18. Howald, $\mathrm{H}$. and $\mathrm{B}$. Segesser.

Ascorbic acid and athletic performance.

Academy of Sciences, New York, 258:485-64, 1975.

19. Huse, D.M. and F.A. Nelson.

Basic, balanced diet meets requirement of athelets.

Physician Sports Med. 5 (1): 52-6, 1977. 
20. Jakowlew, $\mathbf{N}$.

Emăhrunggrundlagen de Leichtatheleten.

Der leichtathlet $28: 5-9,1975$.

21. Keul, J. G. Huber, M. Schmitt, B. Spielenberger and G. Zollner.

Die verăndenungen von Kreislauf - und Stoffwechsel - grossen bei Kindern wathrend eines

Skilanglaufes unter einem Multivitamin-Elektrolyt-Granulat.

Dt. Z. Sport Med. 30 (3): 65-70, 1979.

22. Keul, J. G. Haralambie, K.H. Winker, A. Baumgartner and G. Bauer.

Die Wirkung eines Multivitamin-Elektrolyt-Granulats auf Kreislauf undStoffwechsel bei langwăhrender Köperarbeilt.

Schweiz Z. Sportmed. 22 (4): 169-84, 1974.

23. Kindermann, $W$.

Beeinflusssung des Leistungsvermögen durch Ernährung, Elektrolyte und Vitamine.

Schweiz Zeitschrift Sportmed. 25 (4): 191-4, 1977.

24. Lawrence, J.D. R.C. Bower, W.P. Riehl and J.L. Smith.

Effects of alpha-Tocopherol acetate on the swimming endurance of trained swimmers.

Amer. J. Clin. Nutr. 28 (3): 205-8; 1975.

25. Levander, O.A. and L. Chang.

Micronutrients interactions: vitamins, minerals and hazardous elements.

Annals of The New York Academy of Science, vol. 355, 1980.

26. Mashford, M.L.

Vitamins for the athlete:.

Austral. J. Sports Med. 5 (2): 38-9, 1973.

27. Mathews, D.K. and E. L. Fox.

The physiological basis of physical education and athletics.

W.B. Saunders Company, Philadelphia, 1979.

28. National Research Council: Committee on Dietary Allowances.

Recommended Dietary Allowances.

National Academy of Sciences, Washington, 1980.

29. Newmark H.L. et al.

Stability of vitamin B12 in the presence of ascorbic acid.

Am. Journal of Clin. Nutr. 29:645, 1976.

30. Nöcker, J.

Die Ernăhrung des Sportlers, Chapter 4, page 51-8.

Hoffmann Verlag, Schondorf, 1978.

31. Prokop, $L$.

Vitamine und sportlliche Leilstungstähigkeit.

Oesterr J. Sportmed. $8 \cdot(4):$ 3-8, 1978.

32. Saris, W.H.M.

Aerobic power and daily physical activity in children. Dissertation Nijmegen.

Krips Repro Meppel, 1982. 
33. Saris, W.H.M.M. van Em-Baart and F. Brouns.

Nutritional problems in professional cyclists.

In preparation, 1986.

34. Saltin, B. and J. Karlsson.

Die Ernahrung des Sportlers.

In: "Zentrale Themen der Sportmedizin", p. 142.

W. Holiman (ed). Springer Verlag, Berlin, 1977.

35. Schneider, $F$.

Die Enahnung des Spontlers.

Med. U. Sport 19 (11): 321-9, 1979.

36. Sichreurs $W$.

Vitaminen in Nederland.

Instituut CIVO-TNO. Publication L. Zeist, The Netherlands, 133, 1981.

37. Sharmain, 1.M.

The alleged ergogenic properties of vitamin $E$.

Med. dello Sport 29 (6): 223-7, 1976.

38. Shephard, R.J.

Vitamin $E$ and athletic performance.

J. Sports Med. 23: 461-70, 1983.

39. Senger, $H$. and $S$. Israel.

Konzentrationsänderungen der Askorbinsăure im Blut und im Harn wăhrend und nach körperlichen Belastungen.

Med. u. Sport 15 (4): 105-10, 1975.

40. Strauzenberg S.E.

Food intake in the different sports activities.

In". "Nutrition dietetics and sport"', p. 717-8.

Ficci, G. A. Venerando (eds).

Edizioni Minerva Medica, Rome, 1978.

41. Talbol, D. and $\mathrm{U}$. Jamieson.

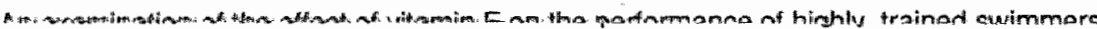

Can. J. Appl. Sport Sci. 2 (2): 67-9, 1977.

42. Troll, $A$.

La préparation au sport.

Moniteur des Pharmacies et des Laboratoires 32 (1327): 2121-33, 1978.

43. Vitousek, S.H.

is more better?

Nutrition Today $14(6): 10-4,1980$.

44. Williams, M.H.

Nutritional aspects of human physical and athletic performance.

Charles C. Thomas, Springfield, 1976. 
45. Wise, $A$.

Nufrient interrelationships.

Nutrition Abstracts and Reviews $50(5): 319-33,1980$.

46. Wịn, J.F. de and M. van Erp-Baart.

Foodpattem, body-compasition and physical conditions of heavy weight competition rowers.

Voeding $41(1): 13-8,1980$.

47. Weiner, M. and J. Rothschild.

The vitamin that likes oxygen.

Runnersworld Feb 87-9, 1980. 


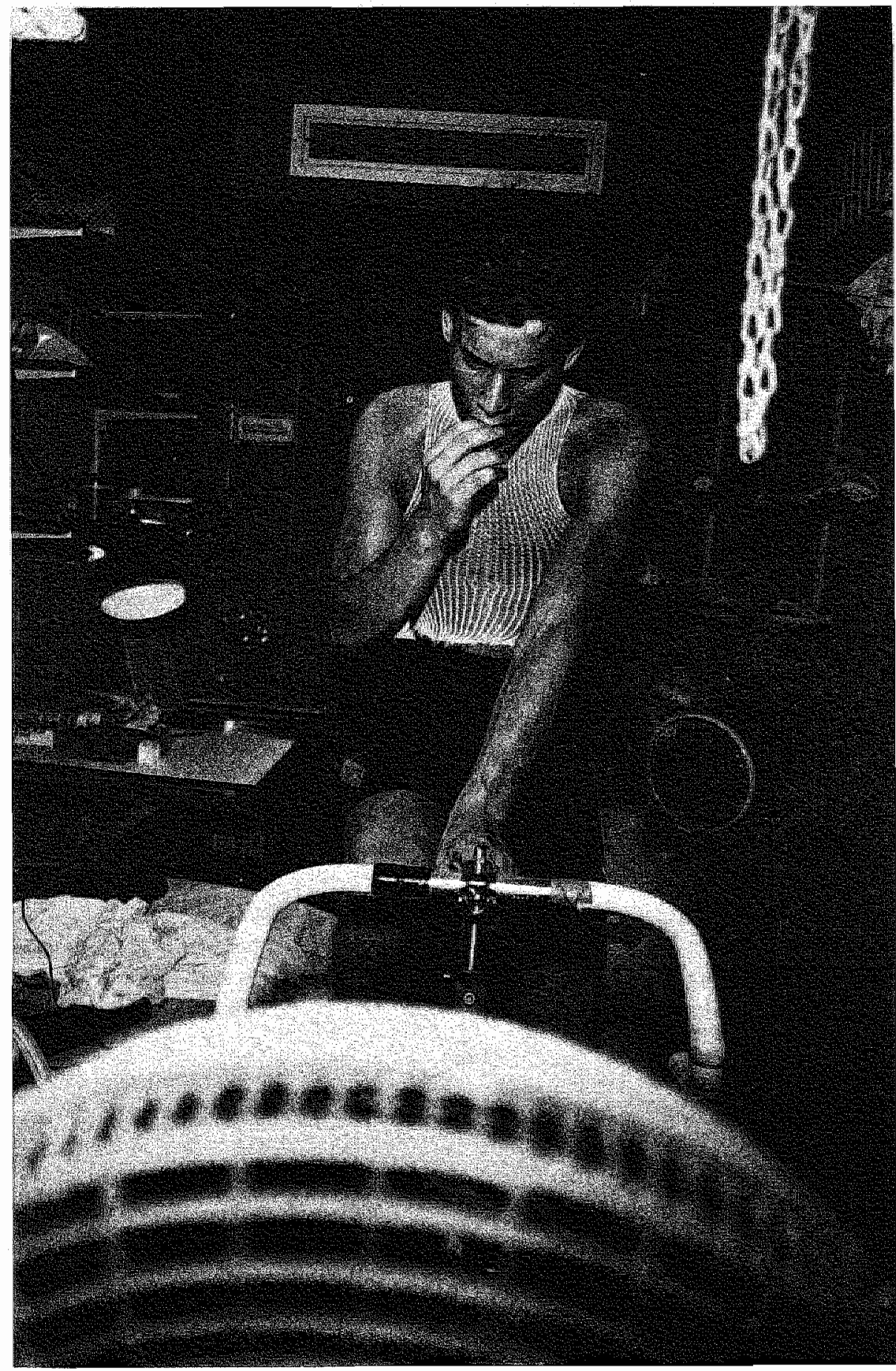




\title{
CHAPTER II: EATING, DRINKING AND CYCLING, A CONTROLLED TOUR DE FRANCE SIMULATION STUDY, PART 1.
}

\author{
F. Brouns, W.H.M. Saris, J. Stroecken, E.Beckers, \\ R. Thijssen, N.J. Rehrer and F. ten Hoor
}

\section{Introduction}

Consensus exists among most nutritionists that a normal, quantitatively and qualitatively well balanced diet will be sufficient for any sportsman or -woman in any situation. However, it has recently been described that athletes performing intensive long lasting exercise on a day to day basis are faced with the problem that consuming a normal well balanced diet may become quite impossible (Brouns, 1986). The reasons for this are the following: 1.-The adverse effect between physical and mental stress and appetite; 2.-Intolerance for large food volume in the exercising athlete, whenever food intake exceeds 20-25 MJ/day; 3 .-The reduced number of 'resting' hours available for consumption and digestion.

It has been suggested that an inverse relationship exists between food intake and energy expenditure (Donath, 1975) so that it may be impossible to maintain regular meal schedules and sufficient energy intake on days that energy expenditure is very high. In order to compensate, athletes may fall into a nibbling eating pattern, more or less eating continuously throughout the day (Kirsch, 1981; v. Erp-Baart, 1988), thus avoiding a large bulk of food in the stomach, which may induce abdominal distress. These nutritional problems in endurance athletes are well known in practice. However, no controlled studies have been performed. Another wide spread belief is that the ingestion of water will always be better for reasons of rehydration and that there is no reason to combine the fluid with nutrients. This in contrast to studies that show that glucose and electrolyte containing beverages restore plasma volume better than water alone, (Costill, 1973; Brandenberger, 1977; Candas, 1977) and to the increasing evidence that ingestion of plain water may lead to abnormally low levels of plasma electrolytes, whenever the volumes of fluid replaced are substantial (Noakes, 1985; Hiller, 1985, Decombaz, 1981). From observations of professional cyclists during the Tour de France (Saris, 1988 ) it is known that it is possible to maintain adequate energy and fluid intakes over a prolonged period of competition, even when energy expenditure exceeds $24 \mathrm{MJ} /$ day and fluid intakes (in order to compensate losses) reach a level of more than 10 l/day. However, these cyclists were only able to do so during competition - which may last up to 8 h/day - by ingestion of energy-rich foods, to a large extent as $\mathrm{CHO}$ - and electrolyte-containing 
liquids. Those subjects who were not able to maintain energy and fluid balance frequently experienced malpertormance and sometimes were forced to quit prematurely. This imbalance was commonly a result of poor food intake and/or gastro-intestinal disturbances such as diarrhea causing malabsorption and excessive fluid loss.

In professional cyciists $\mathrm{CHO}$ intake is closely related to energy intake since the major portion of energy in the selected diet (more than $60 \%$ ) comes from $\mathrm{CHO}$ (Saris, 1988). Because $\mathrm{CHO}$ is a performance limiting substrate in endurance exercise whenever exercise intensity exceeds $50-60 \%$ of maximal oxygen uptake, it may be assumed that a negative energy balance, also leading to a negative 'CHO balance', may impair performance progressively.

This may happen as a result of insufficient glycogen repletion on a day to day basis due to insufficient $\mathrm{CHO}$ intake. For this reason it was decided to do a study on the effect of repeated exhaustive endurance exercise on nutritional indices in which the data obtained in cyclists ingesting a $\mathrm{CHO}$ rich diet composed of normal foodstuffs $(\mathrm{N})$ could be compared with those obtained after the same diet supplemented with $\mathrm{CHO}$ concentrated liquids. In addition it was decided to study the daily contribution of $\mathrm{CHO}$-, fat- and proteinmetabolism to total energy exchange under these circumstances. The study was performed in a cross-over design with a randomized order of treatment. The part of the study in which the subjects received the normal $\mathrm{CHO}$ rich diet will be described and discussed in this Chapter. The effect of dietary manipulation will be discussed in Chapter III. The aim of the study was to test the following hypotheses:

- Cyclists having ad libitum available a normal but $\mathrm{CHO}$ rich diet will be able to maintain energy balance and to meet the daily $\mathrm{CHO}$ needs even in situations of repeated, high intensity, sustained cycling exercise.

- Cyclists having ad libitum available ordinary and mineralized drinks throughout the exercise period will be able to compensate for the exercise induced fluid losses.

\section{PROCEDURES AND METHODS}

\section{Subjects}

Thirteen highly trained cyclists participated in this study. Physical characteristics are presented in Table 1. 


\section{Table 1 Physical characteristics of experimental subjects}

\begin{tabular}{llr}
\hline Age & (yrs) & $20.0 \pm 2.1$ \\
Weight & $(\mathrm{kg})$ & $73.3 \pm 1.7$ \\
Height & $(\mathrm{cm})$ & $179.6 \pm 1.7$ \\
$\mathrm{VO}_{2} \max$ & $(\mathrm{ml} . \mathrm{kg}-1 . \mathrm{min}-1)$ & $65.1 \pm 1.2$ \\
Wmax & $($ Watt $)$ & $390 \pm 8.0$ \\
Wmax.kg-1 & $($ Watt $)$ & $5.3 \pm 0.4$ \\
Body fat & $(\%)$ & $12.0 \pm 0.8$ \\
\hline
\end{tabular}

Mean values \pm SEM $(n=13)$

\section{Experimental design}

The subjects were asked not to participate in vigorous training or competition during the two days preceding the stay in the laboratory and to ingest a normal but $\mathrm{CHO}$ rich diet. All subjects were informed about the nature, purpose and possible risks of the study, before giving their voluntary written consent to participate. The experiment was conducted over seven sequential days using a semi-automated respiration chamber system.

The subjects reported to the laboratory on Sunday evening (day 1) at 9:00 PM in order to get accustomed to the chamber (Fig 1). During the first day the chamber was not closed. They received a time schedulle for all activities in the forthcoming week. The next morning (day 2) a by each subject selected supply of food and fluid of known quantity and composition was made available. This supply was provided each day until the end of the experiment on Saturday morning 9:00 AM six days later. Foodstuffs for breakfast and lunch were supplied at 7:30 AM. However, extras could be obtained throughout the day upon request. Dinner was served at 6:00 PM There were no quantitative limitations. The cyclists were instructed about the importance of adequate food and fluid intake and were encouraged to eat and drink as much as desired.

Weight and volumes of foods and drinks were measured and registered in a diary allowing for analyses of $24 \mathrm{~h}$ intake as well as intake over specific periods of the day. The latter was done in order to analyze main meal and inbetween meal energy consumption. All leftovers were re-weighed and accounted for in the final calculation of energy and nutrient intake. Energy and nitrogen content of all food items had been previously determined. Protein intake was calculated daily immediately after dinner. To assure a minimum intake of $1.2 \mathrm{~g} . \mathrm{kg}^{-1}$, subjects were supplemented with a protein con- 
centrate whenever intake was calculated to be too small for that day. The reason why protein intake was set at a minimum level is discussed later.

Actual performance capacity Wmax (Watt) and maximal oxygen uptake ( $\mathrm{VO}_{2}$ max; I. min-1) were determined at 10:00 AM on day 2 during an incremental bicycle ergometer test.

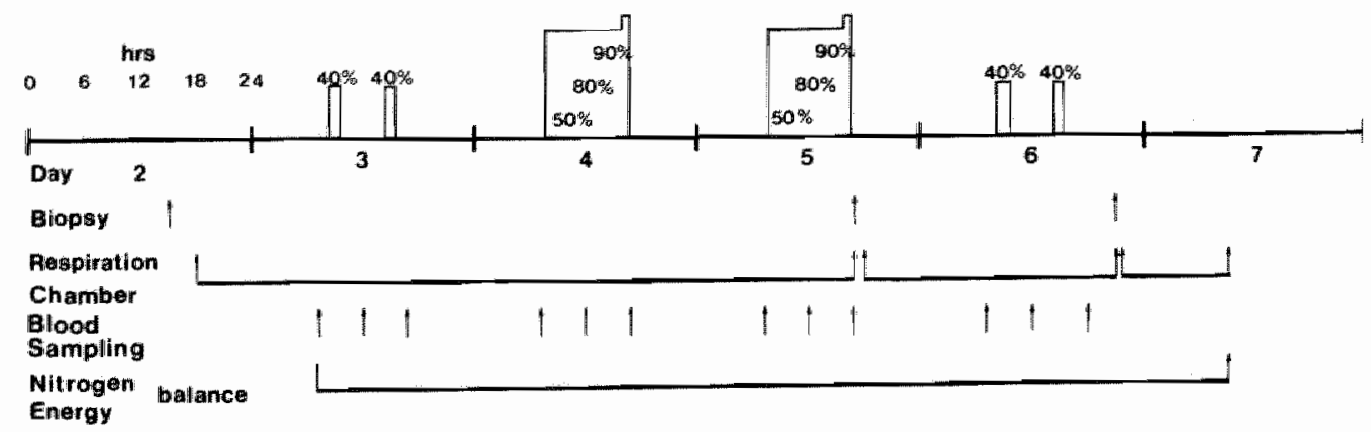

Fig 1 Experimental schedule. On day 2 actual performance capacity (Wmax; Watt) and maximal oxygen uptake ( ${ }^{*} \mathrm{O}_{2}$ max $\left.^{-} \mathrm{ml} \cdot \mathrm{min}^{-1}\right)$ were determined at 10:00 AM using an incremental bicycle ergometer test. Day 3 and 6 were rest days; cycling at $40 \%$ Wmax during 45 min at 10:00 AM and 2:00 PM. Day 4 and 5; exercise to exhaustion. Day 7; end of the experiment at 9:00 AM. A muscle biopsy (Chapter V) was taken on days 2, 5 and 6. Blood sampling was done at 7:00 AM, 12:00 AM and 4:00 PM on days 3 to 6.

The respiration chambers were closed at 4:00 PM on day 2 and measurements for calculation of energy expenditure were started. Days 3 and 6 represent standardized rest days during which each subject cycled for $45 \mathrm{~min}$ at $40 \%$ Wmax at 10:00 AM and 2:00 PM respectively. Rest days were included in the program in order to determine resting metabolism and resting food and fluid intake for comparison with those gathered from the two exhausting exercise days. On days 4 and $5_{*}$ each subject exercised until exhaustion. Exercise was started at 10:00 AM with a 30 min warming-up, followed by exercise at intensities of $80 \%$ and $50 \%$ Wmax respectively. $80 \%$ and $50 \%$ Wmax were chosen in order to mimic riding ahead of the group or benefitting from wind shielding within the group respectively. At 12:00 AM exercise was interrupted for 5 min to collect blood samples, to measure body weight and to change the sweat capsules. Thereafter exercise was continued 
at $50 \%$ and $60 \%$ Wmax allowing for food intake. After 3 h 44 min exercise was continued again at $80 \%$ and $50 \%$ Wmax in 3 min intervals. Finally at about 2:30 $\mathrm{PM}$, the Wattload was set at $90 \%$ Wmax and the cyclists were asked to maintain pedaling frequency greater than 60 revolutions per min. $90 \%$ of Wmax - equivalent to about $80 \% \mathrm{VO}_{2}$ max - was chosen in order to simulate a finish on a mountain top (Fig 2). During exercise, fluids were available ad libitum (tea, coffee, milk "lemonade and a placebo 'sport drink' artificially sweetened, colored, and mineralized water).

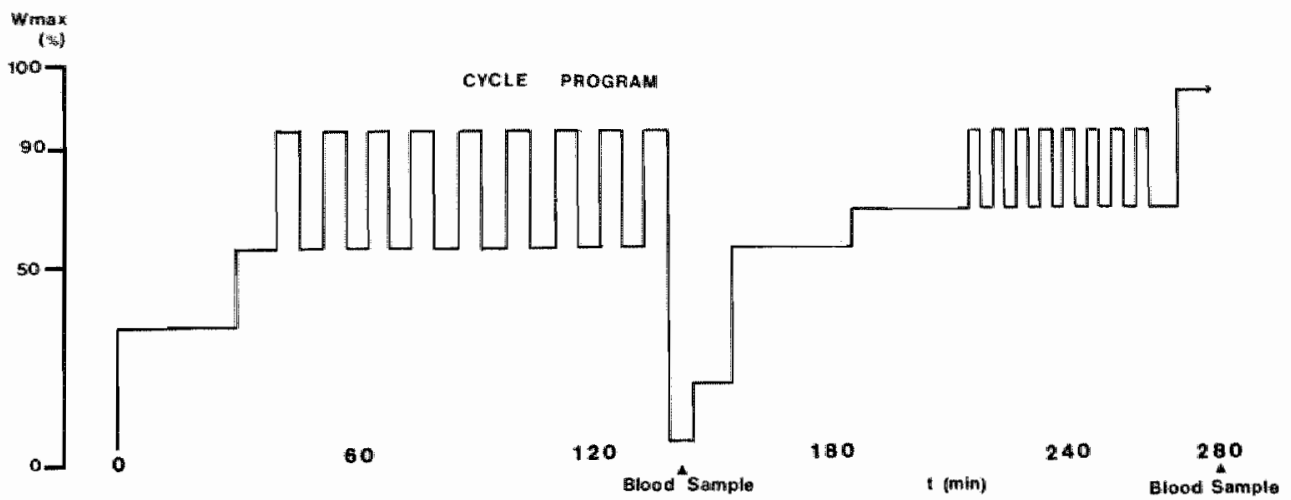

Fig 2 Cycling program during days 4 and 5. There was a warming-up of 30 min at $30 \%$ Wmax, followed by $10 \min 50 \%$ Wmax, followed 9 times by $6 \min 80 \%$ Wmax and $6 \min 50 \%$ Wmax. Thereafter exercise was shortly internupted for collecting blood and sweat samples and was then continued at $50 \%$ Watt for $10 \mathrm{~min}$, followed by 50 and $60 \%$ Wmax both for $30 \mathrm{~min}$. Exercise intensity was than increased to $80 \%$ Wmax for 3 min followed by $3 \mathrm{~min}$ at $50 \%$ Wmax, which was repeated 8 times. Finally exercise intensity was increased to $90 \%$ Wmax which had to be performed to exhaustion.

Blood samples were drawn into EDTA evacuated tubes from a teflon catheter which was inserted into an antecubital vein at 7:00 AM and was connected with a three-way stopcock. Sweat samples were collected by absorption into pre-dried pads located in water and air tight capsules (Lemon, 1983). The sweat capsules were placed in the infraspinous fossa of the scapula and kept in place by an elastic mesh vest.

Body weight (naked) was measured daily with a digital balance accurate to $100 \mathrm{~g}$, and registered at 7:00 AM, 12:00 AM, 3:00 PM and 9:00 PM respectively. 12:00 $\mathrm{AM}$ and 3:00 $\mathrm{PM}$ coincided with halfway and end of cycling exercise on days 4 and 5 . Feces and urine were kept at $-20^{\circ} \mathrm{C}$ in a 
deep freezer toilet and were collected in $24 \mathrm{~h}$ periods.

\section{Analyses}

Energy expenditure was measured using an indirect automated calorimeter as previously described by Schoffellen et al (1986), allowing for continuous determination of $\mathrm{VO}_{2}$ and $\mathrm{VCO}_{2}$ and registration of environmental conditions (temperature, relative humidity and barometric pressure). Gasflows were measured with a dry gasmeter (Dort, the Netherlands), oxygen was analyzed using a Servomex(\$) paramagnetic oxygen analyzer (Taylor, England) and carbon dioxide using an intrared $\mathrm{CO}_{2}$ analyzer (Hartmann and Braun, Germany).

Energy expenditure was calculated according to the formula of Consolazio (1963):

\section{$E=3.78 \dot{V O}_{2}+1.14 \dot{V C O}_{2}-2.98 \mathrm{Nu}$}

Where $\mathbf{E}$ is energy expenditure ( $\mathrm{kCal}$ ), $\mathbf{V O}_{2}$ is oxygen consumption ( $\mathrm{ml}$. min${ }^{1}$ ), $\vee \mathrm{CO}_{2}$ is $\mathrm{CO}_{2}$ production ( $\left.\mathrm{ml} \cdot \mathrm{min}-{ }^{-1}\right)$ and $\mathrm{Nu}$ is the amount of nitrogen excreted in urine $(\mathrm{mg})$.

Daily energy balance was calculated from energy expended and energy intake as calculated from daily food and fluid consumption. Corrections were made for energy losses from feces, urine and sweat and for the blood samples drawn. Energy content of food, fluid, feces, urine and blood was determined by bomb calorimetry (IKA Germany). Energy content from sweat was calculated from total sweat urea, assuming that the remainder was negligible.

Sweat volume collected in the capsules was determined by capsule weight changes using a Mettler( ${ }^{\circledR}$ analytical balance. Total sweat loss was determined from body weight change while accounting for fluid intake, urine production, blood volume loss, and respiratory water loss (Mitchel, 1972). Sweat urea content was determined enzymatically (urease method Boehringer (396346).

Nitrogen content of feces, blood and urine was determined by the chemoluminescence method (Antek Germany). Daily nitrogen losses were then calculated.

The quantitative contribution of $\mathrm{CHO}$, fat and protein to total daily energy intake was calculated from daily intake records using a UCV computer coding system for Dutch foodstuffs (Hautvast, 1975, Boeyen, 1983). CHO and fat oxidation was calculated from non-protein respiratory quotient $(R)$.

Protein oxidation was calculated from daily nitrogen losses in urine and sweat. From the data gathered the relative contribution of $\mathrm{CHO}$, fat and protein to total $24 \mathrm{~h}$ energy metabolism as well as the relative contribution to energy metabolism during exercise was calculated. 
Plasma volume changes were calculated from hemoglobin and hematocrit values according to Dill and Costill (1974). Hematocrit was determined in all blood samples. Hemoglobin was measured with the hemoglobincyanide method.

\section{Statistics}

Student's paired t-test was used to compare the data of the first standardized rest day to those of the following exercise and recovery days.

For all analyses, the 0.05 level was used as the minimum level of confidence for statistical significance.

\section{RESULTS}

\section{Energy}

Energy intake (EI) from food and fluid was markedly constant during the whole experimental period despite the fact that exhausting cycling exercise was executed on days 4 and 5 of the experiment (Table 2) A small but not statistically significant increase in El was found during the recovery day.

\section{Table 2 Energy intake and expenditure}

\begin{tabular}{ccccc} 
Day & 3 & 4 & 5 & 6 \\
\hline
\end{tabular}

$\begin{array}{lllll}\text { Intake } & 19.4 \pm 1.1 & 19.3 \pm 0.8 & 19.5 \pm 0.9 & 21.2 \pm 0.9 \\ \text { Expenditure } & 16.1 \pm 0.3 & 26.8 \pm 0.6 \ldots & 25.2 \pm 0.4 \ldots & 16.1 \pm 0.3\end{array}$

(Mean values \pm 1 SEM (MJ.day-1).

Day 3 and 6 are resting days, day 4 and 5 are exercise days.

Statistical significance of differences with respect to the values on day 3 is indicated by $\ldots$...p $<0.001$

Energy expenditure (EE) as measured in the respiration chamber was similar on both rest days and increased by more than $60 \%$ to $26 \mathrm{MJ} /$ day as a result of exhaustive cycling. This level of $E E$ is equivalent to $E E$ levels previously observed during the Tour de France (Saris, 1988).

As a result of the constant El but strongly increased $E E$, energy balance was -8 and $-10 \mathrm{MJ}$ negative during the exhaustive cycling days, 4 and 5 respectively (Fig 3). 


\section{Nutrient intake}

$\mathrm{CHO}$ and protein intake levels - 62.5 en\% and 12.5 en\% respectively - were comparable to those observed during the Tour de France (Saris, 1988). The relative contribution of $\mathrm{CHO}$, protein and fat to total $\mathrm{El}$ also remained constant. (Figs 4 and 5), except for the recovery day when $\mathrm{CHO}$ intake increased significantly to $70 \mathrm{en} \%$.

The absolute amount of $\mathrm{CHO}$ and protein intake $(\mathrm{g})$ increased during the recovery day as a result of increased food intake.

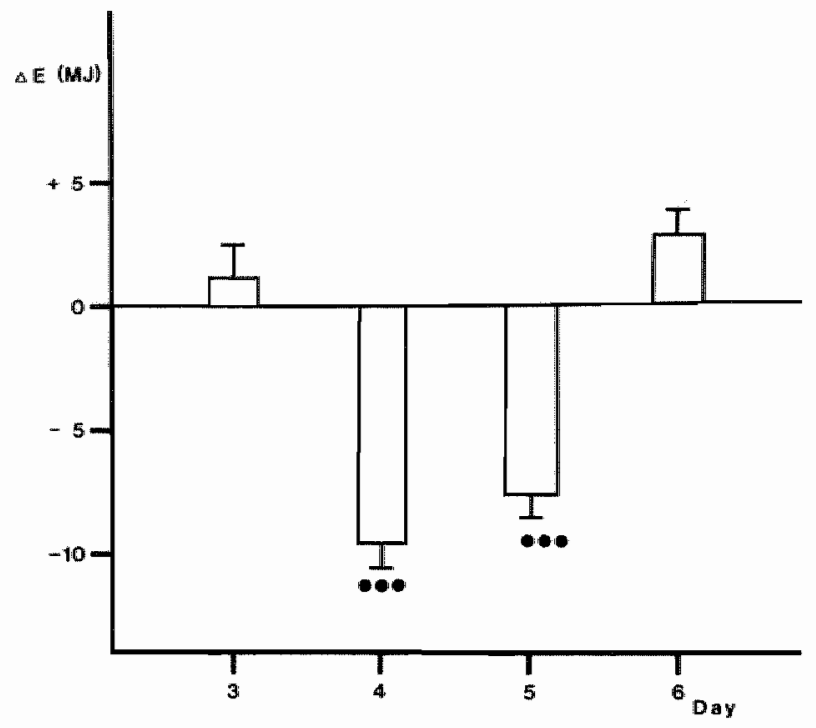

Fig 3 Mean daily energy balance derived from total energy intake minus total energy expenditure. Corrections were made for energy losses in urine, foces, bloodsamples and sweat. Day 3 and 6 are resting days; 4 and 5 are exercise days. Vertical bars indicate 1 SEM ( $n=13)$. Statistcal of differences with respect to the corresponding values on day 3 is indicated by $\ldots<0.001$. 


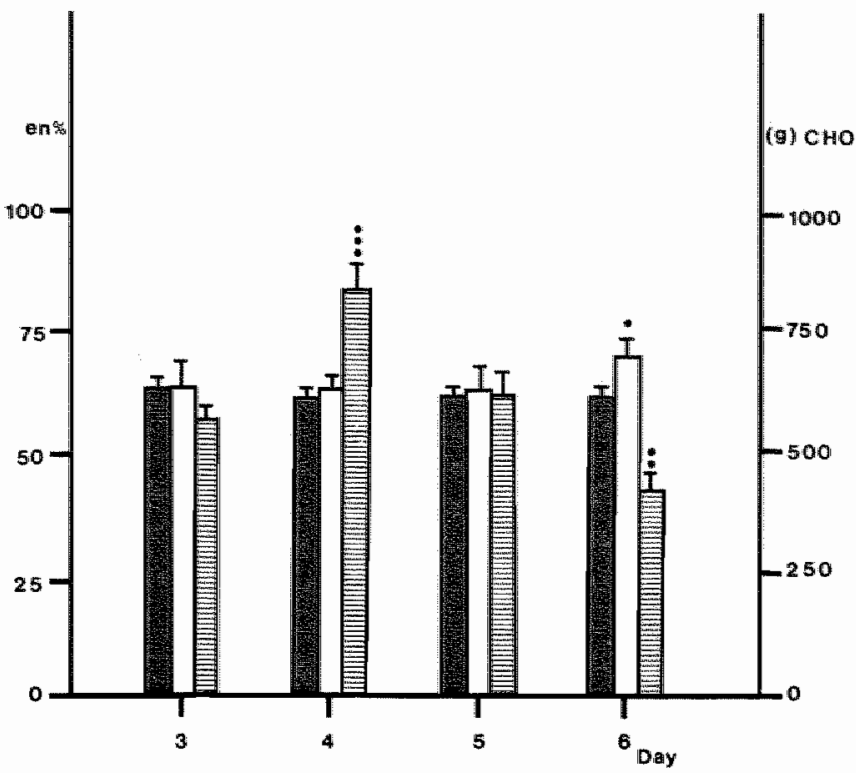

Fig 4 Mean daily $\mathrm{CHO}$ intake ( $\square \mathrm{g}$; 国en\%) and $\mathrm{CHO}$ oxidized ( $\mathrm{Og}$ ). The amount of $\mathrm{CHO}$ oxidized was calculated from nom protein R. Vertical bars indicate 1 SEM $(n=13)$. Statistical significance of differences with respect to the corresponding values on day 3 is indicated by $. p<.05 ; . . p<.01 ;$...p $<0.001$.

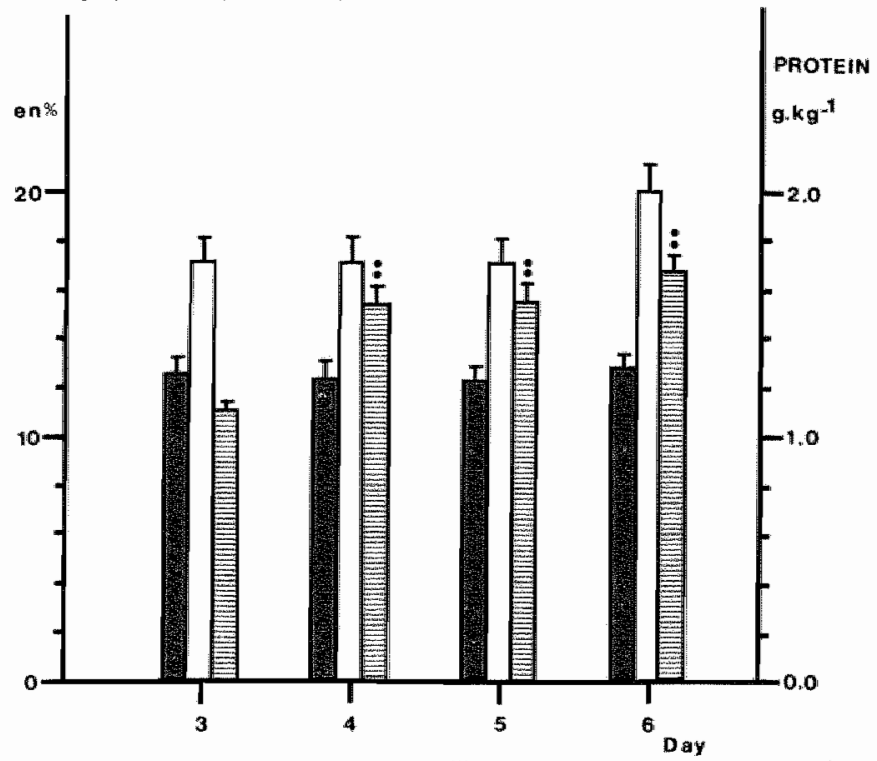

Fig 5 Mean daily protein intake ( $\square \mathrm{g} \cdot \mathrm{kg}^{-1} ; \mathrm{en \%}$ ) and protein oxidized ( amount of protein oxidized was calculated from nitrogen excretion in urine and sweat. Vertical bars indicate 1 SEM $(n=13)$. Statistical significance of differences with respect to the corresponding values on day 3 is indicated by $\ldots$ p $<.01$. 


\section{Nutrient oxidation}

The amount of $\mathrm{CHO}$ and protein oxidized have also been plotted in Figs 4 and $5 . \mathrm{CHO}_{\text {, tat }}$ and protein oxidation were estimated from the calculated $\mathrm{R}$ and the measured nitrogen excretion urine and sweat. A comparison with the intake of these nutrients reveals that $\mathrm{CHO}$ intake was greater than $\mathrm{CHO}$ oxidation on both rest days, while oxidation exceeded intake on the first exercise day, was similar to intake on the second exercise day and significantly smaller during the recovery day. Protein oxidation as calculated from $\mathrm{N}$ loss in sweat and urine was less than

protein intake on the first rest day. During the following exercise days and also on the recovery day protein oxidation increased significantly, almost balancing protein intake. The mean levels of oxidation and intake both exceeded $1.5 \mathrm{~g} \cdot \mathrm{kg}^{-1} \mathrm{BW}$. The daily relative contribution of $\mathrm{CHO}$, protein and fat to energy expenditure is presented in Fig 6 .

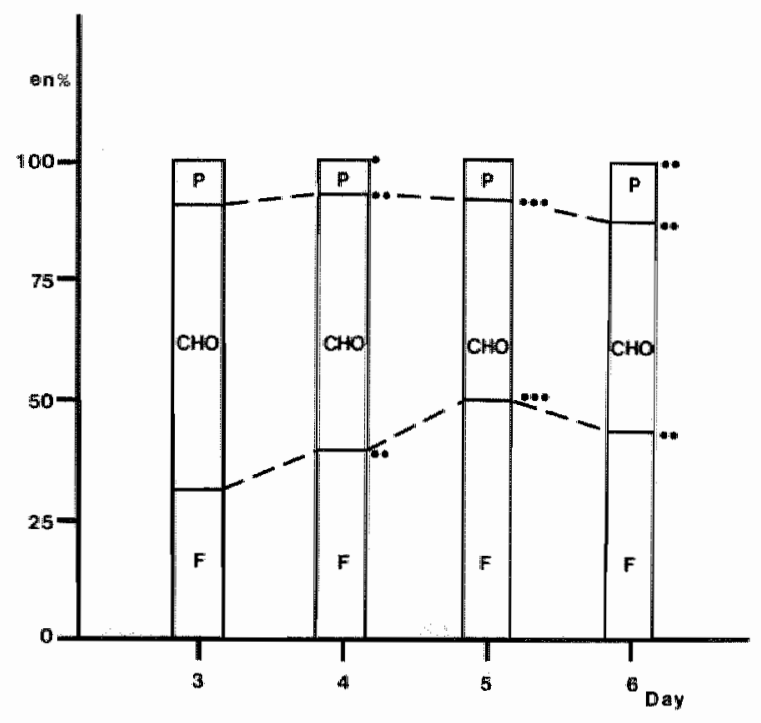

Fig 6 Relative contribution of multrients to total energy expenditure calculated from non protein $\mathrm{R}$ and nitrogen excretion in urine and sweat. $\mathrm{CHO}=$ carbohydrate; $\mathrm{F}=$ fat; $P=$ protein. Statistical significance of differences with respect to the values on day 3 is indicated by .p<.05; ..p $<.01 ;$. $p<0.001$.

During the rest day $\mathrm{CHO}$ had the largest contribution to energy metabolism $(58.2 \pm 6.1 \%)$. This contribution decreased gradually and significantly on days 4 and $5(51.4 \pm 3.1 \%$ and $40.6 \pm 3.4 \%$ respectively) whereas it remained significantly lower during the recovery day $(55.3 \pm 4.0 \%)$ compared to day 3 .

Concurrently the contribution of fat to total energy supply gradually increased. 
The percentual contribution of protein decreased significantly on the first exercise day from $9.5 \pm 0.7$ to $7.1 \pm 0.5 \%$ and remained unchanged on the second exercise day $(8.2 \pm 0.7 \%)$. A significant increase occurred during the recovery day. $(14.6 \pm 1.3 \%)$ compared with day 3 . Calculation of the relative contribution of $\mathrm{CHO}$, fat and protein during the sustained exercise period on day 4 and 5 revealed a highly significant increase in fat and decrease in $\mathrm{CHO}$ metabolism on day 5 compared to day 4 (Table 3). The quantitative rellative contribution depended largely on the level of energy expenditure so that the figures obtained at rest and during exercise are quite different. This difference is the most pronounced with respect to protein.

\section{Food consumption pattern}

Analysis of the daily consumption pattern shows that the contribution of main meals (breakfast, lunch, dinner) to total energy intake amounted $65.7 \%$ to $69.5 \%$ on the different experimental days. There was no significant difference between rest and exercise days. The in-between meal food consumption accounted for 30.5 to $34.3 \%$ of total energy intake. This eating pattern remained markedly constant throughout the experiment (Fig 7).

Table 3 Substrate oxidation at rest and during the entire exercise period

\begin{tabular}{|c|c|c|c|c|}
\hline & \multicolumn{2}{|c|}{ Day 4} & \multicolumn{2}{|c|}{ Day 5} \\
\hline & Rest & Ex & Rest & Ex \\
\hline $\mathrm{CHO}$ & $35.6 \pm 4.3$ & $58.8 \pm 3.2$ & $27.2 \pm 4.4$ & $46.6 \pm 3.9$ \\
\hline Fat & $47.4 \pm 4.8$ & $37.9 \pm 3.1$ & $52.8 \pm 4.0$ & $49.8 \pm 3.9 \ldots$ \\
\hline Prot & $17.5 \pm 1.0$ & $3.3 \pm 0.3$ & $19.2 \pm 1.5$ & $3.6 \pm 1.9$ \\
\hline
\end{tabular}

Relative contribution (\%) of nutrients to energy exchange as calculated from non protein $\mathrm{R}$ and nitrogen excretion in urine and sweat.

Statistical significance of differences with respect to the values on day 4 is indicated by $. p<0.05 ; \ldots p<0.001$. 
FOOD INTAKE

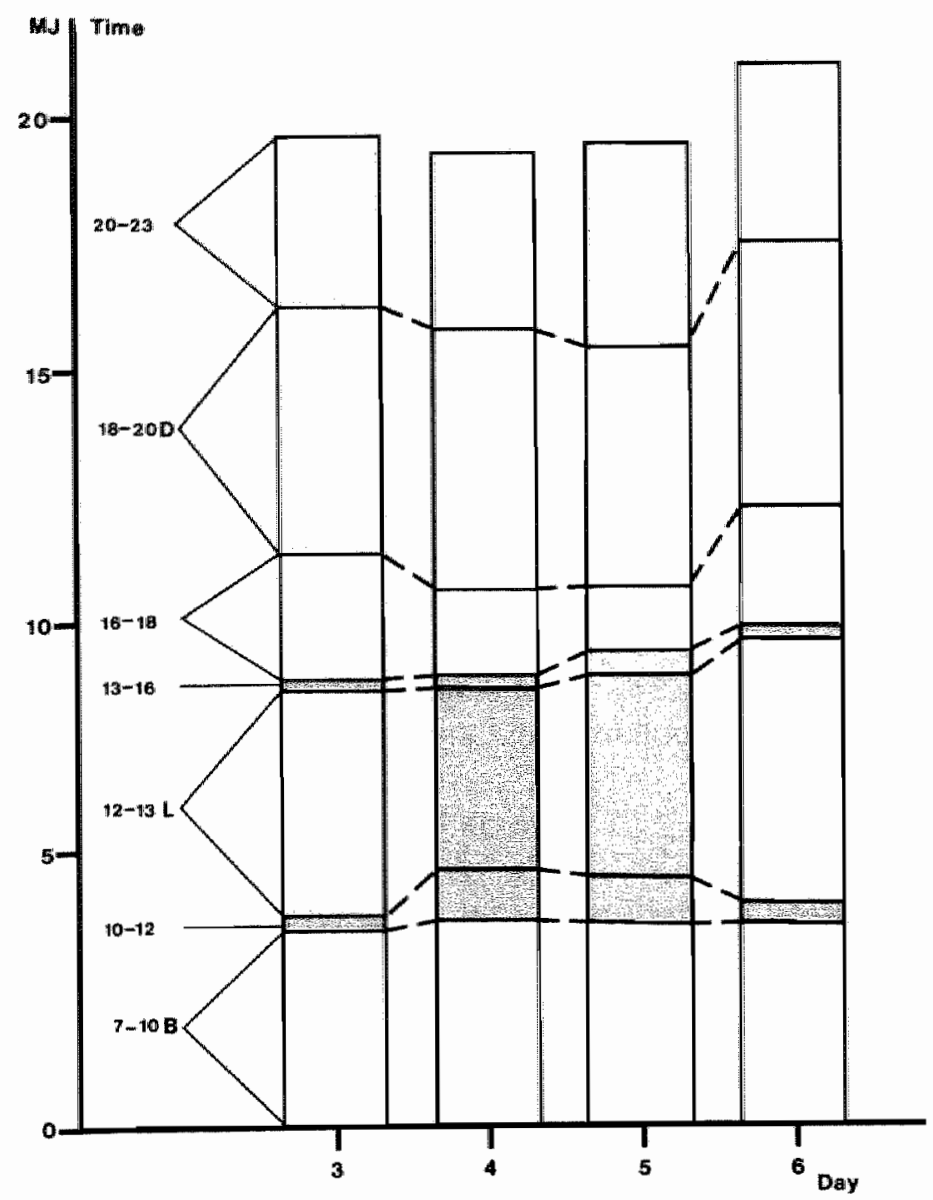

Fig 7 Relative contribution of main meals and in-between meals to total daily energy intake. $B=$ breakfast $: L=$ lunch; $D=$ dinner .

Tood intake during exercise.

\section{Fluids}

Daily fluid intake and loss at rest and during exercise periods is presented in Table 4. As a result of fluid intake during exercise, total fluid intake increased to more than $6 \mathrm{l} /$ day. Fluid intake at rest remained about the same over the whole period $(3-4 \mathrm{l} /$ day). Fluid intake during exercise exceeded $3 \mathrm{l} /$ day; sweat loss and respiratory fluid loss approximated $4 \mathrm{l} /$ day (Table 4). Mean urine production increased on both exercise days, compared to the rest days. 
Table 4 Fluid intake/loss

\begin{tabular}{|c|c|c|c|c|c|c|c|c|}
\hline Day & & & & & & & & \\
\hline Conditions & 3 & & 4 & & 5 & & 6 & \\
\hline & intake & loss & Intake & loss & Intake & loss & Intake & loss \\
\hline REST & $4.01 \pm 0.19$ & & $3.14 \pm 0.22$ & & $3.50 \pm 0.29$ & & $3.70 \pm 0.25$ & \\
\hline Urine & & $1.81 \pm 0.19$ & & $2.81 \pm 0.32$ & & $2.11 \pm 0$ & & 1.6840 .11 \\
\hline Feces & & $0.15^{4}$ & & $0.15^{*}$ & & $0.15^{\circ}$ & & $0.15^{*}$ \\
\hline Resp.water & & $0.40^{\circ}$ & & $0.32^{*}$ & & $0.32^{*}$ & & $0.40^{\circ}$ \\
\hline Sweat & & $0.50^{\star}$ & & $0.40^{\circ}$ & & $0.40^{\prime \prime}$ & & $0.50^{*}$ \\
\hline EXERCISE & & & $3.18 \pm 0.16$ & & $3.17 \pm 0.20$ & & & \\
\hline Sweall & & & & $3.50 \pm 0.25$ & & $3.38 \pm 0$ & & \\
\hline Resp.water & & & & $0.55 \pm 0.02$ & & $0.52 \pm 0$. & & \\
\hline Mean total & 4.01 & 2.86 & 6.32 & 7.74 & 6.67 & 6.89 & 3.70 & 2.73 \\
\hline
\end{tabular}

Mean values \pm 1 SEM $\left(l_{;} n=13\right)$. Fluid loss from sweat and respiratory water was not calculated on the rest days ( 3 and 6 ). "mean daily loss under resting conditions taken from Weitzman (1980).

On both rest days plasma volume, as a reflection of the hydration status of the blood, showed a significant increase at 12:00 and 4:00 PM compared to 7:00 AM on the first day. This increase was not observed on either of the following exercise days. The increase during the recovery day was significantly greater than during the first rest day (Fig 8 ).

Body weight significantly decreased during the exercise days, and increased somewhat during the following $11 / 2$ day of recovery (Table 5). However, final body weight was still significantly lower than initial body weight.

Table 5 Body welght changes of experimental subjects

\begin{tabular}{lccccc}
\hline $\begin{array}{c}\text { Day } \\
\text { Time }\end{array}$ & 3 & 4 & 5 & 6 & 7 \\
\hline & & & & & \\
$7: 00 \mathrm{AM}$ & $73.7 \pm 2.2$ & $73.4 \pm 2.3$. & $72.4 \pm 2.2 \ldots$. & $72.4 \pm 2.1 \ldots$ & $72.8 \pm 2.2 \ldots$ \\
$4: 00 \mathrm{PM}$ & $73.7 \pm 2.3$ & $72.9 \pm 2.3 .$. & $72.2 \pm 2.1 \ldots$. & $72.7 \pm 2.2 \ldots$ & \\
$9: 00 \mathrm{PM}$ & $74.7 \pm 2.3$ & $73.4 \pm 2.2 \ldots$. & $73.1 \pm 2.2 \ldots$. & $73.5 \pm 2.2 \ldots$ &
\end{tabular}

Mean values \pm SEM $(\mathbf{k g} ; n=13)$ Significant changes with respect to initial values on day 3 are indicated by mp< $0.01, \ldots<<0.001$. 


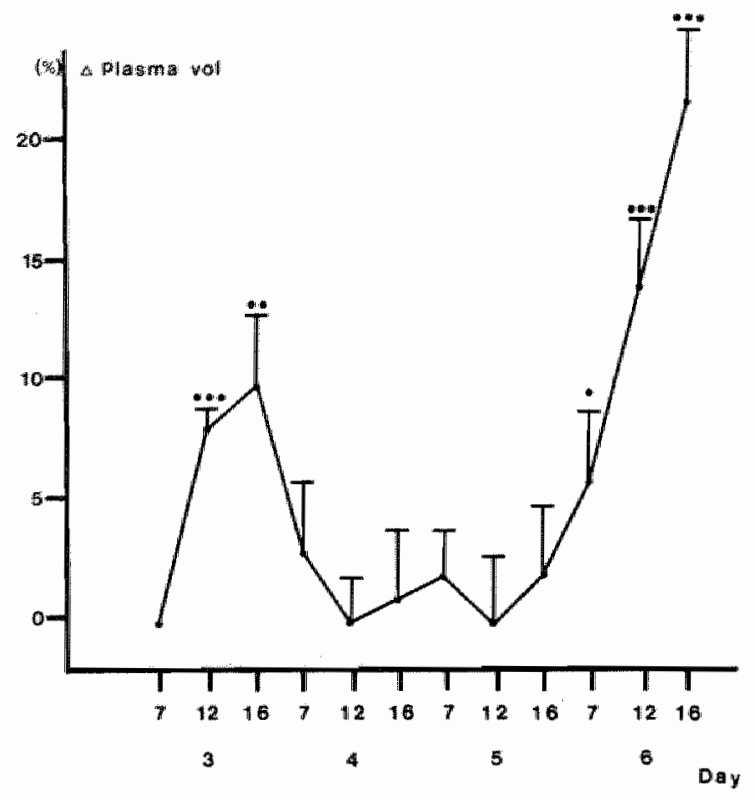

Fig 8 Percentual changes in plasma volume at rest (day 3 and 6) and during exhaustive exercise (day 4 and 5). Plasma volume on day 3 at 7:00 AM was taken as the initial value.

Statistical significance of differences with respect to the corresponding values on day 3 is indicated by,$p<05 ; \ldots p<.01 ; \ldots+0.001$.

\section{Discussion}

Although a normal well balanced diet is often recommended as being sufficient to meet the needs under all circumstances, we recently described that consuming such a diet may become impossible during long lasting intensive competitions when energy expenditure exceeds $20 \mathrm{MJ} /$ day (Brouns, 1986).

This may be of particular importance in situations where sustained competitive exercise is executed on consecutive days over a prolonged period of time, such as cycling the Tour de France (21 days). The present study was designed to analyse the effect of repeated highly intensive cycling exercise on food consumption, energy balance and fluid status of the body, when consuming a conventional but sport adapted $\mathrm{CHO}$ rich diet. The cyclists were instructed to refrain from intensive training or competition during the last 2 days prior to the stay in the laboratory and to ingest a normal but $\mathrm{CHO}$ rich diet (dietary advise was given by a dietician). During the first day in the laboratory, which was a preparation day, food intake and amount of exercise 
was controlled. At least $60 \mathrm{en} \% \mathrm{CHO}$ and a minimal protein intake of 1.2 $\mathrm{g} . \mathrm{kg}-1$ were assured. This was done in order to realize a complete build-up of endogenous substrate pools and to minimize inter individual differences in pre-test metabolic status, as it is known that hormonal changes and substrate mobilization and utilization during exercise are influenced by the state of the organism prior to exercise. Involved in this state are nutrition, degree of training, plasma hormone levels and level of physical activity (Galbo, 1983). An illustration of the influence of the pre-test state is the finding that subjects who have reduced $\mathrm{CHO}$ depots due to intake of a diet low in $\mathrm{CHO}$, to previous exercise, or to a combination of both - combust more fat and protein and less $\mathrm{CHO}$ during exercise compared to subjects with adequate $\mathrm{CHO}$ intake and sufficient rest prior to the test (Galbo, 1979, 1981; Gollnick, 1981; Lemon, 1981; Maughan, 1978). After the controlled preparation phase, the final study in the respiration chamber was started.

The results show that total energy intake exceeds total energy output whenever the cyclists have an active rest day. When competitive cycling comparable to a hard day in the Tour de France (Saris, 1988) was simulated, the cyclists showed a marked constancy in energy intake. Although they were all aware of the importance of adequate food intake, they were not able to ingest sufficient food to compensate for the increased energy expenditure.

Because the set-up of the experiment was such that food and drink was available ad libitum within handreach throughout the day the reason for this maladaptation of energy consumption most probably is due to a suppressed appetite and/or intolerance of the gastro-intestinal tract to bear and digest large bulk loads of food. Moreover, the cyclists indicated that the exercise was too intensive to be able to ingest large amounts of food and/or were too exhausted to eat. As a result there was no change in quantitative food intake during the both exercise days compared to the foregoing standardized active rest day.

The nibbling eating pattern as described by Kirsch and Von Ameln (1981) was also present in this study. In-between meal snacking represented 30 $34 \%$ of the total energy intake in these cyclists, the majority of which took place in the evening (Fig 7). This in-between meal energy consumption is quantitatively comparable to that found in other competitive sport events (De Wijn, 1981; Van Erp-Baart, 1988) and may be explained by a continuous hunger for small, $\mathrm{CHO}$ rich snacks.

Although we expected that energy consumption during the evening would be increased after intensive cycling, in order to compensate for the increased energy expenditure, we did not see such a compensation. There tended to be what might be called a 'voluntary energy depletion' which finally led to a slightly but not significantly increased energy intake and a significantly increased $\mathrm{CHO}$ intake $(70 \mathrm{en} \%)$ during the following recovery day, indicating a preference for $\mathrm{CHO}$ rich foods. As a result, energy balance was positive on 
the active rest days but significantly negative during the exercise exhaustion days (Fig 2). CHO had a large contribution to energy production on the first cycling day most probably, because exercise intensity was greater than $50 \%$ of $\mathrm{VO}_{2}$ max. On that day $\mathrm{CHO}$ intake was insufficient to meet the needs, as indicated by the difference between $\mathrm{CHO}$ intake and calculated $\mathrm{CHO}$ oxidation ( $\mathrm{Fig} \mathrm{4}$ ). This relatively low $\mathrm{CHO}$ intake can to a large extent be explained by the negative energy balance. The reason is that $\mathrm{CHO}$ contributed the largest fraction of total energy intake whereas on the other hand $\mathrm{CHO}$ also contributed the major fraction in energy expenditure during exercise. As a result of this 'CHO imbalance', endogenous $\mathrm{CHO}$ must have contributed considerably to energy production. In the case of endogenous CHO depletion the body will adapt with enhanced fat mobilization and gluconeogenesis (Newsholme, 1983; Rennie, 1977). It has been shown that enhanced availability of free fatty acids increases the fraction of oxidized fat and decreases $\mathrm{CHO}$ oxidation because both substrates act competitively at the site of transport across the muscle cell membrane and subsequent oxidation (Randle, 1963; Felber, 1964; Büber, 1968; Gomez, 1972; Rennie, $1976,1977)$. This may explain the increased fat oxidation on the second exercise day and consequently the smaller $\mathrm{CHO}$ contribution (Table 3, Fig 6). Protein intake per $\mathrm{kg}$ body weight was more than adequate according to RDA standards ( 1.7 vs $0.8 \mathrm{~g} . \mathrm{kg}-1$ RDA). However, the calculated fraction of protein, involved in energy exchange, indicates that during both exercise days and the following recovery day, when protein oxidation was significantly increased (Fig 6), protein intake almost equalled protein loss.

In this situation of stressful exercise and negative energy balance, protein oxidation per $\mathrm{kg}$ body weight was far in excess of the amount of protein intake advised by the National Research Council (RDA). The amount of protein oxidized indicates that even $1.5 \mathrm{~g} . \mathrm{kg}^{-1}$ in these circumstances may not be sufficient to meet the needs. (This will be discussed more in detail in Chapter IV). Increased protein degradation as an indication of energy depletion and catabolic status of the body is supported by Lemon and Mullin (1980) who showed that $\mathrm{CHO}$ depleted subjects had a significant increase in protein breakdown compared to CHO loaded subjects. Recently Lemon (1987) suggested a protein requirement of 1.2 to $1.6 \mathrm{~g} \cdot \mathrm{kg}^{-1}$.day.

Fluid intake appeared to be sufficient to meet the requirements both during rest and exercise days. The fact that plasma volume increased during day 3 may be explained by changes in blood composition due to absorption of nutrients, electrolytes and water during the day. That this did not occur during the exercise days may be indicative of the smaller fluid ovenload ffluid intake fluid loss) due to severe sweating on these days, compared to both rest days, or to fluid shifts within the body. The fact that urine volumes increased during the exercise day indicates a stimulus to water elimination from the body rather 
than to retain it. Moreover, some of the subjects had to urinate during the cycling sessions. Indicative of an adequate fluid supply also during exercise is further the observation that plasma volume did not fall below the initial 'zero' value as measured at 7:00 AM after an overnight fast on the first standardized rest day. It has to be kept in mind however, that plasma volume due to changes in osmolality may not necessarily reflect the tissue hydration status. It may thus well be that tissue dehydration has taken place at cost of maintaining a normal plasma volume especially during day 4 when fluid loss exceeded fluid intake by approximately one liter. During the recovery day, plasma volume increased significantly above the values of the first rest day, which may be explained by sodium and water retention which has been shown to occur after periods of severe prolonged sweating (Costill, 1977).

In summary the results lead to the following conclusions:

- When prolonged intensive cycling increases energy expenditure to levels above a certain threshold (probably around $20 \mathrm{MJ}$ ), athletes are unable to consume enough conventional food to provide adequate energy to compensate for the increased energy expenditure.

- A sport adjusted CHO rich diet (>60 en\% CHO) is in itself no guarantee that $\mathrm{CHO}$ intake will be sufficient during days of hard, long lasting exercise.

- Drinking $0.75-11 . h^{-1}$ is sufficient to maintain a normal plasma volume during prolonged intensive cycling under situations as in this study (ambient temperature $20 \pm 2^{\circ} \mathrm{C}$, relative humidity $65-75 \%$ ).

- Protein requirement in the exercise circumstances described is greater

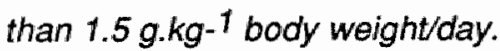




\section{REFERENCES}

1. Boeyen, W.G.M.

Achtergronden en gebruik van de UCV tabel.

Ned. Tijdschr. Dietetiek 38/9: 269-272, 1983.

2. Brandenberger, G., V. Candas, M. Follenius, J.P.Libert et all.

Vascular shifts and endocrine responses to exercise in the heat.

Eur. J. Appl Physiol. 55: 123-129, 1986. 1977

3. Brouns,F.J.P.H., W.H.M. Saris, and F. ten Hoor.

Dietary problems in the case of strenuous exertion.

Part 1: A literature review

J. Sports Med. 26: 306-312, 1986.

4. Büber, V., J.P. Fellberr, and A. Vanotti.

Glucose tolerance improvement after cute medicamentous lowering of plasma free fatty acids.

Schweiz. Med. W. Schr. 99: 711, 1968.

5. Candas, V., J.P. Libert, G. Brandenberger, et al.

Hydration during exercise, effects on thermal and cardiovascular adjustments.

Eur. J. Appl. Physiol. 55: 113-122, 1986.

6. Costill, D.L, and K.E. Sparks.

Rapid fluid replacement following thermall dehydration.

J. Appl. Physiol. 34: 299-303, 1973.

7. Costill, D.L.

Sweating: its composition and effects of body fluids.

Ann. N.Y. Acad. Sci. 301: 160-174, 1977.

8. Decombaz, J., A. Chiesa, G. von Glutz, and H. Howald.

Nutritional follow-up of a $100 \mathrm{~km}$ footrace.

Abstract Experientia 37: 623, 1981.

9. Dill, D.B., and D.L. Costill.

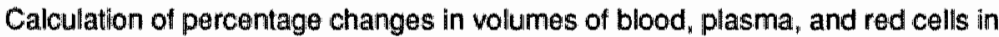
dehydration.

J. Appl. Physiol. 37/2: 247-248, 1974.

10. Donath, $R_{\text {., and S.E. Stratuzenberg. }}$

Beitrâgen zu Fragen der Ernahrung der Sportler.

Medizin und Sport 15/5: 144, 1975.

11. Erp-Baart, A.M.J. van, W.H.M. Saris, R.A. Binkhorst, J.A. Vos and J.W.H.

Elvers.

Nationwide survey on nutritional habits in elite athletes.

Part I Energy, carbohydrate, protein and fat intake.

Int. J. Sport Med. Suppl 1988. In press. 
12. Felber, J.P., and A. Vannotti.

Effect of fat infusion on gluciose tolerance and insulin plasma levels.

Med. Exp. (Basel) 10: 153-160, 1964.

13. Galbo, $H$.

Hormonal and metabolic adaptation to exercise.

George Thieme Verlag Stuttgart, 1983.

14. Galbo, H., N.J. Cristensen, K.J. Mikines, ef al.

The effect of fasting on the hormonal response to graded exercise.

J. Clin. Endocrinol. Metab. 52: 1106-1112, 1981.

15. Galbo, $H_{2}$ H.J. Holst, and N.J. Cristensen.

The effect of different diets and of insulin on the hormonal response to prolonged exercise.

Acta Physiol. Scand. 107: 19-32, 1979.

16. Gollnick, P.D., B. Pernow, B. Essen, E. Jansson and B. Saltin.

Availability of glycogen and plasma FFA for substrate utillzation in leg musclle of man during exercise.

Clin. Physiol. 1: 27-42, 1981.

17. Gomez, F., E. Jéquier, V. Chabot, V. Büber, and J.P. Felber.

Carbohydrate and lipid oxidation in normal human subjects; its influence on glucose tolerance and insulin response to glucose.

Metab. 21: 381-391, 1972 .

18. Hautvast, J.G.A.J.

Ontwikkeling van een systeem om gegevens van voedingsenquetes met hulp van een computer te verwerken.

Voeding The Hague 36: 356-361, 1975.

19. Hiller, W.D.B., M.L. O'Toole, F. Masimino, R.E. Hiller, et al.

Plasma electrolyte and glucose changes during the Hawailan ironman triathlon.

Med. Sci Sports Exerc. 17: 219, 1985 abstract.

20. Kirsch, K.N., and $H$. von Amein.

Feeding patterns of endurance athletes.

Euro. J. Appl. Physiol. 47/2: 179-208, 1981.

21. Lemon, P.W.R.

Protein and exercise: an update 1987.

Med. Sci. in Sports and Ex. S179-S190, 1987.

22. Lemon, P.W.R.

A simple and inexpensive method for making sweat collection capsules.

Research quartery for exercise and sport. 54/3: 299-301, 1983.

23. Lemon, P.W.R., and J.J. Nagle.

Effects of exercise on protein and amino acid metabolism.

Med. Sci. Sp. Ex. 13/3: 141-149, 1981. 
23a.Lemon, P.W.F., and J.P. Mullin.

Effect of initial muscle glycogen levels on protein catabolism during exercise.

J. Appl. Physiol. 48: 624-629, 1980.

24. Maughan, R.J., C. Williams, and D.M. Campbell.

Fat and carbohydrate metabolism during low intensity exercise: effects of the availability of muscle glycogen.

Eur. J. Appl. Physiol. 39, 7-16, 1978.

25. Mitchell, J.W., E.A. Nadel, and J.A.J. Stowijk.

Respiratory weight losses during exercise.

J. Appl. Physiol. 32/4: 474-476, 1972..

26. National Research Council

Recommended daily allowances.

National Academy of Sciences, Washington, 1980.

27. Newsholme, E.A., and A.R. Leech.

Integration of carbohydrate and lipid metabolism.

In: Biochemistry for the medical sciences pp 336-356.

John Wiley and Sons, Chichester, 1983.

28. Noakes, T.D. N. Goodwin, B.L. Rayner, et al.

Water intoxication: a possible complication during endurance exercise.

Med. Sci. Sports Exerc. 17: 370-375, 1985.

29. Rennie, M.J., W.W. Winder, and J.O. Holloszy.

A sparing effect of increased plasma latty acids on muscle and liver glycogen content in the exercising rat.

Biochem. J. 156: 647-655, 1976.

30. Rennie, M.J. and J.O. Holloszy.

Inhibition of glucose uptake and glycogenolysis by availability of oleate in well-oxygenated perfused skeletal muscle.

Biochem. J. 168: 161-170, 1977 .

31. Saris, W.H.M. M.A. van Erp-Baart, and F. Brouns.

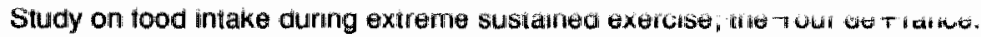

Int. J. Sports Med. Suppl: 1988. In press.

32. Schoftelen, P.F.M., W.H.M. Saris, K.F. Westerterp, and F. ten Hoor.

Evaluation of an automated indirect calorimeter for measurement of energy balance in man.

In: Human energy metabolism: Physical activity and energy expenditure measurements in epidemiological research based upon direct and in direct calorimetry.

Es, A.J.H. van, (Ed.) pp. 51-141 (Euro, Nut. Rep. 5), 1984.

33. Weilzman, R., and C.R. Kleeman.

Water melabolism and the neurohypophysial hormones.

In: Bondy, L.E. Rosenberg (eds.).

Metabolic control and disease. Philadelphia "W.B. Saunders Company, pp 1241-1324, 1980. 
34. Wijn, J.F. de, and M. van Erp-Baart.

Food pattern, body composition and physical condition of heavy weight competition rowers.

Voeding 41: $1,1980$. 


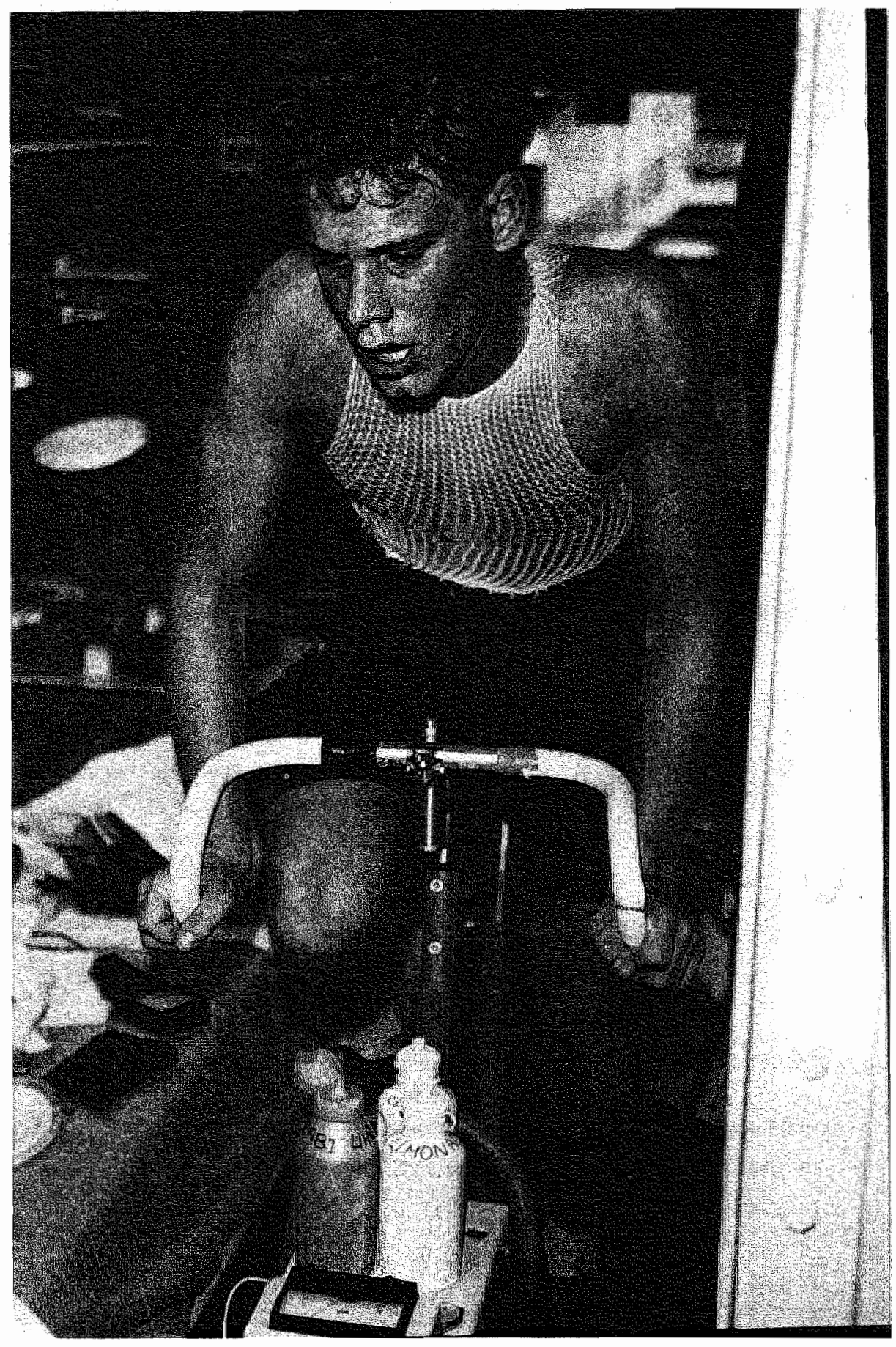


CHAPTER III: EATING, DRINKING AND CYCLING, A CONTROLLED TOUR DE FRANCE SIMULATION STUDY PART 2, THE EFFECT OF DIET MANIPULATION

\author{
F. Brouns, W.H.M. Saris, J. Stroecken, E. Beckers, \\ R. Thijssen, N.J. Rehrer and F. ten Hoor
}

\title{
Introduction
}

Whenever energy requirement in athletes increases to levels above $20 \mathrm{MJ} /$ day, the athlete is faced with the problem of how to ingest and digest such a large quantity of food when long lasting exercise has to be executed at the same time. Kirsch (1980) described a spontaneous nibbling eating pattern of athletes who, in such circumstances, tend to eat more or less continuously throughout the day. Practical experience shows that especially foods and liquids are selected that are sweet in taste, high in energy and are convenient. Consequently it is found that in-between meals composed of such foods and drinks may make up more than $30 \%$ of total energy intake ( $D e$ Wijn 1980; Van Erp-Baart, 1988; this study, Chapter II). One of the main problems of athletes during competion days seems to be the intolerance of the gastro-intestinal tract to take up and digest large amounts of food whenever intensive exercise is executed at the same time. Apart from the exercise induced changes in appetite (Brouns, 1986) it is clearly indicated from practice that athletes must rely on easily digestible and energy dense foods that are low in dietary fiber, for the following reasons:

- The amount of feces produced from a normal diet would require the cyclist to defecate several times during the day and consequently to interrupt exercise.

- Large volumes of food may interfere with fluid intake which in itself may be exceptionally high during hot days (more than $10 \mathrm{l} /$ day, Saris, 1988).

As a result the athlete will either undereat when only a conventional diet is available during such competition days (Chapter II) or will maintain energy balance when a combination of normal foods and carbohydrate $(\mathrm{CHO})$ rich liquids is supplied as was observed during the Tour de France (Saris, 1988). In order to investigate more specifically the influence of such dietary practices on food and fluid intake, energy balance, fluid status and nutrient utilization during repeated exhausting cycling, it was decided to do a controlled laboratory study in which the effects of a normal $\mathrm{CHO}$ rich diet (N) (Chapter II) were compared to those of the same diet, but supplemented with a concentrated liquid $\mathrm{CHO}$ beverage.

The reason for $\mathrm{CHO}$ supplementation as diet intervention was two fold:

1) Depletion of $\mathrm{CHO}$ stores in the body is related to physical exhaustion (Bergström, 1967, 1967a; Sherman, 1984, Saltin, 1967) while increased CHO 
intake may delay exhaustion (Coyle, 1983; Edwards, 1984; Ivy, 1983).

2) A survey among professional cyclists competing in the Tour de France showed that liquid $\mathrm{CHO}$ supplements had the largest relative contribution to total CHO intake (Saris, 1988).

Although there is a wide variety of $\mathrm{CHO}$ sources, it was specifically decided to select a solution composed of mainly maltodextrin (Mf) and a solution with a high free fructose fraction (FM). Mf was selected because the use of maltodextrin may be of advantage for the athlete by means of maximizing $\mathrm{CHO}$ intake and absorption, while minimizing gastro-intestinal distress (Brouns, 1987). FM was selected for the following reasons. The effect of fructose on insulin secretion is minimal, which allows for a better stimulation of lipolytic activity under exercise circumstances compared to glucose alone which has a strong influence on insulin secretion. The second reason was to compose a CHO solution with a $50 \%$ contribution of both glucose and fructose but with a lower osmolality as would be derived from eucaloric sucrose.

\section{Experimental design, analyses and statistics}

The experimental set-up used during the diet manipulation trial is exactly the same as has been described in Chapter II for the normal diet $(N)$ study. The same holds for the analysis of samples and the statistics used to analyze the data. Therefore only the differences due to diet manipulation, not described before, will be outlined here.

The total group of 13 subjects receiving $\mathrm{N}$ as described in part $\mathrm{I}$, chapter $\mathrm{I}$, was divided into two sub-groups for diet manipulation. Six subjects were supplemented with an experimental high maltodextrin, low fructose beverage (Perform@, Wander Ltd) (Mf). The seven other subjects were supplemented with another experimental beverage, composed of $50 \%$ free fructose and $50 \%$ maltodextrin (FM). Subjects were randomly selected for either Mf of FM treatment as was the order of treatment (normal diet or manipulated diet). The composition of the beverages used is presented in Table 1.

\section{Table 1 Composition of beverages}

\begin{tabular}{lrrrrrr}
\hline Beverage & $\begin{array}{l}\text { Malto } \\
\text { dextrin } \\
\text { g.l-1 }\end{array}$ & Fructose & $\mathrm{K}+$ & $\begin{array}{l}\text { Osmola- } \\
\text { lity } \\
\text { mosm }\end{array}$ & $\mathrm{pH}$ & $\begin{array}{l}\text { Energy } \\
\text { content } \\
\text { kJ.1-1 }\end{array}$ \\
\hline Placebo & 0 & 0 & 8.5 & 106 & 4.38 & - \\
Mf & 150 & 33 & 8.5 & 390 & 4.45 & 3158 \\
FM & 90 & 93 & 8.5 & 788 & 4.52 & 3158
\end{tabular}


beverages in MI and FM treatment. The placebo was flavored with citruspowder, sweetened with saccharin and cyclamate and artificially colloured. In all beverages the same vitamin - mineral mix was added.

The supplement was made available for intake together with normal food during cycling and during the evening, as follows: standardized resting days $500 \mathrm{ml}$ during the morning, afternoon and evening (total supply $1500 \mathrm{ml}$ ). Exercise days during cycling ad libitum and in the evening, after dinner, 1000 $\mathrm{ml}$. The cyclists in the $\mathrm{N}$ treatment were supplied with a placebo drink (see Table 1), in order to rule out psychological effects due to the drink.

\section{Results}

\section{Energy}

The data on energy intake (EI) and energy expenditure (EE) are presented in Table 2.

Table 2 Energy intake (EI) and expenditure (EE)

\begin{tabular}{|c|c|c|c|c|}
\hline \multicolumn{5}{|l|}{ Day } \\
\hline Treatment & 3 & 4 & 5 & 6 \\
\hline EIMf & $23.5 \pm 1.0$ & $29.2 \pm 0.9^{*}$ & $27.0 \pm 1.0^{*}$ & $20.3 \pm 1.6$ \\
\hline EE Mf & $16.5 \pm 0.4$ & $26.6 \pm 1.1$ & $25.8 \pm 1.2$ & $16.2 \pm 0.5$ \\
\hline ElFM & $22.2 \pm 1.4^{* *}$ & $26.3 \pm 0.9^{* *}$ & $25.3 \pm 1.5^{* *}$ & $18.9 \pm 1.6$ \\
\hline EE FM & $16.1 \pm 0.5$ & $26.9 \pm 1.0$ & $26.3 \pm 1.1$ & $16.0 \pm 0.6$ \\
\hline
\end{tabular}

Mean values $\pm S E M$ are given in MJ. For Mf group $n=6$, for $F M$ group $n=7$, For composition of the beverages see Table 1 . El was determined by weighed food intake, EE was determined by indirect calorimetry. Asterisks in-dicate a significant difference with respect to values abtained with con-ventional diet ( $N$ ), (Each subject is his own control. For $N$ values see Table 2 , Chapter II), "p<0.05; "*p<0.01.

When the values of diet manipulation were compared to those of $\mathrm{N}$ (each subject was his own control) there were large statistically significant differences for $E I$, while there were no differences in $E E$ between the treatment groups. In Mf, mean El was always greater than mean EE, despite the fact that $E E$ increased to levels far above $20 \mathrm{MJ}$ on both exercise exhaustion days. In contrast to this, in cyclists with $F M$ treatment $E I$ was smaller than $E E$ on both exercise days. El was significantly higher $(p<0.05)$ in Mf compared to FM on the first exercise exhaustion day but not on the second exercise day.

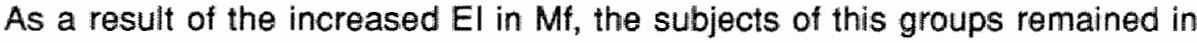


energy balance, whereas in the FM treatment subjects were not. In this group energy balance was negative during the sustained cycling days, however, to a lesser extent than during $N$ (Fig 1 ).

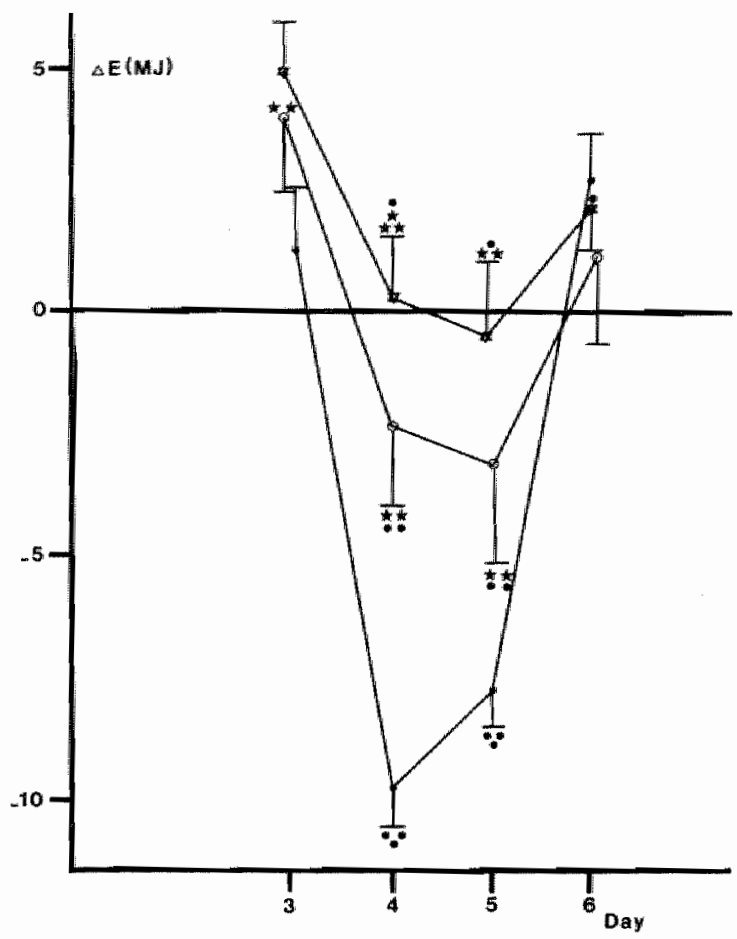

Fig 1 Mean daily energy balance (E) derived from total energy intake minus total energy expenditure. Corrections were made for energy losses in urine, feces, blood and sweat. Day 3 and 6 are resting days, 4 and 5 are exercise days. Vertical bars indicate 1 SEM:- - conventional tood group $(N) ; n=13,-*-$ Mt group $(n=6),-\infty=$ FM group $(n=7)$. Indicales statistical significance of differences compared to the initial value on day $3 ; . p<0.05 ; \ldots 0<0.01 ; \ldots$ p $<0.001 \%$. Indicates a statistically significant difference with respect to comparative data of groups $N$ (each subject is his own control). " $p<0.01$; *** $p<0.001$.

\section{Nutrient intake}

In contrast to $N$, dietary manipulation caused a significant shift in the relative contribution of macro-nutrients to total energy intake. During the exercise exhaustion days $\mathrm{CHO}$ intake increased significantly to a mean level of 80 
en\% in Mf and 77 en\% in FM respectively.

The $\mathrm{CHO}$ intake is shown in Fig 2. As a result of the diet manipulation $\mathrm{CHO}$ intake increased significantly on all days, reaching a mean maximum value of $1300 \mathrm{~g}$ and $1180 \mathrm{~g}$ in Mf and FM respectively. As a consequence fat intake dropped significantly to $15 \mathrm{en} \%$ and protein intake to $7.5 \mathrm{en} \%$ in both supplemented groups (Table 3).

Table 3 Relative contribution of nutrients to energy intake

\begin{tabular}{|c|c|c|c|}
\hline $\begin{array}{l}\text { Food } \\
\text { component }\end{array}$ & $\mathrm{N}$ & $\begin{array}{l}\text { iet group } \\
\qquad \mathrm{Mf}\end{array}$ & FM \\
\hline \multicolumn{4}{|l|}{$\mathrm{CHO}$} \\
\hline Day 3 & $61.8 \pm 1.7$ & $66.8 \pm 2.7$ & $68.0 \pm 1.9^{*}$ \\
\hline Day 4 & $62.9 \pm 1.3$ & $80.5 \pm 1.50^{* * *}$ & $75.6 \pm 2.0^{*}$ \\
\hline Day 5 & $62.4 \pm 1.6$ & $79.7 \pm 1.3^{*}$. & $77.9 \pm 2.2^{*} \ldots$ \\
\hline Day 6 & $62.7 \pm 1.6$ & $67.5 \pm 2.6$ & $66.9 \pm 2.7$ \\
\hline \multicolumn{4}{|l|}{ FAT } \\
\hline Day 3 & $25.7 \pm 1.3$ & $22.7 \pm 2.1$ & $21.9 \pm 1.5^{*}$ \\
\hline Day 4 & $24.7 \pm 1.0$ & $13.2 \pm 1.0^{*}$. & $16.7 \pm 1.4^{*} * *$ \\
\hline Day 5 & $25.6 \pm 1.3$ & $17.0 \pm 0.9^{*}$ & $14.9 \pm 1.7^{*} \ldots$ \\
\hline Day 6 & $24.5 \pm 1.2$ & $21.2 \pm 1.9$ & $21.2 \pm 1.9$ \\
\hline PROTEIN & & & \\
\hline Day 3 & $12.5 \pm 0.6$ & $10.5 \pm 0.8$ & $10.3 \pm 0.4^{*}$ \\
\hline Day 4 & $12.3 \pm 0.6$ & $6.3 \pm 0.4$ & $7.4 \pm 0.5^{*} . * *$ \\
\hline Day 5 & $12.1 \pm 0.7$ & $8.3 \pm 0.6^{*}$ & $7.4 \pm 0.6^{*}$ \\
\hline Day 6 & $12.8 \pm 0.4$ & $1.3 \pm 1.0$ & $10.3 \pm 0.9^{* * *}$ \\
\hline
\end{tabular}

Mean values \pm SEM are given in en\%. $N=$ normal diet $(n=13) . M f=$ diet supplemented with high maltodextrin/low fructose beverage $(n=6)$. $F M=$ diet supplemented with fructose/maltodextrin beverage ( $n=7)$. Days 3 and 6 are resting days; days 4 and 5 are exercise days. Statistical significance with res-pect to the corresponding initial values on day 3 is indicated by $. p<0.05 ; .0<0.01 ; \ldots+0<0.001$. Statistical significance of groups MI and FM with respect to corresponding data of group $\mathrm{N}$ (each subject is his own control) is indica ted by "p<0.005; ** $p<0.01$; *** $p<0.001$. 


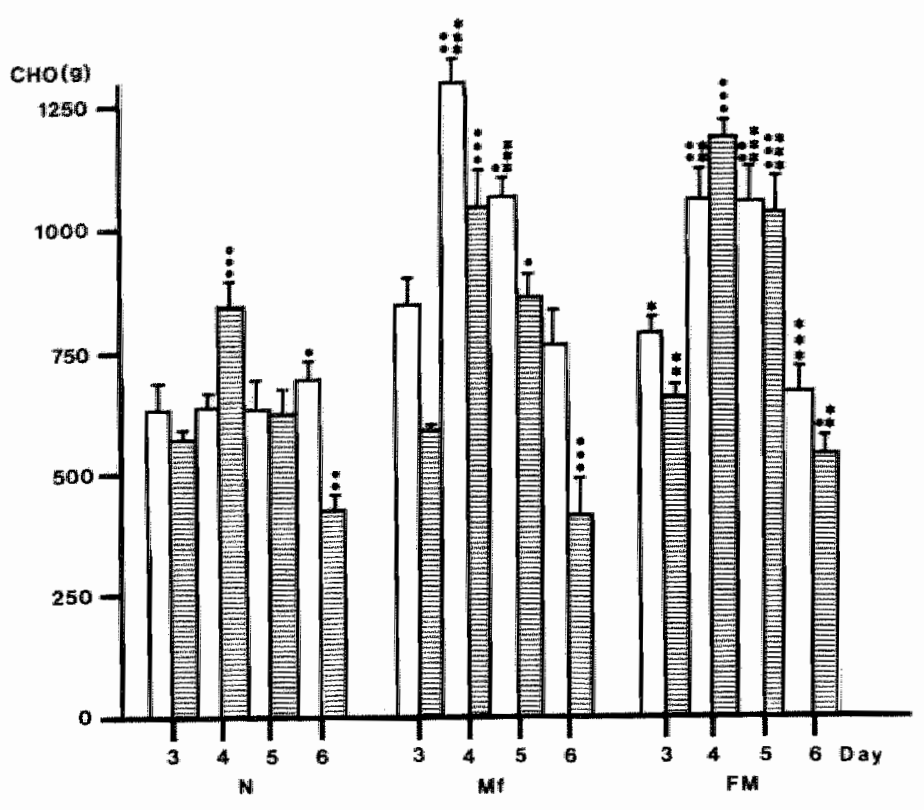

Flg 2 Mean daily $\mathrm{CHO}$ intake $(\square, g)$ and $\mathrm{CHO}$ oxidized $\mathrm{Q}$, g). The amount of $\mathrm{CHO}$ oxidized was calculated from nonprotein $R$. Vertical bars represent 1 SEM. For the $N$ treatment group $n=13$, for the Mf treatment group $n=6$, for the $F M$ treatment group $n=7$. Statistical significance with respect to the initial values on day 3 is indicated by.p $<0.05$; $. . p<0.01$. Statistical signilicance of groups Mf and FM with respect to comparative data of group $N$ (each subject is his own control) is indicated by ${ }^{*} p<0.05 ;{ }^{* * *} p<0.01$; *** $\mathrm{p}<0.001$.

The protein intake per $\mathrm{kg}$ body weight, is presented in Fig 3. Although there was a significant reduction in the relative contribution of protein intake to total energy intake, it can be seen that the quantitative protein intake remained more or less constant during the different treatments.

The largest intake occurred during $N$ whereas the supplemented groups had lower intakes, but still markedly above the RDA of $0.8 \mathrm{~g} . \mathrm{kg}^{-1} \mathrm{BW}$ (mean lowest value $1.4 \mathrm{~g} \cdot \mathrm{kg}^{-1}$ on day 4 in $\mathrm{Mf}$ ), and above the preset minimal intake of 1.2 $\mathrm{g} . \mathrm{kg}^{-1} \mathrm{BW}$. There were no differences in intake in the different treatments between the first and last standardized rest day. However, when $\mathrm{N}$ was compared to the supplemented diets, it becomes apparent that fat and protein intake during the rest days is larger in $N$. 


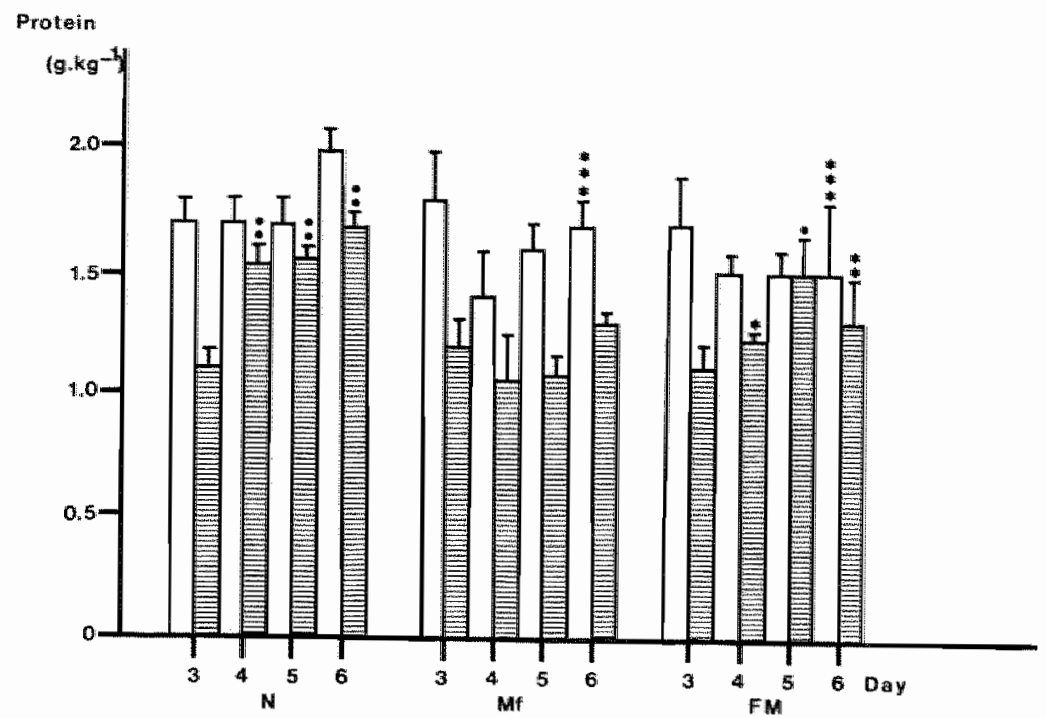

Fig 3 Mean daily protein intake ( $\square, g . \mathrm{kg}-1$ ) and protein oxidized ( $\mathrm{Z} \mathrm{g} \cdot \mathrm{kg}$ ). The amount of protein oxidized was calculated from nitrogen excretion in urine and sweat. Vertical bars indiciate 1 SEM. $N=$ conventional diet $(n=13)$; $M f=$ diet supplemented with high malto. dextrin/low fructose beverage $(n=6) ; F M=$ diet supplemented with "high' tructose/malto. dextrin beverage $(n=7)$. For exact composition of diets and beverages see text. Day 3 and 6 are resting days, 4 and 5 are exercise days. Statistical significance with respect to the initial values on day 3 is indicated by $.0<0.05 ; 0<0.01 ; 0<0.001$. Statistical significance of groups Mf and FM with respect to comparative data of group $N$ (each subject is his own control) is indicated by " $p<0.05 ;$;" $p<0.01 ; " * * 0<0.001$.

\section{Nutrient oxidation}

The absolute amounts of $\mathrm{CHO}$, fat and protein oxidized, are also graphically presented in Fig 2 and 3 . With respect to $\mathrm{CHO}$ it can be seen that when oxidation is compared to intake. Mf treatment resulted in a positive ' $\mathrm{CHO}$ balance' during the entire experiment. This is in contrast to $\mathrm{N}$ and $\mathrm{FM}$ which resulted in negative $\mathrm{CHO}$ balance due to increased $\mathrm{CHO}$ oxidation. The calculated relative contribution of the nutrients to total daily energy metabolism is presented in Fig 4. 


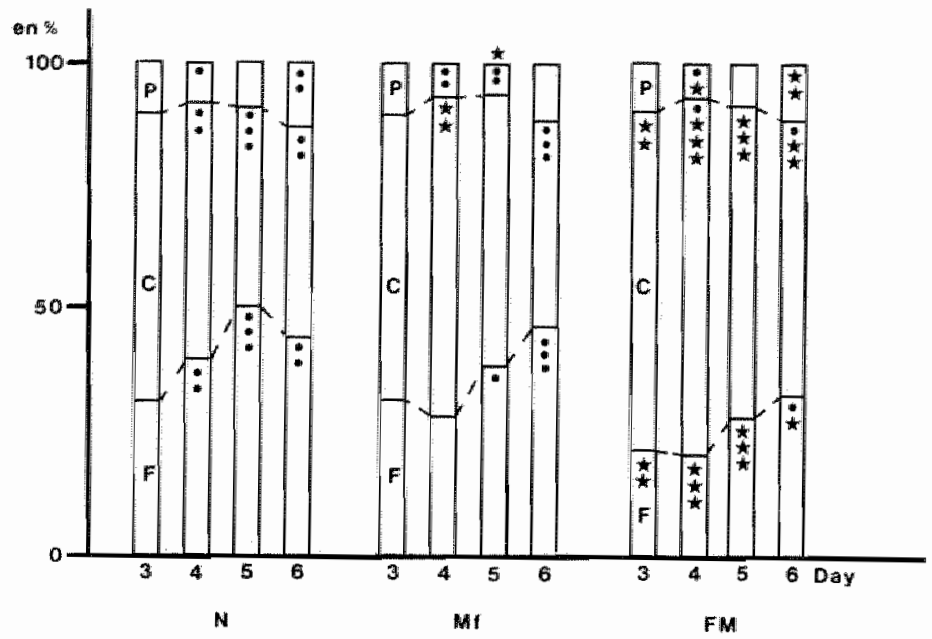

Fig 4 Mean relative contribution of $\mathrm{CHO}$, fat and protein to total energy expenditure as calculated trom non protein $\mathrm{A}$ and nitrogen excretion. $\mathrm{C}=$ carbohydrate; $\mathrm{F}=$ fat; $\mathrm{P}=$ protein. The amount of $C$ and $F$ oxidized was calculated from non protein $R$. The amount of protein oxidized was calculated from nitrogen excretion in unine and sweat. Vertical bars indicate 1 SEM. Statistical significance with respect to the initial values on day 3 is indicated by $. p<0.05 ; ., 0<0.01 ; \ldots<0.001$. Statistical significance of groups Mf and $F M$ with respect to comparative data of group $N$ (each subject is his own control) is Indicated by "p<0.05; "p<0.01; "**p<0.001.

In contrast to $\mathrm{N}$ the relative contribution from fat to energy metabolism in the supplemented groups decreased during the first exercise day, followed by a stepwise increase during the second exercise day and following recovery day, however, at a lower level than in N. Consequently the oxidized fraction of $\mathrm{CHO}$ in both groups was larger. The lowest contribution from fat to energy metabolism, together with the highest $\mathrm{CHO}$ contribution, occurred in the 'high' fructose group, during both rest and exercise days. Compared to $N$ this was highly significant on all days.

Protein oxidation remained constant in Mf, despite sustained exercise. This is in contrast to $\mathrm{N}$ which showed a large significant increase during exercise and recovery days. In FM the amount of protein oxidized tended to increase during the first exercise day, then increased significantly during the second exercise day and almost returned to the initial level during the recovery day. Compared to $N$, exercise caused less protein degradation probably as a result of diet manipulation, which became significant in FM and tended towards significancy in Mf. The relative contribution of protein to overall energy metabolism as calculated from nitrogen losses in sweat and urine decreased significantly during both exercise days in Mf, but in FM only during the first exercise day. Compared to $\mathrm{N}$ the relative contribution was smaller, 
except on the first rest day. During the recovery day all 3 treatment groups showed an increased protein oxidation compared to the pre-exercise rest day. However, this increase was only significant in N. Compared to N, FM had a significantly lower value on this day while Mf tended to be significantly lower $(p<.07)$.

\section{Food consumption pattern}

The food consumption pattern presented in Fig 5 shows that the supplementation of $\mathrm{CHO}$ rich beverages during exercise caused a significant increase in energy intake, being almost entirely responsible for the increased total energy intake compared to $\mathrm{N}$. In general, energy intake derived from the three main meals remained constant. 


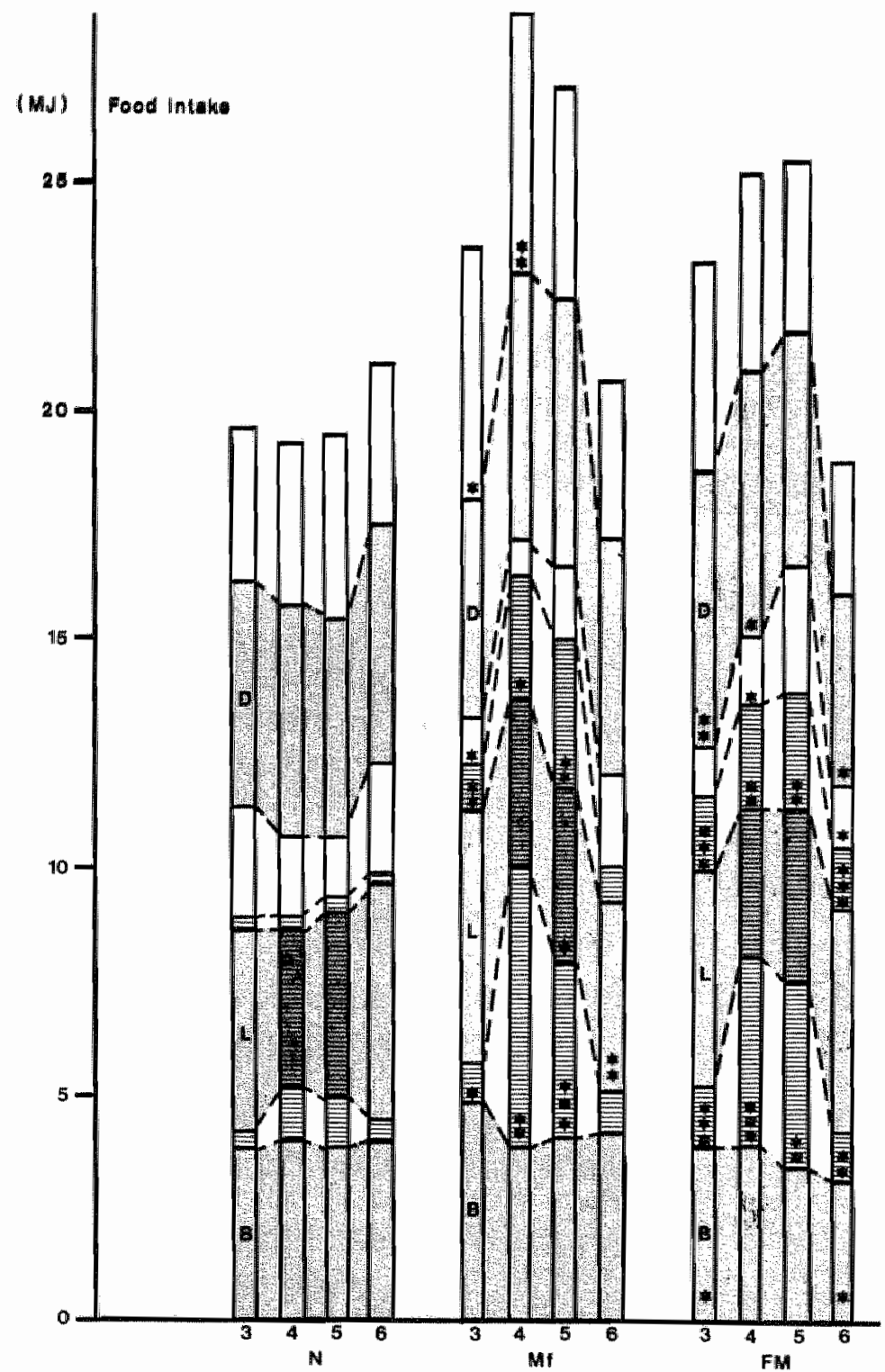

Fig 5 Relative contribution of main meals and in-between meals to total daily energy intake. $B$ $=$ breakfast $\mathrm{L}=$ lunch; $\mathrm{D}=$ dinner; $\mathrm{Z}$ tood intake during exercise. Statistical significance of groups $M f$ and $F M$ with respect to comparative data of group $N$ (each subject is his own control) is indicatted by "p<0.05; ** $p<0.01 ; * * 0.001$.

In FM breakfast and dinner were significantly smaller during the recovery day than during the same day in the control experiment ( $N$ ). This resulted in a lower total energy intake on this day. After exhaustive exercise in between meal snacking sometimes was reduced before dinner and increased in the evening after dinner in both $\mathrm{CHO}$ supplemented groups. 


\section{Fluids}

Fluid intakes and losses in Mf and FM are represented in Table 4.

Table 4 Fluid intake and loss in Mf (a) and FM (b) treatment

\begin{tabular}{|c|c|c|c|c|c|c|c|c|}
\hline Day & & & & & & & & \\
\hline b Condition & 3 & & 4 & & 5 & & 5 & \\
\hline Mf & Intake & loss & Intake & loss & Imttake: & loss & Intake & loss \\
\hline REST & $4.08 \pm 0.17$ & & $3.34 \pm 0.50$ & & $3.12 \pm 0.44$ & & $4.08 \pm 0.26$ & \\
\hline Urine & & $1.82 \pm 0.11$ & & $2.03+0$ & & $1.85 \pm 0.25$ & & $1.88 \pm 0.14$ \\
\hline Faeces & & $0.15^{*}$ & & $0.15^{*}$ & & $0.15^{*}$ & & $0.15^{*}$ \\
\hline Resp water & & $0.40^{*}$ & & $0.32^{*}$ & & $0.32^{*}$ & & $0.40^{\circ}$ \\
\hline Sweat & & $0.50^{*}$ & & $0.40^{\circ}$ & & $0.40^{*}$ & & $0.50^{\circ}$ \\
\hline EXERCISE & & & $3.15 \pm 0.41$ & & $3.47 \pm 0.41$ & & & \\
\hline Sweat & & - & & $3.99 \pm 0$ & & $4.07 \pm 0.35$ & & . \\
\hline Resp.water & & - & & $0.56 \pm 0$. & & $0.53 \pm 0.04$ & & . \\
\hline Mean total & 4.08 & 2.87 & 6.49 & 7.45 & 6.59 & 7.31 & 4.08 & 2.93 \\
\hline Day & & & & & & & & \\
\hline a Condition & 3 & 4 & 5 & 6 & & & & \\
\hline$F M$ & Intake & loss & Intake & loss & Intake & loss & Intake & loss \\
\hline AEST & $3.60 \pm 0.24$ & & $3.72 \pm 0.51$ & & $2.55 \pm 0.26$ & & $3.70 \pm 0.37$ & \\
\hline Urine & & $1.74 \pm 0.17$ & & $2.69 \pm 0$ & & $2.35 \pm 0.42$ & & $1.46 \pm 0.16$ \\
\hline Faeces & & $0.15^{\star}$ & & $0.15^{*}$ & & $0.15^{*}$ & & $0.15^{*}$ \\
\hline Resp water & & $0.40^{*}$ & & $0.32^{\star}$ & & $0.32^{*}$ & & $0.40^{*}$ \\
\hline Sweat & & $0.50^{*}$ & & $0.40^{\circ}$ & & $0.40^{\circ}$ & & $0.50^{*}$ \\
\hline EXERCISE & & & $3.03 \pm 0.31$ & & $3.53 \pm 0.24$ & & & \\
\hline Sweal & & - & & $3.40 \pm 0$ & & $3.54 \pm 0.60$ & & - \\
\hline Resp.water & & - & & $0.56 \pm 0$. & & $0.56 \pm 0.04$ & & . \\
\hline Mean total & 3.60 & 2.79 & 6.75 & 7.52 & 6.09 & 7.32 & 3.69 & 2.51 \\
\hline
\end{tabular}

Mean values \pm 1 SEM $[$; M $n \approx 6 ; F M n=7)$

* Mean daily loss under resting conditions, taken from Weitzman (1980). 
As in N, fluid intakes were larger than the calculated fluid losses during both rest days. During both sustained cycling days losses via urine, sweat and respiratory water loss exceeded fluid intake by approximately one liter. Urine losses increased during exercise days and were not different from $\mathrm{N}$. Respiratory water loss during exercise was remarkably constant reaching a mean level of around $550 \mathrm{ml}$ or approximately $110 \mathrm{ml} / \mathrm{hr}$. In general plasma volume showed a similar response pattern to food and fluid intake and to exercise as described for $\mathrm{N}$ (Fig 6 and Fig 8 of Part I, Chapter II).

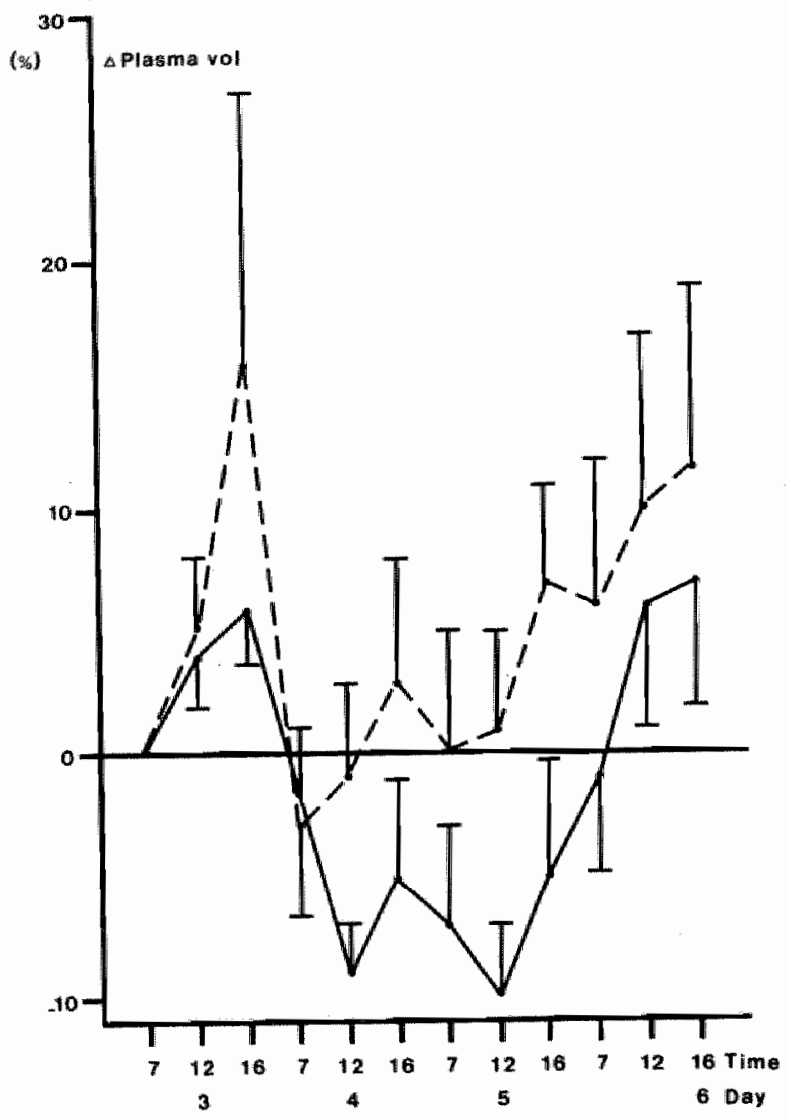

Fig 6 Relative changes in plasma volume at rest (day 3 and 6 ) and during exhaustive exercise days (day 4 and 5) — Mf treatment group; - - FM treatment group. Vertical bars indicate 1 SEM. There was no statistically significant difference belween the treatment groups

Although Mf subjects tended to have decreased plasma volumes below the initial level on exercise days compared to in $\mathrm{N}$ treatment, this was not statistically significant. Body weight remained markedly stable during the experiment in 
both Mf and FM. This is in contrast to in $\mathrm{N}$ where a significant body weight reduction occurred which was not corrected during the studied recovery period. Although in FM as well as in Mf body weight decreased at the same measuring points during exercise, there was a tendency to significantly smaller weight changes than those measured during $N$. In contrast to $N$ the subjects in $M f$ and FM restored their individual weight on a daily basis, by 9:00 PM. (Table 5).

Table 5 Body weight changes of experimental subjects

\begin{tabular}{l|ccccc}
\hline \multicolumn{2}{c}{ Day } & 3 & 4 & 5 & 6 \\
\multicolumn{7}{c|}{ Time } & \multicolumn{5}{c}{3} & & \\
\hline 7 AM & Mf & $75.5 \pm 0.4$ & $75.7 \pm 0.4$ & $75.3 \pm 0.4^{*}$ & $75.3 \pm 0.3$ \\
& FM & $71.7 \pm 0.3$ & $71.4 \pm 0.2$ & $70.6 \pm 0.2^{*}$. & $70.7 \pm 0.2$ \\
& & & & & \\
& & & & & \\
& M PM & $75.5 \pm 0.4$ & $74.7 \pm 0.4^{*}$. & $74.7 \pm 0.4$. & $75.3 \pm 0.4$ \\
& FM & $71.4 \pm 0.2$ & $70.9 \pm 0.2$ & $70.2 \pm 0.2$. & $70.9 \pm 0.2$ \\
& & & & & \\
& Mf & $76.1 \pm 0.4^{*}$ & $75.8 \pm 0.4$ & $76.0 \pm 0.4^{*}$ & $76.0 \pm 0.4$ \\
& FM & $72.1 \pm 0.2^{*}$ & $71.7 \pm 0.2$ & $71.5 \pm 0.2$ & $71.6 \pm 0.2$ \\
\hline
\end{tabular}

Mean values \pm SEM (kg); Mf $n=6$; FM $n=7$ ).

Changes with respect to initial values on day 3 are indicated by dots. $p<0.05$. Significance of changes with repect to values found when on a normal diet are indicaled by asterisks " $p<0.05$.

\section{Discussion}

The present study was designed to analyse the effect of diet manipulation on nutritional indices during repeated days of highly intensive cycling and to compare these effects to those present after a supply of a normally composed $\mathrm{CHO}$ rich diet $(\mathrm{N})$. The diet manipulation consisted of ad libitum supplementation of liquid $\mathrm{CHO}$ concentrates, along with the normal $\mathrm{CHO}$ rich diet. The parameters specifically of interest were energy intake, expenditure and balance, nutrient utilization and fluid status.

The results of this study show that the subjects of both MI and FM increased their daily $\mathrm{El}$ significantly more during days of intensive cycling than under $\mathrm{M}$ treatment (Table 2). However, only the Mf group was able to maintain energy balance. FM subjects did not increase their intakes sufficiently to bridge the deficit caused by exercise. The fact that Mf subjects were able to increase their El was clearly the result of the ad libitum supplementation with a beverage high in maltodextrin and low in fructose. The same subjects were not able to reach energy balance when using a conventional $\mathrm{CHO}$ rich diet. Furthermore, the FM group showed that a beverage high in fructose led to lower mean intakes compared to one with a small fructose fraction. This can 
partially be explained by the fact that a $20 \%$ FM solution was not always tolerated by the subjects. A high osmolality $(788$ mosm) together with the extreme sweetness of the drink, due to fructose, caused gastric distress and impalatability. Although a reduction of the $\mathrm{CHO}$ concentration to $10 \%$ during exercise increased palatability, this did not necessarily lead to the intake of larger volumes to compensate for the reduced $\mathrm{El}$.

As a result of the supplementation, total $\mathrm{CHO}$ intake increased significantly, on the first exercise day somewhat more in Mf (mean max. intake $1302 \pm 549 \mathrm{~g}$ equal to $17.5 \pm 1.0 \mathrm{~g} \cdot \mathrm{kg}-1 \mathrm{BW})$, than in $F M(1059 \pm 609 \mathrm{~g}$ equal to $14.9 \pm 1.0$ g. $\mathrm{kg}^{1} \mathrm{BW}$. Despite these high $\mathrm{CHO}$ intakes none of the cyclists reacted with (osmotic) diarrhea caused by malabsorption. This was especially surprising in FM since it has been described that free fructose solutions introducing more than $50 \mathrm{~g}$ of fructose in the gastro-intestinal tract cause diahrrea and gastric distress (Andersson, 1978; Dubach, 1969) also during exercise (Levine, 1983). During the day of the highest $\mathrm{CHO}$ intake the FM subjects derived $566 \pm 29 \mathrm{~g}$ from the supplement, half of which was free fructose. The discrepancy with data from literature may be caused by the additional presence of glucose or by differences in training status.

The relative contribution of $\mathrm{CHO}$ intake to total $\mathrm{EI}, 80 \mathrm{en} \%$ and $77 \mathrm{en} \%$ in $\mathrm{Mf}$ and FM respectively, is far above intakes normally advised (50-65 en\%). Some studies showed that $\mathrm{CHO}$ intake leading to elevated blood glucose levels stimulates $\mathrm{CHO}$ metabolism and inhibits fat metabolism, finally resulting in increased degradation rates of endogenous $\mathrm{CHO}$ stores. (Hargreaves, 1984; Foster, 1979). With respect to this, the question is raised whether or not $\mathrm{CHO}$ supply can match the increased utilization of $\mathrm{CHO}$. In the present study it is shown that Mf subjects were able to remain in positive 'CHO balance'. CHO intakes were always larger than the calculated $\mathrm{CHO}$ oxidation, which must have led to sparing of endogenous $\mathrm{CHO}$ stores. This is in contrast to $\mathrm{N}$ where " $\mathrm{CHO}$ balance' was negative.

Although FM subjects also significantly increased their $\mathrm{CHO}$ intake, they were not able to completely compensate for the increased oxidation. Surprisingly, the treatment with the high fructose moiety in the drink showed the largest increase in $\mathrm{CHO}$ oxidation and decrease in fat oxidation, as calculated from non protein $R$. Although fructose is insulin independent and may therefore have a smaller effect on lipolytic activity than glucose, allowing for a larger energy exchange from fat, we did not observe such on effect. This observation is supported by the recent work of Tappy et al (1987) and contradicts the general bellef that fructose may lead to a sparing of endogenous $\mathrm{CHO}$ by enhancing fat metabolism.

Fat and protein intake, in absolute quantities and relative to total $\mathrm{El}$, decreased as a consequence of the high $\mathrm{CHO}$ intake; in the $\mathrm{N}$ group intake was remarkably constant. The reduction in protein and fat intake was entirely 
caused by the intake of the protein- and fat-free energy supplement and the reduced intake of normal foodstuffs containing fat and protein, especially during the cycling hours. Interesting to note is that this reduced intake of normal foodstuffs remained present during the recovery day in contrast to the $N$ group, where food intake increased. Probably the subjects undergoing diet intervention were less stimulated to increase food intake during recovery because the exercise induced deficits were smaller.

A value of 7.5 en\% for protein intake may sound alarming. However this should be interpreted with respect to the level of daily energy expenditure. In fact the mean lowest absolute daily intake within this value of $7.5 \mathrm{en} \%$ still was $1.4 \mathrm{~g} \cdot \mathrm{kg} \cdot{ }^{-1}$."

Protein utilization in energy metabolism was significantly increased in $\mathrm{N}$ but not in Mf. It is also known that $\mathrm{CHO}$ depletion leads to catabolic stress which, through a variety of biochemical changes, leads to increased protein degradation in order to supply precursors for gluconeogenesis (Lemon, 1980; Newsholme, 1981; Felig, 1971, 1971a; Lemon, 1981). The response of the $\mathrm{N}$ subjects being in negative energy- and ' $\mathrm{CHO}$ balance' confirms these findings. Mf subjects, remaining in positive energy- and "CHO balance' did not show an increased protein oxidation which further confirms that the same type of exercise, performed with the same intensity, even with a significantly longer performance time during the final 90\% Wmax load (see chapter V), causes less ca-tabolism stress when energy intake and especially $\mathrm{CHO}$ intake meets the requirements.

The fact that FM subjects had a significantly increased protein oxidation on the second exercise day but not during the first may be explained as follows. The subjects under this treatment were almost in balance with respect to $\mathrm{CHO}$ intake and $\mathrm{CHO}$ oxidation. However, their energy balance was negative on both days. Initially the high $\mathrm{CHO}$ intake may have counter-regulated the biochemical factors inducing protein degradation but when energy balance remained negative for a longer period of time, protein catabollism must have been initiated. The fact that nitrogen losses remained significantly increased during the next 36 hours of recovery in $N$ indicates that biochemical disturbance was more pronounced in these subjects in contrast to that in subjects with $\mathrm{CHO}$ supplementation. Recovery of a normal metabolic status may have been enhanced under this condition.

Some observations may indicate that fluid intakes have been sufficient to compensate for the losses during all days. Increased urine production during the exercise days indicates an increased drive to eliminate water from the body rather than to retain it.

The reason why this is so, while at the same moment plasma volumes are decreased compared to rest days, remains obscure. One possibility may be 
that urine production is increased due to the potassium content of the drink. Nielsen (1986) observed a diuretic and natriuretic effect of increased plasma potassium after rehydration with a high potassium drink, in spite of a low plasma volume. They could not explain this effect. The fact that plasma volume tends to decrease more in Mf cannot be explained by a fluid shift towards the splanchnic bed caused be the osmolality of the drink ( 380 mosm) since osmolality of FM was higher(788 mosm). Electrolyte influences have to be ruled out also since electrolyte content in both drinks was identical. The fast restoration of body weight further indicates that fluid loss and substrate loss must have been minimal in $\mathrm{Mf}$ and FM compared to $\mathrm{N}$ subjects who, even after $36 \mathrm{~h}$ of recovery, did not regain their initial body weights. This finding together with a better maintenance of energy balance, $\mathrm{CHO}$ balance and lower protein oxidation indicate a less pronounced catabolic state and a better recovery in the diet manipulated situation as compared to the situation in which a normal $\mathrm{CHO}$ rich diet was fed.

Summarizing the results of this study lead to the following conclusions.

- Cyclists are able to maintain energy balance when energy expenditure levels exceed $20 \mathrm{MJ}$ by using concentrated $\mathrm{CHO}$ solutions in addition to a normal $\mathrm{CHO}$ rich diet. In contrast, by using a normal $\mathrm{CHO}$ rich diet alone energy balance cannot be maintained in such a situation.

- The ad libitum supply of 20 and $10 \%$ CHO solutions during cycling as described does not impair fluid intake nor overall fluid status of the body compared to water intake.

- The intake of substantial amounts of a CHO solution during exercise causes an increased CHO-, a decreased fat- and a decreased protein oxidation as compared to the situation in which a normal CHO rich diet alone is eaten.

The recommended level of protern intake tor enourance athleres pertorming highly intensive sustained exercise, consuming a $\mathrm{CHO}$ rich diet andbeing in positive energy balance most probably is in the range of 1.5 to $1.8 \mathrm{~g} . \mathrm{kg}^{-1}$ bady weight. 


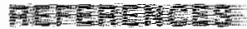

僖

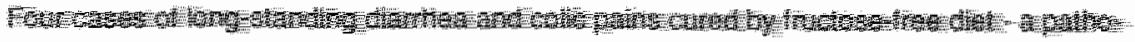

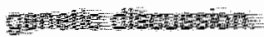

A

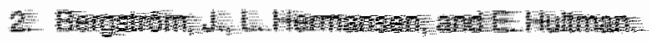

Din

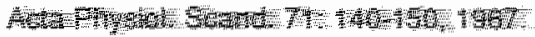

3i

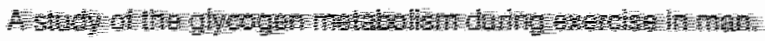

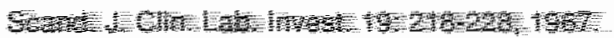

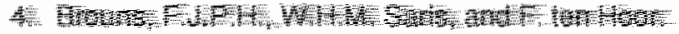

Dit

Fin

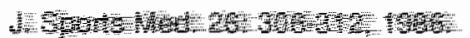

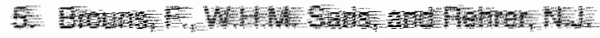

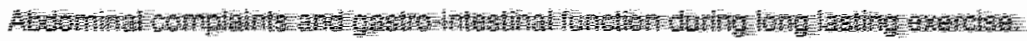

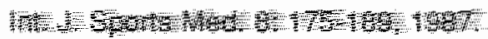

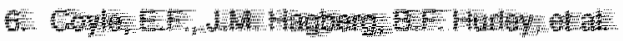

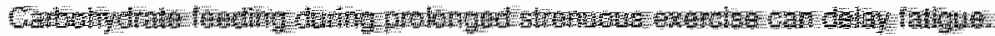

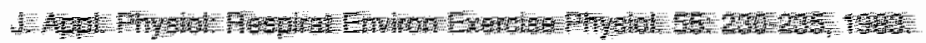

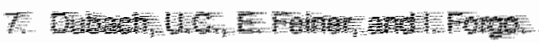

OM

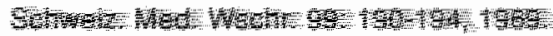

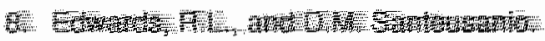

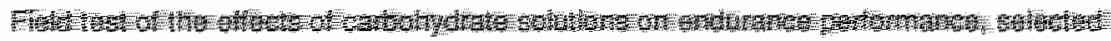

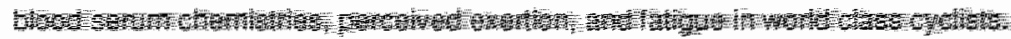

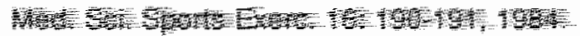

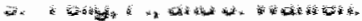

Anino acti melaboism in exercising man.

1. Chin. trvest $50,2703-2714,1971$.

10. Falg. $P$ and $J$. Wakren.

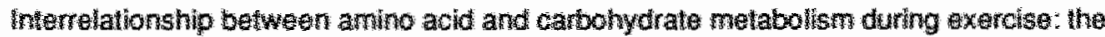
givcose alanine-cycla.

h. Advances in experimentat medicine and biology vol 1.

New Vork-London - Plamum Press pp 205-213, 1971a.

1. Foster $\mathrm{s}_{\kappa_{2}}$ O.L. Costill and W.J. Fink.

Elects of pre-exercise ledings on endurance pertomance.

Med. Sol Sports 1: 1-5, 1979 . 
12. Hargreaves, M., D.L. Costill, A. Coggan, et al.

Effect of carbohydrate feedings on muscle glycogen utitization and exercise performance. Med. Sci. Sports Exerc. 16: 219-222, 1984.

13. Ivy, JL. W. Miller, V. Dover, L.G. Goodyear, el al.

Endurance improved by ingestion of a glucose polymer supplement.

Med. Sci Sports Exerc. 15: 466-471, 1983.

14. Kirsch, K.N. , and H. von Ame In.

Feeding patterns of endurance athlettes.

Eur. J. Appl. Physiol. 47/2: 179-208, 1981.

15. Lemon, P.W.R., and J.J. Nagle.

Effects of exercise on protein and amino acid metabolism.

Med. Scl. Sp. Ex. 13/3: 141-149, 1981.

16. Lemon, P.W.R., and J.P. Mullin.

Effect of initial muscle glycogen levels on protelin catabolism during exercise.

J. Appl. Physiol 48: 624-629, 1980.

17. Levine, L., W.J. Evans, B.S. Cadarette, E.C. Fisher, et al.

Fructose and glucose ingestion and muscle glycogen use during submaximal exercise.

J. Appl. Physiol. 55: 1767-1771, 1983.

18. Newsholme, E.A., and C. Start.

Regulation in metabolism pp 253-261.

John Wiley and Sons, Chichester, 1981.

19. Newsholme, E.A., and A.R. Leech.

Integration of carbohydrate and lipid metabolism.

In: Biochemistry for the medical scilences pp 336-356.

John Wiley and Sons, Chichester, 1983.

19a. Nielsen, B., G. Sjøgaard, J. Ugelvig, B. Knudsen, et al.

Fluid balance in exercise dehydration and rehydration with different glucose-electrolyte drinks.

Eur. J. Appl. Physiol. 55: 318-325, 1986.

20. Saltin, B., and L. Hermansen.

Glycogen stores and prolonged severe exercise.

In: Blix G. (Ed.) Nutrition and physical activity 5. Sweden

Almquist and Wiksells pp 32-46, 1967.

21. Saris, W.H.M., M.A. van Erp-Baart, and F. Brouns.

Study on food intake during extreme sustained exercise; the Tour de France.

Int. J. Sports Med. Suppl. 1988. In press.

22. Sherman, W.M., and D.L. Costill.

The marathon: dietary manipulation to optimize performance.

Am. J. Sports Med. 12: 44-51, 1984. 
22a. Tappy, L., J.P. Randin, J.P. Felber, et al.

Comparison of thermogenic effect of fructose and glucose in normal humans.

Am. J. Physiol 250: E 718-E 724, 1986.

23. Weitzman, R., and C.R. Kleeman.

Water metabolism and the neurohypophysial hormones.

In: Bondy, P.K., L.E. Rosenberg (eds).

Metabolic control and disease. Philadelphia, W.B. Saunders Company, pp

1241-1324, 1980.

24. Wijn, J.F. de, and M. van Erp-Baart.

Food pattern, body composition and physical condition of heavy weight competition rowers.

Voeding 41: 1, 1980. 

CHAPTER IV: THE EFFECT OF DIET MANIPULATION AND REPEATED SUSTAINED EXERCISE ON NITROGEN BALANCE, A CONTROLLED TOUR DE FRANCE SIMULATION STUDY, PART 3.

\section{F. Brouns, W.H.M. Saris, J. Stroecken, E. Beckers, R. Thijssen, N.J. Rehrer and F. ten Hoor}

\section{Introduction}

It is known that the dietary energy level has a direct effect on nitrogen balance. A reduction of energy intake normally is followed by increased nitrogen losses from the body (Inoue, 1983; Galloway, 1975; Garza, 1976).

Starvation leads to a depletion of endogenous carbohydrate (CHO) stores, which will result in increased amino acid oxidation and enhanced gluconeogenesis from alanine (Felig, 1969, 1970; Chang, 1978). This increased protein oxidation will last until the body adapts towards enhanced utilization of fat and ketones (Felig, 1969). It has also been observed that prolonged exercise may influence nitrogen balance. A number of studies have shown that protein is used as a source of energy during sustained physical exercise (Dohm, 1980; Cerny, 1975; Decombaz, 1979; Haralambie, 1975). Recently Lemon and Mullin (1980) observed that glycogen depletion enhances the rate of protein degradation and nitrogen loss from the body during prolonged exercise. In this respect it can be stated that a certain analogy exists between the initial phase of starvation and prolonged exercise. In both situations lacal glycogen stores become depleted and protein degradation will be increased. Because energy balance, glycogen levels, as well as the blood glucose level (Long, 1976) may influence the extent to which protein can serve as an energy substrate, it was hypothesized that diet manipulation in the exercising athlete has a substantial influence on protein degradation during exercise. Therefore it was decided to study nitrogen balance on rest days and on days of prolonged intensive physical exercise in highly trained subjects.

The main purpose of this study was to evaluate the effect of diet manipulation during exhausting physical exercise on nitrogen balance.

\section{Experimental design, analyses and statistics}

Experimental set up, analyses and statistics used are described in detail in Chapter II and III.

Nitrogen balance was calculated according to the formula 
where $\mathbf{N}$ in = nitrogen intake from foods and fluids

$\mathbf{N}$ out = nitrogen loss from the body by urine, feces, sweat and blood samples taken.

\section{Results}

The results concerning energy intake (EI), energy expenditure (EE) and energy balance (EB) have been discussed in detail in Chapter II and III.

The data of EB are summarized in Table 1. Important is the observation that the performance of exhausting endurance exercise on day 4 and 5 resulted in a negative energy balance in $N$ and $F M_{1}$ whereas subjects in Mf treatment were able to maintain energy balance.

Table 1 Mean daily energy balance on rest days ( 3 and 6 ) and exercise days (4 and 5 ).

\begin{tabular}{|c|c|c|c|c|c|}
\hline Day & & & & & \\
\hline Treatment & 3 & 4 & 5 & 6 & $\begin{array}{l}\text { Cumulative } \\
\text { day } 4+5+6\end{array}$ \\
\hline$N$ & $1.3 \pm 1.2$ & $-9.6 \pm 0.8$ & $-7.9 \pm 5.1 \ldots$ & $2.9 \pm 0.9$ & $-15.3 \pm 2.1$ \\
\hline Mf & $4.9 \pm 0.9$ & $0.3 \pm 1.2^{*}$ & $-0.5 \pm 1.7^{*} .^{*}$ & $2.1 \pm 1.3$ & $1.9 \pm 2.1$ \\
\hline FM & $3.9 \pm 1.7$ & $-2.5 \pm 2.0^{*}$ & $3.3 \pm 1.9^{*} . *$ & $1.0 \pm 1.8$ & $4.8 \pm 3.8$ \\
\hline
\end{tabular}

Mean values \pm SEM (MJ).

$\mathrm{N}=$ conventional $\mathrm{CHO}$ rich diet $(\mathrm{n}=13)$.

$M f=N$ supplemented with a maltodextrin - low fructose solution $(n=6)$.

$\mathrm{FM}=\mathrm{N}$ supplemented with a $50 \%$ tructose $-50 \%$ maltodextrin solution $(n=7)$.

Asterisks indicate a significant difference with respect to values obtained with the conventional diet $(N) * * 0.01 ; * * * 0.001$, (each subject is his own con-trol). Statistical significance with respect to the initial values on day 3 is indi-cated by $\neq p<0.05 ; \ldots \infty<0.01 ;$ m.p $<0.001$.

Mean energy and nitrogen content ( \pm SEM) of blood from a sample taken at 7:00 AM on day 3 were $5.32 \pm 0.10 \mathrm{~kJ} . \mathrm{ml}^{-1}$ and $33.4 \pm 1.0 \mathrm{mg} . \mathrm{ml}-1$ respectively. The total amount of blood sampled was $50 \mathrm{ml}$. day-1, on day 3 to 6 .

Mean nitrogen excretion with urine, feces and sweat is given in Table 2. Sweat was only collected during day 4 and 5 .

Mean daily nitrogen intake from food and mean daily nitrogen balance are given in Table 3 and 4. 
Table 2 Mean dally nitrogen excretion on rest days ( 3 and 6 ) and exercise days ( 4 and 5 ).

\begin{tabular}{|c|c|c|c|c|c|c|}
\hline \multirow{2}{*}{\multicolumn{2}{|c|}{ Day }} & \multirow[b]{2}{*}{3} & \multirow[b]{2}{*}{4} & \multirow[b]{2}{*}{5} & \multirow[b]{2}{*}{6} & \multirow{2}{*}{$\begin{array}{l}\text { Cumulative } \\
\text { day } 4+5+6\end{array}$} \\
\hline & & & & & & \\
\hline \multirow[t]{3}{*}{ FECES } & $N$ & $2.9 \pm 0.2$ & $2.8 \pm 0.5$ & $2.6 \pm 0.3$ & $2.6 \pm 0.3$ & \\
\hline & $M f$ & $2.6 \pm 0.2$ & $3.2 \pm 0.7$ & $2.2 \pm 0.5$ & $1.9 \pm 0.4$ & \\
\hline & $\mathrm{FM}$ & $2.9 \pm 0.3$ & $1.9 \pm 0.3$ & $2.7 \pm 0.4$ & $2.3 \pm 0.5$ & \\
\hline \multirow[t]{3}{*}{ URINE } & $N$ & $13.0 \pm 1.0$ & $15.5 \pm 1.0$ & $16.2 \pm 1.1$ & $19.7 \pm 1.6 \ldots$ & $44.7 \pm 2.5$ \\
\hline & Mf & $14.1 \pm 0.9$ & $11.5 \pm 0.6$ & $11.6 \pm 1.3$ & $15.5 \pm 1.2$ & $38.6 \pm 2.6$ \\
\hline & FM & $12.7 \pm 1.2$ & $12.4 \pm 0.8^{*}$ & $14.9 \pm 1.5$ & $15.1 \pm 2.4^{\star}$ & $42.4 \pm 2.8$ \\
\hline \multirow[t]{3}{*}{ SWEAT } & $N$ & - & $1.9 \pm 0.3$ & $1.9 \pm 0.2$ & - & \\
\hline & Mf & - & $1.6 \pm 0.3$ & $1.5 \pm 0.2$ & - & \\
\hline & FM & - & $2.2 \pm 0.6$ & $2.3 \pm 0.6$ & - & \\
\hline
\end{tabular}

Mean values $\pm S E M(g)$.

Asterisks indicate a significant difference with respect to values obtained with the conventional diet (N) ${ }^{*} p<0.05$ (each subject is his own control). Statistical significance with respect to the initial values on day 3 is indicated by $. p<0.05 ; . .0<0.01$.

Table 3 Daily nitrogen intake calculated from weighed food intake

\begin{tabular}{l|cccccc}
\hline \multicolumn{2}{r}{ Day } & 3 & 4 & 5 & 6 & $\begin{array}{c}\text { Cumulative } \\
\text { day } 4+5+6\end{array}$ \\
\hline Treatment & 3 & 4 & 5 & 6 & & \\
\hline $\mathrm{N}$ & $19.3 \pm 0.9$ & $18.9 \pm 1.2$ & $18.6 \pm 1.1$ & $21.5 \pm 1.0$. & $58.9 \pm 2.6$ \\
$\mathrm{Mf}$ & $19.7 \pm 1.0$ & $15.7 \pm 1.5$. & $17.7 \pm 1.4$ & $17.9 \pm 1.2^{* * *}$ & $51.4 \pm 2.8$ \\
$\mathrm{FM}$ & $19.0 \pm 1.6$ & $15.4 \pm 1.3$ & $15.7 \pm 1.7$ & $15.9 \pm 2.4^{*}$ & $47.0 \pm 4.9$ \\
\hline
\end{tabular}

Mean values \pm SEM (g).

Nitrogen content of all foods supplied was determined previously by the che-miluminescence method.

Asterisks indicate a significant difference with respect to corresponding values obtained with conventional diet ( $N$ ) * $p<0.05$; " $p<0.01 ; * * " p<0.001$ (each sub-ject is his own control). Statistical significance with respect to the initial values on day 3 is indicated by $. p<0.05 ;$, $p<0.01$. 
Table 4 Mean daily nitrogen balance on rest days (3 and 6) and exercise days (4 and 5 ).

\begin{tabular}{|c|c|c|c|c|c|}
\hline$\frac{\text { Day }}{\text { Treatment }}$ & 3 & 4 & 5 & 6 & $\begin{array}{l}\text { Cumulative } \\
\text { day } 4+5 \div 6\end{array}$ \\
\hline$N$ & $1.9 \pm 1.5$ & $-2.6 \pm 1.3$ & $-3.7 \pm 1.1$ & $-2.5 \pm 1.4$ & $-8.7+2.5$ \\
\hline Mf & $1.4 \pm 0.7$ & $-2.1 \pm 0.4$ & $1.2 \pm 2.2$ & $-1.1 \pm 1.0$ & $-2.1 \pm 2.5$ \\
\hline$F M$ & $1.7 \pm 1.8$ & $-2.9 \pm 1.4$ & $-6.0 \pm 2.4$ & $-2.5 \pm 2.9$ & $-11.3 \pm 4.5$ \\
\hline
\end{tabular}

Mean values \pm SEM (g).

In $N$ treatment urinary nitrogen increased significantly during day 4,5 and 6 . In contrast, subjects with Mf treatment had a significant reduced nitrogen excretion in the urine on the first exercise day and tended to be reduced on the second exercise day $(p=0.06)$ compared to the first rest day (day 3). Mf subjects reached their initial resting excretion level again on the second rest day (day 6). In FM treatment there was no difference between the first rest and exercise day. On day 5 and 6 mean urinary nitrogen excretion was increased. However, compared to $N$ (each subject was his own control) the values in $F M$ were significantly lower on day 4 and 6 . Sweat nitrogen excretion was similar in the 3 treatments on the two exercise days.

Mean nitrogen intake from food tended to be lower in Mf and FM compared to $\mathrm{N}$ (Table 3). Nitrogen balance as a reflection of total daily nitrogen intake and nitrogen losses from the body was positive on day 3 and became negative on the first exercise day (day 4) in all treatments. On the second exercise day mean nitrogen balance became more negative in $\mathrm{N}$ and $\mathrm{FM}$ whereas it tended to be positive in Mf. On day 6 nitrogen balance was negative in all treatments.

\section{Discussion}

Energy balance was positive on the first resting day in all treatments and became negative as a result of sustained exercise on day 4 and 5 in $\mathrm{N}$ and FM. In contrast Mf treatment resulted in a positive energy balance over the entire exercise period (see Table 1). Notwithstanding the large contribution of $\mathrm{CHO}$ to total daily energy intake, in the $N$ and MF treatment this intake was inadequate to balance the amount of $\mathrm{CHO}$ oxidized, most probably due to the high levels of energy expenditure during sustained exercise. In the $\mathrm{Mf}$ treatment $\mathrm{CHO}$ intake appeared to be adequate even under these circumstances (For a detailed analysis see Chapter III). Based on the observed interactions between energy balance and nitrogen losses from the body on the one hand, and $\mathrm{CHO}$ availability and protein degradation on the other hand it 
was assumed that subjects who were able to maintain energy balance and "CHO balance" would not develop a negative nitrogen balance, despite the prolonged exhausting exercise.

As can be seen from the data (Table 2) there was no significant difference in daily nitrogen lass by the feces. This indicates that protein digestion and absorption in the described experimental circumstances were not influenced by the heavy exercise. Urinary nitrogen content increased with exercise and showed the highest mean values for treatment $\mathbb{N}$ and $F M$, where the subjects developed a negative energy balance. In Mf urinary nitrogen excretion tended to decrease during exercise days and increased again to initial values during recovery on day 6.

These data suggest protein sparing in Mf treatment compared to $\mathrm{N}$ and FM. This suggestion is supported by the data of sweat urea excretion which had the lowest values for Mf. It has been observed that muscle glycogen depletion enhances the amount of nitrogen excreted in the sweat (Lemon, 1980). In the present study sweat nitrogen excretion on the first exercise day was similar to that on the second exercise day in each treatment. This may suggest that the glycogen depletion on both exercise days has been similar. The lower mean sweat nitrogen excretion in Mf compared to $\mathrm{N}$ and FM may be related to the observed glycogen sparing in these subjects (see Chapter V). Besides daily energy and $\mathrm{CHO}$ intake it is known that the amount of protein ingested also affects protein metabolism and nitrogen balance. A low protein intake may initiate a negative nitrogen balance whereas a high protein intake stimulates protein synthesis and retainment (Meredith, 1982). Therefore protein intake was fixed to a minimum of of $1.2 \mathrm{~g} \cdot \mathrm{kg}-1$.day -1 in order to rule out a negative influence of decreased protein intake which might result from a changed appetite and food selection during the exercise days. (For a detailed description of food intake see Chapter II and III). From the data summarized in Table 3 it can be seen that in $\mathrm{N}$ treatment nitrogen intake from food was maintained at the initial level also during the exercise days. Mean protein intake decreased 15 to $20 \%$ in $\mathrm{Mf}$ and $\mathrm{FM}$, most probably as a result of changed food selection due to the diet manipulation. The lowest mean daily protein intake in these groups amounted to $1.43 \mathrm{~g} \cdot \mathrm{kg}^{-1}$.day-1 compared to 1.7 g. $\mathrm{kg}^{-1}$ in $\mathrm{N}$. Although this lower level of protein consumption was still markedly above the recommended daily allowance for protein intake of $0.8 \mathrm{~g} \cdot \mathrm{kg}^{-1}$.day-1 (NRC, 1984) it may be hypothesized that this level is too low for subjects performing sustained heavy exercise and thus may have influenced the amount of nitrogen retained and/or excreted.

At present it cannot be concluded which relative roles the negative energy balance and probably protein intake have played in the development of a negative nitrogen balance. Nitrogen balance was positive on the first rest day and became negative on the first exercise day (day 4) irrespective of energy 
balance. However, on the second exercise day, nitrogen balance tended to be more negative in $\mathrm{N}$ and $\mathrm{FM}$ and was positive in Mf. On that day $\mathrm{N}$ and FM were in negative energy and ' $\mathrm{CHO}$ balance', whereas in Mf treatment energy and CHO balance was maintained (see Table 1 and Chapter III of this study).

An interesting observation is that the subjects in Mf who developed a negative nitrogen balance on a particular day always were on a level of protein intake lower than $1.6 \mathrm{~g} . \mathrm{kg}-1$. For example in one subject nitrogen balance was -2.14 $\mathrm{g}$ negative on the first exercise day. Protein intake on this day was $1.2 \mathrm{~g} . \mathrm{kg}^{-1}=$ $12.64 \mathrm{~g}$ nitrogen.day -1 . On the second exercise day nitrogen balance was $3.69 \mathrm{~g}$ positive and protein intake was $1.8 \mathrm{~g} \cdot \mathrm{kg}^{-1}=18.86 \mathrm{~g}$ nitrogen,day- 1 . The delta change in nitrogen balance and nitrogen intake between both days was similar. This relation was present in all subjects in Mf both at rest and during exercise and suggests that the quantitative protein intake becomes critical with respect to the daily nitrogen balance under exercise circumstances in all cases where energy balance is maintained and $\mathrm{CHO}$ intake is sufficient. In Mf a correlation coefficient of $.806, p=<.001$, was derived when all the day to day changes in nitrogen balance were plotted against day to day changes in nitrogen intake (see Fig 1). These data strongly suggest that athletes involved in heavy physical exercise should maintain a constant level of protein intake higher than the RDA of $0.8 \mathrm{~g} . \mathrm{kg}^{-1}$, most probably 1.5 to $1.8 \mathrm{~g} . \mathrm{kg}^{-1}$, in order to maintain nitrogen balance.

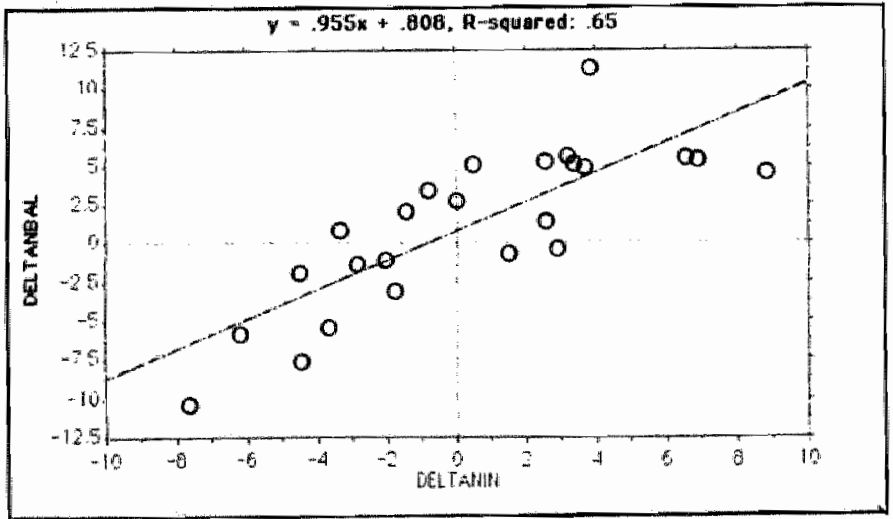

FG 1 Day to day changes in nitrogen intake (g)(Delta nin) and nitrogen balance (g) (Delta $n B a l)$ in subjects receiving Mi treatment $R=806, p<0.001$.

During recovery (day 6), mean nitrogen balance was negative in all treatments, despite the observation that energy balance was positive. It may be assumed that this post exercise negative nitrogen balance may be caused by a persisting effect of exercise on protein synthesis (depression) and 
degradation (maintenance or increase). This may have its consequences in particular for the recovery and adaptation of functional proteins involved in exercise. From the available biochemical data, including muscle glycogen (Chapter V), it cannot be concluded which factor causes this increased protein degradation during recovery. Increased post-exercise nitrogen losses have also been reported in other studies (Decombaz, 1979; Lemon, 1983, 1984).

In one study (Gontzea, 1975) it was observed that physical effort over a prolonged period of time caused a negative nitrogen balance during the first week. In the period thereafter nitrogen balance was reached again. The subjects in this study showed a training-effect, resulting in an increased work capacity. The present study was too short to study long term effects but it can be assumed that exercise to exhaustion causes always the same metabolic effects, irrespective of training adaptations, in contrast to exercise at submaximal work levels where exhaustion is not reached. In the latter training adaptations, leading to an enhanced work capacity, will lower the metabolic stress which may reduce protein catabolism.

In summary the following conclusions can be made:

1. Repeated heary sustained exercise in trained athletes, who are consuming a conventional $\mathrm{CHO}$ rich diet, causes a negative energy balance. As a result nitrogen balance is negative, despite a mean protein intake of $1.7 \mathrm{~g} . \mathrm{kg}^{-1}$. day-1.

2 Supplementation of the conventional diet with a $\mathrm{CHO}$ rich liquid led to a maintenance of energy balance and induces protein sparing.

3. Even under circumstances of maintaining energy and ' $\mathrm{CHO}$ balance', a minimal protein intake of $1.5 \mathrm{~g} \cdot \mathrm{kg}^{-1} \mathrm{day}^{-1}$ was needed to reach nitrogen balance. 


\section{REFERENCES}

1. Cerny, $F$.

Protein metabolism during two hour ergometer exercise.

In: Howald, $H_{\text {, }}$ and $\mathrm{J}_{\mathrm{R}} \mathrm{R}$. Poortmans (eds). Metabolic adaptations to prolonged physical exercise.

Birkhauser Verlag. Basel pp 232-237, 1975.

2. Chang, T.W., and A.L. Goldberg.

The origin of alanine produced in skeletal muscle.

J. Biol. Chem. 253: 3677-3684, 1978.

3. Decombaz, J. P. Reinhardt, K. Anantharaman, et al,

Biochemical changes in a $100 \mathrm{~km}$ run: Free amino acids, urea, and creatinine.

Eur. J. Appl. Physiol. 41:61-72, 1979.

4. Dohm, G.L., G.J. Kasperek, E.B. Tapscott, and G.A. Beecher.

Effect of exercise on synthesis and degradation of muscle protein.

Blochem. J. 88: 255-262, 1980.

5. Felig, P. , O.E. Owen, J. Wahren, G.F. Cahill, G.F. jr.

Arnino acid metabolism during prolonged starvation.

J. Clin. Invest. 48: 584-594, 1969.

6. Felig, P., Th. Pozetsiky. E. Marliss, and G.F. Cahill.

Alanine: key role in gluconeogenesis.

Science 167: 1003, 1970.

7. Garza, C., N.S. Scrimshaw, V.R. Young.

Human protein requirements: the effect of variations in energy intake withim the maintenance range.

8. Galloway, D.H.

Nitrogen balance of men with marginal intakes of protein and energy.

J. Nutr. 105: 914-9-3, 1975.

9. Gontzea, J., R. Sutsescu, and S. Dimitranche.

The influence of adaptation to physical effort on nitrogen balance in man.

Nutrition Reviews 11: 231, 1975.

10. Haralamble, G., and A. Berg.

Serum urea and amino nitrogen changes with exercise duration.

Eur. J. Appl. Physiol. 36: 38-48, 1976.

11. Inoue, G. $Y$. Fujita, and $Y$. Niiyama.

Studies on protein requirements of young men led egg protein and rice with excess and maintenance energy intakes.

J. Nutr. 103: 1673-1687, 1973.

12. Lemon, P.W.R., D.G. Dolny, and U.E. Yarashaski.

Effect of intensity on protein utillization during prolonged exercise.

Med. Sci. Sport Ex. 16: 151 abstract, 1984. 
13. Lemon, P.W.R., D.G. Dolny, and B.S. Sherman.

Effect of intense prolonged running on protein catabolism. In: H.G. Knuttgen, J.A. Vogel,

J. Poortmans (Eds).

Biochemistry of exercise (pp 367-372).

Champaign llinais, Human Kinetics, 1983.

14. Lemon, P.W.R., and J.P. Mullin.

Effect of initial muscle glycogen levels on protein catabolism during exercise.

J. Appl. Physiol. 48: 624-629, 1980.

15. Long, C.L., J.M. Kinney, and J.W. Geiger.

Non-suppressability of gluconeogenesis by glucose in septic patients.

Metabolism 25: 193, 1976.

16. Meredith C. et al.

Whole body amino acid turnover with $13 \mathrm{C}$ tracers: a new approach for estimation of human amino-acid requirements.

In: Clinical Nulrition, 1981, pp 42-59.

R. Wesdorp, P. Soeters Eds., Churchill Livingstone.

17. National Research Council

Recommended daily allowances.

National Academy of Sciences, Washington, 1980. 


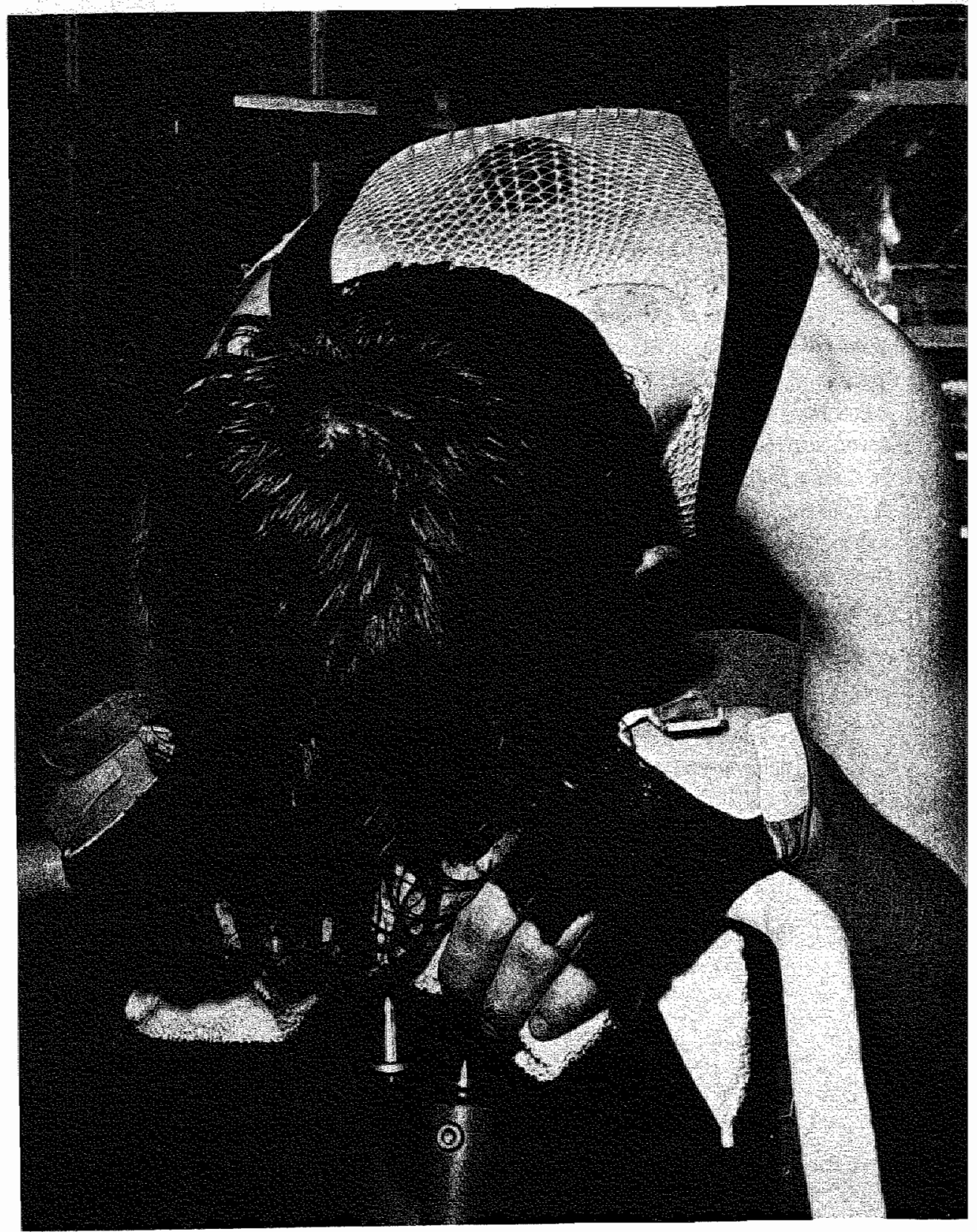


CHAPTER V: METABOLIC CHANGES INDUCED BY SUSTAINED EXHAUSTIVE CYCLING AND DIET MANIPULATION, A CONTROLLED TOUR DE FRANCE SIMULATION STUDY

\author{
F. Brouns, W.H.M. Saris, E. Beckers, H.Adler- \\ creutz, G.J. van der Vusse, P. Menheere and \\ F. ten Hoor
}

\title{
Introduction
}

The human body is able to adapt to extremely heavy workloads and as a result of long term adaptations, professional cyclists are able to increase their energy output to very high levels on a day to day basis. In one of the world's most extreme cycling competitions, the Tour de France lasting 23 days, it was shown that energy expenditure (EE) can exceed $32 \mathrm{MJ}$ on a hot competition day in the mountains, while mean (EE) amounted to $24 \mathrm{MJ}$ per day (Saris, 1988). The same study revealed that the cyclists were only capable of competing at such an extreme level by matching energy intake to energy expenditure. This was achieved mainly by intake of liquid carbohydrate- and energy rich meals throughout the day in addition to the normal diet. Cyclists who were not able to maintain energy balance frequently experienced malperformance and sometimes were forced to quit prematurely. Such imbalance normally resulted from diarrhea or inadequate food intake caused by changes in food tolerance and appetite, due to the extremely fatiguing exercise. Furthermore time for recovery is limited.

In contrast to this diet behavior of professional cyclists, nutritionists and physiologists generally belief that a normal well balanced diet supplying 50-60 en\% carbohydrate $(\mathrm{CHO})$ and $0.8-1 \mathrm{~g}$ of protein $\mathrm{kg}_{\text {.day- }}{ }^{1}$ will be sufficient for any sportsman or woman in any situation. However, the question then arises how athletes can meet their daily energy and $\mathrm{CHO}$ needs, when both are increased to extreme levels.

Apart from problems due to the time available to eat and digest, the volume of the food and the changes in appetite (Brouns, 1986), one may question the possible interaction between changes in energy metabolism as a result of long term training and the influence of changed eating habits or diet manipulation.

It is known that liver and muscle glycogen stores limit endurance performance capacity whenever exercise intensities increase 
above $60 \% \mathrm{VO}_{2}$ max (Bergström, 1967; Saltin, 1967; Sherman; 1984). As a result of longterm training the body adapts towards enhanced fat metabolism in order to minimize this limitation, leading to muscle glycogen sparing and delaying the onset of fatigue (Gollnick, 1982, 1986; Saltin, 1983; Paul, 1975; Stanckiewicz, 1978).

On the other hand it has been discussed that maximal power output decreases with increasing contribution of fat in energy metabolism, such as after endogenous $\mathrm{CHO}$ depletion, or following a high fat diet, both of which will enhance blood fatty acid concentration and utilization. As a result, when fat is the main substrate, power output will drop to $50 \%$ of maximal capacity (Newsholme, 1983), possibly as a result of a decreased maximal energy flow from fat compared to $\mathrm{CHO}$ (McGilvery, 1973). Studies from the early sixties showed that glycogen stores were increased when $\mathrm{CHO}$ intake was increased drastically during the days preceding exercise and that this increase was associated with longer exercise times to exhaustion (Bergström, 1967; Gollnick, 1972; Saltin, 1967). The same holds for ingestion of substantial amounts of $\mathrm{CHO}$ during exercise, possibly delaying glycogen depletion and thereby improving performance (Coyle, 1983; " Ivy, 1983; Edwards, 1984).

However it has also been shown that fat and $\mathrm{CHO}$ behave as competitive substrates when passing the muscle cell membrane for oxidation (Rennie, 1977; Randle, 1963; Newsholme, 1976). Infusion of fat decreases $\mathrm{CHO}$ oxidation and enhances fat metabolism while $\mathrm{CHO}$ infusions cause the opposite effect (Felber, 1964; Büber, 1968; Gomez, 1972). As a consequence, the quantity of $\mathrm{CHO}$ degraded may be larger than the quantity ingested when the latter is small. Intake at rest prior to exercise, enhancing insulin secretion may also lead to enhanced rates of glycogen degradation and reduced times until exhaustion (Hargreaves, 1984; Foster, 1979). From this it may be postulated that the effectivity of diet manipulation to a large extent depends on the quantity of nutrients involved and on the moment of intake.

Apart from this it has been shown that protein degradation during exercise is increased whenever glycogen stores are depleted in order to supply precursors for gluconeogenesis (Ahlborg, 1974; Rennie, 1981a; Lemon, 1981b; Dohm, 1982) and that CHO intake and/or enhanced glycogen availability limits this protein degradation (Lemon, 1981; Rennie, 1981; Munro, 1953; Long, 1976). The fact that protein degradation is also increased at rest 
whenever energy balance is negative for a prolonged period of time, such as during fasting, is also related to glycogen depletion and enhanced gluconeogenesis (Felig, 1969; Sauerwein, 1982). Taking into account these interrelationships it can be hypothesized that performance capacity can be maintained at a higher level, and that protein degradation will be limited, whenever energy balance is maintained and $\mathrm{CHO}$ intake matches $\mathrm{CHO}$ degradation.

Since cyclists competing successfully in the Tour de France were able to maintain energy balance only by using liquid $\mathrm{CHO}$ rich foods in addition to the normal diet and no controlled studies in the field of ultra-endurance sports supporting this practice are available, it was decided to design a cross-over study in which the nutritional and biochemical changes of cyclists ingesting a $\mathrm{CHO}$ rich diet composed of conventional but $\mathrm{CHO}$ rich food (treatment $\mathrm{N}$ ) could be compared with those after diet manipulation, in which the same diet was supplemented with a substantial amount of $\mathrm{CHO}$ concentrated liquids (treatment Mf). The study was performed in a controlled laboratory set-up in which two heavy days with an energy expenditure comparable to that observed in the Tour de France were simulated.

\section{MATERIALS AND METHODS}

\section{Subjects}

Thirteen highly trained cyclists participated in this study. Physical characteristics are presented in Table 1.

\section{Table 1 Physical characteristics of experimental} subjects

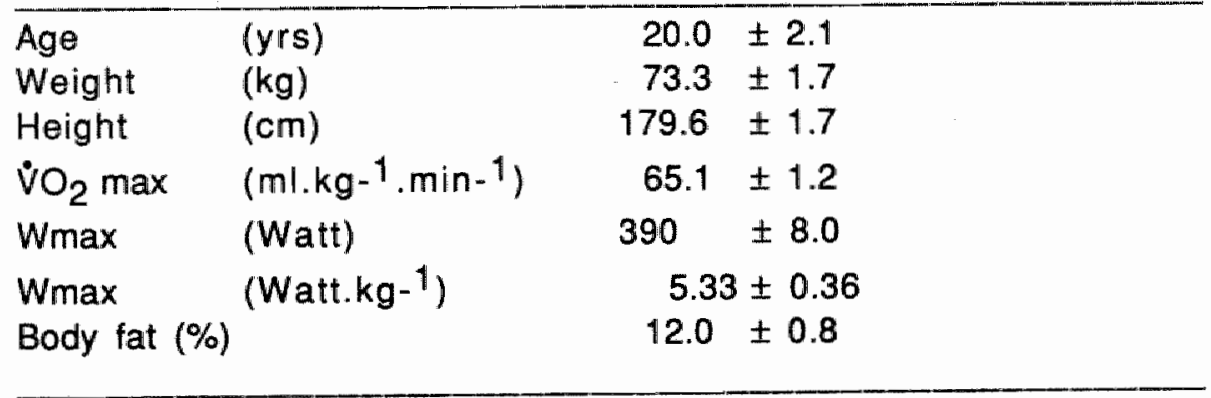




\section{Experimental design}

The subjects were asked not to participate in vigorous training or competition during the two days preceeding the arrival in the laboratory and to ingest a normal but $\mathrm{CHO}$ rich diet (dietary advice was given by a registered dietician). All subjects were informed about the nature, purpose and possible risks of the study, before giving their voluntary written consent to participate. The experiment was conducted over seven sequential days using a semi-automated respiration chamber system.

The subjects reported to the laboratory on Sunday evening (day 1) at 9:00 PM in order to get accustomed to the chamber. They received a time schedule for all activities in the forthcoming week. The next preparation day (day 2) a by each subject selected supply of food and fluid of known quantity and composition was made available. It is known that differences in substrate mobilization and utilizaton may occur depending on diet composition, exercise executed and quantitative endogenous $\mathrm{CHO}$ stores. (Galbo, 1979; Gollnick, 19811; Lemon, 1981; Maughan, 1978). For that reason diet composition and amount of exercise was completely controlled during $24 \mathrm{~h}$ previous to the experiment (day 2). At least 60 en\% $\mathrm{CHO}$ and a minimal protein intake of 1.2 $\mathrm{g} . \mathrm{kg}^{-1}$ were assured in order to realize a complete build-up of endogenous substrate pools and to avoid interindividual differences in pre-test nutritional and metabolic status. Protein intake was calculated daily, immediately after dinner. To assure a minimum intake of $1.2 \mathrm{~g} \cdot \mathrm{kg}^{-1}$, subjects were supplemented with a protein concentrate whenever intake was calculated to be too small for that day. This food supply was continuously provided until the end of the experiment on Saturday morning 9:00 AM six days later. Food for breakfast, lunch and in-between meals was supplied at 7:30 AM. However, extra's could be obtained throughout the day upon request. Dinner was served at 6:00 PM. There were no quantitative limitations. The cyclists were instructed about the importance of adequate food and fluid intake and were encouraged to eat and drink as much as desired.

Weight and volumes of foods and drinks were measured and registered in a diary allowing for analysis of $24 \mathrm{~h}$ intake. The residual amounts were weighed and accounted for in the final calculations. Energy and nitrogen content of all available food items had been previously determined. Actual performance capacity expressed in Watt (Wmax) and maximal oxygen uptake 
$\left(\mathrm{VO}_{2} \max _{;} \mathrm{ml} \cdot \mathrm{kg}^{-1} \cdot \mathrm{min}^{-1}\right)$ were determined at 10:00 $\mathrm{AM}$, day 2 , during an incremental cycle ergometer test.

The respiration chambers were closed at 4:00 PM on day 2 and measurements for calculation of energy expenditure were started (Fig 1).Blood samples were taken daily at 7:00 AM immediately after waking-up, at 12:00 AM and 3:00 PM. This was done through a special designed airlock in the respiration chamber wall. The samples were drawn into EDTA evacuated tubes from a teflon catheter, which was inserted into an antecubital vein at 7:00 AM daily, and was connected with a three-way stopcock. The blood was immediately put in ice water.

Days 3 and 6 of the experiment represent standardized rest days during which each subject cycled $45 \mathrm{~min}$ at $40 \% \mathrm{Wmax}$ at 10:00 AM and 2:00 PM. Rest days were included in the program in order to determine resting status for comparison with the following two exercise days. On days 4 and 5 , each subject exercised to exhaustion (E).

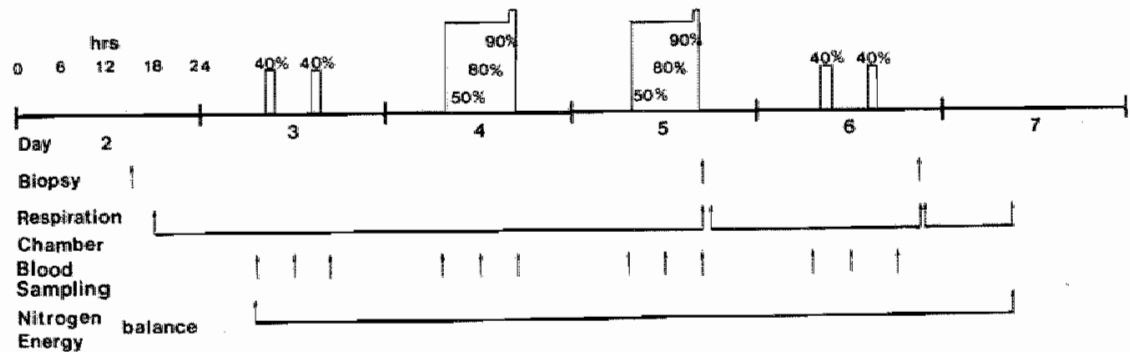

Fig 1 Time schedule of measurements performed. On day 2 actual performance capacity (Wmax; Watt) and maximal oxygen uptake $\left(\mathrm{VO}_{2} \max ; \mathrm{ml} \cdot \mathrm{min}^{-1}\right)$ were determined at 10:00 AM using an incremental bicycle ergometer test. Day 3 and 6 were rest days; cycling at 40\% Wmax during $45 \mathrm{~min}$ at 10:00 $\mathrm{AM}$ and 2:00 PM. Day 4 and 5; exercise to exhaustion. Day 7; end of the experiment at 9:00 AM. A muscle biopsy was taken on day 2,5 and 6. Blood was sampled at 7:00 AM, 12:00 AM and 4:00 PM on day 3 to 6.

Sweat samples were collected on day 4 and 5 by absorption into predried pads located in water- and airtight capsules (Lemon, 1983). Ten $\min$ prior to exercise sweat capsules were placed in the infraspinous fossa of the scapula and kept in place by an 
elastic mesh vest. Exercise was started at 10:00 AM with a 30 min warming-up, followed by exercise at intensities of $80 \%$ and $50 \%$ Wmax respectively. Eighty percent and $50 \%$ Wmax were chosen in order to mimic cycling ahead of the group or benefitting from wind shielding within the group respectively. At 12:00 AM exercise was interrupted for $5 \mathrm{~min}$ to measure body weight, to collect blood samples and to change the sweat capsules. Thereafter exercise was continued at $50 \%$ and $60 \%$ Wmax allowing for a food intake. After $3 \mathrm{~h} 44 \mathrm{~min}$ exercise was continued again at $80 \%$ and $50 \%$ Wmax in $3 \mathrm{~min}$ intervals. Finally at about 2:30 $\mathrm{PM}$, the wattload was set at $90 \% \mathrm{Wmax}$ and the cyclists were asked to maintain pedaling frequency greater than 60 RPM. Ninety percent of Wmax equivalent to approximately $80 \% \mathrm{VO}_{2}$ max - at the end was chosen in order to simulate a finish on a mountain top (Fig 2).

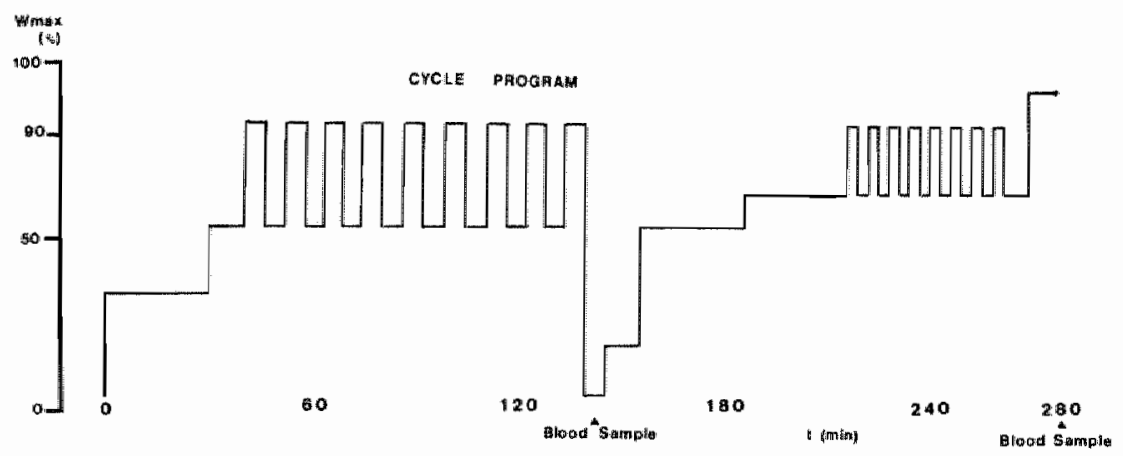

Fig 2 The cycling program was as follows: warming-up $30 \mathrm{~min}$ at $30 \%$ Wmax, followed by $10 \mathrm{~min} 50 \% \mathrm{Wmax}$, followed 9 times by $6 \mathrm{~min} 80 \%$ Wmax and $6 \mathrm{~min}$ $50 \%$ Wmax respectlvely. After this, exercise was shortly interrupted for collecting blood and sweat samples and was then continued at 50 Watt for $10 \mathrm{~min}$, followed by 50 and $60 \%$ Wmax both for 30 min. Exercise intensity was then increased to $80 \%$ Wmax for $3 \mathrm{~min}$ followed by $3 \mathrm{~min}$ at $50 \%$ Wmax, which was repeated 8 times. Finally exercise intensity was increased to $90 \%$ Wmax which had to be performed until exhaustion.

During exercise, fluids were available ad libitum (tea, coffee, milk, lemonade and a placebo 'sport drink" (consisting of artificially sweetened, coloured, and mineralized water). Feces 
During exercise, fluids were available ad libitum (tea, coffee, millk, lemonade and a placebo 'sport drink' (consisting of artificially sweetened, coloured, and mineralized water). Feces and urine were kept at $-20^{\circ} \mathrm{C}$ in a deep freezer toillet and were collected in $24 \mathrm{~h}$ periods.

A percutaneous needle biopsy sample (Evans, 1982) was taken from the. m.vastus lateralis at 4:00 PM at rest on day 2, $45 \mathrm{~min}$ after reaching exhaustion on day 5 and after $24 \mathrm{~h}$ of recovery on day 6 . (The biopsy could not be taken immediately after reaching exhaustion because of measurements which had to be finished before the respiration chamber could be opened). The biopsy sample was immediately frozen in liquid nitrogen for analysis of glycogen and triacylglycerol.

\section{Diet manipulation}

For diet manipulation the total group of 13 subjects was divided into two subgroups. In 6 randomly selected subjects the normal diet was supplemented with an experimental, high maltodextrin low fructose solution (Perform(B), Wander Ltd; Mf). The order of treatment, normal diet or manipulated diet, was randomized. The other seven subjects were supplemented with another experimental beverage. In this paper only the data from $N$ treatment $(n=13)$ and the Mf treatment $(n=6)$ will be presented.

Although there is a wide variety of $\mathrm{CHO}$ sources, it was specifically decided to use a solution composed of mainly longchain glucose polymers and a low fraction of fructose, because long-chain polymers may be of advantage for the athlete by means of maximizing $\mathrm{CHO}$ intake and absorption, while minimizing risks of gastrointestinal distress (Brouns, 1987). A small quantity of fructose was added for reasons of taste, in order to increase palatability. The supplement, prepared as a $20 \%$ (w/v) solution, was made available as follows: standardized resting days $500 \mathrm{ml}$ during the morning, afternoon and evening (total supply $1500 \mathrm{ml}$ ), exercise days during cycling ad libitum and in the evening after dinner, $1000 \mathrm{ml}$. The cyclists during $\mathrm{N}$ treatment were supplemented with equal amounts of a placebo drink at the same times in order to rule out psychological effects due to the drink.

The composition of the drinks is presented in Table 2.

The experimental design used during the Mf trial was exactly the same as described for $N$. The placebo drink was supplied during $N$ treatment in equal quantities and at the same times as the 
beverage in Mf and FM treatment.

The placebo was flavored with citruspowder, sweetened with saccharin and cyclamate and artificially colored.

Table 2 Composition of beverages

\begin{tabular}{lcccccc}
\hline Beverage & $\begin{array}{l}\text { Malto } \\
\text { dextrin } \\
\text { g.1-1 }\end{array}$ & g.l-1 & mmol & $\begin{array}{c}\text { mosm } \\
\text { lity }\end{array}$ & & $\begin{array}{c}\text { Energy } \\
\text { content } \\
\mathrm{kJ} .1-1\end{array}$ \\
Placebo & 0 & 0 & 8.5 & 106 & 4.38 & - \\
Mf & 150 & 33 & 8.5 & 390 & 4.45 & 3158 \\
\hline
\end{tabular}

\section{Analyses}

Energy expenditure was determined using an indirect semiautomated calorimeter as previously described by Schoffelen et al. (1986). Gasflows were measured with a dry gasmeter (Dort, the Netherlands), oxygen was analyzed using a Servomex(B) paramagnetic oxygen analyzer (Taylor, England) and carbon dioxide using on infrared $\mathrm{CO}_{2}$ analyzer (Hartmann and Braun, Germany). Energy expenditure was callculated according to the formula of Consolazio (1963):

$$
\mathrm{E}=3.78 \dot{\mathrm{VO}}_{2}+1.14 \mathrm{~V}_{\mathrm{CO}}-2.98 \mathrm{Nu}
$$

Where $\mathbf{E}=$ energy expenditure $\left(\mathrm{kcal}_{\mathrm{min}}^{-1}\right), \dot{\mathbf{V O}} \mathrm{O}_{2}=$ oxygen consumption $\left(\mathrm{ml} \cdot \mathrm{min}^{-1}\right), \dot{\mathrm{V}} \mathrm{CO}_{2}=\mathrm{CO}_{2}$ production urine $\left(\mathrm{ml} \cdot \mathrm{min}-{ }^{-1}\right)$ and $\mathrm{Nu}$ is the amount of nitrogen excreted in (mg.).

Daily energy balance was calculated from energy expended and energy intake as calculated from daily food and fluid consumption. Corrections were made for energy losses from feces, urine and sweat and for the blood samples drawn. Energy content of food, fluid, feces, urine and blood was determined by bombcalorimetry (IKA Germany). Energy content from sweat was calculated from total sweat urea, assuming that the remainder is negligible. Total sweat loss was determined from body weight change while accounting for fluid intake, urine production, blood volume loss, 
and respiratory water loss (Mitchel, 1972). The sweat volume collected in the capsules was determined by capsule weight changes using a analytical balance (Mettler). Sweat urea content was calculated enzymatically (urease method Boehringer 396346). Nitrogen content of blood and urine was determined by the chemiluminescence method (Antek, Germany). Daily nitrogen losses were then calculated.

$\mathrm{CHO}$ and fat oxidation was calculated from non-protein respiratory quotient (R). Protein oxidation was calculated from daily nitrogen losses in urine and sweat. From the data gathered the daily contribution of $\mathrm{CHO}$, fat and protein to total $24 \mathrm{~h}$ energy exchange as well as the relative contribution during exercise was calculated.

Muscle glycogen content in the biopsy sample, which was freezedried (Leybold Hereaus, GT2, Germany), was determined fluorimetrically after HCL hydrolysis (Passonneau, 1974) and expressed as mmol of glycosyl units. $\mathrm{kg}^{-1}$ dry weight. Muscle triacylglycerol content was assessed as described elsewhere (Van der Vusse, 1982). In short freeze-dried tissue specimen were extracted with chloroform-methanol (2: 1 by vol). The various lipid classes were separated using one dimensional thin layer chromatography. The fatty acids in the triacylglycerol spot were transmethylated with BF3 in methanol. The fatty acid methyl esters were quantitated by gas liquid chromatography.

Plasma volume changes were calculated from hemoglobin and hematocrit values according to Dill and Costill (1974). Hematocrit was determined in all blood samples. Hemoglobin was measured with the hemoglobin cyanide method.

\section{Blood chemistry}

The following methods have been applied for determinations in blood :

Blood glucose - glucose oxidase method (Boehringer 124036), Lactate - oxidimetric analysis (Roche analyzer 640),

Acetoacetate and 3-hydroxybutyrate - enzymatically with 3hydroxy-butyrate dehydrogenase (Bergmeyer, 1965),

Glycerol - glycerol kinase UV test (Boehringer 297771),

Free fatty acids - enzymatic and fluorometrically. Transcon 102 FNR analyzer (OY Elomit, Helsinki, Finland, Härkonen and Adlercreutz 1981).

Blood ammonia - glutamate dehydrogenase UV test (Boehringer 
Urea - urease method (Boehringer 396346).

Catecholamines - HPLC, electrochemical detection system (Smedes, 1982).

Insulin "glucagon and cortisol - Radio-immuno-assay (Medgenix Belgium; DPC Kit, USA).

\section{Statistics}

Wilcoxon signed rank test was used to compare the data of the first standardized rest day to those of the following exercise and recovery days as well as for comparison of differences between the two treatments $N(n=13)$ and $M f(n=6)$. For the latter each subject served as his own control. For all analyses, the 0.05 level was used as the minimum level of confidence for statistical significance.

\section{RESULTS}

The results of the study dealing with food consumption "energy-, fluid- and mitrogen balance, as well as relative contribution of $\mathrm{CHO}$ and fat in energy metabolism have been described and discussed extensively in other papers (Brouns, 1988, 1988a, 1988b see Chapter II, III and IV). The results most important with respect to the studied biochemical parameters are summarized in Tabie 3 and Fig 3.

\section{Plasma Volume}

On both rest days plasma volume in $M$ and $M$ f showed a significant increase at 12:00 $\mathrm{AM}$ and 4:00 PM compared to 7:00 AM on the first day. All though Mf subjects tended to have decreased plasma volumes below the initial level on exercise days compared to $N$ treatment, this was not statistically significant. 
Table 3 Summary of observations with respect to nutritional indices and performance time.

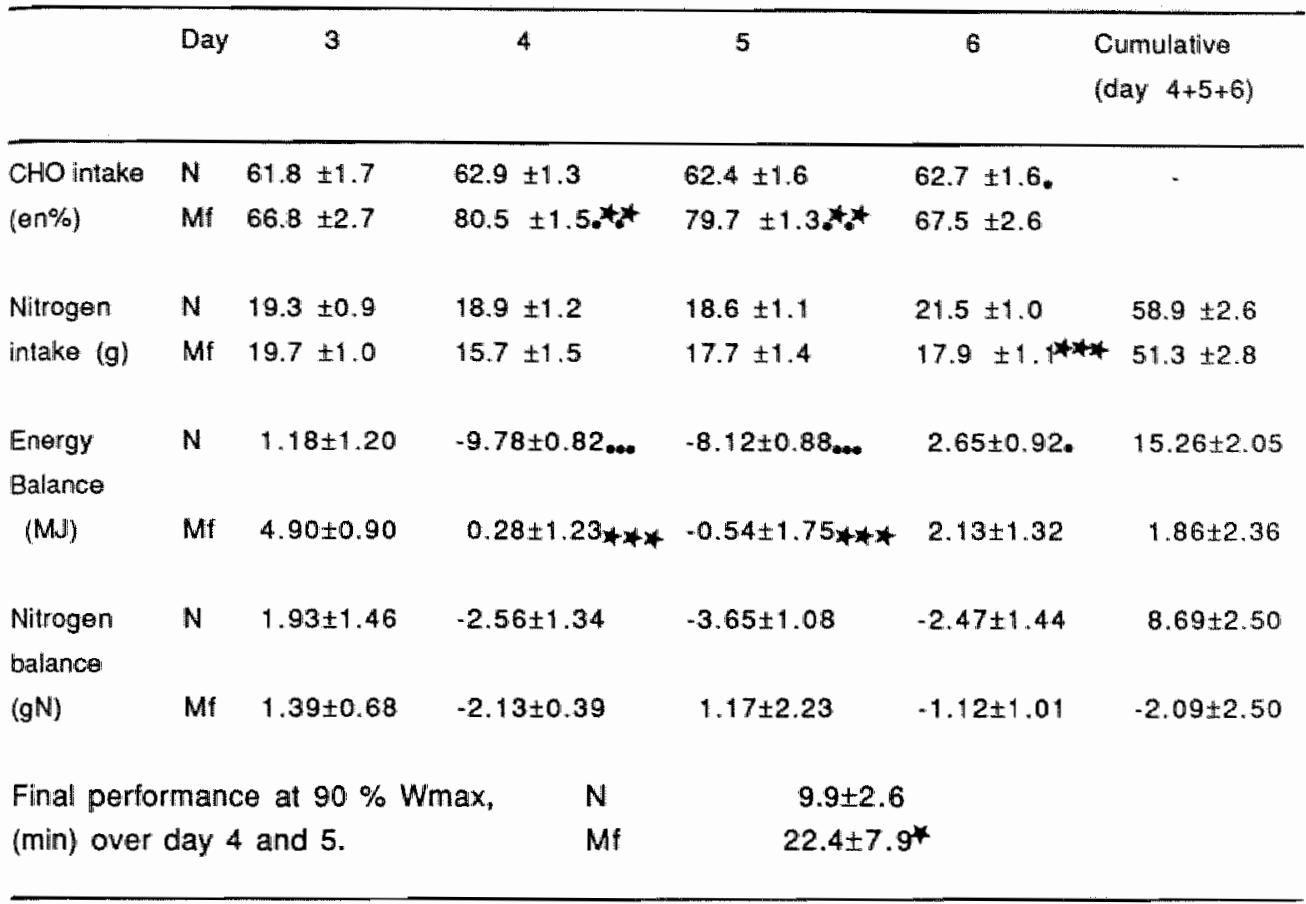

For complete description of the nutritional data see Brouns 1988, 1988a, 1988b. Mean values $\pm S E M$ (for $N, n=13 ; M f, n=6$ ). $C H O$ intake was determined by weighed food intake procedure using a computerized food table for analysis. Nitrogen intake was determined by weighed food intake after previous determination of the nitrogen content of all food items by the chemiluminescense method. Energy balance was determined by indirect calorimetry and weighed food intake after previous determination of energy content of all food items by bomb calorimetry. Nitrogen balance was calculated from total nitrogen intake and nitrogen losses in urine, sweat, feces and blood. Statistical significance with respect to the initial value on day 3 is indicated by $. p<0.05 ; \ldots p<0.01 ; . .0<0.001$. Statistical significance of Mf with respect $10 \mathrm{~N}$ (each subject is his own control) is indicated by " $p<0.05 ;{ }^{* *} p<0.01 ; "{ }^{* *} p<0.001$. 


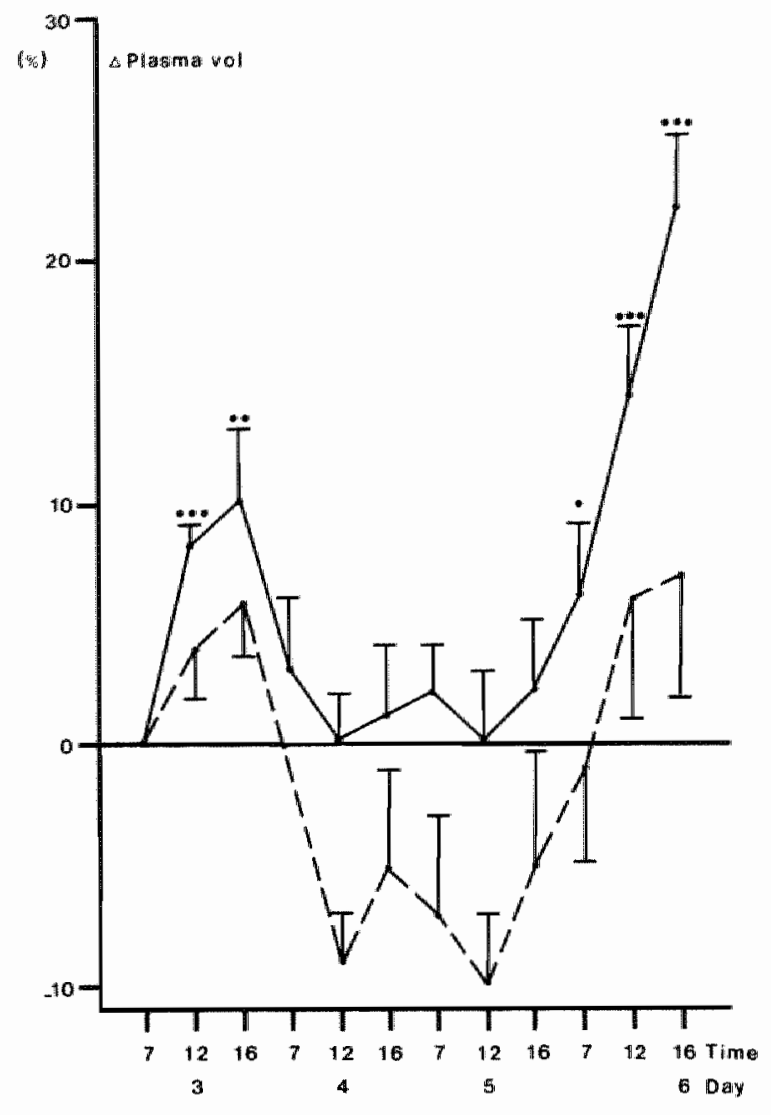

Fig 3 Relative changes in plasma volume at rest (day 3 and 6 ) and during exhaustive exercise days (day 4 and 5). Vertical bars indicate 1 SEM. There was no statistically significant difference between the treatment groups.

Statistical significance with respect to the initial value on day 3 is indicated by $. p<0.05 ; . .0<0.01 ; \ldots p<0.001$; $\mathrm{N}, \ldots$... Mf.

Blood glucose changes are represented in Fig 4. During $N$ treatment blood glucose remained almost the same throughout the entire test. As a result of exercise there was a small but significant elevation on day 4 and 5. During Mf treatment blood glucose values were significantly more elevated on the exercise days than during $N$ treatment. There was no difference between the two rest days. 
Blood lactate was significantly elevated after $2 \mathrm{~h}$ of exercise and at the moment of exhaustion. This elevation was the same for both $\mathrm{N}$ and Mf. Mean maximal lactate values did not exceed 4 mmol.1-1, despite the fact that workload was increased to $90 \%$ Wmax before reaching the moment of exhaustion (Table 4).

\section{Table 4 Blood lactate concentration}

\begin{tabular}{lllll}
\hline & & $7: 00 \mathrm{AM}$ & $12: 00 \mathrm{AM}$ & $4: 00 \mathrm{PM}$ \\
\hline Day 3 & $\mathrm{N}$ & $1.5 \pm 0.1$ & $2.8 \pm 0.3 . *$ & $3.8 \pm 0.5 . *$ \\
& Mf & $1.3 \pm 0.1$ & $2.6 \pm 0.4$ & $3.6 \pm 0.5$ \\
Day 4 & $\mathrm{N}$ & $1.3 \pm 0.1$ & $2.6 \pm 0.2 .$. & $3.0 \pm 0.4 \ldots$ \\
& Mf & $1.5 \pm 0.1 *$ & $2.4 \pm 0.5$ & $3.0 \pm 0.4$ \\
\hline
\end{tabular}

Mean blood lactate values \pm 1 SEM (mmol.1- ${ }^{1}$ ), corrected for changes in plasma volume on exercise days 4 and 5 . Blood samples were taken at 7:00 AM immediately after waking up, at 12:00 AM immediately after cycling at $80 \%$ Wmax and at exhaustion after having cycled at $90 \%$ Wmax. Statistical significance with respect to the initial value on day 3 is indicated by,$p<0.05 ; . . p<0.01$. Statistical significance of Mf with respect to $N$ (each subject is his own control) is indicated by " $\mathrm{P}<0.05$.

Plasma glycerol was stable at rest; post-exercise resting levels (day 6) were not different from pre-exercise resting levels (day 3). During exercise glycerol was significantly elevated in both treatments. However, this elevation was significantly greater during $N$ treatment than during Mf treatment at the end of exercise (Fig 4).

Plasma tree fatty acilds. During the first resting day FFA levels were significantly lower than at 7:00 AM, after an overnight fast (7.00 AM of day 4 serves as reference value). This in contrast to the post exercise rest day where morning levels were elevated. Both treatments showed similar responses during the rest days. During exercise days however. FFA increased significantly more in $N$ than in Mf. This increase remained present during the post exercise night. In both treatments FFA increased more on the second exercise day than on the first (Fig 4). 
Plasma ketones. Acetoacetate at rest in $\mathrm{N}$ was significantly elevated at 4:00 PM compared to 7:00 AM of the first rest day. As a result of exercise the level increased significantly, remained elevated during the night, increased further during the second exercise day and remained significantly elevated throughout the post exercise recovery day. In Mf plasma acetoacetate increased less and tended to be significantly lower throughout the experiment (Fig 4). Beta-hydroxybutyric acid response was similar to that of acetoacetate, except that it returned somewhat faster to basal levels (Fig 4).

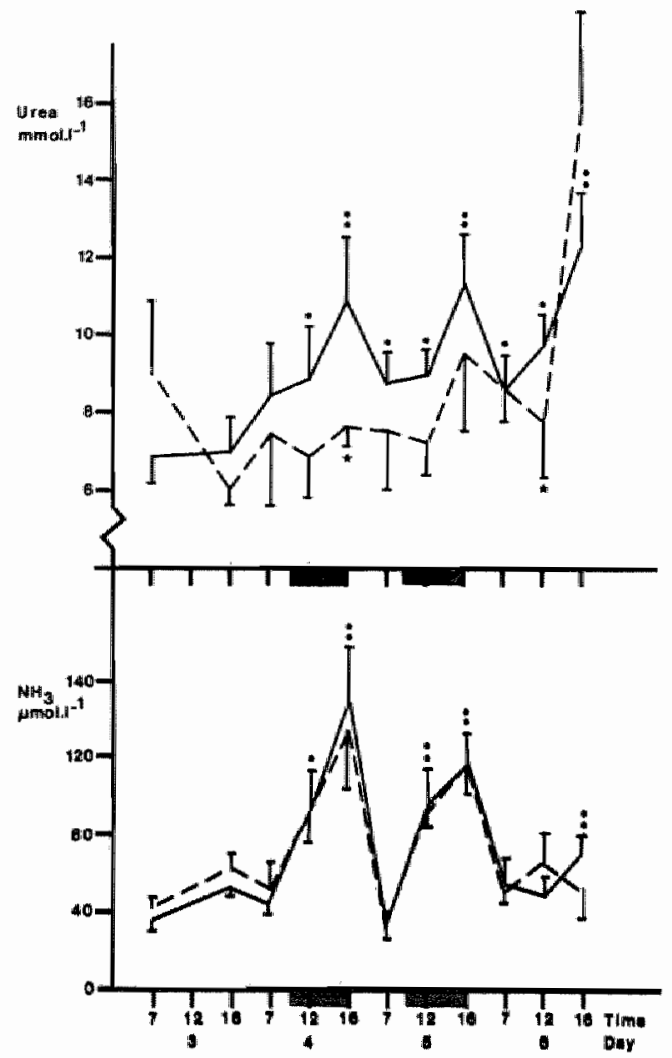

Fig 5 Changes in protein metabolism as measured by ammonia and urea levels in whole blood and blood plasma, corrected for changes in plasma volume.. Statistical silgnificance with respect to the initial value on day 3 is indicated by $. p<0.05 ; \ldots p<0.01 ; \ldots 0<0.001$. Statistical significance of Mf with respect to $\mathrm{N}$ (each subject is his own control) is indicated by ${ }^{*} \mathrm{p}<0.05$. = $\mathrm{N}_{\text {, }}$

$\cdots=$ Mf. = exercise 
Plasma urea was stable in $N$ during day 3 and increased significantly lower during both exercise days, reaching the highest level at the moment of exhaustion. In $M f$ plasma urea was significantly on lower day 4. There was no significant difference in response between $\mathrm{N}$ and Mf on day 5 and 6 (Fig 5). On day 6 plasma urea remained elevated and increased to a level comparable to day 4 and 5 .

Plasma ammonia responses during both treatments were equal. During exercise days plasma ammonia increased significantly and reached the highest values at exhaustion. The values at the moment of exhaustion on the second exercise day tended to be lower than on the first exercise day (Fig 5).

Plasma insulin levels in $N$ and Mf were equal at 7:00 AM of the first rest day (Fig 6). During this day insulin increased significantly. This increase was more pronounced in Mf. During the following exercise days insulin in $N$ was significantly lowered at all measuring times. The food induced insulin response during the day remained entirely absent during the second exercise day. The post-exercise recovery day showed a normal response again. However, the insulin level at 7:00 AM and 12:00 AM remained significantly lower compared to the pre-exercise rest day. The subjects under Mf treatment responded in a similar manner. However, their insulin levels were significantly elevated compared to $\mathbf{N}$ during the exercise days, whereas food induced insulin increase on the second exercise day was not observed at all.

Plasma glucagon responses in $\mathrm{N}$ and $\mathrm{Mf}$ were not different. Plasma glucagon was significantly elevated at the end of both exercise days compared to the 3:30 PM sample of the pre-exercise rest day. The overnight fasting level between both exercise days was not different from that following the first rest day and from that post-exercise. (Fig 6).

Plasma epinephrine and norepinephrine responded to exercise. in a similar way. It should be mentioned, however, that the catecholamines were only determined at the moment of exhaustion and at the same measurement time during day 2 and 6 . Interestingly norepinephrine tended to increase more in $M f$ than in $\mathrm{N}$, whereas the opposite was the case for epinephrine (Fig 6).

Plasma cortisol decreased during the day on both rest days. This decrease was absent on both exercise days resulting in a significant elevation half-way through exercise and at the end of exercise. The response in $N$ and Mf was the same (Fig 6). 


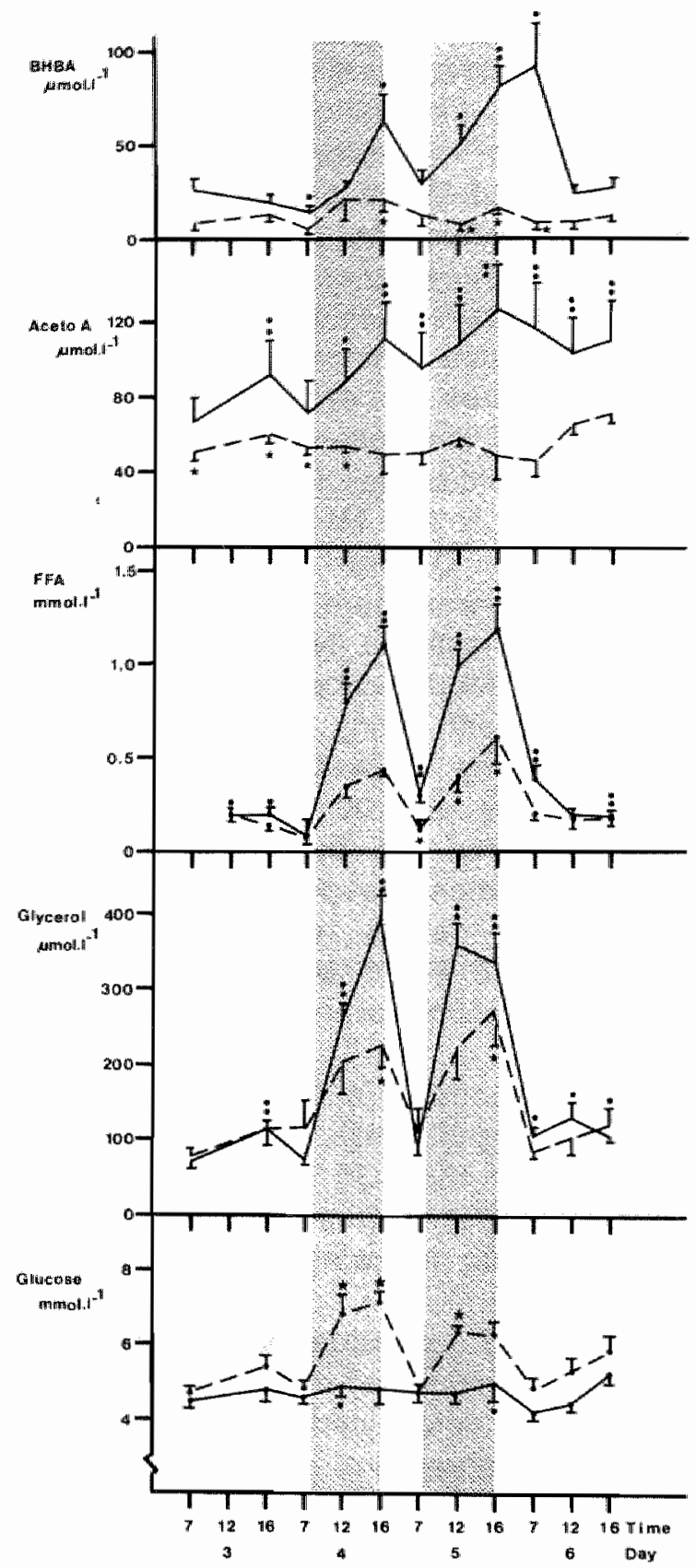

Fig 4 Changes in $\mathrm{CHO}$ and fat metabolism as measured by substrate levels in blood. Blood glucose and FFA are presented as absolute values. Ketones and glycerol are corrected for changes in plasma volume. Statistical significance with respect to the initial value on day 3 is indicated by $. p<0.05 ; . .0<0.01 ; \ldots p<0.001$. For FFA the initial value is day 4, 7:00 AM. Statistical significance of Mf with respect to $N$ (each subject is his own control) is indicated by " $p<0.05=$ $\mathrm{N}, \ldots=\mathrm{Mf}_{n}:$ = exercise 


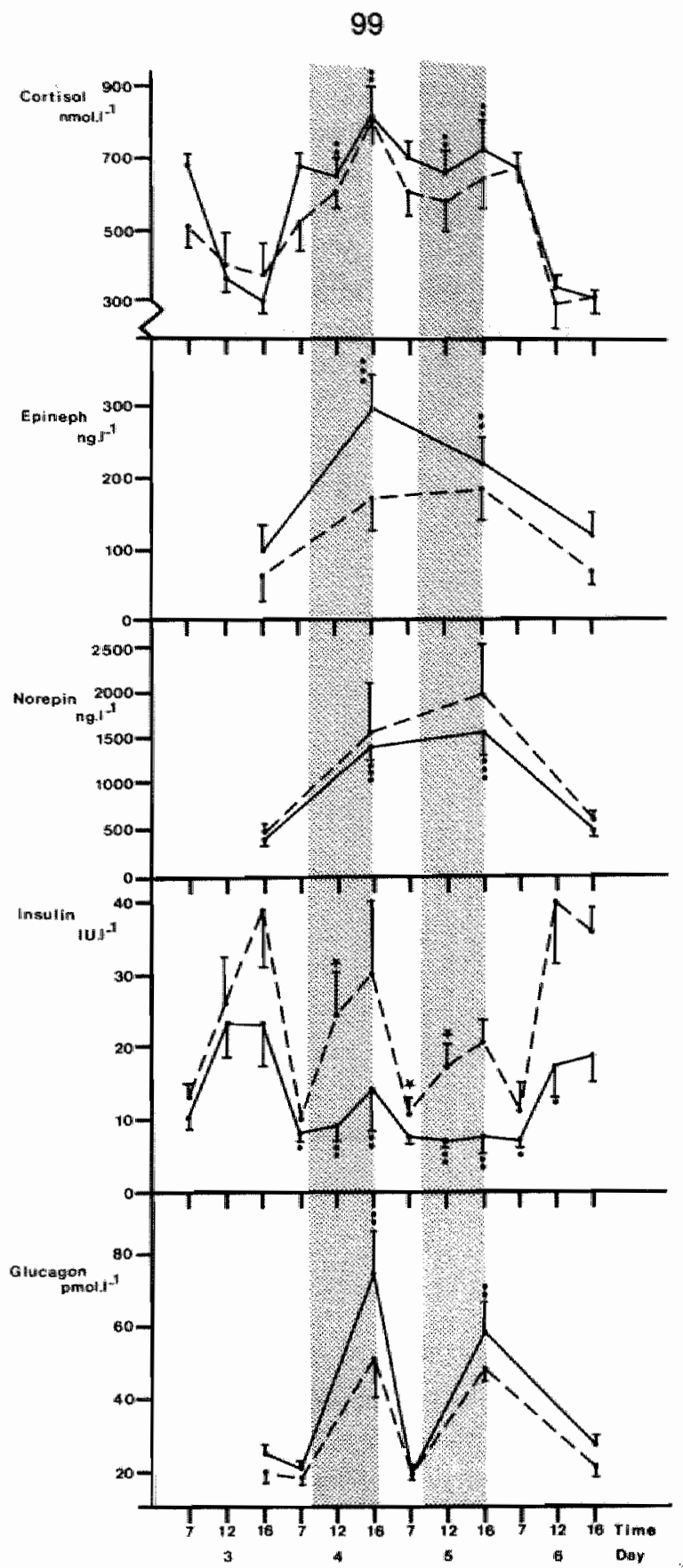

= exercise

Fig 6 Changes in plasma hormone lewels. $=\mathbf{N}_{n}-=$ Mf. Statistical significance with respect to the initial value on day 3 is indicated by $+p<0.05 ; .+p<0.01 ; \ldots p<0.001$. Beciause of the influence of difurnal rhythm, comparison in time was made with respect to the same times on day 3. For glucagon day 4; 7:00 AM was taken as reference morningvalue. Statistical significance of $\mathrm{Ml}$ with respect to $\mathrm{N}$ (each subject is his own control) is indicated by "p<0.05. 
Muscle glycogen on rest day 2 was not different among treatments. As a result of exercise, glycogen decreased significantly in both $\mathrm{N}$ and $\mathrm{Mf}$, however Mf post-exercise levels were significantly higher than the values of the same subjects under $N$ treatment. After $24 \mathrm{~h}$ of recovery $\mathrm{N}$ subjects did not restore their muscle glycogen to initial levels, whereas in Mf subjects glycogen was restored showed supercompensation (Fig 7)

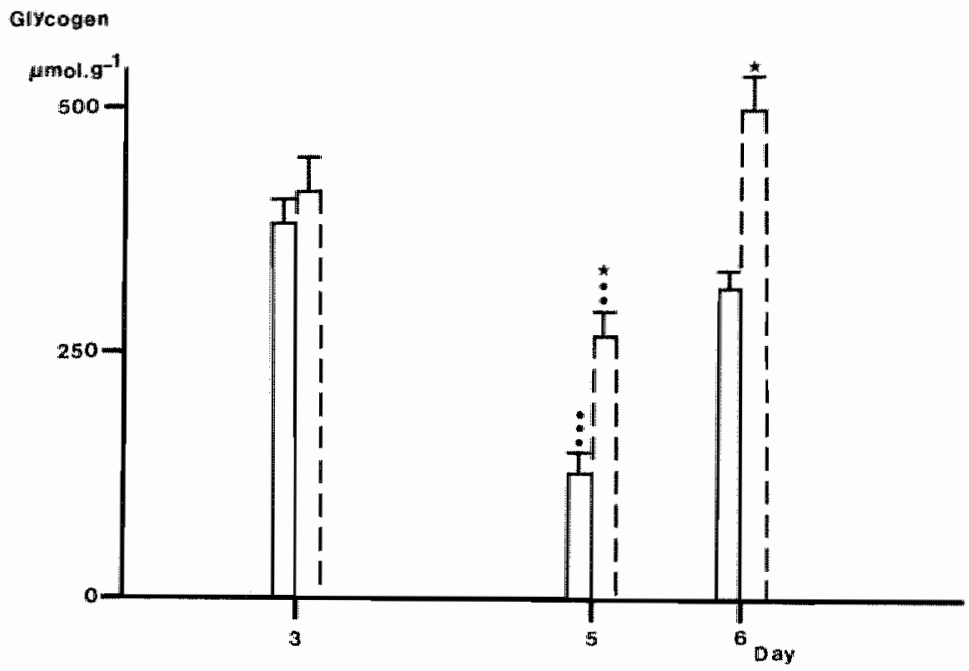

.Fig 7 Mean muscle glycogen content at rest as determined from a biopsy sample on day 2, $45 \mathrm{~min}$ after exhaustion on day 5 , and after $24 \mathrm{~h}$ recovery on day 6 . Statistical significance with respect to the initial value on day 3 is indicated by $. .0<0.01 ; . . .0<0.001$. Statistical significance of Mf with respect to $\mathrm{N}$ (each subject is his own control) is indicated by "p<0.05. Vertical bars indicate 1 SEM (for $N, n=13 ; M t, n=6$ ). $\square=N_{n},{ }^{2}=M f$. 
Muscle triacylglycerol (TG) was equal among treatments in all sample times. Intramuscular triacylglycerol decreased, as a result of exhaustive exercise, significantly in Mf but not in $\mathrm{N}$. However, it should be mentioned that values in $\mathrm{N}$ contained two extreme values (higher value post exercise) most probably caused by subcutaneous fat accompanying the biopsy. Significancy was reached in $\mathbf{N}$ when these two extreme values were not taken into account. Interestingly there was no difference among the treatments in decrease of intramuscular TG levels as a result of exercise. Twenty four hours after finishing exercise, muscle TG content was not restored to initial levels (Fig 8).

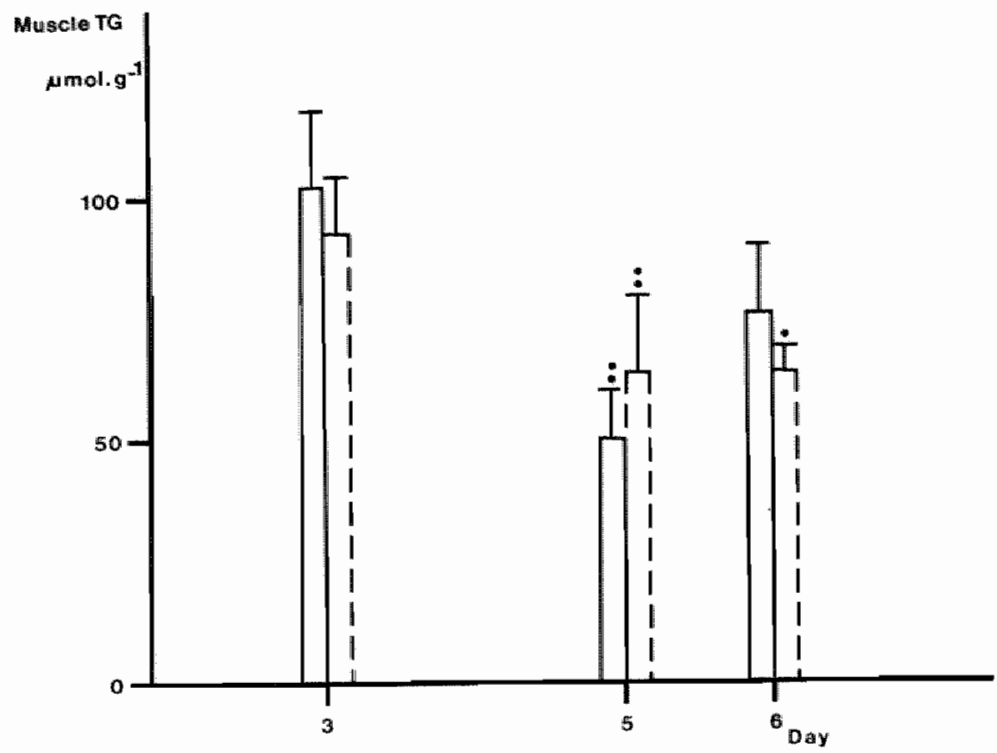

Fig 8 Mean muscle triglyceride content as determined from a biopsy sample, before exercise on day 2, 45 min after exhaustion on day 5 , and after $24 \mathrm{~h}$ recovery on day 6. Statistical significance with respect to the initial value on day 3 is indicated by $. p<0.05 ; 0<0.01$. Vertical bars indicate 1 SEM (for $N, n=13 ; M I, n=6$ ). $\Longrightarrow=\mathrm{N},==\mathrm{=}=$ Mf.

\section{Discussion}

The present study was designed to analyze the effect of repeated long lasting exercise on nutritional indices and metabolic changes and to compare these effects to those present after supplementing 
the same diet with a maltodextrin-low fructose beverage while performing the same exercise program. A survey among professional cyclists competing in the Tour de France showed that liquid $\mathrm{CHO}$ supplements provided the major part of total $\mathrm{CHO}$ intake. Moreover, the study indicated that the athletes were only able to maintain energy balance by using these supplements in addition to the normal conventional meals (Saris, 1988). During a part of this competition the cyclists are competing in the Alps. At this stage finishing on sequential days takes place on the top of a mountain and daily energy expenditure did exceed $35 \mathrm{MJ}$. It is especially during this extremely intensive part of the competition that the athletes have to cope with exhaustion.

It is known that higher exercise intensities will deplete $\mathrm{CHO}$ stores of the body to a low level when performance lasts longer than $45 \mathrm{~min}$ and that this is related to a decrease in power output and finally physical exhaustion (Bergström, 1967, 1967a; Sherman, 1984; Saltin, 1967; Newsholme 1983). Cyclists in practice indicate that the only way to prevent this total exhaustion is to ingest large amounts of $\mathrm{CHO}$ during the competition. Meanwhile a number of studies showed that time to exhaustion is increased when substantial amounts of $\mathrm{CHO}$ are ingested (Coyle, 1983; Ivy, 1983, Edwards, 1984) and that training may enhance the capacity to take up blood borne glucose during exercise (Krzentowski, 1984). In contrast to this it is shown that ingestion of small amounts of CHO may have no effect on performance (Felig, 1982), which suggests that the amount of nutrients ingested may be critical with respect to possible benefits. None of the available studies however has dealt with exhausting exercise over a prolonged period of time during sequential days in highly trained subjects.

The amateur cyclists in the present study were of international level. The athletes cycled $4.5 \mathrm{~h}$ per day while simulating two intensive competition days. During this exercise approximately $1 \mathrm{~h}$ $20 \mathrm{~min}$ were performed at an intensity of $80 \% \mathrm{Wmax}$ and final exercise to exhaustion was performed at $90 \%$ Wmax.

The results of the study show that the subjects ingesting the conventional $\mathrm{CHO}$ rich diet at rest and during exercise were not able to maintain energy balance during days of exhaustive physical work in contrast to when the diet was supplemented with Mf (Table 3).

As a result of the supplementation total $\mathrm{CHO}$ intake increased significantly as did the relative contribution of $\mathrm{CHO}$ to total daily energy intake. From these observations it becomes apparent that 
the two main factors influencing energy exchange processes and performance capacity - energy balance and $\mathrm{CHO}$ availability - were significantly different between the two treatments and must have had their influence on metabolic regulation and substrate availability. Although the subjects receiving the conventional $\mathrm{CHO}$ rich diet were in negative energy balance on day 4 and 5 and the amount of $\mathrm{CHO}$ oxidized was substantially greater than the amount of $\mathrm{CHO}$ intake, especially on day 4 (for a detailed description see Chapter II and III (Brouns 1988a, 1988b), they did not develop hypoglycemia (Fig 4). A possible explanation may be that the ad libitum food intake during exercise conserved sufficient liver glycogen and/or supplied adequate amounts of $\mathrm{CHO}$ to the blood to avoid a fall in blood glucose. A second explanation may be that highly trained individuals have developed an enhanced capacity to synthesize glucose from lactate, glycerol and alanine during exercise.

A contribution of gluconeogenesis to the maintenance of the blood glucose level is supported by the observed increase of hormones that favor gluconeogenesis in the liver and by the observation that blood lactate was significantly increased half way during exercise and at exhaustion. The fact that mean maximal blood lactate did not increase above $3.8 \mathrm{mmol.1}-1$ despite the final exercise intensity of $90 \% \mathrm{Wmax}$, indicates that lactate clearance in these subjects must have been substantial. Recently it was shown that lactate turnover is quantitatively larger during continuous exercise than glucose turnover (Brooks, 1986), whereas trained subjects have an enhanced lactate clearance capacity rather than a change in production (Donovan and Brooks 1983).

Although it may be assumed that lactate production in the exercising muscle is related to the availability of $\mathrm{CHO}$, such that in a state of $\mathrm{CHO}$ depletion less lactate will be produced, no difference could be detected in blood lactate between the two treatments. This occurred despite the large difference in $\mathrm{CHO}$ availability (Table 3). Blood glucose was significantly increased during day 4 and 5 in $\mathrm{Mf}$ as a result of the high $\mathrm{CHO}$ intake whereas it was maintained in a normal physiological range in $N$. The differences between $N$ and $M f$ were statistically significant except at the moment of exhaustion on day 4 . These differences most probably are due to the ad libitum intake of the $\mathrm{CHO}$ beverage started at the onset of exercise, which must have led to a continuous supply of $\mathrm{CHO}$ from the gastro-intestinal tract to the blood. The intake of $300 \mathrm{~g} \mathrm{CHO}$ from the beverage supplemented 
during the rest days did hardly influence the blood glucose level. Oxidation and/or storage in endogenous energy depots at same rate as entry in the blood may have been the reason for this. It has been shown that an increase of the CHO fraction in the diet enhances $\mathrm{CHO}$ metabolism at rest and during exercise (Yoshida, 1984; Gollnick, 1972) and that blood glucose uptake at the site of the muscle membrane increases with both increasing exercise intensity and blood glucose levels (Saltin, 1973; Berger, 1975, Wahren, 1971, 1971a; Felig, 1975).

Insulin is not required for glucose uptake in the muscle cell during exercise, because of an insulin like factor having the same effect on glucose transport through the muscle cell membrane (Holloszy, 1984). However, it is known that insulin in the presence of muscle contractions has an additive effect on glucose uptake (Ivy, 1981; Ploug, 1984, 1985; Constable, 1985). Therefore it may be assumed that during the present study where both blood glucose and insulin were increased in $\mathrm{Mf}$ (compared to $\mathrm{N}$ ), substantial amounts of $\mathrm{CHO}$ will have been available for oxidation in the muscle cell and consequently must have induced glycogen sparing. In studies in which labeled glucose was infused or orally ingested, the observation was made that exogenous $\mathrm{CHO}$ is highly oxidized during exercise leading to a sparing of endogenous $\mathrm{CHO}$. It appeared that the amount of CHO sparing seems is related to the dose of the load infused or ingested, i.e. greater loads induce more elevated blood glucose levels and subsequently an enhanced oxidation thereby reducing the degradation of local glycogen pools (Mosora, 1981; Pallikarakis, 1986; Pirnay, 1977, 1977a; Decombaz, 1985)

Sparing of glycogen may take place in the liver and the muscle. Although liver glycogen was not measured it may be assumed that there was no reason to increase liver $\mathrm{CHO}$ output from liver stores because of the high amount of $\mathrm{CHO}$ ingested. Glucose infusion studies have shown that liver glucose output drops to a low level or is almost entirely blocked when $2 \mathrm{mg} \cdot \mathrm{kg}^{-1} \cdot \mathrm{min}^{-1}$ is infused. Although exercise seems to reverse this inhibition, it was observed that during exercise splanchnic glucose output of glucose and saline infused subjects was identical. This indicates that infusion limits the magnitude of rise in glucose output to an amount equal to infusion rate (Felig, 1979). In the present study $\mathrm{CHO}$ supply to the vena porta must have been substantially greater in the Mf treatment than the above mentioned infusion rate, both at rest and during exercise. 
A statistically significant difference in post exercise muscle glycogen level was observed after exercise on day 5 between $\mathrm{N}$ and Mf. Subjects supplemented with Mf showed a significant glycogen sparing, although cycling time to exhaustion during the final $90 \%$ Wmax load lasted significantly longer in this group (Table 3). Since the muscle biopsy was taken at approximately $45 \mathrm{~min}$ after exercise it can be hypothesized that glycogen resynthesis will have taken place during these $45 \mathrm{~min}$. It has been observed that post exercise glycogen resynthesis can occur from the conversion of lactate (Hermansen 1977; Hultman, 1986).

However, blood lactate levels at exhaustion were equal in both $\mathrm{N}$ and Mf so that this cannot account for the observed difference. Although a substantial amount of $\mathrm{CHO}$ may still have been present in the gastro-intestinal tract in Mf subjects, this can only account for a small part of the observed difference in muscle glycogen. From a recent study (Kuipers, 1987), in which the same beverage was supplied, it was calculated that the average maximal rate of post exercise glycogen synthesis in the trained cyclist amounted to 37 umol.g-1 dry weight.h-1 (range 27-52). This rate was comparable to maximal synthesis rates after exercise as calculated from data of other investigators (Keizer, 1986; McDougal, 1977, Piehl, 1974). Assuming an average maximal post exercise synthesis rate of 37 umol.g- ${ }^{1}$ dry weight only $20 \%$ of the observed difference (141 umol.g- ${ }^{-1}$ dry weight) in the post exercise glycogen can be explained by de novo synthesis.

Taking these findings into account it can be concluded that the majority of the glycogen sparing observed must have been net glycogen sparing during exercise. In this respect it is an interesting observation that exhaustion under Mf treatment, which was delayed significantly as a result of $\mathrm{CHO}$ supplementation, was not caused by a low level of muscle glycogen. Studies in which glycogen depletion in time was related to the state of fatigue indicate that exhaustion occurs when muscie glycogen drops to a low level (Sherman, 1984; Bergström, 1967; Saltin 1971). In the present study mean muscle glycogen at exhaustion in the Mf group was greater than $250 \mathrm{umol}^{-1} \mathrm{~g}^{-1}$ dry weight. Thus other factors than glycogen must have played a role in inducing the state of exhaustion.

As discussed earlier, the availability of fatty acids is of great importance for energy metabolism in the endurance athlete because of it's sparing effect on endogenous $\mathrm{CHO}$ stores. A high 
CHO intake makes a high lipolytic activity superfluous and a low $\mathrm{CHO}$ intake or glycogen depletion enhance lipolytic rate via a number of hormones and mediating substrates (News-holme, 1976, Rennie, 1977). Therefore, the difference in $\mathrm{CHO}$ availability between $N$ and $M f$ must have had it's impact on overall fat metabollism.

Glucagon, catecholamines, growth hormone and sympathatic activity all raise lipolysis whereas insulin has an inhibiting effect (Bagby, 1978; Boyd, 1979; Issekutz, 1975).

The hormonal changes in the present study (Fig 6) were all in favor of an enhanced lipolytic activity especially during $\mathrm{N}$ treatment where energy balance became significantly negative on both exercise days. Plasma levels of glycerol, fatty acids and ketones increased significantly in this group as a result of the exercise.

The presented values of all hormones and of blood glucose and FFA are absolute values (not corrected for changes in plasma volume) in contrast to the values of metabolic intermediates and end products such as lactate, glycerol, ketones, urea and ammonia which are given as corrected values. The reason is that it is the absolute level of the first mentioned parameters which determines the metabolic effects. With respect to the last mentioned parameters it is particularly important to consider the rate of mobilization or production. Therefore a change in those parameters should be corrected for changes in plasma volume.

Since the uptake of FFA is directly related to the plasma fatty acid concentration (Eaton, 1961; Fritz, 1957) and observed $R$ values declined as a result of exercise, it can be concluded that fatty acids have contributed substantially to energy exchange in $N$. The significant increase in plasma ketones may directly be related to the enhanced fat metabolism since a high plasma fatty acid and a low insulin level enhance the rate of ketogenesis (Newsholme, 1976). In Mf fat metabolism was suppressed through the high $\mathrm{CHO}$ intake and the related metabolic changes. Although glycerol and FFA increased also significantly in this group, the magnitude of this increase was significantly smaller than that observed in $\mathbf{N}$. An exception to this was the plasma glycerol level at the end of the second exercise day. The fact that a significant increase in lipolysis occurred in Mf, despite the high blood glucose and insulin level, can only be explained by the mutual action of factors that exert inhibiting and/or stimulating effects on lipolytic activity. The inhibiting effects of increased blood glucose and insulin levels may at the very moment have been overruled by the effect of an 
increase in catecholamines, glucagon and cortisol.

It may be assumed that sympathetic nerve activity, while performing the same exercise protocol, will also have been the same. Interesting is the observation that the plasma glycerol level at exhaustion on day 5 is not significantly different between $N$ and Mi. This coincides with disappearance of the significant differences between $\mathrm{N}$ and $\mathrm{Mf}$ in blood glucose and insulin despite the large $\mathrm{CHO}$ intake from the supplement in the Mf group. Plasma fatty acids on the other hand remained significantly lower under Mf treatment but it has to be kept in mind that plasma fatty acids are a reflection of both fatty acid release and uptake so that it is difficult to conclude about lipolytic activity and/or fatty acid oxidation using this parameter. Despite a small plasma pool, fatty acids may have a rapid turnover rate supplying substantial portions of substrate (Dole, 1956). Glycerol is a better indicator because its conversion to glucose by gluconeogenesis is believed to be slow so that it's accumulation in blood will better reflect overall lipolytic activity (Newsholme, 1983). So far it can be concluded that blood borne fatty acids have contributed significantly to energy exchange despite the high level of $\mathrm{CHO}$ intake during exercise.

Intramuscular TG content, as determined from the biopsy samples decreased due to exercise but was not influenced by the diet treatment. Enhanced uptake of blood borne fatty acids and CHO may lead to a sparing of local glycogen (Newsholme, 1976; Jansson, 1984; this study) but this sparing effect was not observed with respect to muscle triglycerides in the present study. In the trained muscle it may be that the release of intracellular fatty acids from local triacylglycerol during exercise depends on a local regulatory factor and that the amount relleased is always smaller than the oxidative capacity. Fatty acids entering the muscle cell during exercise may then are also be oxidized immediately. This additional fat metabolism may therefore lead to (additional) glycogen sparing but not to a decrease of intracellular lipolytic rate and sparing of TG. The reason why elevated FFA have no sparing effect on intramuscular TG (Stanckiewicz, 1978, the present study) may be partially explained by this, i.e. what is offered is oxidized.

Several studies have indicated that intramuscular fat contributes to a significant extent to overall fat metabolism in the working muscles particularly in the first stage of endurance exercise. Havel (1967) and Paul (1975) calculated in their exercise experiments that approximately $50 \%$ of the fat oxidized was 
derived from local stores. The observation that trained individuals have a greater capacity to rely on intracellular fat (Saltin, 1983; Holloszy, 1984) and have an increased fat storage in the slow twitch muscle fibers in droplets located near the mitochondria (Hoppeler, 1986) while the fractional extraction of FFA does not increase during exercise induced increased bloodflow ,suggests that maximal fatty acid transport across the muscle cell membrane in some way exposes a limiting factor for fat metabolism during endurance exercise. There may thus be a physiological need to store more intracellular TG in muscle cells involved in endurance exercise. From the data obtained it may be hypothesized that intramuscular fat degradation during exercise is under direct control of sympathetic nerve activity and that circulating hormones, blood borne substrates and local glycogen levels may only have an additional influence. Some indirect evidence may support this hypothesis

- Insulin, a strong lipogenic hormone was significantly elevated in $\mathrm{Mf}$ compared to $\mathrm{N}$.

- In Mf muscle glycogen was higher than in $N$.

- In Mf plasma fatty acids were lower than in $\mathbb{N}$.

Nevertheless, muscle TG depletion was similar.

Moreover, elevated plasma FFA were shown to have no sparing effect on intramuscular TG (Stanckiewicz, 1978), the major part of fat oxidized in the first stage of prolonged exercise is derived from intramuscular stores (Paul, 1975; Carlson, 1971), and finally, if moderate continuous exercise or intensive interval exercise with the same mean power outpunt per hour is performed, muscle TG degradation is found to be the same (Essen, 1977).

Protein metabolism is influenced by the concerted action of anabolic and catabolic regulators which are activated or inhibited by physical activity, energy balance, $\mathrm{CHO}$ availability and the level of daily protein intake.

It is known that protein turnover is quite sensitive to the immediate energy supply (Waterlow, 1981) and that the most stable turnover rates appear to be present during a state of stable hormone levels and constant supply of nutrients in a fixed ratio such as during the supply of an enteral feeding formula by nasogastric tube at rest (Golden, 1979). Low energy intakes lead to a negative nitrogen balance, whereas high energy intakes have a possitive effect on nitrogen balance. (Inoue, 1973; Galloway, 1975; Garza, 1976; Rennie, 1981b). An almost linear relationship 
between the level of protein intake and protein synthesis rate has been observed at low levels of protein intake (Meredith, 1982). Das (1972) observed in rats that change from a high- to a low protein diet or vice versa caused an immediate change in urinary nitrogen output which then reached a new constant level after approximately $30 \mathrm{~h}$. This change occurred simultaneously with an adaptation in the activity of urea cycle enzymes. Because exercise induces a negative nitrogen balance by suppressing muscle protein synthesis and increasing protein degradation most probably in the liver and muscle (Rennie, 1981a; Dohm, 1978, 1982; Kasperek, 1980) which may further be influenced by the availability of $\mathrm{CHO}$ (Lemon, 1981a, Long, 1976), it was assumed that an accurate estimation of the changes in protein metabolism due to exercise and diet manipulation could only be made if the pre-exercise nutritionall and metabolic status were controlled as much as possible. Based on this discussion it was decided to standardize a minimum level of protein intake of $1.2 \mathrm{~g} \cdot \mathrm{kg}^{-1}$.day-1 during day 2 and to maintain at least this minimum intake during the entire experimental period. According to Waterlow (1981), in blood the only end products of protein indicating actual changes in protein degradation are urea and ammonia. But for an overall indication of net protein breakdown in the body, resulting in a net nitrogen loss, an accurate analysis of nitrogen excretion in urine and sweat should be performed. During exercise urinary nitrogen excretion falls and plasma urea concentration rises (Rennie, 1981a) most probably because of both a reduced urine production and decreased renal excretion. This leads to an alternative route for elimination of the protein waste products via enhanced secretion in the sweat (Lemon, 1981a). A measurement of both routes is thus essential. The results of the present study show that plasma urea increased significantly, as a result of exercise and negative energy balance, in the subjects with $N$ treatment. In contrast plasma urea remained on a more or less stable level in $\mathrm{Mf}$ and tended only to rise at the point of exhaustion on the second exercise day. This difference in urea response is comparable to that described by Lemon and Mullin (1981a) who observed that endogeneous $\mathrm{CHO}$ depletion led to a significant increase in urea production during exercise.

Plasma ammonia was not different between the two treatments. The reason for this is not clear. Ammonia may be derived from the deamination of amino acids or from the intracellular adenylate pool. The latter takes place during exercise of high intensity when 
immediate energy requirements exceed the amount of energy released from substrate degradation. Rilses in plasma ammonia during exercise may be influenced by the availability of local glycogen stores as is observed in McArdles disease (Wilkerson, 1977; Coleman, 1986; Babij, 1983). In the present experiment the subjects cycled until complete exhaustion. It may thus be that AMP deamination has played a role, apart from the involvement of amino acid degradation for reasons of gluconeogenesis, in ammonia production.

Nitrogen losses were affected by exercise, leading to a negative nitrogen balance in $N$ treatment, also during the recovery day. The mean cumulative nitrogen balance over 2 exercise days and the following recovery day was $-8.69 \pm 2.50 \mathrm{~g}$. In the Mf group there was a tendency to nitrogen sparing despite the significantly longer performance time at $90 \% W \max (-2.09 \pm 2.50 \mathrm{~g})$. However, most probably due to the large variations this effect did not reach significance. This difference in nitrogen balance between the treatments may entirely be explained by the effect of a negative energy balance and 'CHO balance'. A complete picture of all variables regarding protein metabolism studied in the present experiment will be presented in separate papers (Brouns, 1988c; chapter IV). From the data presented it may be concluded that protein degradation and nitrogen loss from the body is increased in athletes during intense sustained exercise and that this increase can be reduced by measures leading to a maintenance of energy balance and enhancement of $\mathrm{CHO}$ intake.

Hormone levels were greatly influenced by the exercise.

Insulin increased as a result of food intake on day 3 but was significantly lowered by exercise on day 4 and 5 . Interesting is the observation that this effect was more pronounced on the second exercise day than on the first. This was not only the case in $\mathrm{N}$ treatment but also in Mf. However in $\mathrm{N}$ the food induced increase disappeared completely on day 5 indicating a strong inhibition of insulin secretion whereas in $M f$ food stimulation still remained present. This further decrease on day 5 cannot be explained by the inhibiting effect of catecholamines on insulin secretion (Porte, 1966, 1966a; 1967; Brouns, 1988), since the level of epinephrine and norepinephrine was not different between the two exercise days. In this respect it is tempting to speculate that local factors such as relative glycogen availability indirectly influence insulin secretion. It may be that low glycogen levels in liver and/or muscle initiate an inhibition of insulin release so that the 
insulin/glucagon ratio decreases to a low level, in order to enhance lipolytic activity as much as possible in order to spare endogeneous $\mathrm{CHO}$. Plasma glucagon as well as cortisol did not differ between the two exercise days nor between the treatments so that the insulin/glucagon ratio decreased as a result of exercise, to the largest extent on day 5. These findings are surprising in the light of the large difference in $\mathrm{CHO}$ avallability between the two treatments.

Glucagon, in contrast to insulin has a strong lipolytic effect (Gerich, 1976), increases hepatic glucose output (Felig, 1972; Ahlborg, 1974) and stimulates hepatic gluconeogenesis (Exton, 1972; Clarck, 1974; Garcia, 1966). It is well documented that glucagon levels will rise whenever blood glucose levels fall or whenever local CHO stores become depleted. Several authors have described that an increase in blood glucose due to $\mathrm{CHO}$ ingestion during or prior to exercise inhibits glucagon secretion (Ahlborg, 1976, 1977; Luykx, 1978; Felig, 1979). However, in the present study such an effect was not observed.

Cortisol also stimulates hepatic gluconeogenesis (Schrago, 1963; Exton, 1972) and appears to become increased indirectly by adrenergic hypothalamic mechanisms via ACTH secretion (Toivola, 1972). Although it has been described that submaximal exercise may not be associated with increments in plasma cortisol (Schrago, 1963; Exton, 1972) we did observe a significant increase. In general it is known that cortisol release during exercise depends largely on exercise intensity, duration and training status (Keibel, 1974; Bloom, 1976). The increase observed may thus be explained by the submaximal exercise over a prolonged period of time and the related adrenergic activity.

Also catecholamines stimulate liver glycogenolysis, gluconeogenesis and overall lipolytic activity (Landsberg, 1980). Catecholamine levels in plasma increase exponentially with work intensity and are most correlated to the relative exercise intensity. However, physiological deterioration by means of hypoglycemia, hyperthermia or hypoxia may further enhance catecholamine release, especially of norepinephrine (Galbo, 1983; Garber, 1976). As a consequence catecholamine increase is abserved to be depressed during exercise trials in which glucose was ingested compared to control (water) trials (Björkman, 1984; Felig, 1982; Galbo, 1983\%. The subjects under $N$ treatment, although being in negative energy balance did not develope hypoglycemia. 
Mf subjects had significantly increased blood glucose levels but nevertheless showed the same response as $\mathbb{N}$ subjects. From these data it may be concluded that hormones which enhance gluconeogenesis, liver glucose output and lipolytic activity, are released during highly intensive and exhausting endurance exercise irrespective of $\mathrm{CHO}$ availability. These findings contradict other studies where during less intensive exercise of shorter duration effects due to substrate availability were observed (Galbo, 1983; Viru, 1985) suggesting that a high level of sympathetic activity over a prolonged period of time in man may be dominant with regard to metabolic regulation of substrate mobilization and availlability.

Cycling performance quantitated by the time that the subjects were able to performe at $80 \%$ and finally $90 \%$ Wmax, was substantially effected by the two treatments. The subjects increased their mean final $90 \%$ Wmax performance over two days from $9.9 \pm 2.6$ to $22.4 \pm 7.9 \mathrm{~min}$ when being under $\mathrm{Mf}$ treatment as compared to $\mathrm{N}$ treatment. The intramuscular glycogen content, a performance limiting factor as discussed before, may have been responsible for this difference. The subjects in $N$ were not able to restore their muscle glycogen levels within $24 \mathrm{~h}$ of recovery (Fig 7). Assuming a similar recovery pattern, glycogen resynthesis during the $18 \mathrm{~h}$ of rest between day 4 and 5 will have amounted approximately $75 \%$ of the measured value on day 6 . This incomplete glycogen recovery may be related to the decreased performance of subjects in $\mathrm{N}$ on the second exercise day. In contrast, in Mf performance on day 5 was improved in 5 of the 6 subjects. One subject could not be motivated to sustain the high workloads already at $80 \%$ Wmax and quitted prematurely (Fig 9). Of particular interest is the observation that subjects in Mf were able to perform significantly longer but became exhausted without any relation to metabolic changes which normally are related to fatigue such as hypoglycemia, high blood lactate, severe dehydration associated with hyperthermia and glycogen depletion. It might be that after the diet manipulation described a shift occurs from glycogen, as limiting factor (subjects in $N$ ), to another unknown factor (Subjects in Mf). It has been suggested that ammonia plays a role in processes of central fatigue (Mutch, 1983) and it is known that ammonia influences a number of steps in the metabolic pathways of energy release (Buono, 1984; Much, 1983, Lowenstein, 1972). 
The plasma ammonia levels observed were similar in the two treatments after reaching the point of exhaustion.

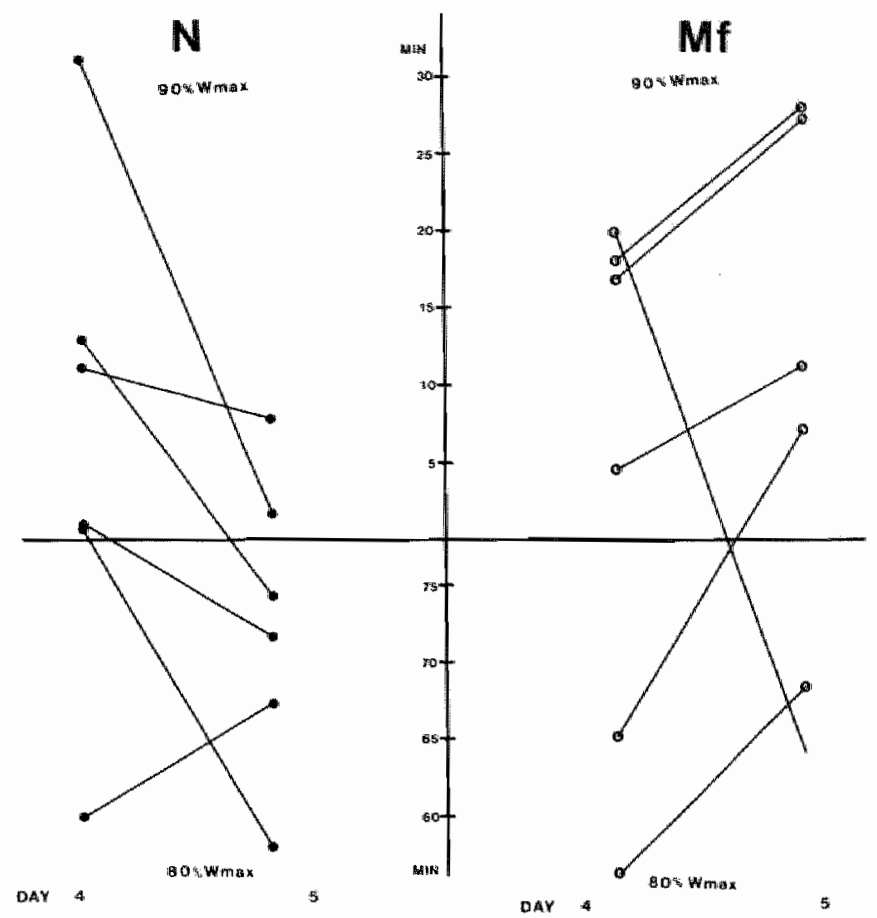

Fig 9 Individual cycling performance in min at $80 \%$ and $90 \%$ Wmax on day 4 and day 5 .

In summary, the results described lead to the following conclusions.

- The supplementation of a conventional CHO rich diet with a $20 \%$ maltodextrin-fructose beverage leads to a marked increase in $\mathrm{CHO}$ availability which induces sparing of intracellular glycogen stores and increases exercise time until exhaustion.

- Glycogen supercompensation can be achieved within $24 \mathrm{~h}$ post exercise.

- A high $\mathrm{CHO}$ intake during sustained exercise reduces protein degradation.

- Local glycogen stores may influence food induced insulin secretion during exercise.

- Intramuscular TG degradation during exercise is not influenced by substrate availability from the blood, nor by intramuscular glycogen content. 


\section{REFERENCES}

1. Ahlborg, G., P. Felig, L. Hagenfeldt, and R. Hendler.

Substrate turnover during prolonged exercise in man.

J. Clin. Invest. 53: 1080-1090, 1974.

2. Ahlborg, G., and P. Felig

Substrate utilization during prolonged exercise preceded by ingestion of glucose.

Am. J. Physiol. 233: E188-194, 1977.

3. Ahlborg, G., and P. Felig.

Influence of glucose ingestion of fuel-hormone response during prolonged exercise.

J. Appl. Physiol. 41: 683-688, 1976.

4. Babij, P., S.M. Matthews, and M.J. Rennie.

Changes in blood ammonia, lactate and amino acids in relation to workload during bicycle ergometer exercise in man.

Eur. J. Appl. Physiol. 50: 405-411, 1983.

5. Bagby, G., H.J. Green, S. Katsuta, and P.D. Gollnick

Glycogen depletion in exercising rats infused with glucose, lactate, or pyruvate.

J. Appl. Physiol. 45: 425-429, 1978.

6. Berger, M., S. Hagg, and N.B. Ruderman.

Glucose metabolism in perfused skeletal muscle.

Blochem. J. 146: 231-238, 1975.

7. Bergmeyer, H.U., and E. Ernt.

Enzym Biol. Clin. 5: 65, 1965.

8. Bergström, J., L. Hermansen, and E. Hultman.

Diet, muscle glycogen and physical performance.

Acta Physiol. Scand. 71: 140-150, 1967.

9. Bergström, J. and E. Hultman.

A study of the glycogen metabolism during exercise in man.

Scand. J. clin. Lab. Invest. 19: 218-228, 1967a.

10. Bjorkman, O., K. Sahlin, L. Hagenfeldt, and J. Wahren.

Influence of glucose and fructose ingestion on the capacity for longterm exercise in well trained men.

Clin. Physiol. 4: 483-494, 1984.

11. Bloom, S.R., R.H. Johnson, and D.M. Park.

Differences in the metabolic and hormonal response to exercise between racing cyclists and untrained individuals.

J. Physiol. 258: 1, 1976.

12. Boyd, A.E., S.R. Giamber, M. Mager and H.E. Lebovitz.

Lactate inhibition of lypolysis in exercising man.

Metabolism 23: 531-542, 1974. 
13. Brooks, G. A.

The lactate shuttle during exercise and recovery.

Med. Sci sports Exerc. 18: 360-368, 1986.

14. Brouns, F.J.P.H., W.H.M. Saris, and F, ten Hoor.

Dietary problems in the case of strenuous exertion.

Part 1: A literature review

J. Sports Med. 26: 306-312, 1986.

15. Brouns, F., W.H.M. Saris, J. Stroecken, E. Beckers, R. Thijssen, N.J. Rehrer, and $F$. then Hoor.

Eating, drinking and cycling, a controlled Tour de France simulation study, Part I.

Int. J. Sports Med. Suppl. 1988. Submitted.

16. Brouns, F., W.H.M. Saris, J. Stroecken, E. Beckers, R. Thijssen, N.J. Rehrer, and $F$. ten Hoor

Eating, drinking and cycling, a controlled Tour de France simulation study.

Part II. The effect of diet manipulation.

Int. J. Sports Med. Suppl. 1988a. Subbmitted.

17. Brouns, F., W.H.M. Saris, J. Stroecken, E. Beckers, R. Thijssen, N.J. Rehrer, and F. ten Hoor.

Eating, drinking and cycling, a controlled Tour de France simulation study, Part III. The effect of repeated sustained exercise and diet manipulation on nitrogen balance.

Int. J. Sports Med. Suppl. 1988b. Submitted.

18. Brouns, F., W.H.M. Saris, E. Beckers, R. Thijssen, A.E.Newsholme, H. v. Eijk, T. Wagemakers, and $F_{\text {. }}$ ten Hoor.

The influence of diet manipulation and sustained exhaustive cycling on protein mellabolism, a controlled Tour de France simulation study.

In preparation 1988c.

19. Brouns, F., N.J. Rehrer, W.H.M. Saris, et al.

The effect of carbohydrate intake during warming-up on the regulation of blood glucase during exercise.

Int. J. Sports Med. Suppl. 1988d. Submitted.

20. Brouns, F. W.H.M. Saris, and N.J. Rehrer.

Abdominal complaints and gastro-intestinal function during long lasting exercise.

Int. J. Sports Med. 8: 175-189, 1987.

21. Buber V., J.P. Felber, and A. Vanotti.

Glucose tolerance improvement after acute medicamentous lowering of plasma free fatty acids.

Schweiz. Med. W.Schr. 99: 711, 1968.

22. Buono, M.J., R.R. Clancy and J.R. Cook

Blood lactate and ammonium ion accumulation during graded exercise in humans.

J. Appl. Physiol. 57: 135-139, 1984. 
23. Carlsson, L.A., L. Ekelund, and S. Fröberg.

Concentration of friglyceride, phospholipid's and glycogen in skeletal muscle and of free fatty acids and beta-hydroxybutyric acid in blood in man in response to exercise.

Eur. J. Clin. Invest. 1: 248-254, 1971.

24. Clark, M.G., N,M. Kneer, A.L. Bosch and H.A. Hardy.

The fructose 1.6 disphosphatase, fosfofructokinase substrate cycle: a site of regulation of hepatic gluconeogenesis by glucagon.

J. Biol Chem. 249: 5695-5703, 1974.

25. Coleman, R.A., J.M. Stajich, V.W. Pact, and M.A. Pericak-Vance.

The ischemic exercise test in normal adults and in patients with weakness and cramps.

Muscle \& Nerve 9: 216-221, 1986.

26. Coyle, E.F.,J.M. Hagberg, B.F. Hurley, W.H. Martin, et all.

Carbohydrate feeding during prolonged strenuous exercise can delay fatigue.

J. Appl. Physiol: Respirat. Environ Exercise Physiol. 55: 230-235, 1983.

27. Constable, S.H., and J.O. Holloszy.

In vitro changes in muscle glucose permeability with insulin and prior contractile activity.

Med. Sci. Sport Ex. 17: 241 abstract, 1985.

28. Das, T.K.

A further observation on urea cycle enzymes in rats during alteration in dietary protein intake.

Proc. Nutr. Soc. 31: 78A, 1972.

29. Decombaz, J., D. Sartori, M.-J. Arnaud, et al.

Oxidation and metabolic effects of fructose or glucose ingested before exercise.

Int. J. Sports Med. 6: 282-286, 1985.

30. Dill, D.B., and D.L. Costill.

Calculation of percentage changes in volumes of blood, plasma, and red cells in dehydration.

J. Appl. Physiol. 37/2: 247-248, 1974.

31. Dohm, G.L., F.R. Puente, C. Smith and A. Edge.

Changes in tissue protein levels as a result of endurance exercise.

Life Sci. 23: 845-850, 1978.

32. Dohm, G.L., R.T. Williams, G.J. Kasperek, and A.M. von Rij.

Increased excretion of urea and $\mathrm{N}$ t-methylhistidine by rats and humans after a bout of exercise.

J. Appl. Physiol.: Resp. Env. Exercise Physiol. 52: 27-33, 1982.

33. Dole, V.P.

A relation between non-esterified fatty acid in plasma and the metabolism of glucose.

J. Clin. Invest. 35: 150-154, 1956. 
34. Donovan, C.M., and G.A. Brooks.

Endurance training affects lactate clearance, not lactate production.

Am. J. Physiol. 244: E83-E92, 1983

35. Eaton, P., and D. Steinberg.

Effects of medium fatty acid concentration, epinephrine and glucose on palmitate-I-C 14 oxidation and incorporation into neutral lipids by skeletal muscle in vivo.

J. Lipid. Res. 2: 376-382, 1961.

36. Edwards, R.L., and D.M. Santeusanio.

Fiell test of the effects of carbohydrate solutions on endurance performance, selected blood serum chemistries, perceived exertion, and fatigue in worldclass cyclists.

Med. Sci. Sports Exerc. 16: 190-191, 1984.

37. Essen, B., L. Hagenfeldt, and L. Kaliser.

Utilization of blood-born and intramuscular substrates during continuous and intermittent exercise in man.

J. Physiol. 265: 489-506, 1977.

38. Evans, W.J., S.O. Pinney, and V.L. Young.

Suction applied to a muscle biopsy maximizes sample size.

Med. Sci. Sp. 14/1: 101.102, 1982.

39. Exton, J.H.

Gluconeogenesis

Metabolism 21: 945-990, 1972.

40. Felber, J.P., and A. Vanotti.

Effect of fat infusion on glucose tolerance and insulin plasma levels.

Med. Exp. (Basel) 10: 153-160, 1964.

41. Felig, P., M.S.A. Cherif, A. Minagawa, and J. Wahren.

Hypoglycemia during prolonged exercise in normal man.

N. Eng. J. Med. 306: 895-910, 1982.

42. Felig, P., and J. Wahren.

Role of insulin and glucagon in the regulation of hepatic glucose production during exercise.

Diab. 28: 71-75, 1979.

43. Felig, P., and J. Wahren.

Fuel homeostasis in exercise.

N. Eng. J. Med. 293: 1078-1084, 1975.

44. Felig, P., J. Wahren, R. Hendler, and G. Ahlborg.

Plasma glucagon levels in exercising man.

N. Eng. J. Med. 287: 184-185, 1972.

45. Felig, P. O.E. Owen, J. Wahren, and G.F. Cahill.

Amino acid metabolism during prolonged starvation.

J. Clin, Invest. 48: 584-594, 1969. 
46. Fitts, R.H., J.B. Countright, O.H. Kim, and F.A. Witzmann, Muscle latigue with prolonged exercise, contractile and biochemical alterations. Am. J. Physiol. 242: C65-C73, 1982.

47. Foster, C., D.L. Costill, and W.J. Fink.

Effects of pre-exercise feedings on endurance performance.

Med. Sci. Sports 11: 1-5, 1979.

48. Fritz, 1.B., D.G. Davis, R.H. Holtrop, and H. Dunder.

Fatty acid oxidation by skeletal muscle during rest and activity.

Am. J. Physiol. 194: 379-386, 1957.

49. Galbo, $H$.

Hormonal and metabolic adaptation to exercise.

George Thieme Verlag. Stuttgart, 1983.

50. Galbo, H., N.J. Christensen, K.J. Mikines, et al.

The effect of fasting on the hormonal response to graded exercise.

J. Clin. Endocrinol. Metab. 52: 1106-1112.

51. Galbo, H., J.J. Holst, and N.J. Christensen.

The effect of different diets and of insulin on the hormonal response to prolonged exercise.

Acta Physiol. Scand. 107: 19-32, 1979.

52. Galloway, D.H.

Nitrogen balance of men with marginal intakes of protein and energy.

J. Nutr. 105: 914-9-3, 1975.

53. Garber, A.J. P.E. Cryer, J.V. Santiago, M.W. Haymond, et al.

The role of adrenergic mechanisms in the substrate and hormonal response to insulin-induced hypoglycemia in man.

J. Clin. Invest. 58: 7-15, 1976.

54. Garcia, A., J.R. Williamson, and H.F. Cahill jr.

Studies on the perfused rat liver. Il Effecll of glucagon on gluconeogenesis.

Diabetes 15: 188, 1966.

55. Garza, C., N.S. Scrimshaw, and V.R. Young.

Human protein requirements: the effecl of variations in energy intake within the maintenance range.

Am. J. Clin. Nutr. 29: 280-287, 1976.

56. Gerich, J.E., M. Lorenzi, D.M. Bier, et al.

Effecis of physiologicall levels of glucagon and growth hormone on human carbohydrate and lipid metabolism.

J. Clin. Invest. 57: 875-884, 1976.

57. Golden, M.H.N., and J.C. Waterlow.

Total protein synthesis in eldery people: a comparison of results with $(15 \mathrm{~N})$ glycine and $\left({ }^{14} \mathrm{C}\right)$ lewcine.

Clin. Scl. Molecular Med. 53: 277, 1979. 
58. Golinick, P.D., K. Piehl, C.W. Saubert, et al.

Diet, exercise, and glycogen changes in human muscle fibers.

J. Appl. Physiol. 33: 421 425, 1972 .

59. Gollnick, P.D., and D.R. Hodgson.

Enzymatic adaptation and its significance for metabolic response to exercise.

In: Biochemistry of exercise VI

Saltin, B. (Ed.)

Human Kinetics, Champaign Illinois pp 191-200, 1986.

60. Gollnick, P.D., B. Pernow, B. Essen, E. Jansson, and B. Saltin.

Availlability of glycogen and plasma FFA for substrate utilization in leg muscle of man during exercise.

Clin. Physiol. 1: 27-42 1981.

61. Gomez, F., E. Jequier, V. Chabot, V. Büber, and J.P. Felber.

Carbohydrate and lipid oxidation in normal human subjects: its in-fluence on glucose tolerance and insulin response to glucose.

Metab. 21: 381-391, 1972.

62. Hargreaves, M., D.L. Costill, A. Coggan, W.J. Fink, et al.

Effect of carbohydrate feedings on muscle glycogen utilization and exercise performance.

Med. Sci. sports Exerc. 16: 219-222, 1984.

63. Hărkonen, M. and $\mathrm{H}$. Adlercreutz.

Fluorometric analyses in routine clinical chemistry

Trends in Analytical chemistry 2: 176-180, 1983.

64. Hermansen, $L$. and $O$. Vaage.

Lactate disappearance and glycogen synthesis in human muscle after exercise.

Am. J. Physiol. 233: E422-E429, 1977.

65. Havel, R.J., B. Pernow, and N.L. Jones.

Uptake and release of free fatty acids and other metabolites in the legs of exercising men.

J. Appl. Physiol. 23: 90-99, 1967.

66. Hermansen, L., and $O$. Vaage.

Lactate disappearance and glycogen synthesis in human muscle after exercise.

Am. J. Physiol. 233, E422-E429, 1977.

67. Holloszy, J.O., and E.F. Coyle.

Adaptations of skeletal muscle to endurance exercise and their metabolic consequences.

J. Appl. Physial. 56: 831-8i38, 1984. 
68. Holloszy, J.

Regulation of glucose metabolism and glycogen resynthesis following prolonged, strenuous exercise.

In: P. Marconnet, J. Poortman, L. Hermansen (Eds).

Physiological Chemistry of training and detraining.

Med. Sport Sci. 17: 111-118, 1984.

69. Hoppeler, $\mathrm{H}$.

Exercise-induced ulltrastructural changes in skelletal muscle.

Int. J. Sports Med. 7: 187-204, 1986.

70. Hultman: E.C.

Carbohydrate metabolism during hard exercise and in the recovery period after exercise.

Acta Physiol. Scand. 128: (suppl, 556) 75-82, 1986.

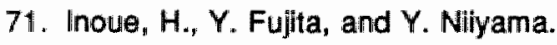

Studies on protein requirements of young men fed egg protein and rice protein with excess and maintenance energy intakes.

J. Nutr. 103: 1673-1687, 1973.

72. Ivy, I.L., W. Miller, V. Dover, L.G. Goodyear, et al.

Endurance improved by ingestion of a glucose polymer supplement.

Med. Scil. Sports Exerc. 15: 466-471, 1983.

73. Ivy, J.L., and H.O. Holloszy.

Persistent increase in glucose uptake by rat skelletal muscle following exercise. Am. J. Physiol. 241: C.200-C203, 1981.

74. Issekutz, J., W.A.S. Shaw and F.B. Issekutz.

Effect of lactate on the FFA and glycerol turnover in resting and exercising dogs.

J. Appl. Physiol. 39: 349-353, 1975.

75. Jansson, E., and L. Kaijser.

Leg citrate metabolism at rest and during exercise in relation to diet and substrate utilization in man.

Acta Physiol. Sciand. 122: 145-153, 1984.

76. Kasperek, G.J., G.L. Dohm, E.B. Tapscott, and T. Powell.

Effect of exercise on liver protein loss and lysosomal enzyme levels in fed and fasted rats.

Proc. Soc. Exp. Biol. Med. 164: 430-434, 1980.

77. Kelbel, iD.

Nebennierentinden hormone und sportliche Leistung.

Med. und Sport 14:65-70, 1974.

78. Keizer, H.A., H. Kuiper, G. van Kramenburg, and P. Geurten.

Inffuence of liquid and solid meals on muscle glycogen resynthesis, plasma fuel hormone response and maximal physical working capacity.

Int. J. Sports Med. 8: 99-104. 1986. 
78a. Krzentowski, G., F. Pirnay, A.S. Luyckx, et al.

Effect of physical training on utilization of a glucose load given orally during exercise.

Am. J. Physioll 246: E 412-E 417, 1981.

79. Kuipers, H., H.A. Keizer, F. Brouns, and W.H.M. Saris.

Carbohydrate feeding and glycogen synthesis during exercise in man.

Eur. J. Physiol. Pflügers Arch. 410: 652-656, 1987.

80. Landsberg, L., and J.B. Young.

Catecholamines and the adrenal medulla.

In:." Metabolic control and disease

Bondy, P.K.n, L.E. Rosenberg (eds) p 6121-1641, W.B. Saunders, 1980.

81. Lemon, P.W.R.

A simple and inexpensive method for making sweat collection capsules.

Research quarterly for exercise and sport 54/3:299-301, 1983

82. Lemon, P.W.R., and F.J. Nagle.

Effects of exercise on protein and amino acid metabolism

Med. Sci. Sp. Ex. 13/3; 141-149, 1981.

83. Lemon, P.W.R., and J.P. Mullin.

Effect of initial muscle glycogen levels on proteiln catabolism during exercise.

J. Appl. Physiol. Respirat. Environ, Exercise Physiol. 48: 624-629, 1980.

84. Long, C.L., J.M. Kinney, and J.W. Geiger.

Non-suppressability of gluconeogenesis by glucose in septic patients.

Metabolism 25: 193, 1976.

85. Lowenstein, J.M.

Ammonia production in muscle and other tissues: the purine nucleotide cycle.

Physiol. Rev. 52: 382-414, 1972.

86. Luyckx, A.S., F. Pirnay, and P.J. Lefebvre.

Effect of glucose on plasma glucagon and FFA during prolonged exercise.

Eur. J. Appl. Physiol. 39: 53-41, 1978.

87. MacDougall, J.D., G.R Ward, D.G. Sale and J.R. Sutton.

Muscle glycogen repletion after high intensity intermittent exericise.

J. Appl. Physiol. 42: 129-132, 1977.

88. Maughan, R.J., C. Williams, and D.M. Campbell.

Fat and carbohydrate metabolism during low intensity exercise: effects of the availabillty of muscle glycogen.

Eur. J. Appl. Physiol. 39, 7-16, 1978.

89. McGilvery; R.W.

The use of fuels for muscular work.

In: Metabolic adaptation to prolonged physical exercise.

Howald, H., J.R. Poortmans (Eds).

Birkhäuser Verlag Basel, pp 12-20, 1973. 
90. Meredith, C. D.M. Bier, M.M. Meguid, et al.

Whole body amino acid turnover with ${ }^{13} \mathrm{C}$ tracers: a new approach for estimation of human amino-acid requirements.

In: Clinical Nutrition 1981, pp 42-59.

R. Wesdorp, P. Soeters Eds., Churchill Livingstone.

91. Mitchel, J.W., E.R. Nadel, and J.A.J. Stolwijk.

Respiratory weight losses during exercise.

J. Appl. Physiol. 32/4: 474-476, 1972.

92. Mosora, F., M. Lacroix, A. Luyckx, et al.

Glucose oxidation in relation to the size of the oral glucose loading dose.

Metab. 30: 1143-1149, 1981.

93. Munro, H.N. and R.S.T. Thompson.

Influence of glucose on amino acid metabolism.

Metab. Clin. Exp. 2: 354-361, 1953.

94. Mutch, B.J.C., and E.W. Banister.

Ammonia metabolism in exercise and fatigue: a review

Med. Sci. Sp. Ex. 15: 41-50, 1983.

95. Newsholme, E.A., and A.R. Leech.

Blachemistry for the medical sciences.

John Wiley and Sons, Chichester England, 1983.

96. Newsholme, E.A.

Carbohydrate metabolism in vivo: regulation of the blood glucose level.

Clin. Endocrinol. Metab. 5: 543-578, 1976.

97. Pallikarakis, N., B. Jandrain, F. Pirnay, et al.

Remarkable metabolic avaliability of oral glucose during long-duration exercise in humans.

J. Appl Physiol. 60: 1035-1042, 1986.

98. Passonneau, J.V., and V.R. Lauderdale.

A comparison of three methods of glycogen determination in tissue.

Anal. Blochem. 60: 279-302, 1974.

99 Paul, P., and W.L. Holmes.

Free fatty acid and glucose metabolism during increased energy expenditure and after training.

Med. Sci. Sports 7:1 176-184, 1975.

100. Piehl, K.

Time course for refilling of glycogen stores in human muscle fibers following exercise-induced glycogen depletion.

Acta Physiol. Scand. 90; 297-302, 1974.

101. Pirnay, F., M. Lacroix, F. Mosora, A. Luyckx, P. Lefebvre.

Glucose oxidation during prolonged exercise evaluated with naturally labeled $\left({ }^{13} \mathrm{C}\right)$ glucose.

J. Appl. Physiol. 43: 258-261, 1977. 
102. Pirnay, F., M. Lacroix, F. Mosora, A. Luycks and P. Lefebure.

Effect of glucose ingestion on energy substrate utilization during prolonged muscular exercise.

Eur. J. Appl. Physiol. 36: 247-254, 1977 a.

103. Ploug. T. H. Galbo, and E.A. Richter.

Increased muscle glucose uptake during contractions: no need for insulin.

Am. J. Physiol. 247: E726-E731, 1984.

104. Ploug, T., H. Galbo, and E.A. Richter.

Contraction induced glucose transport in rat skeletal muscle: additive effect of insulin and monoexponential, glycogen independent reversal in slow and fast twitch red muscle.

Clin. Physiol. 5: 68, 1985.

105. Porte, D.

A receptor mechanism for the inhibition of insulin release by epinephrine in man.

J. Clin. Invest. 46: 86, 1967.

106. Porte, D., and R.H. Williams.

Inhibition of insulin release by norepinephrine in man.

Science 152: 1248-1250, 1966.

107. Porte D., A.L. Graber, T. Kuzuya, and R.M. Willimans.

The effect of epinephrine on immunoreactive insulin levels in man.

J. Clin. Invest. 45: 228-236, 1966.

108. Randle, P.J., P.B. Garland, C.N. Halles, and E.A. Newsholme.

The glucose fatty-acid cycle. Its role in insulin sensitivity and the metabolic disturbances of diabetes mellitus.

The Lancet 34: 785-789, 1963.

109. Rennie, M.J., R.H.T. Edwards, H. Krywawych, and C.T.M. Davies.

Effect of exercise on protein turnover in man.

Clin. Sci. 61: 627-639, 1981a.

110. Rennie, J.M. R.J.T. Edwards, D. Halliday, G.L. Clugston, et al.

Muscle protein synthesis in fed and fasted man.

Eur. J. Clin. Invest. 11: A155, 1981b.

111. Rennie, M.J., and J.O. Holloszy.

Inhibition of glucose uptake and glycogenolysis by availability of oleate in well.

oxygenated perfused skeletal muscle.

Biochem. J. 168: 161-170, 1977.

112. Saltin, B., and P.D. Gollmick.

Skeletal muscle adaptability, significance for metabolism and performance.

In: Peachy L.D., R.H. Adrian and S.R. Geiger (Eds)

Handbook of Physiology: Skeletal muscle pp 555-631, 1983.

Williams and Wilkins, Baltimore. 
113. Saltin $B$.

Adaptive changes in carbohydrate metabolism with exercise.

In: Howald, H., J.R. Poortmans (eds):

Metabolic adaptation to prolonged physical exercise. Proc. of the Second Int. Symp. on Biochemistry.

Basel, Birkhäuser Verlag, pp 94-100, 1973.

114. Saltin, B., and Karlsson.

Muscle glycogen utilization during work of different intensities.

In: Advances in experimental medicine and biology vol 11

New York-London - Plenum Press, pp 289-299, 1971.

115. Saltin, $B_{\text {.. }}$ and $L$. Hermansen.

Glycogen stores and prolonged severe exercise.

In: Nutrition and physical activity, 5.

G. Blix (Ed.).

Almquist and Wiksells, Sweden pp 32-46, 1967.

116. Saris, W.H.M., G. Janssen, N. Rehrer, and F. Brouns.

Biochemical changes during extreme sustained exercise: the Tour de France.

Int. J. Sports Med. Suppl. 1988. Submitted.

117. Sauerwein, H.P.

An introduction in clinicall mutrition.

In: Clinical nutrition 1981.

Wesdorp, R., and P. Soeters (Eds).

Churchill Livingstone pp 375-378, 1982.

118. Schoffelen, P.F.M., W.H.M. Saris, K.R. Westerterp, and F. ten Hoor.

Evaluation of an automated indirect calorimeter for measurement of energy balance in man.

In: Human energy metabolism: Physical activity and energy expenditure measurements in epidemiological research based upon direct and indirect calorimetry.

Es, A.J.H. van, (Ed.) pp. 51-141 (Euro. Nut. Rep. 5), 1986.

121. Schrago, E.H., A. Lardy, R.C. Nordlie, and D.O. Fositer.

Metabolic and hormonal control of phosphoenolpyruvate carboxykinase and malic enzyme in rat liver.

J. Biol "Chem. 238: 3188-3192.

122. Sherman, W., and D.L. Costill.

The marathon, dietary manipulations to optimize performance.

Am. J. Sportsmedicine 12/1: 44-51, 1984.

123. Smedes, J., M. Kraak and Poppe.

Simple and fast soluent extraction system for selective and quantitaive isolation of adrenaline, nor adrenaline wel dopamine from plasma and urine.

J. Chromatography $231: 25-39,1982$. 
124. Stankiewicz-Choroszucha, B., and J. Gørski. Effect of decreased availability of substrates on intramuscular triglyceride utilization during exercise.

Eur. J. Appl. Physiol. 40: 27-35, 1978.

125. Toivola, P.T.K., C.C. Gale, C.J. Goodner and J.H. Werrbach.

Central alpha-adrenergic regulation of growth hormone and insulin. Hormones 3: 193-213, 1972.

126. Viru, A.

Hormones in muscular activity

Volume 1: Hormonal ensemble in exercise

Volume II: Adaptive effect of hormones in exercise.

CRC Press Inc. Boca Raton, Florida, 1985.

127. Vusse, G.J. van der, T.H.M. Roemen, F.W. Prinzen, W.A. Coumans, and R.S. Reneman.

Uptake and tissue content of fatty acids in dog myocardium under nor-moxic and ischemic conditions.

Circ. Res. 50: 538-546, 1982.

128. Wahren, J., G. Ahlborg, P. Felig " and L. Jorfeldt.

Glucose metabolism during exercise in man.

In: Pernow, B, B. Saltin (eds.).

Muscle metabolism during exercise pp 179-203, 1971.

New York; Plenum Press.

129. Wahren, J., P. Felig, G. Ahiborg, and L. Jorfeldt.

Glucose metabolism during leg exercise in man.

J. Clin. Invest. 50: 2715-2725, 1971.

130. Waterlow, J.C.

Endproduct methods for measuring protein turnover in man.

In: Clinical Nutrition pp 35-, 1981.

Wesdorp, R. and P. Soeters (eds).

Churchill Livingstone.

131. Wilkerson, J.E., D.L. Batterton, and S.M. Horvath.

Exercise-induced changes in blood ammonia levels in humans.

Eur. J. Appl. Physiol. 37: 225-263, 1977.

132. Yoshida, $T$.

Effect of dietary modifications on lactate threshold and onset of blood lactate accumulation during incremental exercise.

Eur. J. Appl. Physiol. 53: 200-205, 1984. 


\title{
CHAPTER VI THE EFFECT OF CARBOHYDRATE INTAKE DURING WARMING-UP ON THE REGULATION OF BLOOD GLUCOSE DURING EXERCISE
}

\author{
F. Brouns, N.J. Rehrer, W.H.M. Saris, E. Beckers, \\ P. Menheere, F. ten Hoor
}

\section{Introduction}

It has generally been accepted that the maintenance of a fairly constant blood glucose level is one of the pre-requisites for the ability to perform longlasting intense exercise. It has been shown that performance impairement is often associated with low blood glucose levels and hypoglycemia has been suggested as one of the causes of central fatigue and exhaustion.In 1924 Levine, Gordon and Derick (Levine, 1983) were the first authors reporting that in runners at the finish of a marathon a close relationship was found between blood glucose level and grade of well being; hypoglycemic runners having the most problems. They therefore suggested that ingestion of carbohydrate prior to and during exercise would be of considerable benefit in preventing hypoglycemia.

A few years later however it was observed that instead of maintenance of a desired blood glucose level, a reactive hypoglycemia could occur as a result of pre-exercise carbohydrate feedings (Beje, 1940; Christensen, 1939). Since then many studies have been performed in which the effect of car-bohydrate ingestion on substrate utilization has been investigated. The out-come of these studies showed considerable disagreement about the effect and value of carbohydrate ingestion in relation to endurance exercise. This has led to confusion among athletes and their advisors. Analysis of the available literature leads to several conclusions:

1. Intake of carbohydrate drinks after an overnight fast in resting conditions may induce hypoglycemia by a rebound mechanism involving insulin secretion (Burns, 1965; Cahill, 1974) especially during subsequent exercise (Bøje, 1940; Christensen, 1939; Costill, 1977; Koivisto, 1987).

2. On the contrary, exercise studies which were carried out in the fed state did not show hypogiycemia after CHO intake at rest (Bonen,1980; Keller,1984; Keul, 1986; Levine, 1983).

3. Studies in which carbohydrate solutions were ingested immediatelly prior to exercise showed increased blood glucose and depressed insulin values and no rebound mechanism (Bonen, 1980-1981; Keul, 1973).

4. Intake of carbohydrate solutions during exercise enhances blood glucose values while insulin remains low. In (Water) control experiments blood glucose values always tend to be lower (Björkman, 1984; Bonen, 1975; Brooke, 1975; Felig, 1983-1982; Flynn, 1987; Luyckx, 1987; Palikaraki, 
1986; Pirnay, 1977).

5 . Insulin secretion during exercise is inhibited by catecholamines (Bloom, 1976; Malaisse, 1969; Porte, 1966a-1966b) and/or sympathetic pancreas innervation (Richter, 1984).

It is apparent in the available studies that the methodological set up of a number of studies doesn't simulate the actual situation in sports practice. First of all, the idea to compete after an overnight fast does not seem to be logical compared to the advice generally given that athletes should ingest a light digestable carbohydrate rich breakfast in order to restore liver glycogen. Secondly, there is no reason to ingest carbohydrate at rest prior to exercise because muscle glycogen levels should be high as a result of a high carbohydrate intake during the day(s) prior to the competition. With respect to the last point, the question may be raised why drinks should be ingested at all prior to exercise.

There may be one important reason to do so. During most competitions, especially long distance running (Rehrer, 1988), athletes drink far less during exercise than the amount of fluid that is lost by sweating, leading to dehydration and performance impairment. Therefore, the measure of prehydration becomes very important. After fluid intake there will be a period of overhydration. Whenever this period coincides with the exercise period during which urine production and insulin secretion may be decreased, one may hypothesize that the extra fluid will become available for sweating while the carbohydrates may not elicit an insulin response sufficient enough to induce hypoglycemia, but rather may enhance or maintain blood glucose level.

Because initial gastric emptying and absorption of carbohydrate containing drinks may take place within approximately $7 \mathrm{~min}$ (Costill, 1973) the advice should then be to ingest a drink immediately prior to competition or during warming-up, when competition follows immediately thereafter. We therefore decided to study the effect of prehydration with carbohydrate containing drinks in competition-like circumstances in order to test the following two hypotheses:

1. Warming-up induced catecholamines secretion will be insufficient to inhibit insulin secretion after intake of carbohydrate containing drinks.

2. Ingestion of selected $\mathrm{CHO}$ containing drinks during warming-up in trained athletes, in the fed state, leads to a reactive hypoglycemia and results in subjective feelings of fatigue.

\section{Methods}

Subjects. Eighteen highly trained male amateur cyclists participated in this study. Their mean physical characteristics are presented in Table 1. The maximal oxygen uptake and the maximal achieved watt load were deter- 
mined during an incremental bicycle ergometer test in the week prior to the first test session.

Table 1 Subject characteristics (mean \pm SEM)

$$
n=18
$$

\begin{tabular}{llc}
\hline Age & (yrs) & $21.7 \pm 4.5$ \\
Weight & $(\mathrm{kg})$ & $74.2 \pm 9.3$ \\
Vo2 max & $\left(\mathrm{ml}^{\mathrm{kgg}-1} \cdot \min -1\right)$ & $63.2 \pm 4.6$ \\
Wmax & (Watt) & $390.0 \pm 30$ \\
Wmax & $\left(\right.$ Watt.kg- $\left.{ }^{-1}\right)$ & $5.4 \pm 0.7$ \\
\hline
\end{tabular}

The subjects were asked not to participate in vigorous training or competition on the day prior to the test and to ingest a normal $\mathrm{CHO}$ rich diet. All subjects were informed of the nature, purpose, and possible risks involved in the study, before giving their voluntary written consent to participate.

The study was done in a cross-over set-up with each subject being his own control.

\section{Procedure}

The subjects were divided into three groups of six subjects. Each group was studied after at random ingestion of a placebo drink (control) or a selected carbohydrate drink (Table 2).

Table 2 CARBOHYDRATE COMPOSITION OF SELECTED DRINKS $(\mathrm{g} / 100 \mathrm{ml})$

Malto-dextrin Sucrose Fructose Glucose

1 CONTROL

2 "FRUC"

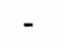

3 "SUC"

1.3

6.0

$44^{~ " M A L T " ~}$

15.2

3

5 "GLUC"
.

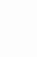


The drinks were: a low fructose drink (FRUC) (Isostar- Light(B), a sucrose-low maltodextrin drink (SUC) (Isostar(B)), and a highly concentrated maltodextrinlow fructose drink (MALT) (Perform@). Six al random selected subjects performed one extra test in which a free glucose solution was ingested (GLUC). The set up of the treatments was such that information could be gathered about the effect of different commercially available carbohydrate sport drinks with different carbohydrate sources on the regulation of blood glucose. The carbohydrate composition of the drinks is listed in Table 2.

In SUC the fructose content, derived from the sucrose, is equal to that in FRUC ( $3 \mathrm{~g}$ ). In GLUC the amount of glucose units is kept equal to the amount present in MALT. This was done in order to compare the effects induced by a glucose polymer - to those induced by a free glucose solution with an equal amount of glucose units.

The subjects came to the laboratory at 7:30 AM after an overnight fast. At 8:00 AM each subject received a standard low tat, high carbohydrate and protein breakfast of normal caloric content (2076 Joules, 13.2 en\% fat, 23.8 en\% protein, 62.9 en\% carbohydrate). The breakfast consisted of solid food (bread without butter or anything else) and a complete nutritional liquid (Powerplay(i). Bread was given as $1 \mathrm{~g} . \mathrm{kg}^{-1} / \mathrm{BW}$ and the liquid as $5 \mathrm{ml} . \mathrm{kg}^{-1}$. This was done in order to standardize both food intake and quantitative contribution of nutrients that may exert an effect on insulin secretion. At 9:00 AM a teflon catheter was inserted percutanously into an antecubital vein. Patency of catheter was maintained by continuous drip of saline solution between insertion and blood sampling.

The subjects remained in resting position on a couch for the whole preparation period. At 10:00 AM exercise warming-up procedure was started on the bicycle ergometer. The warming-up consisted of five min bicycling at 1.5

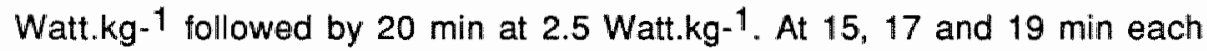
subject performed an acceleration sprint during $10 \mathrm{sec}$, watt load 5 Watt.kg- 1 , simulating normal warming-up procedures prior to competition.

All drinks were ingested at $10 \mathrm{~min}$ (50\% of the drink) and 20 min. Treatments (Table 2) were performed in random order. Warming-up was followed by a resting period of $7 \mathrm{~min}$ (preparation time for start and line-up according to competition practice), after which 45 min of exercise was performed at an intensity such that a heart rate of $150 \mathrm{~min}^{-1}$ was maintained continuously (Fig. 1).

Heart rate was monitored throughout the test (Sporttester(B), Polar-Electro ky, Kempele, Finland). 


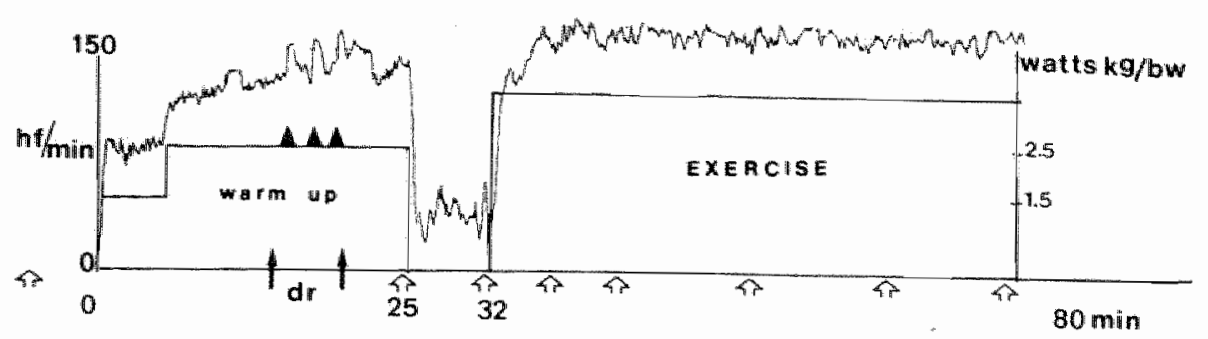

FIg 1 TIME-EXERCISE SCHEDULE

Open arrows indicate blood sampling. Solid arrows represent drink ingestion.

Black triangles represent acceleration sprint. The theart trequency curve of one typical subject is represented.

Blood samples were drawn at rest, before - and immediately after warmingup, immediately before the final exercise period, and at several times during exercise. The Borg scale score of perceived exertion (Borg, 1973) was obtained during the last minute of warming-up and three times during the final exercise bout. In order to establish a possible $\mathrm{CHO}$ dose related response the whole procedure was performed twice with ingestion of $300 \mathrm{ml}$ and $600 \mathrm{ml}$ of drink respectively.

Analyses: Glucose was analyzed in plasma (G.O.D.-perid method). Insulin was analyzed by radio-immuno assay (RIA Kit, Medgenix BV, Nederland), catecholamines were analyzed on a HPLC electro chemical detection system (Smedes Kraak, 1982). Perceived exertion was analyzed using the Borg scale.

The data in the text, tables and figures are given as means \pm SEM of the delta changes relative to time zero (rest value) for each individual within each treatment group. These delta values were also used for further analyses.

Standard statistical methods were employed using the paired t-test with each subject"s control values being compared with values obtained (from the same subject) after ingestion of a selected carbohydrate drink.

A regression analysis was performed to determine possible relationships between insulin on the one hand and epinephrine, norepinephrine or dopamine on the other hand in the different treatments. A stepwise regression was performed to see if the best single correlation could be improved by including 
ane or both of the other independent variables.

\section{Results}

\section{Hormones}

Blood insulin levels decreased in control trials as a result of war-ming-up (Fig $2 \mathrm{a}$ and $\mathrm{c}$ ). At the same time the catecholamine levels were increased (Fig 3a). The ingestion of the $300 \mathrm{ml} \mathrm{SUC}$ and FRUC did not in-fluence this blood insulin fall during warming-up. However, when the volume of the drink was doubled a marked reduction of this decrease was observed with the glucose and maltodextrin drink but not with the fructose drink (Fig $2 b, 2 d$ ).

As a result of the seven min break between warming-up and final exercise, insulin levels increased in all treatments including the control trials.

The increase of insulin was more pronounced with the more concentrated carbohydrate solutions (Fig 2b), whereas doubling the dose further potentiated the insulin response (Fig 2d).

We could not detect a quantitative difference in insulin response between the GLUC and MALT trial when $600 \mathrm{ml}$ was drunk (Fig 2d), although insulin response in the glucose trial was initially somewhat faster and significantly increased at all times (relative to the control drink), whereas increase in the MALT trial was only significant at the onset of exercise. Norepinephrine levels rapidly decreased during the seven min break to the same extent in control as in carbohydrate trials ( $\mathrm{Fig} 3 \mathrm{a}, \mathrm{c}$ ). In the control trial epeniphrine showed the same response, but in all carbohydrate trials the epinephrine increase was markedlly blunted as a result of carbohydrate intake except for the glucose trial (Fig $3 \mathrm{c}$ ). Linear regression analysis pertormed over all times showed that a good correlation existed between response of insulin and norepinephrine but less between insulin and epinephrine (Table 3).

When stepwise regression analysis was performed it was found that, with inclusion of both norepinephrine and epinephrine, the correlation coefficient decreased to -0.71 and -0.82 in the maltodextrin- and free glucose drink trial respectively. During the first part of the heavy exercise period both insulin and catecholamines showed the same response as during warming-up. However, after 20 min of exercise norepinephrine reached a plateau level. From that moment on insulin levels did not further fall. Epinephrine continued to rise throughout the experiment. 
Antation and

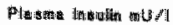

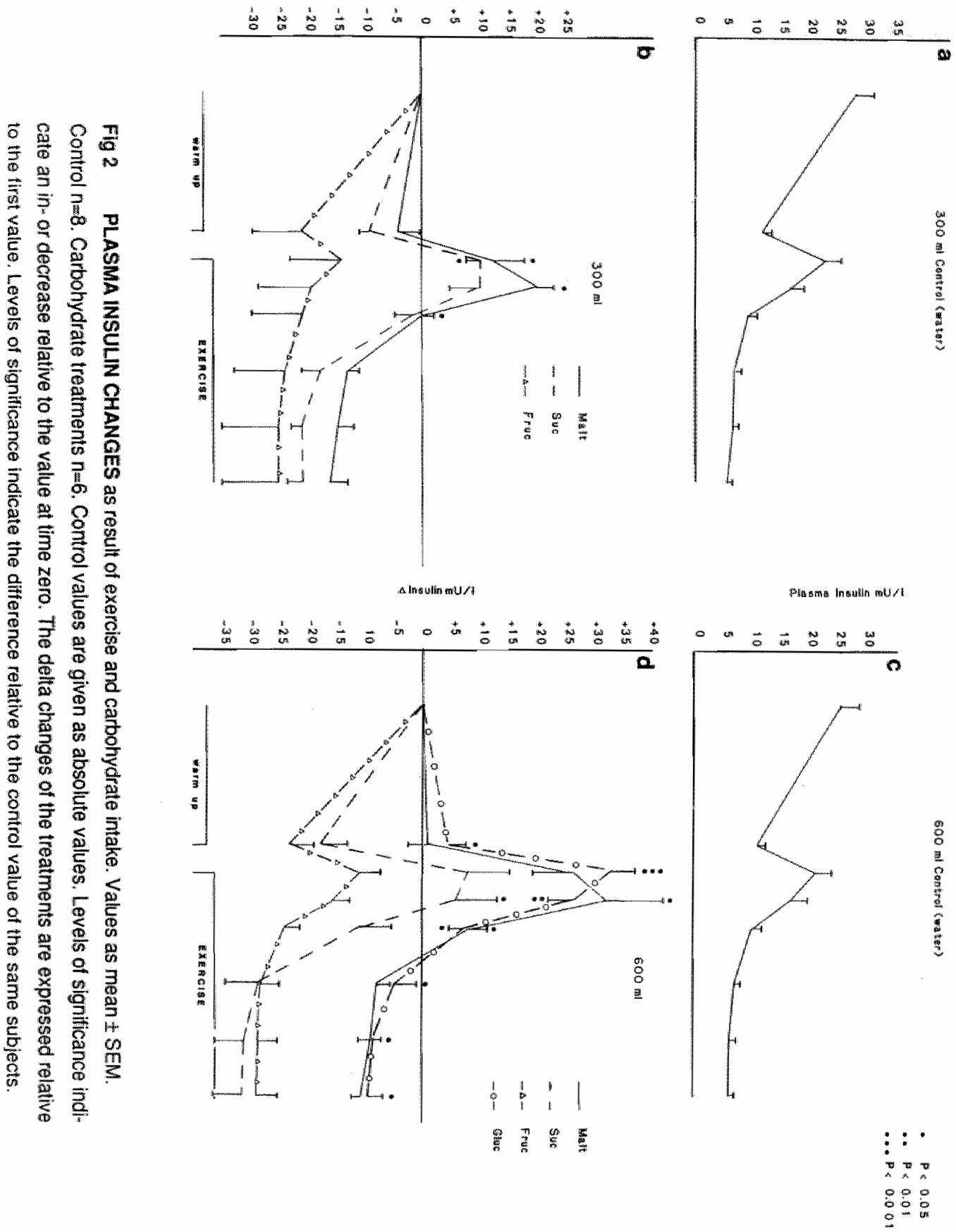



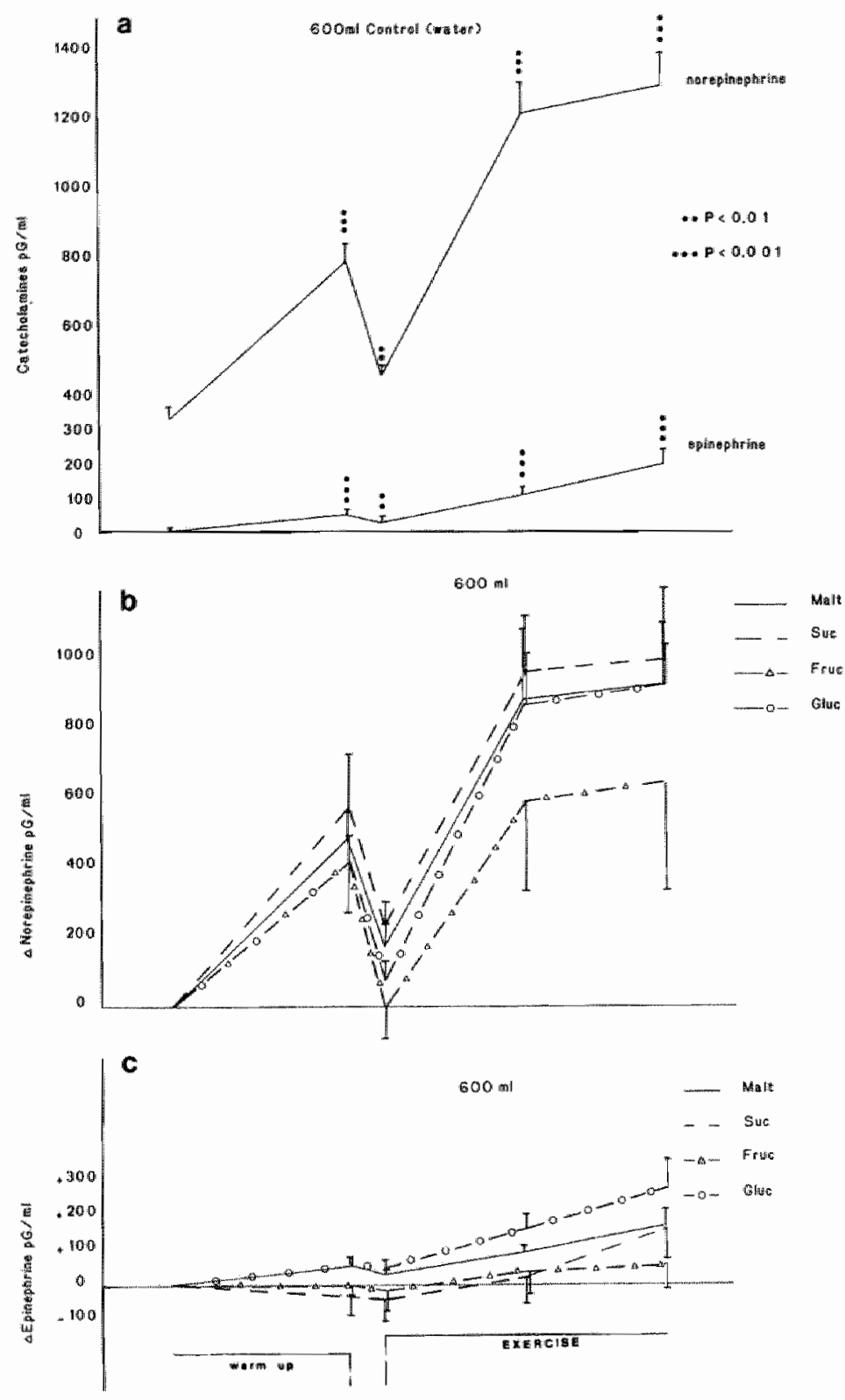

Fig 3 PLASMA CATECHOLAMINE CHANGES as result of exercise and carbohydrate intake. Values as mean $\pm S E M$. Control $n=8$. Carbohydrate treatments $n=6$. Control values are given as absolute values. Levels of significance indicate a significant in- or decrease relative to the first value at time zero. The delta changes of the treatments are expressed relative to the first value. Levels of significance indicate the difference relative to the control value of the same subjects. 


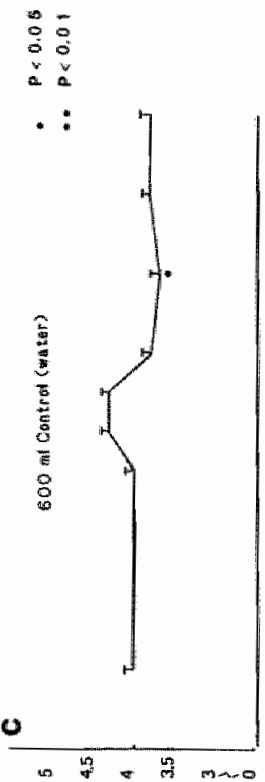

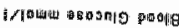

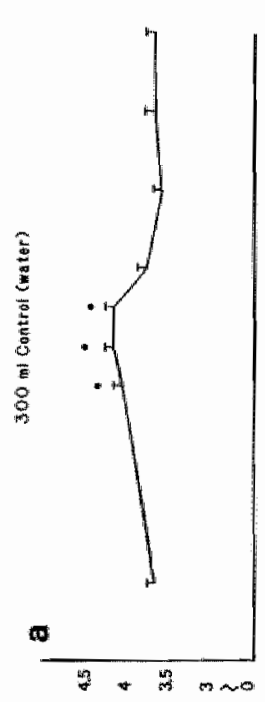

H/A

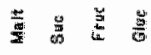

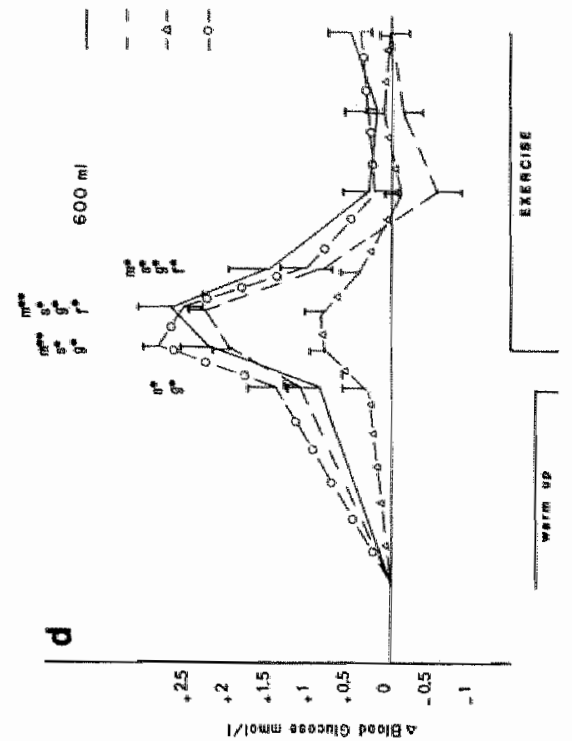

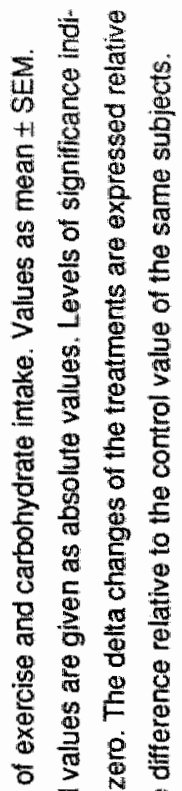

言 은 욜

㒖

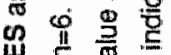

岁

空窎

동 틀

嵌 害

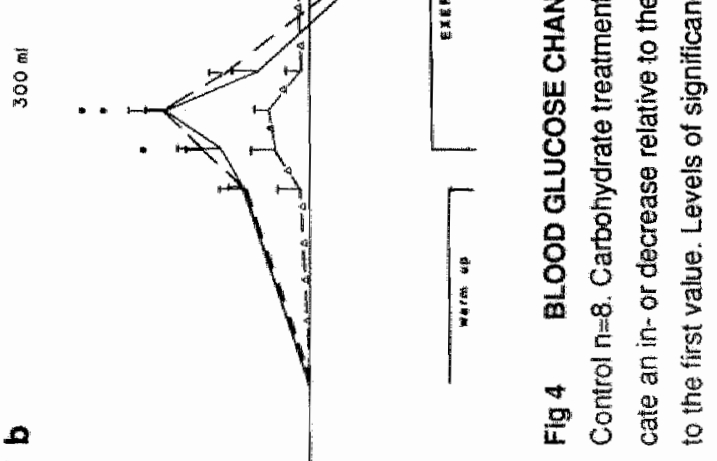




\section{Blood gllucose}

Blood glucose remained constant during warming-up in both control trials. There was a small rise during the seven min break followed by a decrease below baseline values during the following exercise task (Fig $4 a, 4 c$ ). In the $300 \mathrm{ml}$ carbohydrate trials blood glucose increased significantly following the SUC and MALT ingestion but not following the FRUC ingestion (Fig). However, when the amount of FRUC was doubled to $600 \mathrm{ml}$, blood-glucose values were significantly higher than during the control (Fig $4 \mathrm{~d}$ ). In the $300 \mathrm{ml}$ carbohydrate drink trials blood glucose decreased to the values of the control trial after approximately $20 \mathrm{~min}$ of exercise and remained stable thereafter. However, after ingestion of $600 \mathrm{ml}$ of the highly concentrated carbohydrate drinks blood glucose values remained above the control values for a longer period of time (Fig $4 \mathrm{~d}$ ).

Hypoglycemia $\left(<2.5 \mathrm{mmol} . \mathrm{l}^{-1}\right)$ did not occur at all. In the 36 control trials blood glucose fell 7 times below $3 \mathrm{mmol} . \mathrm{l}-1$. In the 42 carbohydrate drink trials blood glucose fell 3 times below 3 mmol.l-1. In both cases the lowest measured blood glucose value was $2.7 \mathrm{mmol} .1-1$. In the fructose trials blood glucose always remained above $3 \mathrm{mmol} .1-1$.

The Borg scale score for subjective fatigue did not reveal any difference between the trials.

\section{Discussion}

The intake of $\mathrm{CHO}$ containing drinks has been promoted in order to maintain or enhance blood glucose values and to spare muscle glycogen so that performance can be maintained at a high level and for a longer period of time. However, intake of carbohydrate solutions in resting conditions after an overnight fast may induce a reactive hypoglycemia (Bøje, 1940" Christensen, 1939; Costill, 1977; Koivisto, 1981) which may be mediated by enhanced insulin secretion (Koivisto, 1981).

Such a hypoglycemic reaction does not seem to occur when the exercise is performed in the fed state (Bonen, 1980; Keller, 1984; Keul 1986; Levine, 1983) or when carbohydrates are ingested immediately prior to exercise (Bonen, 1980-1981; Keul, 1973) or during exercise (Björkman, 1984; Bonen, 1981; Brooke, 1975; Felig, 1983-1982; Flynn 1987; Luyckx, 1978; Pallikarakis 1986; Pirnay, 1977). The differences may be explained by differences in feeding status, gastric emptying and substratereceptor regulation.

In the fed state gastric emptying may be decreased compared to the fasting state because of receptor feed back from the duodenum due to food substances present (Brouns, 1987). As a result of this and also because of mixing with food remnants in the stomach, gastric emptying of the initial bolus of the drink may be quantitatively less, which will have its consequences for the 
magnitude of receptor activation and in turn will affect insulin secretion. Another factor which may induce differences in the regulation of blood glucose may be the difference in the insulin status between the fed and fasted state, as well as the difference in liver glycogen level, which will be substantially reduced after an overnight fast (Hultman, 1981).

Differences in pre-exercise insulin status can affect blood glucose levels during exercise by modification of insulin receptor binding (Berger, 1978). It has been shown that insulin can down or up-regulate its receptor number depending upon previous food intake and related blood glucose and insulin levels (Garrel, 1984; Gorden, 1980; Grundleger, 1982). As a result of this the insulin receptor number at the cell surface will be increased after an overnight fast while insulin levels are low. If carbohydrate is then introduced in the gut and blood glucose increases rapidly it may be assumed that 'massive' insulin binding takes place leading to a strongly enhanced blood glucose withdrawal while at the same time glucose output from the liver is largely inhibited by an increase of the insulin glucagon ratio (Felig, 1982; Rizza, 1981; Wahren, 1971). In fact it has been shown that a close correlation exists between fasted pre-exercise blood glucose and insulin levels and the magnitude of blood glucose decrease at the beginning of exercise (Koivisto, 1981).

Whenever blood glucose increases during exercise there will be no strong insulin response because insulin secretion is inhibited as a result of increased catecholamine levels (Bloom, 1976; Malaisse, 1969; Porte, 1966a$1966 \mathrm{~b})$. In our study we wanted to test the hypothesis that warming-up prior to exercise is an insufficient stress to cause a catecholamine increase large enough to inhibit insulin secretion. We also wanted to test if ingestion of carbohydrate containing drinks (with differing concentration and $\mathrm{CHO}$ sources) in the fed state, during warming-up induces a reactive hypo-glycemia and results in feelings of fatigue during the following endurance exercise.

After analysis of the data we had to reject these null hypotheses. The results demonstrate that the catecholamines increase as a result of warming-up and continued (strenuous) exercise and that this increase is accompanied by a decrease in insulin concentration. By their nature catecholamines are involved in the regulation of rapid adjustments to a changing environment such as homeostatic disturbance. Accordingly, their effects are induced rapidly and dissipated quickly (Landsberg, 1980). From the data it can be seen that a warming-up procedure of $20 \mathrm{~min}$ with a heart rate of approximately 130-140 min and including three acceleration sprints is sufficient to cause catecholamines to rise and insulin to fall. During the $7 \mathrm{~min}$ break and following strenuous exercise this pattern was subsequently and quickly reversed. The fall in insulin concentration may be explained by the inhibiting effects of both epi-nephrine and norepinephrine on insulin secretion in combination with insulin binding at the site of muscle tissue (Berger, 1978; 
Dohm, 1985; Le Blanc, 1979), rather than by changes in insulin clearance which does not seem to be increased as a result of exercise (Franckson, 1971a; Galbo, 1983a).

Innervation of sympathetic nerve endings in the pancreas may also be involved (Richter, 1984). Norepinephrine appears to inhibit insulin secretion in a manner similar to epinephrine. However, when equivalent doses are infused the effects of norepinephrine are quantitatively less (Porte, 1966).

From this finding one may conclude that epinephrine is more important with respect of modifying liver glucose production and blood insulin levels.

However, norepinephrine levels increase quicker and reach higher levels than epinephrine which only seems to increase significantly later during exercise when blood glucose levels tend to fall (Galbo, 1975; Hartly, 1972; Manhem, 1978). In this study we found the best correlation between the norepinephrine and insulin response (Table 3). This relation is further underlined by the fact that insulin did not fall to lower levels after norepinephrine reached a plateau level after approxi-mately 20 minutes of exercise, at a time that epinephrine further increased.

Table 3 Correlation coefficients of insulin and catecholamines in the different treatment groups with insulin as dependent variable.

Treatment Epinephrine Norepinephrine Dopamine

\begin{tabular}{lrlr}
\hline Fructose dr. & 0.21 & 0.06 & 0.19 \\
Sucrose dr. & -0.30 & $-0.60 p<0.01$ & 0.06 \\
Maltodextrin dr. & -0.47 & $-0.62 p<0.01$ & -0.15 \\
Free glucose dr. & -0.33 & $-0.76 p<0.01$ & -0.27
\end{tabular}

This is in line with the findings of Galbo et al (Galbo, 1975) who found that early in exercise insulin levels decreased at the same time as norepinephrine increased and epinephrine remained stable and that variations in epinephrine concentrations during exercise are not accompanied by insulin variations (Galbo, 1977). The fact that the insullin decrease was suppressed after ingestion of the more concentrated carbohydrate solutions may be explained by the fast increase in blood glucose which may have had a stronger effect on insulin secretion than the counter-active hormone during warmingup of this intensity.

During the more intense final exercise this effect was not present anymore.

No apparent difference was observed in blood insulin level between the fructose drink and the control supporting the findings that fructose exerts only a 
very small effect on insulin secretion (Bohannon, 1980; Crapo, 1980; Koivisto, 1978).

Although a quick increase in blood insulin occurred during the break after warming-up, especially in the concentrated carbohydrate trials, we did not find a reactive hypoglycemia as described by Koivisto (Koivisto, 1981).

In all cases insulin fell below baseline levels again within 10-15 minutes of exercise, whereas blood glucose levels remained elevated for a prolonged time. The fact that blood glucose remained elevated for a longer period of time after ingestion of $600 \mathrm{ml}$ boli can be explained by the fact that a phased gastric emptying takes place so that carbohydrates are introduced into the gut over a prolonged period of time, especially if gastric emptying rate is further depressed by higher carbohydrate concentrations (Brouns, 1987).

The fact that hypoglycemia did not occur and that lowered blood glucose values occurred more frequently during the control trials than during the carbohydrate trials underlines the assumption that the intake of carbohydrate containing drinks during warming-up in athletes who are not in the fasted state, is not detrimental with respect to the regulation of blood glucose and enhances blood glucose levels as long as carbohydrate absorption from the gut takes place. Although the cyclists consumed only one bolus of drink during warming-up it can be assumed that whenever the ingestion of $\mathrm{CHO}$ containing drinks is continued throughout the duration of the exercise period, the fall in blood glucose levels to baseline levels, as seen after 15-20 min with the low concentrated drinks supplied in $300 \mathrm{ml}$ boli, will not occur. The validity of this assumption is underlined by a number of studies (Björkman, 1984; Bonen, 1981; Brooke, 1975; Felig, 1982; Flynn, 1987;Pallikarakis, 1986).

\section{Summary}

The effect of carbohydrate drink ingestion on blood glucose regulation during exercise was tested in eighteen highly trained amateur cyclists. ingestion of the drinks took place during warming-up after having consumed a solid-liquid breakfast.

in contrast to other studies where drinks were ingested after an overnight fast, in a resting condition, no negative effects on the blood glucose level were observed.

A close relationship was found between the changes in insulin and the catecholamines, norepinephrine being the most important inhibiting hormone.

Catecholamines increased as a result of exercise while insulin decreased.

The study shows that prehydration with carbohydrate containing drinks during warming up in the fed state does not affect gilucoregulation negatively, nor subjective fatigue during the following endurance exercise. 


\section{REFERENCES}

1. Berger M. Halbar P.A, Muller W.A. et al.

Mobilization of subcutaneously injected tritiated insulin in rats: effects of muscular exercise.

Diabetol 15: 133-140, 1978 .

2. Bohanmon N.V., Karam J.H., Forsham P.H.

Endocrine responses to sugar ingestion in man.

J Am Diet Ass 76: 555-560, 1980.

3. Boje 0 .

Arbeitshypoglykămie nach Glulkoseeingabe.

Scand Arch Physiol 83: 308-312, 1940.

4. Bjorkman 0. , Sahlin K., Hagenteldt L., Wahren $J$.

Influence of glucose and fructose ingestion on the capacity for longterm exercise in well trained men.

Clin Physiol 4: 483-494, 1984.

5. Bloom S.R., Johnson R.H., Park D.M. Rennie M.J. et al.

Difference in the metabolic and hormonal responses to exercise between racingcyclists and untrained individuals.

J Physiol 258: 1, 1976.

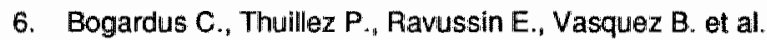

Effect of muscle glycogen depletion on in vivo insulin action in man.

J Clin Invest 72: 1605-1610, 1983.

7. Bonen A., Belcastro A.N., Macintyre K., Gardner J.

Hormonal responses during intense exercise preceded by glucose ingestion.

Can J Appl Sports Sci 5: 85-90, 1980.

8. Bonen A., Malcolm S.A., Kilgour R.D., Madintyre K.D. et al.

Glucose ingestion before and during intense exercise.

J Appl Physiol 50: 766-771, 1981.

9. Borg Q.A.V.

Percelved exertion: a note on "history' and methods.

Med Sci Sports 5: 90-93, 1973.

10. Broake J D. Davies G.J., Green L.F.

The effects of normal and glucose syrup diets on the performance of racing cyclists.

J Sports Med 15: 257-265, 1975.

11. Brouns F., Saris W.H.M., Rehrer N.J.

Abdominal complaints and gastro-intestinal function during long-lasting exercise.

Int J Sports Med 8: 175-189, 1987. 
12. Bums T.W., Bregant R., Van Peenan H.J., Hood T.E.

Observations on blood glucose concentration of human subjects during continuous sampling.

Diab 14: 186-193, 1965.

13. Cahill G.F., Soeldner J.S.

A non-editorial on non-hypoglycemia.

N Eng J Med 291: 905-906, 1974.

14. Christensen $\mathbb{E} . H_{\text {., Hansen }} \mathbf{O}$.

Hypoglykămie, Arbeitstăhg gakeit und Ermüdung.

Skand Arch Physiol 81: 171-179, 1939.

15. Costill, D.L., Bennett A., Branan G., Eddy D.

Glucose ingestion at rest and during prolonged exercise.

$J$ Appl Physiol 34: 764-769, 1973.

16. Costill D.L., Coyle E., Dalsky G., Evans W. et al.

Effects of elevated plasma FFA and insulin on muscle glycogen usage during exercise.

J Appl Physiol 43: 695-699, 1977.

17. Crapo P.A. Kolterman O.G. Oleisky J.M.

Effects of oral fructose in nonnal diabetic and impaired glucose tolerance subjects.

Diab care 3: $575-582,1980$.

18. Davidson P.E., Albrink M.J.

Metabolism 14: 1059, 1965.

19. Dohm G.L., Caro J.F. Sinha M.F.

Insulin receptors and insulin receptor protein kinase activity in muscles of endurance trained rats

Med Sci Sport Ex 17: 240. Abstract, 1985

20. Felig $P$.

Effects of exercise and physical training on field utilization, insulin sensitivity, and insulin secretion, in Borer K.T., Edingston D.W., White T.P. (eds):

Frontiers of exercise biology. New York, Human

Knethe Publishers mi, 1983, pp 186-197.

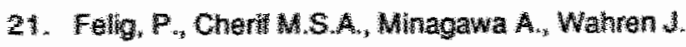

Hyogycema dung prolonged exercise in nomal man.

W Eng J Med 306: 895-910, 1982 .

22. Fetg P. Wahrens.

Role ol insum and gucagon in the regulation of hepatic gucose production dwing axercise..

Diab 28: $71-75,7979$.

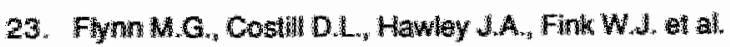

nhence of selected carbohydrate ornks on cycho pertomance and gyogen use.

Med Sci Spors Exerc 19:37-40, 1987 . 


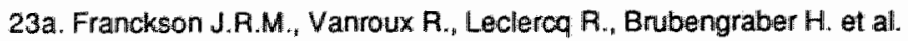

Labelled insulin catabolism and pancreatic responsiveness during longterm exercise in man.

Horm Metab Res 3: 366-373, 1971.

24. Galbo H., Holst J.J., Christensen N.J.

Glucagon and plasma catecholamine responses to graded and prolonged exercise in man.

$J$ Appl Physilol 38: 70-76, 1975.

25. Galbo H., Christensen N.J. Holst, J.J.

Glucose-induced decrease in glucagon and epinephrine responses to exercise in man. J Appl Physiol 42: 525-530, 1977.

25a. Gabo H.

Hormonal and metabolic adaptation to exercise.

Thieme-Stratton Inc. 1983.

26. Garrel D.R., Todd K.S., Calloway D.H.

Effects of marginally negative energy balance on insulin binding to erythrocytes of normal men.

Am J. Clin Nutr 39: 716-721, 1984.

27. Gorden P., Carpentier J.C., Freychet P., Orci L.

Internalization of polypeptide hormones, mechanism, intracellular localization and significance.

Diabetologica 18: 236-237, 1980.

28. Grundleger ML., Thenen S.W.

Decreased insullin binding, glucose transport and glucose metabollism in soleus muscle of rats fed a high fat diet.

Diabetes 31: 232-237, 1982.

28a. Hartly L.H., Mason J.W., Hogan P.

Multiple hormonal responses to prolonged exercise in relation to physical training.

J Appll Physiol 33: 607-610, 1972.

29. Hultman E. Nilsson L.HH.

Liver glycogen in man. Effect of different diets and muscular exercise, in: Pernow

G., Saltin B. (eds): Muscle metabolism during exercise, New York, Plenum, 1981, pp 143152.

30. Keller K., Schwarzkopt R.

Premexercise snacks may decrease exercise performance.

Phys Sportsmed 12: 89-91, 1984.

31. Keul, ل., Harallambie $G$.

Die Wirkung von Kohlenhydraten auf die Leistungstăhigkeit und die energieliefernden Substrate im Blut bei langwährender Köperarbeit.

Disch Med Wochschr 98: 1806-1811, 1973. 
31a. Keul J., Berg A., Lehmann M., Dickhuth H.H. et al.

Die Wirkung von Dextrose und Maltose aut kardiozirkulatorische, metabolische und hormonale Grössen im Blut sowie die Leis-tungsfăhigkeit bei Ergometerarbeit.

Akt Ernăhr 11: 145-152, 1986.

32. Koivisto V.A.

Fructose as a dietary sweetener in diabetes mellitus.

Diab care 1: 241-246, 1978.

33. Koivisto V.A., Karvonen S.-L., Nikkilae, E.A.

Carbohydrate ingestion before exercise: comparison of glucose, fructose, and sweet placebo.

J Appl Physiol 4: 783- 787, 1981.

34. Landsberg L., Young J.B.

Catecholamines and the adrenal medulla

In: Metabolic control and disease pp 1621-1676

Bondy PK., Rosenberg L.E. (eds).Saunders, New York" 1980.

35. Le Blanc J. et al.

Effects of physical training and adipocity on glucose metabolism and ${ }^{125}$-insulin binding. J Appl Physiol 46: 235, 1979.

36. Levine S.A., Gordon B., Derick E.L.

Some changes in chemical constituents of blood following a marathon race: with special reference to the development of hypoglyce-mia.

JAMA B2: 1778-1779, 1924.

37. Levine L., Evans W.J., Cadarette B.S., Fisher E.C. et al.

Fructose and glucose ingestion and muscle glycogen use during sub maximall exercise.

J Appl Physiol 55: 1767-1771, 1983.

38. Luyckx A.S., Pirnay F., Lefebvre P.J.

Effect of glucose on plasma glucagon and FFA during prolonged exercise.

Eur J Appl Physiol 39: 53-41, 1978.

39. Malaisse W.

Elude de la secretion insulinique in vitro.

Vol 1, Arscia and Maloine

Brussels-Paris 1969.

40. Manhem P., Lecerof H., Hökfelt, B.

Plasma catecholamine levels in the coronary sinus, the left renal vein and peripheral vessels, in healthy males at rest and during exercise.

Acta Physiol Scan 104: 364-369, 1978.

41. Pallikarakis N., Jandrain B., Pirnay F., Mosora F. et al.

Remarkable melabolic availability of oral glucose during long-duration exercise in humans.

J Appl Physiol 60: 1035-1042, 1986. 
42. Pirnay F. Lacroix M., Mosora F., Luyckx A, Lefebvre P.

Glucose oxidation during prolonged exercise evaluated with naturally labeled $\left[{ }^{13} \mathrm{C}\right]$ glucose.

\rfloor Appll Physiol 43: 258-261, 1977.

43. Porte D., Graber A.L., Kuzuya T., Williams R.H.

The effect of epinephrine on immunoreactive insulin lewels in man.

J Clin linvest 45: 228-236, 1966.

44. Porte D, Williams R.H.

Inthibition of insulin release by norepinephrine in man.

Science 152: 1248-1250, 1966.

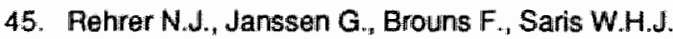

Fluid intake and gastro-intestinal problems in runners competing in a $25 \mathrm{~km}$ race and a marathon.

Int J Sport Med 1988 suppl.

46. Richter E.A.

Influence of the sympatho-adrenal system on some metabolic and hormonal responses to exercise in the rat.

Acta Physiol Scand 528 (suppl): 11-42, 1984.

47. Rizza R.A., Mandarino L.J., Gerich J.E.

Dose-response characteristics for effects of insulin on production and utilization of glucose in man.

Am J Physiol 240: E630-E639, 1981.

47a Smedes Kraak and Poppe.

Simple and fast soluent extraction system for selective and quantitative isolation of adrenaline, nor adrenaline wel dopamine from plasma and urine.

J Chromatography 231: 25-39, 1982.

48. Wahren J., Felig P., Ahlborg Gi, Jorfeldt L.

Glucose metabolism during leg exercise in man.

$\checkmark$ Clin Invest 50: 2715-2725, 1971. 


\section{CHAPTER VII ABDOMINAL COMPLAINTS AND GASTRO-INTES- TINAL FUNCTION DURING LONG LASTING EXER- CISE}

F. Brouns, W.H.M. Saris, N.J. Rehrer

Nutrition Research Center University of Limburg, Department of Human Biology, Beeldsnijdersareef 101, 6200 MD Maastricht, The Netherlands

keywords: exercise, stomach, intestines, digestion, absorption, regulation, gastric emptying, disorders.

\section{Abstract.}

Over the last several years there has been an increased popularity of endurance sport, with a concommitant rise in ailments which hinder optimal performance. The "ultra" distances, running, bicycling, swimming, skating, and combinations of these, are popular at an elite-competitive, as well as recreational level. Among the problems which are associated with these activities, gastro-intestinal disturbance is one of the most common and one of the most disruptive. Gastro-intestinal distress, at the very least, decreases the pleasure experienced during training or competition and may decrease performance. Disturbances range from mild to severe, from abdominal discomfort to bloody diarrhea. Physical condition, degree of dehydration, and food ingestion prior to or during competition may play a role in the development of these complications. This article deals with the etiology of gatro-intestinal problems in sport and the increased incidence associated with activities where the vertical component of movement is large (i.e. running) in comparison to "gliding" sports such as bicycling, skating, and swimming. where the movement is mainly horizontal and there is minimal jolting. Gastric acid reflux and regurgitation appear to be related to ingestion of food and drink. Bloody diarrhea may occur independent of food and drink and is caused by physiological and morphological changes in the intestinal tract during exercise with dehydration. Suggestions for further research include a systematic study of the changes in the gastro intestinal system resulting from intense endurance-sport activity.

\section{Introduction}

During the last decade sports physicians have emphasized the intake of liquid during long lasting exercise in order to overcome the problems of severe dehydration and subsequent heat stroke. Coaches and physiologists have 
promoted the regimes of carbohydrate (CHO)-loading prior to, and $\mathrm{CHO}$ intake during long lasting exercise in order to avoid early glycogen depletion and subsequent exhaustion. Furthermore the occurrence of muscle cramps in the fatigued athlete has led to the advice that body salts that are lost with profuse sweating be replaced. Abdominal cramps or diarrhea often impels the athlete not to eat for 3-5 hours prior to exercise or to ingest complete nutritional liquids. Referring to dehydration, glycogen depletion and loss of electrolytes, Seiple, Vivian and Fox (105) wrote:

"The ideal beverage for athletes

1) should have a rapid gastric emptying rate to provide fast rehydration,

2) should provide minerals to replace those lost in sweat and,

3) should be a substantial energy source."

Taking these points as a beginning for further discussion we are faced with the following questions:

re 1. Gastric emptying is influenced by a large number of factors and fast supply of water and nutrient requires fast absorption in the gut. How will this be achieved, especially during exercise?

re 2. How large is sweat loss and which minerals are lost in sweat in a quantity large enough to consider replacement?

re 3. How much energy is optimal and which energy source is the best for the athlete in which circumstance?

The practical problem is whether or not the intake of nutrients during exercise may lead to abdominal compllaints which may hinder the athlete performing optimally. The following discussion tries to answer questions dealing with the occurrence of abdominal complaints, possibly as a consequence of the effect of exercise on the functioning of the intra-abdominal organs.

\section{PROBLEM ORIENTATION}

\subsection{Abdominal complaints}

During the last decade long distance running has become very popular for both adults and children. Large numbers of trained and more or less untrained people participate in competitions of $20 \mathrm{~km}$ and longer and physicians and first aid teams have frequently become aware of abdominal problems or abnormal feces and urine associated with this type of exercise. Although these complaints are often a matter of discussion and several publications in the sport medical literature have given attention to this topic $c_{n}$ it must be stated that research in this field is only fragmentary. The stitch in the side has been known for a long time. However, the process causing the stitch is still open for discussion (114) and needs further research. Post-exercise proteinuria may 


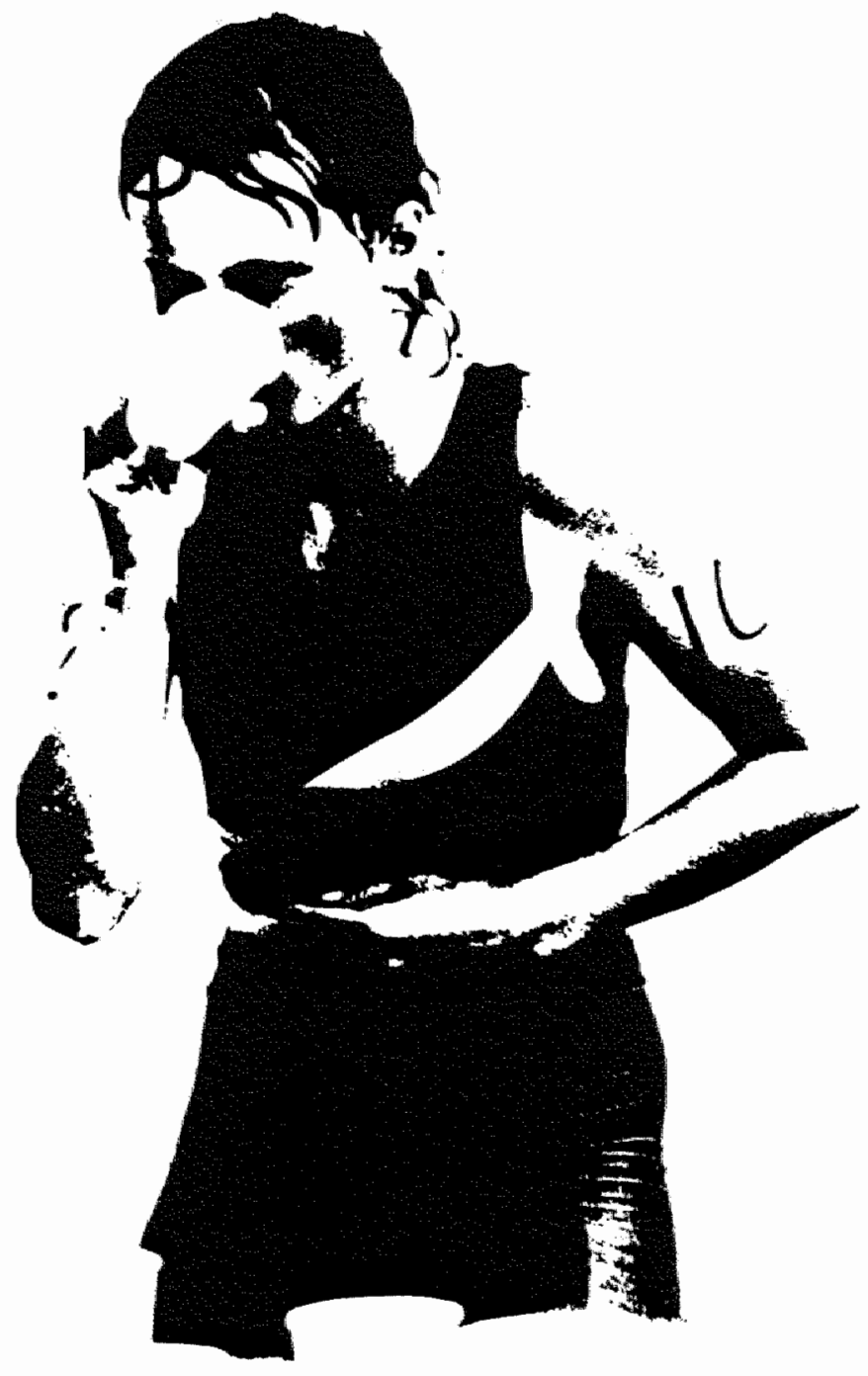


last 48 hours and may be related to renal ischemia (4). Nowadays this is not considered to be pathological but is seen as a normal consequence of sports activity. The presence of blood in the urine is of more serious character and may be due to superficial biadder trauma (13). From the foregoing it becomes clear that caution is needed when suggesting causal mechanisms. The presence of hematuria may initiate discussions about what a normal consequence of intensive exercise is, as may the statement by Derek Clayton after setting his world record on the marathon in 1979. "Two hours later the elation had worn off: I was urinating large dots of blood and I was vomiting black mucus and had a lot of black diarrhea. I don't think too many people can understand what I went through for the next 48 hours" (Runners World, May 1979: $p$ 72).

Systematic information was gathered by Sullivan (116) who interviewed 57 runners, (running $29-160 \mathrm{~km} /$ week). He reports the following results:

- while running, $30 \%$ occasionally or frequently had the urge to defecate

- $25 \%$ had abdominal cramps or diarrhea during or after competition

- $6 \%$ had severe nausea or retching

In 1969 Dancaster described two well trained distance runners who suffered acute tubular necrosis. Both runners had diarrhea during or immediately after the race. It was speculated by Forgoros (48) that it is especially the combination of diarrhea and severe dehydration that might be extremely dangerous. The resulting combination: dehydration + hypokalemia + hyperthermia was suspected to cause rhabdomyolysis and acute necroses. Fogoros (48) described two cases of long distance runners suffering from loose bowel movements and bloody diarrhea. These problems occurred in periods of very intensive training and competitions. This was suggested to be caused by relative gut ischemia. In one athlete the combination with hyperthermia was present and the result was a bloody diarrhea. Bloody stools have also been reported by Cantweil (24) and Keeffe (75). Hyperthermia due to dehydration has often been reported and may reach values of more than 40 degrees Celsius (32). Such high temperatures might predispose one to ischemic necrosis. Lately Keeffe et al (75) carried out a questionnaire survey on 1700 participants of a marathon. (Response $n=707$ ). The results were:

- Lower gastro-intestinal (G.I.) symptoms were more commonly associated with running than upper $G . I$. complaints.

- The urge to defecate was the most common symptom experienced by runners ( $36.4 \%$ at moderate intensity (M.I.) to $38.6 \%$ at high intensity (H.I.)) and appeared both during and immediately after running.

- Bowel movements (34.9\% or diarrhea (19.2\%) were relatively frequent immediately after running.

- Runners needed to interrupt runs for bowel movements $-18.4 \%(\mathrm{M} . \mathrm{I}$.) to $16 \%$ (H.I.) - or diarrhea - $8.2 \%$ (M.I.) to $10 \%$ (H.I.). 
- 1.2 (M.l.) $2.4 \%$ (H.I.) of runners had bloody bowel movements.

- All lower G.I. symptoms were noted more commonly by women than by men.

- Some symptoms were more reported by younger than older runners.

- Nausea - $(11.6 \%$ (M.I.) to $12.7 \%$ (H.I.) - and vomiting (1.8\% were more troublesome during hard runs or after running.

From these figures it becomes clear that the number of complaints among those athletes is considerable. However, the authors discuss the fact that it cannot be disregarded that primarily those who suffer the most from G.I. problems may have responded. Total response was $40 \%$. The complaints that are related to the intra-abdominal organs may be explained by a combination of two or more of the following factors:

- type of exercise and exercise intensity

- dietary habits (qualitative and quantitative)

- alterations in blood flow and oxygen supply

- alterations in absorption

- hormonal changes

- gastric content and gastric emptying (G.E.)

A few other observations from daily sports practice may be interesting.

1. In sports events where the body is relatively stable, such as in cycling, swimming, speed skating, or cross country skiing the number of abdominal complaints is far less than in running, irrespective of nutritional intake.

2. Training seems to decrease the occurrence of G.I. disturbances.

It is difficult to explain these observations from available scientific data. The pathophysiology of G.I. disturbances associated with running has not been studied and remains speculative (75). In spite of a resurgence of interest in physiologic investigations of marathon running, the G.I. tract has been neglected (80). The lack of knowledge underlines the need for research $(48,116,117,114)$. The athlete, the coach, and the physician are left with a number of questions, which may be summarized as follows:

A. Is there a real need to ingest solid or liquid nutrition during the exercise, if so, what and when?

B. Is it possible to eliminate abdominal problems by ingesting water only or by modulation of the food and drink composition?

With regard to the first question it can be said that there is extensive literature available emphasizing the importance of taking measures for maintaining water, electrolyte and energy ( $\mathrm{CHO}$ ) balance in endurance athletes in order to maintain optimal performance capacity and to reduce the risk of early 
exhaustion (For review see: $10,14,66,35,44,102$ ). How, when and which measures should be taken to achieve this deserves further discussion, especially because abdominal complaints may interfere with nutrient intake and absorption. For example the intake of a concentrated glucose solution during exercise may inhibit gastric emptying and induce a water flux into the gastric lumen (this will be explained later). This leads to the feeling of having an overfilled stomach and refrain from drinking. Regurgitating of food and the reflux of gastric juice often occurring in this situation are very unpleasant events. An overview of the main problems of food intake such as quantity, quality, time, etc. related to exercise is presented elsewhere (19). The second question initiates a discussion about the logic of the advice not to eat and drink prior to and during the exercise, or about possibilities to modify the composition of the food and/or the fluid to be taken in such a way that the risk of causing problems will be minimized. Indications for possible modifications may be derived from the available literature in the field of gastro-intestinal, splanchnic, and renal physiology. A brief discussion of the importance of water and/or carbohydrate intake in relation to endurance exercise will follow.

\subsection{The need for fluld intake}

Between 1931 and 1966 twenty-six football players died from hyperthermia and dehydration (113). In the last decade numerous cases of heat stroke due to dehydration have been reported during long distance running. Costill (32) reported a rectal temperature of a non-finisher, following a marathon in the heat, at 41.3 degrees Celsius. During a 2 hour laboratory running trial, with a workload of $70 \% \mathrm{VO}^{2}$ max and no water ingestion, the weight loss in a runner was $4.02 \mathrm{~kg}$ and rectal temperature increased to $40.6^{\circ} \mathrm{C}$. During the Olympic marathon trial in 1968 Costill measured a mean body weight loss of $6.1 \mathrm{~kg}$. Such body weight losses are not only present in elite athletes setting their top performances but occur in general whenever long lasting exercise is executed at an intensity that is high for the individual in question. Dressendorfer (41) reported a mean sweat loss of 3 liters in five trained coronary patients running a marathon. Depending on temperature, humidity, sunshine, clothing, wind and altitude the fluids lost can be substantially greater. Saltin reported a sweat loss of 7 liters during exercise lasting 3.5 hours (103). It is obvious that such fluid losses have to be replaced in time. Practical experience has shown that this is possible during cycling. Saris et al. (104) measured fluid intakes of more than 10 liters on a hot competition day in the 1984 Tour de France.

Fluid intake was closely related to external temperature. 


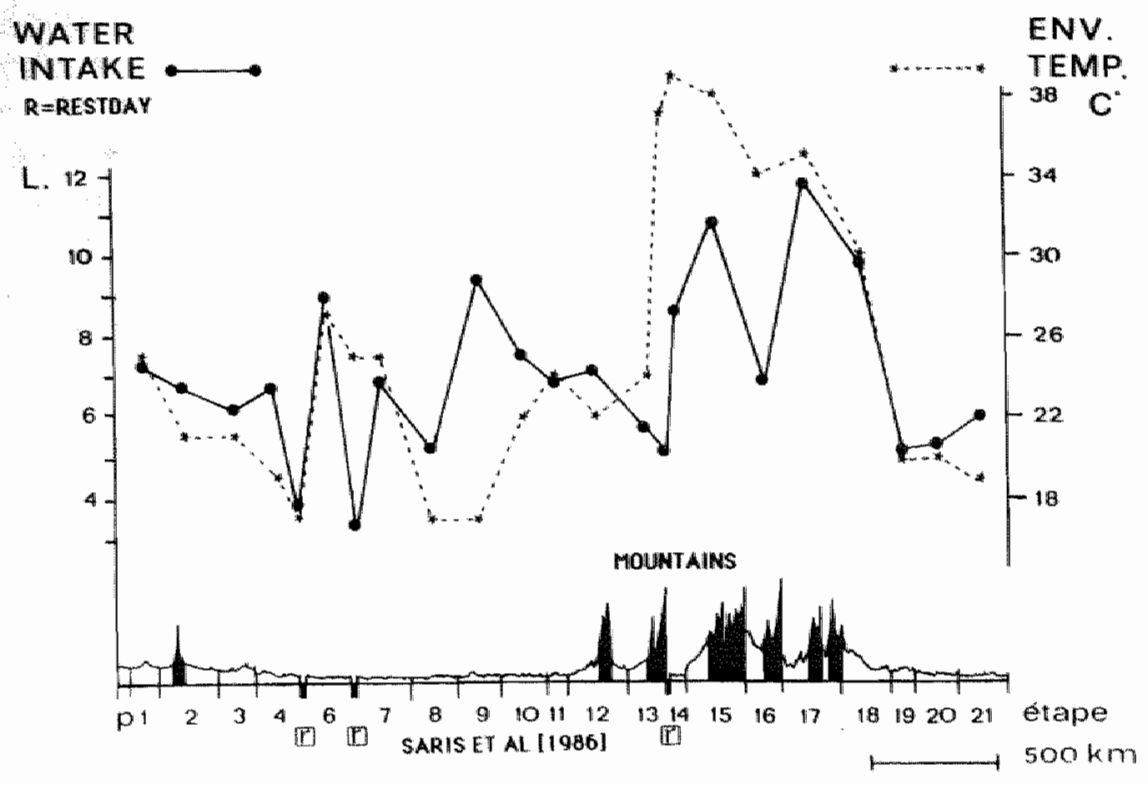

Fig. 1 Water intake during the Tour de France.

WATER INTAKE (n NGS KM DAY) $\mathrm{ml} \cdot \mathrm{km}^{-1}$

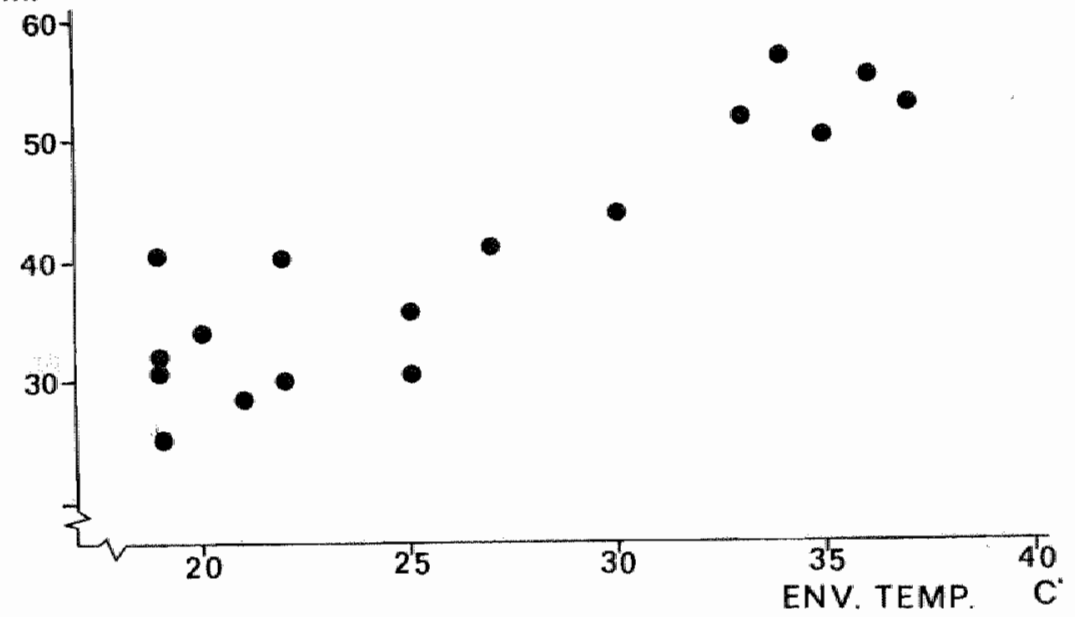

Fig. 2 Water intake in rellation to environmental temperature. 
During running, howewer, drinking seems to be problematic. Running initiates

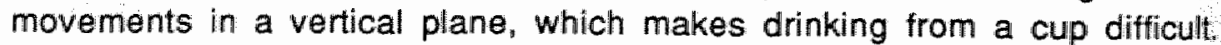
Breathing frequency, which is normally related to stride frequency (some fixed ratio eg. 3 strides inhaling - 3 strides exhaling) is also disturbed, which is unpleasant. As a result total fluid intake per hour during running is much less than during cycling which initiates dehydration and heatstress more frequently. In this context it is difficult to understand how elite marathon runners sometimes periorm so well with very little fluid intakes (less than $200 \mathrm{ml}$ ), while others run into serious problems.

\subsection{The need for carbohydrates}

Controlled studies have shown that muscle glycogen availability is a strong limiting factor for long lasting exercise of high intensity $(10,35)$. The higher the intensity, the more $\mathrm{CHO}$ metabolism is stimulated. Energy flow from $\mathrm{CHO}$ is faster than from fat (90). Thus the prerequisite for maximal, endurance exercise is the availability of $\mathrm{CHO}$ since energy flow from fat only enables $50-60 \%$ of maximal power output (94). The problem of $\mathrm{CHO}$ depletion and subsequent exhaustion can be avoided or delayed by taking the following measures:

1. Enhancement of $\mathrm{CHO}$ intake 3 to 4 days prior to exercise in combination with a training volume reduction, so called "glycogen loading during tapering off"

2. Intake of $\mathrm{CHO}$ during exercise

3. Adequate training in order to increase exercise induced fat metabolism

Point 1 may lead to a maximal glycogen content in liver and muscles at the onset of exercise, whereas 2 and 3 may lead to glycogen sparing. In general it can be stated that the intake of $\mathrm{CHO}$ during exercise will be beneficial. However, fluids and nutrients have to be tolerated and it should be realized that they first become available after passage of the stomach. For better understanding it will therefore be necessary to discuss some details of normal G.I. functioning and regulation first. The influence of exercise on the G.I. tract and the possible relation to the development of disturbances and abdominal complaints will be discussed after that.

\section{GASTRO INTESTINAL FUNCTIONING AND REGULATION AT REST}

\subsection{Gastric emptying (G.E.)}

The pylorus is opened most of the time (letting liquid pass through unhindered and closes only in cooperation with the terminal antrum and some duodena contractions $(42,115)$. This is evidenced by the finding that the passage 0 
liquids remains the same after pylorectomy or placing a transpyloric cannule $(40,115)$. It seems that the tone of the proximal part of the stomach determines to a large extent the moments for emptying of liquid and half solid substances (61) and that the motor activity of the distal segment determines the passage of solid particles (84). The complex of contraction and relaxation of proximal and distal gastric compartments in close cooperation with pyloric action is regulated to a large extent by a number of stimuli resulting from:

- osmolality

- caloric density

- type of carbohydrate

- fatty acids

- amino acids

- acidity $(\mathrm{pH})$
- particle size

- meal volume

- meal temperature

- dietary fiber

- hormones

- other factors

A summary of research in which these effects have been studied is given in tables $4-8$ at the end of this review. In the following paragraphs the most important factors will be discussed.

\subsubsection{Intra- gastric regulation of gastric emptying}

Particle size, meal volume, and meal temperature exert an intra-gastric effect on G.E. These factors will be described first.

\subsubsection{Particle size}

Using labeled meals, Moore (88) measured the G.E. of solid and liquid parts. The solid parts were emptied at a rate of $2 \mathrm{gm} / \mathrm{min}$. Chicken liver given as large cubes emptied more slowly than small cubes due to "grinding down" and "liquefying" work done by the stomach (64). Bernier (11) measured emptying of two identically composed meals, one solid, one homogenized.

The homogenized meal emptied faster (4 hours vs 6 hours). It seems that the pylorus refuses particles larger than $1 \mathrm{~mm}$ to pass $(11,84)$. Fink $(46)$ showed that complete liquid meals $(12.4-14 \%$ protein, $31.4-37.4 \%$ fat, $49.8-54.7 \%$ carbohydrate) emptied by $70 \%$ within the first hour and almost completely within two hours. The liquid meal emptied substantially faster than the solid meal. (This might lead one to question the value of ingesting solid nutrition in order to enhance energy intake during long lasting exercise, especially because the ability to chew and to swallow may be impaired during higher exercise intensities and onset of food availability to the intestines will last several hours). However, in the fasted subject, G.E. of both solids and liquids is not immediately inhibited after ingestion (when duodenal receptor contral is still inactivated). During this phase rapid G.E. occurs and leads to the escape of larger nutrient particles (11) after which G.E. becomes inhibited and stomach digestive activities are stimulated. Thus, regulation of $G$.E. seems to 
function in a bi-phasic response in which particle size control is initiated subsequent to duodenal receptor control. At the onset of food intake, the gastro-duodenal cooperation can be considered as an "open loop" in which the initial effluent depends primarily on gastric activity and little upon any inhibitory influence of the duodenum. This means that a bolus will be emptied immediately after the initial intake (rapid emptying phase). Once received in the duodenum the food will influence local processes such as hydrolysis and receptor activation or inhibition. Once the receptors are activated they will exert their effect on G.E. resulting in a phased emptying (18).

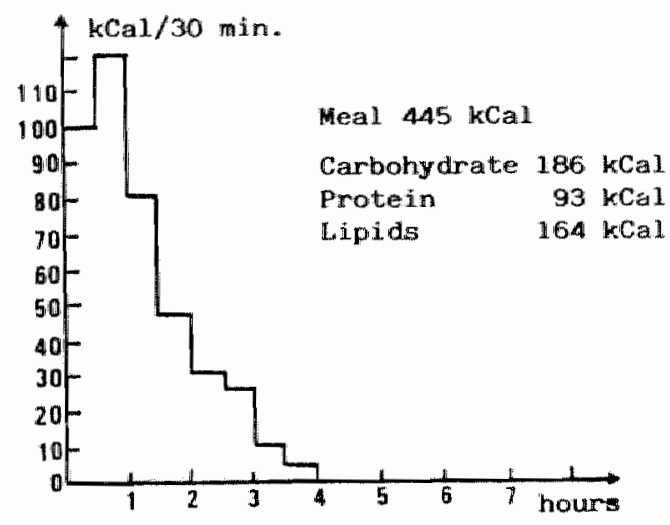

(Homogenized)

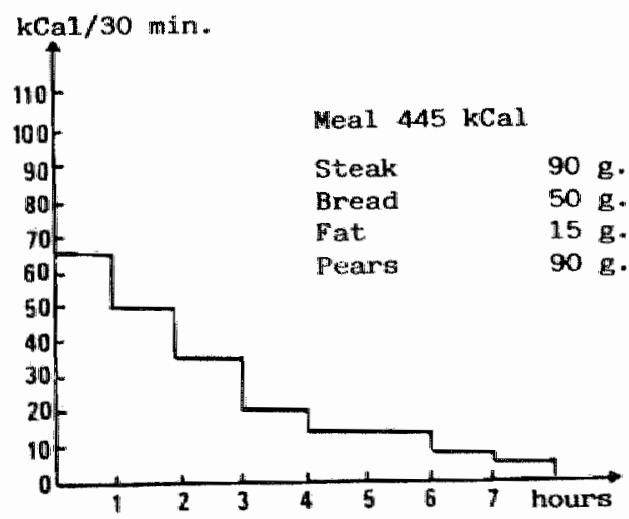

(Solid)

Fig. 3 Gastric emptying of identical solid and homogenized meals.

Adapted from Bernier (1985). 


\section{Testing procedures}

From this information one may speculate about the legitimacy of analyzing G.E. by serial measurements in between which the stomach is washed with water or saline and gastric residue is aspirated by a G.I. tube. It can be assumed that this procedure has its limitations, since it is primarily the composition of the duodenal content that determines gastric emptying of liquids and not the composition of the gastric content. It would therefore be more appropriate to have a longer time between the trials in order to "wash out" the duadenum before the next trial is performed. Unfortunately most studies done have not taken into account this fact. Probably the best procediure is to do a post-trial emplying test of saline and to start the next trial at the moment that saline empties in a normal rate again, suggesting that post pyloric inhibition is reduced to a desired "standard" level. Another point of interest is that a recent study (2) indicated that the presence of a gastro-intestinal tube delays gastric emptying and accelerates bowel transit. The development of non-invasive techniques thus seems the most appropriate way to study G.I. function in the future.

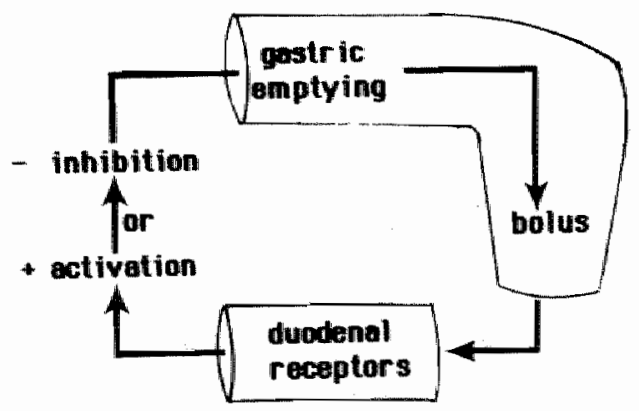

Fig. 4 Dynamic closed loop feedback system. 
Fluid ingestion<smiles>C=CC</smiles>

OPEN LOOP

I. Rapid emptying phase<smiles>C=CC</smiles>

Bolus, size dependent on

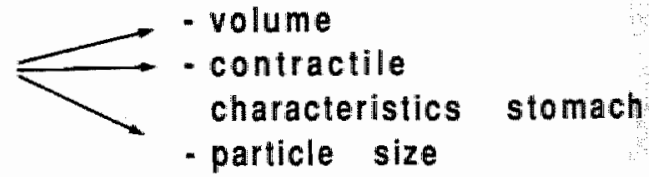

Duodenal receival + feedback control<smiles>C=CC</smiles>

I1. CLOSED LOOP

Phased bolus emptying

Fig. 5 Fasted subject - stomach and duodenum are empty.

\subsubsection{Meal volume}

Volume effects G.E. Hunt (67) showed that the rate of G.E. increased $3.3 \mathrm{ml}$ for every $100 \mathrm{ml}$ increase in gastric content. Costill (33) found a value of $3.7 \mathrm{ml}$ for each $100 \mathrm{ml}$ increase with a maximum at a volume of $600 \mathrm{ml}$. It is hypothesized that the increased stomach wall pressure leads to wall distention which stimulates gastric motility and subsequent G.E. This might be an exponential function (71).

\subsubsection{Meal temperature}

The studies on the effect of meal temperature on G.E have all been done with liquids. Gershon-Cohen (55) showed that decreased thermal temperatures are associated with an increase in gastric motility and a rapid flow through the jejunum. As a result of this cold drinks tend to leave the stomach earlier than do warm drinks (38). Lower temperatures enhance G.E. When a drink of $5^{\circ} \mathrm{C}$ was ingested, the gastric rest volume after $15 \mathrm{~min}$ was $50 \%$. However, when the temperature of the same drink was $35^{\circ} \mathrm{C}$ the rest volume was $73 \%$ (33). It may be that these effects on G.E can be counter affected by changes in duodenal receptor activity. Other factors exerting an effect on the regulation of G.E., are located in the gut or are of more central character such as hormones. 


\subsection{Gut regulation of Gastric Emptying}

The most important site in the regulation of G.E. is the duodenum which contains a large number of receptors sensitive for osmolality, acidity, fatty acids, mono- and di-glycerides, amino acids and carbohydrates $(9,31)$. Stimulation of these receptors delays G.E.

\subsubsection{Osmoreceptors}

Hunt and Pathak (68) hypothesized that solutions of glucose isosmotic with plasma are thought to make the duodenal osmoreceptor permeable to sodium. This leads to receptor swelling (penetration of solute + sodium), a signal to allow G.E. Whenever the concentration of solutes in the duodenum is too high (and thus is hypertonic) sodium and water will be drawn from the receptor vescicle and subsequent shrinking will take place, a signal for inhibition of G.E. If the latter takes place, the duodenal content will first be adjusted to isotonicity. resulting in subsequent increase in receptor permeability, before a new bolus may leave the stomach. Meeroff (82) stated very clearly: "The rate of emptying is not influenced by non isotonic solutions in stomach or jejunum as long as duodenal contents remain isotonic". Hunt $(68,70)$ reported that isotonic saline solutions empty more rapidly than water. The findings of Hunt suggest that pure water entering the duodenum will be adjusted to isotonicity too by electrolyte fluxes (from hypo-isotonicity) or that slow water diffusion may be the stimulus for decreased G.E. compared to saline. Ruppin (101) found that the osmolality of a liquid meal correlated with its G.E. rate (higher osmolalities slower G.E. rates), as does fluid and nutrient absorption $(20,109)$. Foods always leave the duodenum with an osmolality of $300 \mathrm{~m}$.osmol// (11). It is suggested that the two most important ways to realize this adjustment to isotonicity is a synchronized process of water secretion and nutrient absorption. Water secretion also may take place in the stomach but even though gastric secretion may dilute the gastric content, the emptying rate of a hypertonic solution remains the same because of direct duodenal control (18). From this it is concluded that osmoreceptors are not present in the stomach or intestine beyond Treitz ligament. Since isotonic drinks have been promoted for rapid fluid replenishment there have been a lot of controversial discussions about their effectiveness and value. There is no doubt, however, that in the gut water together with nutrients is absorbed as isotonic solution and that after liquid intake, there will be an adjustment towards isotonicity which subsequently will influence G.E. Water alone can enter the blood stream by simple diffusion. In the jejunum the solute absorbed is isotonic (112). In experiments in which constant perfusion with a triple lumen catheter was used it was found that the osmolality of the fluids down the jejunal test segment was unaltered despite different flow rates of test solutions. Water absorption took place together with solute in isotonic proportions. Also the human colon 
absorbs water and sodium from an isotonic medium (79). However, literature on absorption of nutrients is conflicting. Single nutrients can be absorbed from a hypertonic medium in contrast to what is believed for water absorption (see also section 3.8). If water absorption is the primary factor for rehydration in the athlete then adjustment to isotonicity may play a limiting role. Theoretically there are three ways to realized this:

1. secretion of water and/or electrolytes into the G.I. lumen

2. absorption of nutrients

3. duodenal escape of nutrients

Apart from effects exerted by osmoreceptors, there is evidence that receptors responding to specific nutrients may exert the strongest effect on the regulation of G.E. Glucose, fatty acids and amino acids may be important to consider in this respect. Another subject for discussion may be the absorption of these nutrients in the duodenum and jejunum. Because glucose, fructose and amino acids as single nutrients have been tauted as important for sports performance, many athletes ingest these nutrients in a purified form. The question then arises whether glucose taken as a concentrate is absorbed with a maximal speed and if not, whether for example sodium has to be added to the nutrient to increase absorption. Some of these interactions will be described more in detail in section 3.8.

\subsection{Water secretion}

Water secretion as a result of increasing osmotic gradient between the G.l. lumen and the blood has been described for the individual G.I. sections.

\subsubsection{Stomach}

Foods that are hypertonic at the onset of ingestion will leave the stomach partly as iso- to hypotonic boli at the end of the digestive process (101). A similar situation has been described in the canine stomach (5). Hypertonic solutions increase gastric secretion $(18,46)$. Costill $(33)$ suggested that, despite the movement of a hypertonic solution out of the stomach at the onset of ingestion, gastric residue may increase due to gastric secretion. Glucose polymers (having a lower osmolality) induced a smaller secretion than free glucose (33).

\subsubsection{Duodenum and jejunum}

Sessions (106) found that infusion of $300 \mathrm{ml}$ hyperosmolar $(50 \%)$ glucose solutions directly into the duodenum led to the so-called "dumping syndrome". This was associated with a plasma volume decrease and a large intestinal water increase in order to reduce intestinal osmotic pressure $(106,21)$. These changes in the upper intestine did not take place if the solution was infused into the stomach. Launiala (77) described that unsplit di-saccharides led to 
water secretion in the gut. The amount of water secreted depends on the amount of maldigested di-saccharides.

\subsubsection{Colon}

Increased water movement into the G.I. lumen due to an osmotic gradient has also been described for the colon (12). With hypertonic solute perfusion the water absorption ceased when osmotic pressure of the solute was 350 $\mathrm{mOsm} / \mathrm{kg}$. In that occasion water was secreted. This was also the case with rising osmalalities of infused mannitol solutions.

\subsection{Nutrient absorption}

The second proposed way to adjust to isotonicity is via the absorption of solutes (25). After ingestion of a labeled diet $\left(3 \mathrm{H}_{2} \mathrm{O}\right.$ and $\mathrm{U}^{14} \mathrm{C}$ Sucrose) rates of tracer appearance in blood plasma suggested that both water and carbohydrate absorption were accelerated with increasing osmolality. By 30 minutes apparent $3 \mathrm{H}_{2} \mathrm{O}$ absorption from a $700 \mathrm{mosm} / \mathrm{kg}$ diet was three times greater than that absorbed from a 250 mosm diet. Water absorption is closely coupled to that of total solute since glucose absorption can stimulate water absorption directly $(20,49,51,111)$. Water absorption is also observed with fructose (51) and leucine (1). This absorption does not exclude the possibility that water secretion can take place at the same moment so that the end result of inward and outward $\mathrm{H}_{2} \mathrm{O}$ flux is a net water increase in the gut. A more detailed description of the effects of $\mathrm{CHO}$ absorption on gut regulation of G.E. is given in section 3.7 .

\subsection{Duodenal "escape" of nutrients}

If the duodenum is the prime site of regulation then it is clear that foods after leaving this section loose their influence on the receptors located in the duodenal lumen. Ruppin (101) performed an experiment in which $400 \mathrm{ml}$ test solutions were infused into the stomach. The solutions used were 1. polycose (a glucose polymer), 2. po-lycose + sucrose, 3. sucrose. All had an identical caloric content. Osmolality, however, was different. The volume emptied from solution 1. was significantly larger during the first 80 minutes. Osmolallity of duodenal contents was equal for all meals at Treitz ligament. From these findings they suggested that the glucose polymer was less completely hydrolyzed than the sucrose at the site of duodenal receptors and more in the proximal jejunum. Mollison (87) described that patients with severe deficiency of pancreatic amylase had normal inhibition of gastric emptying after a glucose load. However, boilled starch solutions left the stomach nearly as quickly as water. Presumably the starch passed the osmoreceptors in the duodenum and exerted no large osmotic effect because hydrolysis and subsequent osmolality increase did not take place at this regulation site. The use of polymers in 
nutritional liquids may thus be of advantage compared to the use of nutrients in their mono-form because reduced osmolality may minimize dumping syndrome-like reactions $(81,110)$.

Recently this principle has been applied to the composition of sportdrinks. Studies have been performed to test the effect of glucose polymer ingestion on G.E. Since hydrolysis of glucose polymers is not rate limited and the duodenum has the capacity for rapid absorption $(15,101)$, it is assumed that ingestion of a glucose polymer might induce a larger quantity of carbohydrate to be emptied from the stomach and thus lead to a larger energy contribution to the body. Two studies support this assumption. Seiple (105) showed that G.E. of a $7 \%$ glucose polymer solution was not significantly different from cold water. Foster (52) found that ingestion of a $5 \%$ glucose polymer solution resulted in $69 \%$ more fluid and $33 \%$ more carbohydrate deliverance to the small intestine than from a $5 \%$ free glucose solution. The underlying factor making this possible might be the earlier proposed "escape" of a part of the polymers to the upper jejunum. However, the available studies should be interpreted with care since the tests have been carried out at rest and not during intensive exercise.

Summarizing the foregoing we can conclude that the bio-availability of nutrients and liquids to the intestinal system is dependent on the rate of gastric emptying which in itself is regulated to a large extent by the chemical composition of the duodenal luminal content.

\subsection{Acid receptors}

$\mathrm{pH}$ receptors are assumed to be present at the site of G.E. regulation, the duodenum. Foods leave the stomach with a $\mathrm{pH}$ between 5 and 2 depending on the type of food ingested. At the end of the duodenum $\mathrm{pH}$ is systematically 7 $\mathrm{pH}$ neutralization is a consequence of the absorption of $\mathrm{H}^{+}$ions and alkaline secretions from the pancreas and duodenum (11). Adjustment to $\mathrm{pH} 7$ takes time and therefore G.E. will be inhibited by $\mathrm{pH}$ deviations of the duodenal content (107).

\subsection{Carbohydrate receptors}

The type of $\mathrm{CHO}$ ingested may act on the regulative site of $\mathrm{G} . \mathrm{E}$ in two ways:

1. specific single nutrient effect on the receptors.

2. indirect osmolality effect due to rapid hydrolysis.

\section{Specific effects}

Especially glucose tends to be a very potent inhibitor once present in the duodenum. In a studie of Coyle (36) plain water emptied $39 \%$ faster than a preparation containing $4.6 \mathrm{~g} \mathrm{dl}-1$ of free glucose. This is in line with earlier 
studies $(49,68,70)$, in which water was compared to glucose-saline solutions. Elias (43) found that glucose is more effective in G.E. inhibition than galactose or fructose. Subjects showed little slowing of G.E. with concentrations of fructose up to $200 \mathrm{mosm} / \mathrm{l}$ compared to glucose. At higher concentrations this difference remained although to a lesser extent. From these findings it was concluded that fructose is relatively ineffective in slowing $G$.E. This confirms the findings of McHugh and Moran (89).

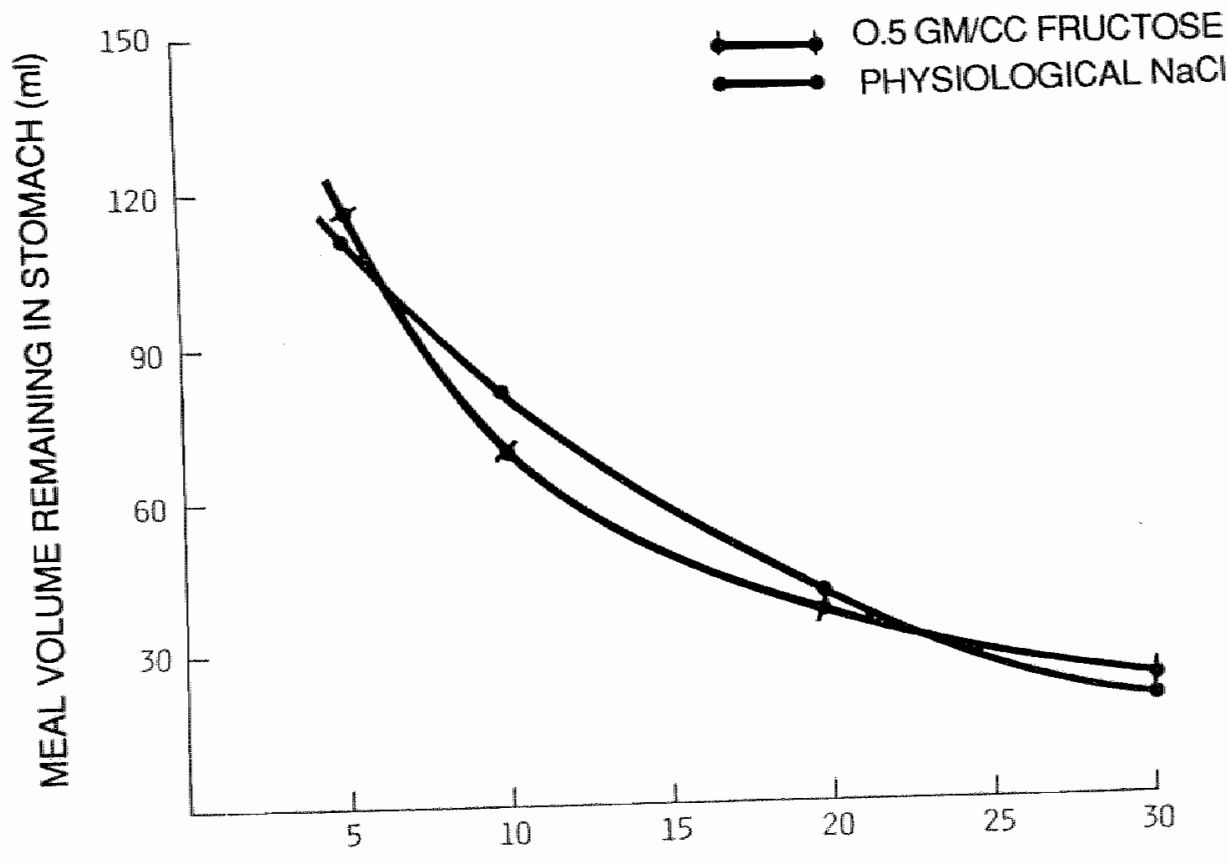

Fig. 6 Gastric emptying of $150 \mathrm{ml}$ meals, $0.05 \mathrm{~g} / \mathrm{ml}$ fruclose and $0.9 \% \mathrm{NaCl}$. Moran, T. and McHugh, P.R. (1981): Distinction among three sugars in their effects on gastric emptying and satiety. Am. J. Physiol. 241: R25-R30. 
Table 1 Gastric emptying rates on test meals

\begin{tabular}{|c|c|c|c|c|c|c|}
\hline Test meal & $\begin{array}{l}\text { Concn } \\
(\mathrm{g} / \mathrm{mil})\end{array}$ & $\mathrm{N}$ & mosm & $\mathrm{m} / \mathrm{min}$ & $\begin{array}{l}\text { Emptying rate } \\
\text { g/min }\end{array}$ & $\mathrm{kcal} / \mathrm{min}$ \\
\hline & 0.05 & 9 & 291 & $1.76 \pm 0.27$ & $0.088 \pm 0.01$ & $0.352 \pm 0.05$ \\
\hline \multirow[t]{3}{*}{ Glucose } & 0.125 & 16 & 722 & $0.754 \pm 0.06$ & $0.095 \pm 0.01$ & $0.377 \pm 0.03$ \\
\hline & 0.25 & 16 & 1.425 & $0.381 \pm 0.04$ & $0.095 \pm 0.01$ & $0.381 \pm 0.04$ \\
\hline & 0.05 & 20 & 293 & $3.52 \pm 0.42$ & $0.18 \quad \pm 0.02$ & $0.72 \pm 0.08$ \\
\hline \multirow[t]{2}{*}{ Fructose $e^{\star}$} & 0.125 & 24 & 721 & $1.36 \pm 0.14$ & $0.17 \pm 0.02$ & $0.68 \pm 0.08$ \\
\hline & 0.25 & 12 & 1.426 & $0.679 \pm 0.08$ & $0.17 \pm 0.02$ & $0.68 \pm 0.08$ \\
\hline $\mathrm{NaCl}^{*}$ & 0.009 & 20 & & 290 & $3.86 \pm 0.62$ & \\
\hline
\end{tabular}

N. No. of test meals from which the regression was derived, emptying rates although exponenvial are expressed as average over time.

Moran, T, and McHugh, P.R. (1981): Distinction among three sugars in their effects on gastric emptying and satiety. Am. J. Physiol. 241: R25-R30.

Table 2 Volume of $400 \mathrm{ml}$ meal emptied from the stomach in 5 min.

Meal constitution

Saline $0.9 \%$

Glucose 0.2

(290mosm/)

$\mathrm{kcal} / \mathrm{ml}$

$(290 \mathrm{mosm} / \mathrm{l})$

Subject 1

Subject 2
$259 \mathrm{ml}$

$150 \mathrm{ml}$
$69 \mathrm{ml}$

$80 \mathrm{ml}$

Brener et. (1983): Regulation of the gastric emptying of glucose. Gastroenterology 85: 76-82.

It has been suggested that in particular glucose loads quickly initiate the phased G.E. by closed-loop control (18). The delivery of glucose seems to be subject to a specific tight regulation and depends on the amount received by the duodenum directly. The resulting "steady state" of G.E. then is a balanced outcome of two reciprocally interdependent functions: gastric delivery and its post-pyloric inhibition by glucose. Di- saccharides (once present in the duodenum being hydrolyzed very rapidly) are approximately twice as effective per mole as mono-saccharides, assuming that the molar concentration at the moment of ingestion is the same (43). After $\mathrm{CHO}$ ingestion intraluminal 
enzymes are secreted in excessive amounts to hydrolyse starch $(7,37,47)$, or maltose or sucrose (56). The breakdown of carbohydrate is not the rate limiting step for glucose uptake (119), hydrolysis of $\mathrm{CHO}$ is usually more rapidly than absorption (124). Thus the inhibiting effects by receptor activation may be maintained to a larger extent by a relatively slow absorption which may differ depending on the CHO source. For example, the absorption of lactose is rate limiting (57) which may explain the complaints of diarrhea always present in cases of lactose intolerance or with high lactose intakes. Glucose is absorbed actively and fructose passively and there is no competitive inhibition between glucose and fructose in their absorption (63). Passive fructose absorption is believed to be slow. In the jejunum it is half as quick as glucose. (57). Andersson Nygren (6) performed a study in which 50 gramms of fructose was given orally either in $10 \%$ or $20 \%$ solutions. Ten out of 14 subjects showed incomplete absorption (71\%) with the $20 \%$ solution and 6 out of 10 with the $10 \%$ solution $(60 \%)$. Complaints during this period of malabsorption were gas, abdominal cramps, and diarrhea. When the dose was reduced to $37.5 \mathrm{gm}$ only 2 subjects out of 14 had malabsorption with the $20 \%$ solution and there was no malabsorption with the $10 \%$ solution. After ingestion of $25 \mathrm{gm}$ no problems were reported. There may thus be an upper limit of approximately $30 \mathrm{gm}$. Some studies indicate that glucose absorption from sucrose may be enhanced by the presence of fructose, a so called di-saccharide effect (118). This is further underlined by the fact that glucose and fructose ingested in the mono form raise plasma triglycerides significantly less than an equivalent amount of sucrose. With equimolar intake of starch and sucrose the blood glucose after starch feeding was the lowest (95). The speed of absorption may play a central role in exerting osmotic effects at the site of regulation. If absorption is inadequate osmotic diarrhea may follow. At the same time G.E. will be inhibited.

It may be concluded that carbohydrates exert their duodenal mediated effect on G.E by:

- the type of carbohydrate ingested

- the concentration

This effect may be mediated by."

- factors underlying hydrolysis

- factors underlying absorption

- enzymes

- kinetic differences

- active/passive processes

- competitive actions

- stimulating interactions

- water and electrolyte fluxes 


\subsection{Electrolyte interactions}

With increasing osmolalities, water and electrolytes are secreted into the G.l. lumen. Sodium, potassium, calcium and magnesium are found to be increased in gastric residues in such conditions $(36,105)$. Electrolytes are necessary for hydrolysis and absorption. The hydrolysis of sucrose is sodium dependent (26). The translocation of glucose by a bifunctionall carrier, with two binding sites, one for $\mathrm{Na}^{+}$and the other for glucologues (D-glucose of D-galactose), also requires sodium. A one-way or two-way interaction between water and sodium as being coupled to glucose absorption has been discussed. Glucose absorption stimulates water absorption and water movement across the mucosa stimulates passive absorption of $\mathrm{Na}^{+}$by solvent drag (50). SladenDawson (111) suggested that gllucose stimulates both water and sodium absorption by the jejunum and that water absorption from isotonic solutions is ordinarily coupled to that of total solute. Water follows passively in isosmotic proportions. Brown (20), on the other hand, suggested that glucose can stimulate water absorption directly without mediation of sodium and that glucose follows at a rate which maintains isotonicity. Fordtran (51) hypothesized that these two mechanisms may act at the same time:

1. Glucose stimulates active sodium transport, water follows

2. Glucose stimulates water transport, sodium follows

Summarizing this information it may be postulated that water movement, as coupled to glucose, may have an optimum at a certain concentration and will cease if glucose absorption ceases or if electrolyte fluxes are inadequate. This information may play a significant role in the discussion about optimal intake and absorption of water, water plus electrolytes, or water, electrolytes and $\mathrm{CHO}$, depending on the athletes immediate needs determined by the sport event and climatological circumstances. One factor seems to be of special interest here: active transport is dependent on the integrity of the sodiumpotassium pump. This pump requires energy (ATP) in order to work. Thus depriving cells of energy (i.e. anoxia, energy depletion) or inhibition of the sodium-potasslum pump will inhibit glucose transport (26). If transport ceases then G.E. may be inhibited and osmotic diarrhea may follow. The question thus arises whether or not oxygen and energy available to the epithelial gut cell is adequate during higher exercise intensities and different levels of dehydration.

\subsection{Calorlc or energy density}

Another proposed and some what "confusing" mechanism for the regulation of gastric emptying is the caloric density of the food leaving the stomach (91). Starch and glucose in isocaloric solutions leave the stomach at the same rate $(68,72)$, although the osmolalities of the solution are different. A progressive slowing of G.E. correlated with increasing calories is found. This was not influenced by the fat, $\mathrm{CHO}$, or protein content, or by the initial volume of the 
meal ingested. Moore (88) showed that G.E. of mixed solid and liquid meals differ " dependent upon the weight and caloric content. Meals with larger weight and caloric content had slower emptying rates for both solids and liquids. Isocaloric casein, mct-oil, and glucose empty at the same rate, independent of the changes in osmolality at onset of ingestion (91). Regulation is thought to be direct via the closed loop feed-back system from the duodenum

Fig. 7

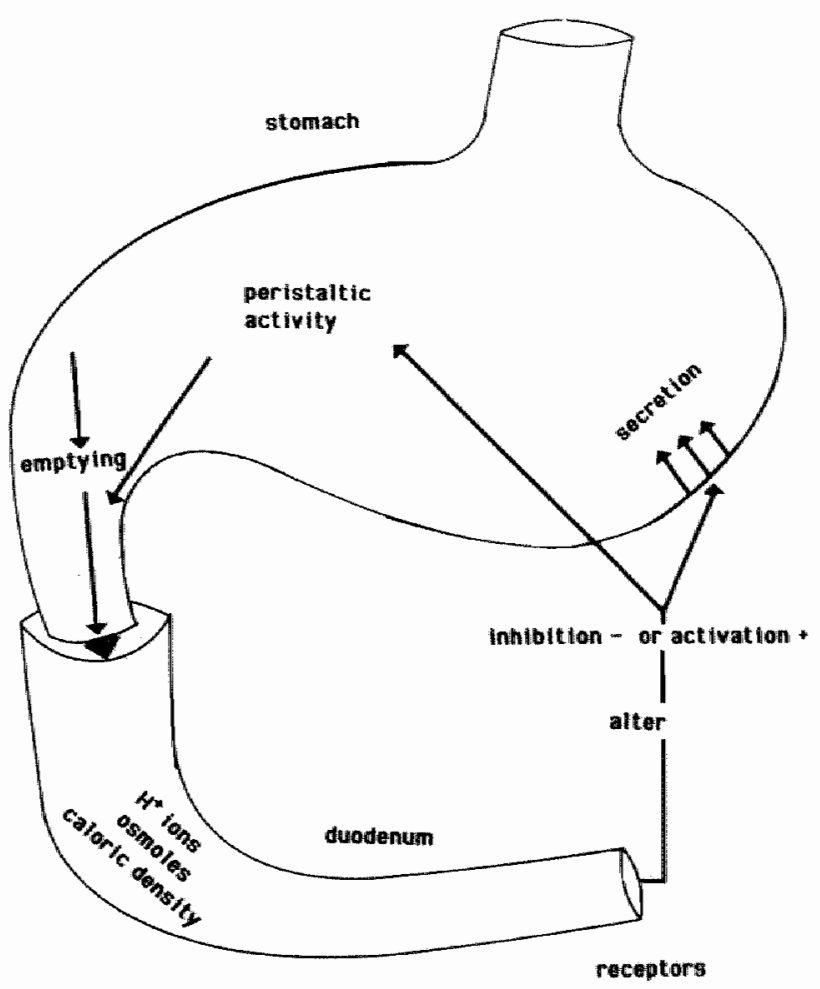

If meals composed of solids and liquids are homogenized then the rates of emptying are similar (61). There are, however, indications that caloric control may be different for pure solids and liquids. Solids may be primarily under caloric and particle size (84) control and liquids primarily under combination of other factors such as acidity, osmolality and single nutrient composition. Bernier (11) found that $t 1 / 2$ for $G$.E. of liquids is around $40-50 \mathrm{~min}$ after ingestion, although the caloric content varied from 0-550 calories. On the other hand isotonic $\mathrm{NaCl}$ drinks had a $\mathrm{t} 1 / 2$ of $14 \mathrm{~min}$ compared to milk (also about isotonic) with a $11 / 2$ of $62 \mathrm{~min}$. 


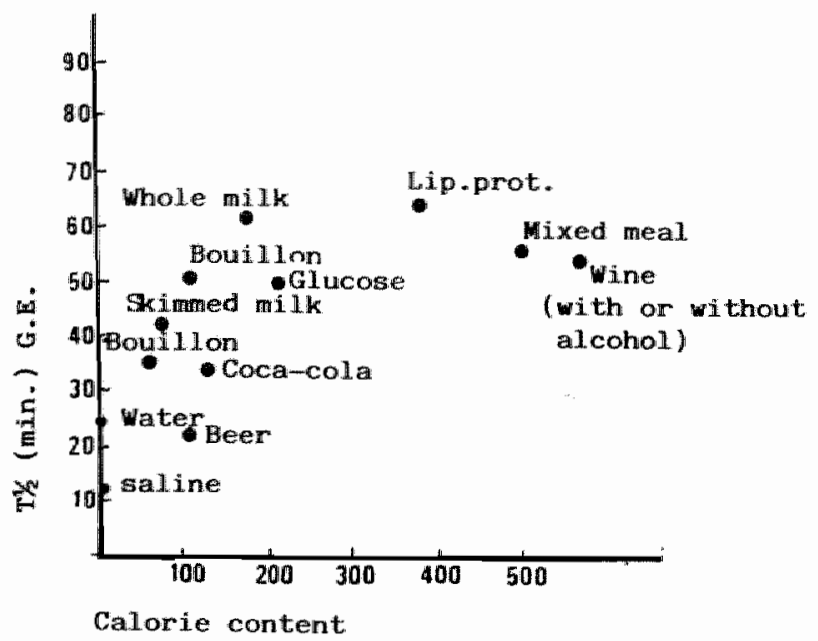

Fig. 8 (adapted from Bernier, 1985)

Moran (89) showed in Rhesus monkeys that glucose and D-xylose empty linearly and more slowly with increasing concentration. Delivery to the duodenum is constant at $0.1 \mathrm{~g} / \mathrm{min}$ or $0.4 \mathrm{Kcal} / \mathrm{min}$, regardless of concentrations, osmolality, or volume of the intragastric meal. Fructose, however, emptied exponentially and more rapidly than the other sugars: $0.2 \mathrm{~g} / \mathrm{min}$ or $0.8 \mathrm{Kcal} / \mathrm{min}$. Brener (18) compared the effect of saline solutions and glucose solutions on G.E. Even the most dilute glucose solution ( 0.2 $\mathrm{Kcal} / \mathrm{ml}$ ), comparable to the osmolality of saline, only emptied $63 \%$ of $400 \mathrm{ml}$ in 20 minutes, compared to $84 \%$ of saline (glucose receptor or energy density control?). However, when the same quantity of glucose calories (with widely different osmolarities) was introduced into the duodenum, then the inhibition times of G.E. was similar. The number of glucose calories passed per unit time remained the same over a five fold concentration range $(2.13 \mathrm{Kcal} / \mathrm{min})$. These findings are in line with McHugh (92) and Moore (88) who found $4.6 \mathrm{Kcal} / \mathrm{min}$ passed for large meals in humans. The quantitative figures are different, possibly because of differences in the meal consistency (i.e. liquid, half solid, solid) and differences in species. From the discussions about osmotic- and energy density control one may raise the question about the effectiveness of the duodenum to reduce the activating signals to absorb nutrients quickly. The faster the absorption is the less the influence will be of nutrients that induce osmolality or energy density stimuli. One might also discuss the validity of an energy density concept, since increasing energy density also means an increased content of nutrients that will exert an inhibiting effect on the receptors located in the duodenum. From this it may be hypothesized that the energy density effects found are mainly the result of a cumulative effect of 
different specific nutrient receptor activities.

\section{THE EFFECTS OF EXERCISE ON GASTRO-INTESTINAI REGULATION}

\subsection{Oxygen and energy availability in the G.I. tract}

Tissues which may undergo large changes in activity and energy expenditure are for their energy supply to a large degree dependent upon blood flow, substrate and oxygen availability. It is hypothesized that under local hypoxic circumstances energy liberation in the G.I. mucosa cells may be impaired.

\subsection{Blood flow}

Exercise causes a quantitative redistribution of tissue blood flow. The working tissues (skeletal muscles) undergo a vasodilatation to increase their blood flow, while the G.I. tract undergoes a vasoconstriction. As a result, splanchnic and gastric blood flow will be diminished $(16,53,76,121)$. Clausen (29) reported that during maximal exercise in both trained and untrained people, bloodflow to the gut is reduced as much a $80 \%$. Rowell $(100)$ found that splanchnic blood flow during workloads of $70 \% \mathrm{VO}^{2}$ max is only $30-40 \%$ of the resting value. However, at submaximal loads splanchnic blood flow in the trained is better than in the untrained, which may be explained by metabolic adaptation of the body in such a way the same sub-maximal exercise induces less stress. This also becomes evident from the lower heart rate during submaximal exercise after a period of training. Studies on $\mathrm{CHO}$ absorption in dogs showed that absorption was diminished when blood flow decreased $(120,123)$. If this happens, G.E. will be inhibited due to malabsorption and subsequent increase of osmotic pressure in the duodenum. From these findings it may be hypothesized that the problems of diarrhea present after carbohydrate intake during high intensity work may be related to malabsorption. The cause of diahrrea during long distance running, independent of prior food and/or fluid intake, may be a change of the epithelial tissue in the gut due to necrosis caused by hypoxia. Anoxia or hypoxila may lead to lesions of the inner surface of the gut. These lesions may also explain the occurrence of blood or metabolites from blood in the feces of long distance runners. Schaub (108) described a case of a 33 year old marathon runner with complaints of nausea, urge to defecate, and diarrhea (sometimes bloody) during high intensity training sessions or competitions. Colonoscopic inspection showed epithelial surface changes such as are known to occur during gut ischemia. These lesions were predominantly present in the caecum and colon. Because bleeding, pain, and diahrrea are the normal symptoms in a situation of gut ischemia, it was concluded that hypoxia of the lower G.I. sections may induce the problems. 


\subsection{Exercise and hormonal influences}

An important factor in the regulation of gut tissue activity and metabolism at rest is hormonal control. Hormonal regulation at rest is strongly influenced by the activity of the sympathetic and parasympathetic nervous

system. A summary of hormonal influences in the G.I. tract in normal resting conditions is presented in table 3.

\section{Table 3 Functional effects of gastrointestinal hormones.}

\begin{tabular}{|c|c|c|c|c|c|c|}
\hline & \multicolumn{2}{|r|}{ Secretion } & \multicolumn{4}{|c|}{ motillity } \\
\hline & $\mathrm{H}^{+}$ & $\mathrm{HCO}_{3}$ & $\begin{array}{l}\text { pancreas } \\
\text { enzymes }\end{array}$ & stomach & $\begin{array}{l}\text { small } \\
\text { bowell }\end{array}$ & $\begin{array}{l}\text { gall } \\
\text { bladder }\end{array}$ \\
\hline gastrin & $\|$ & {$[1]$} & {$[\uparrow]$} & $t$ & 4 & {$[\uparrow]$} \\
\hline $\mathrm{CCK}-\mathrm{Pz}$ & {$[1]$} & {$[\uparrow]$} & $\uparrow$ & $\downarrow$ & $\uparrow$ & $\uparrow$ \\
\hline secretin & 1 & 1 & 0 & $\downarrow$ & $\downarrow$ & 0 \\
\hline G.I.P. & 1 & 0 & 0 & $\downarrow$ & 0 & 0 \\
\hline V.I.P. & $i$ & 1 & $\downarrow$ & 0 & 0 & $?$ \\
\hline motilin & 0 & 0 & 0 & 1 & 1 & 0 \\
\hline glucagon| & $\downarrow$ & $\downarrow$ & $\downarrow$ & 1 & $t$ & $\downarrow$ \\
\hline \multicolumn{7}{|c|}{ [ 1] slight increase } \\
\hline \multicolumn{7}{|c|}{$\uparrow$ increase } \\
\hline \multicolumn{7}{|c|}{ [ | ] slight decrease } \\
\hline \multicolumn{7}{|c|}{ decrease } \\
\hline
\end{tabular}

Adapted from :Ernährungsmedizin und Diătetik, H. Kasper. Urban and Schwarzenberg, 1980.

However, the influence of quantitative changes of G.I. hormones during exercise is poorly understood. Sympatho-adrenal activity changes during long lasting exercise. Enhanced concentrations of catecholamines have beem found during dynamic exercise. Higher workloads, induce larger increases (exponential). The concentration of norepinephrine in plasma varies inversely with the oxygen saturation of mixed venous blood. Hyperthermia and hypoglycemia are related to enhanced cate-cholamine concentrations. All these factors play a role during long lasting exercise in the untrained, as well as in the trained individual during maximal exercise. (For a complete review see the extensive work of Galbo, 54). Catecholamines, by their classical actions, would delay G.E. and prolong transit time $(73,99)$. However, this is not in line with the increased G.E. of solid meals during prolonged exercise of 
moderate intensity in untrained man (22). It can be hypothesized, however, that this inhibiting influence of increased catecholamines may be countereffected by an enhanced influence of other hormones such as the gastroentero-pancreatic hormones. Feldman (45) found that serum gastrin levels after a steak meal were significantly enhanced by exercise. He suggested that this might be explained by the exercise induced catecholamine release "since these are capable of increasing serum gastrin levels in humans (28). This gastrin increase was also confirmed by other studies $(17,96)$. However, in Feldman's (45) study the increased gastrin levels did not influence secretion. Perhaps this was counter effected by a release of substances that inhibit gastric acid secretion such as somatostatin and vaso intestinal peptide $(60,117)$. Plasma motilin levels also increase during long lasting exercise and this may account for the regular bowel function and enhanced gut transit of food which is assumed to be the result of light endurance exercise $(116,117)$. The motilin levels raise to a level which is normally seen after ingestion of a mixed meal and which that stimulates gastric emptying, and gut motility (117). The reason why these increases occur during exercise remains unknown. It has been hypothesized however, that the decreased splanchnic bloodflow during exercise might lead to a decreased hepatic and renal clearance of the peptides with a resulting plasma level increase.

The effect of hormones on G.l. function during exercise remains obscure.

\subsection{Endorphins}

Endogenous opiate-like agents may influence G.I function. As a result of endurance exercise endorphins are released into the peripheral blood $(3,58)$. They may interact with opiate receptors present in the gut (97) to influence gastro-intestinal motility. In general however, opiates tend to delay gastric emptying (27), so that the conclusion that endorphins will influence G.I. motility remains very speculative.

\section{EXERCISE RELATED STUDIES}

Most studies on exercise and G.I. function have been done with liquids. Only a few studies deal with solid or homogenized food. An overview of these studies is presented in table 9. Fordtran-Saltin (49) studied four men and one woman during one hour of treadmill running at an exercise intensity of $70 \% \mathrm{VO}_{2}$ max. They found no effect on G.E. af a $13.3 \%$ glucose, $0.3 \%$ sodium chloride solution, and a slight inhibition when pure water was ingested. Intestinal absorption of water in both jejunum and lleum was studied with poly-ethylene glycol (a non absorbable marker) which was supplied together with the test liquid by constant infusion. There was no difference in absorption of water, glucose, and electrolytes, compared to the resting situation. The luminal 
content of these substances was measured at the beginning and at the end of the gut test segment by triple iumen catheter. Costill (32) performed a two hour treadmill test at the same intensity $\left(70 \% \mathrm{VO}_{2}\right.$ max) with four highly trained marathon runners. Total fluid ingestion was $2000 \mathrm{ml}$, consisting of either a glucose-electrolyte solution (glucose $4.37 \mathrm{~g} / \mathrm{dl}$, potassium $96 \mathrm{mg} /$, sodium 460 $\mathrm{mg} / \mathrm{l}$, chloride $536 \mathrm{mg} / \mathrm{l}$ ) or water. No post-exercise gastric residue differences were found. Feldman (45) studied G.E. of a blenderized steak meal in untrained persons after 45 min of exercise at either 50 or $70 \%$ of their maximal workload G.E. after a period of two hours (including the exercise trial) was $87 \%$, compared to $88 \%$ for the control group (no exercise). Assuming that the rise in serum triglyceride concentration after a fat containing meal is a reflection of lipid absorption, he concluded that fat absorption was unimpaired. Cammack (22) studied G.E. and gut transit time of solid meals labelled with technetium. G.E. was measured at $10 \mathrm{~min}$ intervals by determining gastric radio-activity. Gut transit of the "head" of the meal was defined as the time that passed between ingestion of the meal and the first consistent increase in breathing hydrogen concentration (caused by $\mathrm{CHO}$ fermentation in the gut). Exercise (cycling) significantly accelerated G.E. but had no effect on transit time. Exercise intensity however was low: (heart frequency $117 / \mathrm{min}$, pedaling rate $33 / \mathrm{min}$ ). In terms of $\mathrm{VO}_{2}$ max this is equivalent to approximately $30 \% \mathrm{VO}_{2}$ max. G.E. time (t1/2) of the control group was $1.5 \pm 0.1$ hours, for the exercise group $1.2 \pm 0.1$ hours. Possibilities for the reduction in of G.E. proposed were:

1. relative dominance in parasympathetic tone

2. increase in endogenous opiates

3. decreased gastric acid secretion (23)

Points 2 and 3 are questionable, since endorphins may inhibit G.E. as discussed earlier, and gastric acid secretion was found to be unchanged in a more recent study (49).

Very recently the effect of a 6 weeks running programme ( 3 times $30 \mathrm{~min}$ at 70 $80 \% \mathrm{VO}_{2}$ max/week) on bowel transit time was determined (30). The authors found a $22.8 \%$ reduction in transit time but could not define the causative mechanism. It was hypothesized that an exercise-induced increase in sympathetic nervous system activity may cause a relaxation of the G.I. tract which may facilitate the passage of contents from colon to rectum, in particular during running exercise which has an additional mechanical effect due to up and down motion. From the studies available it may be concluded that exercise intensities up to $70 \% \mathrm{VO}_{2}$ max do not influence G.E. or absorption in the gut and that G.E. and bowel transit may be enhanced, compared to testing conditions. The fact that some studies show contradictory results may be due to differences in training status, pre-exercise feeding status or order of serial testing (section 3.1.2). 


\section{CONCLUSIONS AND SUMMARY}

If the studies cited are analyzed critically one may conclude that the experimental situation (exercise intensity and duration), and degree of dehydration and hyperthermia, never reflected the situation in sports practice in which G.I. disturbances and complaints occur most frequently (see introduction). In Fordtran's study the exercise time was only 1 hour, so that the combination of dehydration, hyperthermia and high intensity exercise which is expected to cause G.I. problems, was not present. In Costill's study, however, this combination was present, but energy density ( $\mathrm{CHO}$ content) and hence the possible inhibition of G.E. by duodenum, was minimal. In Feldman's study (45) exercise duration was only 45 minutes. In the study of Cammack (22) the subjects performed a 3 hour cycling test as part of the total test trial which lasted 6 hours. However, exercise intensity was very low as discussed before. Thus, the available research does not answer the question: to what extent will absorption of a single nutrient such as $\mathrm{CHO}$ be changed in a situation of dehydration, hyperthermia and minimal G.I. bloodflow, as has been demonstrated in dogs $(120,123)$ ? If we summarize the sections described here we may conclude that G.I. complaints occur in relation to long lasting, exhaustive exercise.

Further, that complaints seem to be present to a larger extent during running than during the more "gliding" sports such as cycling, swimming and cross country skiing. From the available data we have the impression that symptoms such as regurgitation, gastric acid reflux and vomiting may be related to the composition of the gastric content together with changes in motility. However symptoms such as diahrrea or the occurrence of blood in the feces may be related to functional and morphological changes in the gut tissue primarily. To what extent mechanical factors (type of exercise) play an important role has to be elucidated. Much data is available on G.I. function at rest, however, G.I. functioning during long lasting, high intensity exercise has only been studied incidentally. The influence of exercise induced hormonal changes, especially of the G.I. hormones, cannot be explained at the moment. 


\section{Suggestions for sports practice}

- Solid food should be avoided during the last 3 hours prior to exercise.

- Liquid foods can be taken as pre-competition meal and also during exercise, however, fat and protein should not be included.

- Whenever fluid intake is of first priority, drinks should be low in CHO.

- When maximal intake rates of both $\mathrm{CHO}$ and water is desired the optimal concentration should be in the range of isotonicity.

- When CHO intake is the first priority drinks may be concentrated and hypertonic. A combination of glucose polymers with fructose may be advantagous.

- Athletes suffering frequently from diahrrea or the urge to defecate may benefit from complete nutritional liquids (low in fiber content) during the last day preceding the competition, so that gastro-intestinal contents will be minimized.

- Drinking during exercise should be part of the training programme.

Preparation of this article was possible by grants of Wander Ltd., Bern, Switzerland. We kindly thank prof.dr. F. ten Hoor and prof.dr. P. Webb for their critical reading and suggestions

\section{Table 4 Observed effects of gastric content on gastric emptying}

\begin{tabular}{|c|c|c|}
\hline Variable: & $\begin{array}{l}\text { G.E. rate } \\
\text { Increase | } \\
\text { Decrease | }\end{array}$ & Author \\
\hline Liquidity & & $\begin{array}{l}\text { Holt 1982, Bernier } 1985 \\
\text { Fink 1983, Meyer } 1980\end{array}$ \\
\hline Particle size & 1 & Holt 1982, Meyer 1980 \\
\hline Temperature & 1 & $\begin{array}{l}\text { Gershon-Cohen } 1940 \text {, } \\
\text { Costill } 1974\end{array}$ \\
\hline Volume & 1 & $\begin{array}{l}\text { Hunt } 1951,1968 \\
\text { Costill } 1974\end{array}$ \\
\hline Weight [bulk] (solids) & $\downarrow$ & Moore 1981 \\
\hline
\end{tabular}


Table 5 Possible effects of duodenal content on gastric emptying

\begin{tabular}{|c|c|c|c|}
\hline Variable: & & $\begin{array}{l}\text { G.E. rate } \\
\text { Increase } \uparrow \\
\text { Decrease }\end{array}$ & Author \\
\hline Osmolality & $\begin{array}{l}1 \\
1\end{array}$ & $t$ & $\begin{array}{l}\text { Barker 1974, Simko } 1976 \\
\text { Meerof 1975, Cooke } 1977 \\
\text { Brown 1981, Ruppin } 1981\end{array}$ \\
\hline Glucose content & $\downarrow$ & $\begin{array}{l}1 \\
1\end{array}$ & $\begin{array}{l}\text { Hunt-Pathak } 1960 \text {, Hunt } 1961 \\
\text { Fordtran } 1967 \text {, Elias } 1968 \\
\text { Coyle } 1978 \text {, Brener } 1983\end{array}$ \\
\hline $\begin{array}{l}\text { Amino acid } \\
\text { content }\end{array}$ & $\uparrow$ & $\downarrow$ & Barker 1974 \\
\hline $\begin{array}{l}\text { Fatty acid } \\
\text { content }\end{array}$ & $\uparrow$ & $t$ & Cooke 1977, Bermier 1985 \\
\hline Acidity & $\uparrow$ & $\downarrow$ & Shapiro 1950, Bernier 1985 \\
\hline Caloric density & $\uparrow$ & 1 & $\begin{array}{l}\text { Hunt } 1960 \text {, Hunt-Stubs } 1975 \text {, } \\
\text { McHugh-Moran } 1979, \\
\text { Moore } 1981 \text {, Brener } 1983\end{array}$ \\
\hline Sodium content & 1 & $\uparrow$ & Hunt 1960, Barker 1970 \\
\hline Potassium content & 1 & $\downarrow$ & \\
\hline
\end{tabular}


Table 6 Possible effects of duodenal processes on gastric emptying

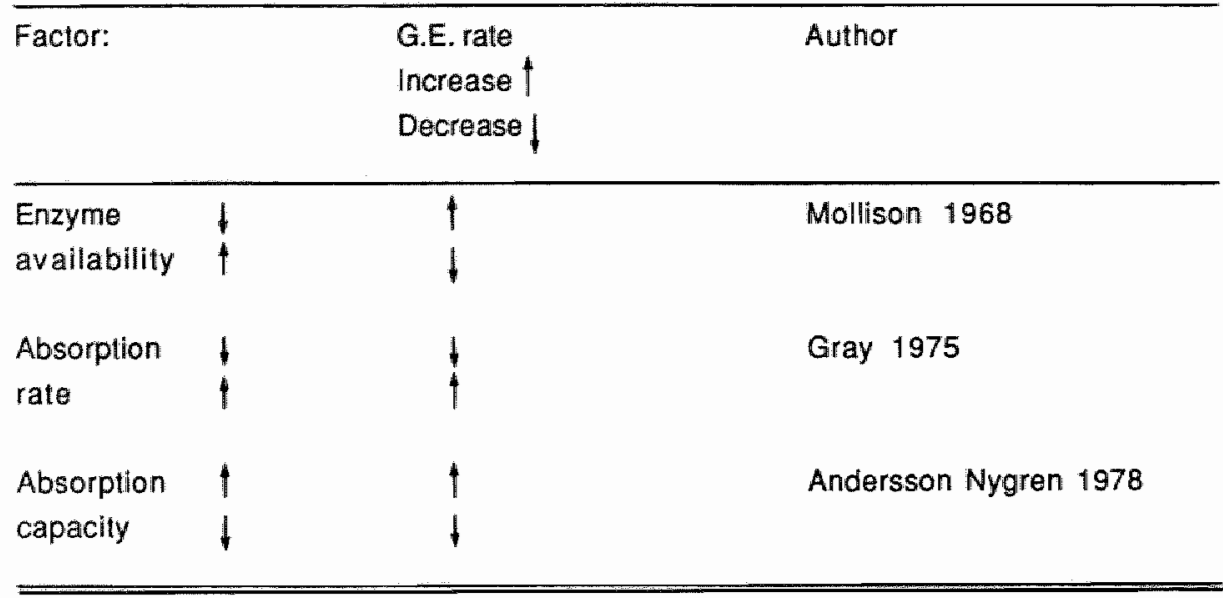

Table 7 Possible factors influencing duodenal absorption

\begin{tabular}{lll}
\hline Factor & $\begin{array}{l}\text { Absorption } \\
\text { Increase } \uparrow \\
\text { Decrease }\end{array}$ & Author \\
&
\end{tabular}

Sodium

$\uparrow$ (carbohydrate) Hirschhorn 1980

Glucose

$\uparrow$ (water)

$\uparrow$ (sodium)

Splanchnic bloodflow

Sodium pump

inhibition $\downarrow$ (glucose) 
Table 8 Some hormonal factors influencing gastric emptying

\begin{tabular}{llll}
\hline Hormone: & $\begin{array}{c}\text { G.E. rate } \\
\text { Increase } \uparrow \\
\text { Decrease } \downarrow\end{array}$ & Author \\
\hline Catecholamines & $\uparrow$ & + & Jenkinson 1967, Rees 1980 \\
Gastrin & $\uparrow$ & $\uparrow$ & Feldman 1982 \\
Motilin & $\uparrow$ & $\uparrow$ & Sullivan 1984 \\
Endorphins & $\uparrow$ & $\downarrow ?$ & Chapman 1950
\end{tabular}

Table 9 Effect of exercise on gastric emptying

\begin{tabular}{ll}
\hline Liquids & Gastric Emptying \\
During & Method
\end{tabular}

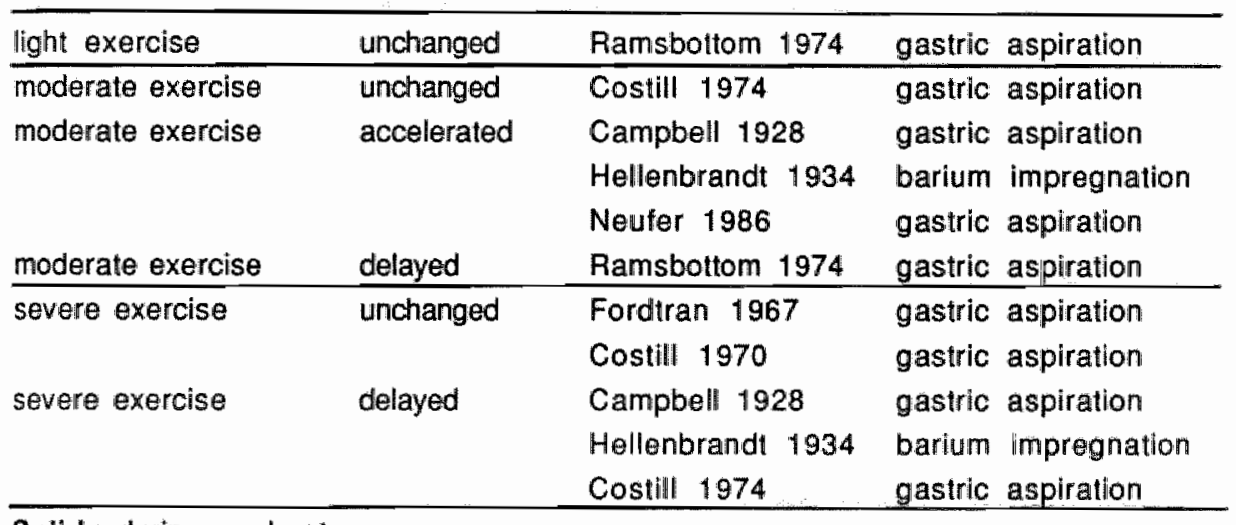

Solids during moderate

exercise enchanged Cammack 1982 labelling/breath

"halfsolids" during

moderate and severe

exercise

unchanged Felldman 1982

serum T.G.

measurements 


\section{REFERENCES}

1. Abidi, S.A.

Leucine absorption rate and net movements of sodium and water in human jejunum.

J. Appl. Physiol 28: 753-757, 1970.

2. Al Janabi, M.N.

The relationship between motor activity in the small intestine and the gastrointestinal transit of food, thesis.

University of Sheffield, 1981 .

3. Allen, $M$.

Activity generated endorphins:" a review of their role in sports science.

Can. J. Appl. Spt. Sci. 8: 115-133, 1983.

4. Alyea, E.P., H.H. Parrish

Renal response to exercise: urinary findings.

Jama 167: 807-813,. (1958)

5. Altamirano, M. and C. Marinoya.

The premeability of the gastric mucosa of dog.

J. Physiol 187: 77, 1966.

6. Andersson, D.E.H., A. Nygren

Four cases of longstanding diarthea and colic pains cured by fructose free diet - A pathogenetic discussion.

Acta Med. Scand. 203: 87-92, 1978.

7. Auricchio, S.P. and A. Vegnente.

Studies on intestinal digestion of starch in man. II. Intestinal hydrolyses of amylopectin in infants and children.

Pediatrics 39: 853-862, 1967.

8. Barker, G.R., G.M. Chochran, G.A. Corbet, et al.

Glucose, glycine and diglycine in testmeals as stimuli to a duodenal osmoreceptor slowing gastric emplying.

J. Physiol. 283: 341-346, 1978.

9. Barker, G.A., G.M. Cochrane, G.A. Corbett et al Actions of glucose and potassium chloride on osmoreceptors slowing gastric emptying.

J. Physiol. 237: 183-186, 1974.

10. Bergström, J., E. Hultman

A study of the glycogen metabolism during exercise in man.

Scan. J. Clin. Lab. Invest. 19: 218-228, 1967.

11. Bernier, J.J.

L'etall postprandial "vidange gastrique et role du duodenum.

Cah. Nutr. Diet 20 (1): 13-17, 1985 . 
12. Billich, C.O., R. Levitan

Effects of sodium concentration and osmolarity on water and electrolyte absorption from the intact human colon.

J. Clin. Invest. 48: 1336-1347, 1969.

13. Blacklock, N.J.

Bladder trauma in the long distance runner; 10.000 meters hematuria.

Br. J. Urol. 49: 129-132, 1977.

14. Blom, P.C.S., N.K. Vollestad, L. Hermansen

Diet and recovery process.

Med. Sport Sci. 17 (1984): 148-160, 1980.

15 Borgström, B. and A. Dahlquist.

Studies on intestinal digestion and absorption in the human.

J. Clin. Invest. 36: 1521-1536, 1957.

16. Bradley, S.E.

Variations in hepatic bloodflow in man during health ad disease.

N. Engl. J. Med. 240: 456-461, 1949.

17. Brandsborg, O., N.J. Christensen, H. Galbo et al

The effect of exercise, smoking and propanololl on serum gastrin in patients with duodenaluicer and in vagotomized subjects.

Scand. J. Clin. Lab. Invest. 38: 441-446, 1978.

18. Brener, W., F. Hendrix, P.R. McHugh

Regulation of gastric empyting of glucose.

Gastro-enterology 85: 76-82, 1983.

19. Brouns, F, W. Saris and F. ten Hoor.

Dietary problems in the case of strenuous exertion. Part I. A literature review.

Part II. The top athlete's menu nutrient dense enough?

J. Sports Med. 26: 306-319, 1986.

20. Brown, R.D., H.V. Ammon

Effect of glucose on jejunal water and solute absorption in the presence of

glycodeoxycholate and oleate in man.

Digestive diseases and sciences 26: 710-717, (1981).

21. Burry, K.O.

Chemically defined diets.

In: Gastro-intestinal tract vol. II: 429. Warren-Leeds, eds, 1975.

22. Cammack, J., N.W. Read, P.A. Cann

Effect of prolonged exercise on the passage of a solid meal through the stomach and small intestine.

Gut 23: 957-961, 1982. 
23. Campbell, J.H., M.B. Mitchel, A.T.W. Powell

The influence of exercise on digestion.

Guy's Hosp. Rep. 78: 279-293, 1928.

24. Cantwell, J.D.

Gastro-intestinal disorders in runners.

Jama 281: 1404-1405, 1981.

25. Case, G.L, R.W. Philips, L.D. Lewis et al

Effects of osmolarity of liquid nutrient dieis on plasma equilibration of water and carbohydrate in yucatan minialure swine.

Am. J. Clin. Nutr. 34: 1861-1867, 1981

26. Caspary, W.F.

Intestinal glucose and sodium transport and its relation to hypertension.

Int. J. of Obesity 5: 34-43, 1981.

27. Chapman, W.P., E.N. Rowlands, C.M. Jones

Multiple balloon kymographic recording of the comparative action of demerol, morphine and placebos on the motility of the upper small intestine in man.

N. Engl. J. Med. 243: 171-177, 1950.

28. Christensen, K., F. Stadil

Effect of epinefrine and norepinefrine on gastric release and gastric secretion of acid in man.

Scand. J. Gastro-enterol. 37: 441-446, 1976.

29. Clausen, J.P.

Effect of physical training on cardiovascular adjustments to exercise in man.

Physiol. Rev. 57: 779-815, 1977.

30. Cordain, L., R.W. Latin and J.J. Behnke.

The effects of an aerobic running programme on bowel transit time.

J. Sports Med. 26:101-104, 1986.

31. Cooke, A.R.

Localization of receptors inhibiting gastric emptying in the gut.

Gastro-enterology 72: 875, 1977.

32. Costill, D.L., W.F. Kammer, A. Fisher

Fluid ingestion during distance running.

Arch. Environ. Health 21: 520-525, 1970.

33. Costill, D.L., B. Sallin

Factors limiting gastric emptying during rest and exercise.

J. Appl. Physiol. 37: 679-683, (1974).

34. Costill, D.L.o E. Coyle, G. Dalsky et al.

Effects of elevated plasma FFA and insulin on muscle glycogen usage during exercise.

J. Appl. Physiol/ 43: 695-699, 1977. 
35. Costill, D.L., J.M. Miller

Nutrition for endurance sport: carbohydrate and fluid balance.

Int. J. Sports Med. 1: 2-4.

36. Coyle, E.F., D.L. Costill, W. Fink

Gastric emptying rates of selected athletic drinks.

Res. Quart. Vol. 49 2: 119-124, 1976.

37. Dahlquist, A. and B. Borgström.

Digestion and absorption of disaccharides in man.

Biochem. J. 81: 411-418, 1961.

38. Davenport, H.W.

Physiology of the digestive tract, ed 2.

Chicago Year Book Medical Publ. 1969.

39. Dancaster, C.P., W.C. Duckworth, C.J. Roper

Nephropathy in marathon runners.

South African Med. J. 43: 758-760, 1969.

40. Dozois, R.R., K.A. Kelly, C.F. Code

Gastro-enterology 61: 675, 1971.

41. Dressendorfer, R.H., J.H. Scaff, J.O. Wagner et all

Metabolic adjustments to marathon running in coronary patients.

Annals New York Acad. Sci. vol. 301: 466-483, 1977.

42. Ehrlein, H.J., J. Prove, W. Schweiker

In: Christensen ed.

Gastro-intestinal motility p. 177, Raven Press, New York, 1980.

43. Elias, E., G.J. Gibson, L.F. Greenwood et al

The slowing of gastric emptying by monosaccharides and disaccharides in test meals.

Physiol. 19.4: 317-326, 1968.

44. Evans, W.J. and V.A. Hughes.

Dietary carbohydrates and endurance exercise.

Am. J. Clin. Nutr. 41:1146-1154, 1985.

45. Feldman, M., J.R. Nixon

Effect of exercise on postprandial gastric secretion and emptying in humans.

J. Appl. Physiol. 53: 851-854, 1982.

46. Fink, W.J., D.L. Costill, C.F. Stevens

Gastric-emptying characteristics of complete nutritional liquids in nutrient utilization diuring exercise.

Ross. Lab. Ohio (ed.), 1983.

47. Fogel, M.R. and G.M. Gray.

Starch hydrolysis in man: an intraluminal process not requiring membrane digestion.

J. Appl. Physiol. 35: 263-267, 1973. 
48. Fogoros, R.N.

Gastro-intestinal disturbances in runners. "Runners trots".

ama 243: 1743-1744, 1980 .

49. Fordtran, J.S., B. Saltin

Gastric emplying and intestinal absorption during prolonged severe exercise.

J. Appl. Physiol. 23: 331-335, 1967.

50. Fordtran, J.S., F.C. Rector and N.W. Carter.

The mechanisms of sodium absorption in the human small intestine.

J. Clin. Invest. 47: 884-900, 1968.

51. Fordlran, J.S.

Stimulation of active and passive sodium absorption by sugars in the human jejunum.

J. Clin. Invest. 55: 728-737, 1975.

52. Foster, C., D.L. Costill and W.J. Fink.

Gastric emptying characteristics of glucose polymer solutions.

Ries. Q. 51: 299-305, 1980.

53. Fronek, $\mathrm{K}$.

Combined effect of exercise and digestion on hemodynamics in conscious dogs.

Am. J. Physiol. 218: 555-559, 1970.

54. Galbo, $H$ (ed).

Hormonal and metabolic adaptation to exercise.

Gastro-entero-pancreatic hormones pp. 59-61.

Thieme, New York, 1983.

55. Gershon-Cohen, J., H. Shay, S. Fels

The relation of meal temperature to gastric motility and secretion.

Am. J. Roentgenol. Radium Therapy Nucl. Med. 43: 237-242, 1940.

56. Gray, G.M. and F.J. Ingelfinger.

Intestinal absorption of sucrose in man. Interrelation of hydrolyses and monosaccharide product.

J. Clin. Invest. 45: 388, 1966.

57. Gray, G.M.

Carbohydrate digestion and absorption. Role of the small intestine.

New. Eng. J. Med. 292: 1225, 1975.

58. Harber, V.J., J.R. Sutton

Endorphins and exercise.

Sportsmedicine 1: 154-174, 1984.

59. Hellenbrandt, F.A., R.H. Tepper

Studies on the influence of exercise on the digestive work of the stomach. II Its effect on emptying time.

Am. J. Physiol. 107: 355-363, 1934. 
60. Hilsted, J., H. Galbo, B. Sonne et al Gastro-entero-pancreatic hormonal changes during exercise.

Am. J. Physiol. 239: 136-140, 1980.

Am. J. Clin. Nutr. 34: 1861-1867, 1981.

61. Hinder, R.A., K.A. Kelly

Camine gastric emptying of solids and liquids.

Am. J. Physiol. 233: E 335-40, 1977.

62. Hirschhorn, $N$.

The treatment of acute diarrhea in children. An historical and physiological perspective.

Am. J. Clin. Nutr. 33: 637-663, 1980.

63. Holdsworth, C.D. and A.M. Dawson.

The absorption of monosaccharides in man.

Clin. Sci. 27: 371-379, 1964.

64. Holt, S., J. Reid, T.V. Taylor et al

Gastric emptying of solids in man.

Gut 23: 292-296, 1982.

65. Hultman, E. and J. Bergström.

Muscle glycogen synthesis in relation to diet studies in normal subjects.

Acta. Med. Scand. 182: 109-117, 1967.

66. Hultman, E., L.H. Nilsson

Liver glycogen in man, effect of different diets and muscular exercise.

In: Muscle metabolism during exercise. B. Pernow and B. Saltin (eds.)

New York, Plenum (1971), 143-152, 1971.

67. Hunt, J.N., W.R. Spurrel

The pattern of emptying of the human stomach.

J. Physiol. London 113:" 157-168, 1951.

68. Hunt, J.N., J.O. Pathak

The osmotic effects of some simple molecules and ions on gastric emptying.

J. Physiol. 154: 254-269, 1960.

69. Hunt, J.N.

The site of receptors slowing gastric emptying in response to starch in test meals.

J. Physial. 154: 270-276, 1960.

70. Hunt, J.N.

The osmotic control of gastric emptying.

Gastro-enterol. 41: 49-51, 1961.

Brit. J. Clin. Pharmacol. 10: 551-554, 1980.

71. Hunt, J.N. and M.T. Knox.

Regulation of gastric emptying.

Handb. Physiol. 4: 1971-1935, 1968. 
72. Hunt, U.N., D.F. Stubbs

The volume and energy contenit of meals as determinants of gastric emptying.

J. Physiol. 245: 209-225, 1975.

73. Jenkinson, D.H., I.K.M. Morton

The rol of alpha and beta adrenergic receptors in some actions of catecholamines on intestinal smooth muscle.

J. Physiol. 188: 387-402, 1967.

74. Kasper, H.

Enahrungsmedizin und Diatetik.

München, Urban und Schwarzenberg, 1980.

75. Keeffe, E.B., D.K. Lowe, J.R. Goss el al

Gastro-intestinal symptoms of inarathon rumners.

West. J. Med. 141: 481-484, 1984.

76. Konturek, S., J. Fasler and W. Obtulowicz.

Effect of exercise on gastro-intestinal secretions.

J. Appl. Physiol. 34: 324-328, 1973.

77. Launiala, $\mathrm{K}$.

The mechanisms of diarnhea in congenital disaccharide malabsorption.

Acta Paed. Sicand 57: 425-432, 1968.

78. Lepkovski, S., M.K. Dimich, F. Furuta et al.

Stomach and upper intestine of the rat in the regulation of food intake

J. Nutr. 105: 1491-1499, 1975.

79. Levitan, R., J.S. Fordtran, B.A. Burrows et al

Water and salt absorption in the human colon.

J. Clin. Invest. 41: 1754, 1962.

80. Maron, M.B., S.M. Horvath

The marathon; a history and review of the literature.

Med. Sci. Sports 10: 137-150, 1978.

81. Marvola, M., L. Lehmussari and L. Ninimall.

The effects of osmotic pressure on the intestinal absorption of sulfagurazol annnd ethanol in the rat.

Drug. Res. 30: 1631-1634, 1980.

82. Meeroff, J.C., V.L. Go, S.F. Philips

Control of glastric emptying by osmolarity of duodenal contents in man.

Gastro-enterology 68: 1144-1151, 1975.

83. Mertz, D.P.

Flüssigkeits- und Elektrolytbewegungen durch gastro-intestinale Membranen:

Salzsăure-Bildung im Magen und intestinaler Wassertransport.

Klin. Wochenschr, 45: 57-68, 19676. 
84. Meyers, J.H., I.L. McGregor, R. Gueller, et al. ggmm Tc tagged chicken liver as a marker of solid food in the human stomach. Am. J. Digest Dis. 21: 296-303, 1975.

85.Meyer, J.H.

Gastric emypting of ordinary food: effect of antrum on particle size.

Am. J. Physiol. 239: 133, 1980.

86. Miller, D and R.K. Crane.

The digestive function of the epithelium of the small intestine.

Biochem. Biophys. Acta. 52: 293-298, 1961.

87. Mollison, C.N.

Effect of pancreatic insufficiency and intestinal lactase deficiency on the gastric emptying of starch and lactose.

Gut 9: 737, 1968.

88. Moore, J.G., B.E. Christian, R.E. Coleman

Gastric emptying of varying meal weight and composition.

Dig. Dis. Sci. 26: 16-22, 1981.

89. Moran, R.H. and P.R. McHugh.

Distinctions among three sugars in their effects on gastric emptying and satiety. Am. J. Physiol. 241: 25-30, 1982.

90. McGilvery, R.W.

The use of fuels for muscular work.

In: Metabolic adaptation to prolonged physical exercise.

Eds.: H. Howald, J.R. poortmans, Birhauser Verlag, 1975.

91. McHugh, P.R., T.H. Moran

Calories and gastric emptying: a regulatory capacity with implications for feeding.

Am. J. Physiol. 236: 254-260, 1979.

92. Mchugh, P.R., T.H. Moran and J.B. Wirth.

Post-pyloric regulation of gastric emptying in rhesus monkeys.

Aim. J. Physiol. 243: 408-415, 1982.

93. Neufer, P.D., D.L. Costill, W.J. Fink, et al.

Effect of exercise mode and carbohydrale composition on gastric emptying.

Med. Sci. Sports Exer. 18: 658-662, 1986.

94. Newsholme, A., A.R. Leech

Biochemistry for the medical sciences. pp. 425-426.

John Whiley and sons 1983 .

95. Noirot, S., M. Quqged and A. Girard-Globa.

Comparative effects of some carbohydrates on serum sugars, triglycerides and digestive hydrolases.

Reprod. Nutr. Develop. 21 (5A): 727-735, 1981. 
96. Oektedalen, O., P. Flaten, P.K. Opstad

LPP and gastric response to a liquid meal and oral glucose during prolonged severe exercise,caloric deficit and sleep deprivation.

Scand. J. Gastro-enterol. 19: 619-624, 1982.

97. Peat, C.B. S.H. Snijder

Opiate receptors: demonstration in nervous tissue.

Science 19: 1367-1369, 1973.

98. Ramisbottom, N., J.N. Hunt.

Effect of exercise on gastric emptying and gastric secretion.

Digestion 10: 1.8, 1974.

99. Rees, M.R., R.A. Clark, C.O. Holdsworth

The effect of beta adrenoceptor agonists and antagonists on gastric emptying in man.

Effect of exercise on gastric emptying and gastric secretion.

Digestion 10: 1-8, 1974.

100. Rowell, L.B., J.R. Blackman, R.A. Bruce

Indocyanine-green clearance and estimated hypatic blood flow during mild exercise in upright men.

J. Clin. Invest. 43: 1677-1690, 1964.

101. Ruppin, H., S. Bar-Meir, H. Soergel

Effect of liquid formula diets on proximal gastro-intestinal function.

Dig. Dis. Sci. 26: 202-207, (1981).

102. Saltin, B., L. Hermansen

Glycogen stores and prolonged severe exercise.

In: Blix G. (ed.) Nutrition and physical activity, pp. 32-44.

Almquist and Wiksells, Uppsala, 1967.

103. Saltin, B.

Aerobic work capacity and circulation at exercise in man: with special reference to the effect of prolonged exercise and/or heat exposure.

Acta Physiol. Scand. 62: 1-52, 1964.

104. Saris, W., M. van Erp-Baart, F. Brouns

Nutritionall problems in professional cyclists.

In preparation.

105. Seiple, R.S., V.M. Vivian, E.L. Fox

Gastric emplying characteristics of two glucose polymer-electrolyte solutions.

Med. Sci. Sports and Exercise 15: 366-369, 1983.

106. Sessions, R.F., V.H. Reynolds, J.L. Ferguson

Correlation between intraduodenal osmotic pressure changes and

Cr51-blood volumes during induced dumping in men with normal stomachs.

Surgery 52: 266-279, 1962. 
107. Shapiro, H., E.R. Woodward

Inhibition of gastric motility by acid in the duodenum.

J. Appl. Physiol. 8: 121-127, 1955.

108. Schaub, N., H.P. Spicktin, G.A. Stalder

Ischamische Kolitis als Ursache einer Darmbluting bel Marathonlauf?

Schweiz. med. Wschr. 115: 13, 1985.

109. Simko, V., W.G. Linscheer.

Absorption of different elemental diets in a sort-bowel syndrome lasting 15 years.

Dig. Dis. Sci. 21: 419-425, 1976.

110. Silk, D.B.A. and P.P. Keohane.

Formulation of enteral diets.

Clinical Nutrition, pp 125-132, 1981.

111. Sladen, G.E., A.M. Dawson

Interrelationships between the absorption of glucose, sodium and water by the normal human jejunum.

Clin. Sci. 36: 119-132, 1969.

112. Sladen, G.E., A.M. Dawson

Effects of flow rate and the absorption of glucose in a steady state perfusion system in men.

Clin. Sci. 36: 133-145, 1969.

113. Spickard, W.A.

Blocking out a tough opponent.

Me

114. Stamford, B.

A stitch in the side.

Phys. Sports Med. 13: 187, 1985.

115. Stemper, T.J., A.R. Cooke

Effect of a fixed pyloric opening on gastric emptying in the cat and dog.

Am. J. Physiol. 23: 915, 1976.

116. Sullivan, S.N.

The gastro-intestinal symploms of running.

New Engl. J. Med. 304: 915, 1981.

117. Sullivan, S.N., N.C. Champion, N.D. Christofides

Gastro-intestinal regulation peptide responses in longl distance runners.

Phys. Sports Med. 12: 77-82, 1984.

118. Thompson, R.G., J.T. Hayford and J.A. Hendrix.

Triglyceride concentrations: the disaccharide effect.

Science 206: 838-839, 1979. 
119. Torsdottir, 1., M. Aplsten and O. Andersson.

Effect of different starchy foods in composite meals on gastric emptying rate and glucose metabolism.

Human Nutr. Clin. Nutr. 38c: 329-338, 1979.

120. Varro, G.E., J.A. Harris, J.E. Geenen

Effect of decreased local circulation on the absorptive capacity of a small intestine loop in the dog.

Am. J. Dig. Dis. 10: 170-177, 1965.

121. Wade, O.L., B. Combes, A.W. Chilos et al

The effect of exercise on the splanchnic blood flow and splanchnic blood volume in normal men.

Clin. Sci. 15: 457-463, 1956.

122. Wahlquist, M.L., E.G. Wilmhurst and C.R. Murton.

The effect of chain length on glucose absorption and the related metabolic responses.

Am. J. Clin. Nutr. 31: 1998-2001, 1978.

123. Williams, J.H., M. Mager, E.D. Jacobson

Relationship of mesenteric blood flow on intestinal absorption of carbohydrates.

J. Lab. Clin. Med. 63: 853-863, 1964.

124. Wilson, F.H. (ed).

Sugars, in Intestinal Absorption.

W.B. Saunders, p. 69, 1962. 


\section{CHAPTER VIII: GENERAL DISCUSSION AND CONCLUSIONS}

'You are what you eat' and "eat to win' are popular statements from the athletic world which have had a large influence on the sporting population during the last decade.

Nutrition has become important with respect to performance at the time that athletes have reached their limits in training volume and -intensity. This has led to a renewed interest among athletes, coaches and exercise physiologists in the role of nutrition and the influence of gastro-intestinal problems on physical performance and well being. Clear cut nutritional counseling, however, is often difficult for a number of reasons.

First of all there is no generally accepted nutritional recommendation for athletes involved in heavy physical training. In contrast, most countries have accepted standards for the recommended daily allowance (RDA) of nutrients, given for different age groups, sexes, as well as different levels of physical activity. The RDA for people involved in heavy physical work is normally derived from studies done among miners and lumberjacks. Information about the daily requirements of athletes, who with respect to the relative work intensities differ from miners and lumberjacks, is lacking.

Another reason for the absence of clear nutritional advises for athletes is the diverse outcome and conflicting results present in the large number of studies that have been done on the influence of specific nutrients on metabolism and performance. Although such differences often can be explained by the wide variation in age, training status, duration, intensity and type of exercise as well as the dose of nutrients given, it makes generalization difficult.

A third reason is the lack of information from controlled studies about the causes of gastro-intestinal problems during exercise. This situation leads to a diversity of opinions often based on subjective experience and/or misinterpretation of available studies.

In the present work an attempt was made to analyze the dietary problems that occur in the case of strenuous exertion. The two main goals were:

1) To gather information about diet and nutrition problems in the elite athlete under field circumstances.

2) To perform experiments in which the effects of diet manipulation on nutritional and metabolic parameters could be studied in a laboratory setting as close as possible to the practical situation.

The results of the available literature show that athletes have altered eating patterns and have an increased number of in between meals on days when training is intensive and resting hours are limited. As a result, foodstuffs are selected that are often energy rich but low in micronutrients. The conse- 
quence may be a decreased nutrient density, with the risk of long term marginal intakes of micronutrients, whereas fat intake may be too high (see Chapter 1). Therefore it should be advised to teach the athletes about the selection of high quality foods. A prerequisite for adequate food selection however is the availability of the foods desired in the immediate surrounding. Especially sport canteens at training centers should therefore adjust the foods items offered toward a variety of carbohydrate $(\mathrm{CHO})$ and dietary fiber rich foods among which full grain products, fresh fruits and vegetables.

Apart from this problem it has been observed that an adequate energy intake from conventional $\mathrm{CHO}$ rich foods may become impossible on days at which energy expenditure is increased above $20 \mathrm{MJ}$ and athletes cope with physical exhaustion. The results from the present work (Chapter II) give evidence that a high $\mathrm{CHO}$ content of the diet perse is not a guarantee for an adequate $\mathrm{CHO}$ and energy intake during days of hard sustained physical exercise. In this case the addition of liquid foods to the normal meals during long lasting exercise has proved to be efficient with respect to maintaining energy balance and improving performance (Chapter III).

The observation that athletes who consumed a conventional $\mathrm{CHO}$ rich diet, with a mean protein intake of $1.7 \mathrm{~g} \cdot \mathrm{kg}^{-1}$.day-1, were not able to maintain nitrogen balance, questions the validity of an extrapolation of the RDA for protein intake, derived from studies on 'normal' populations, towards athletes working at the upper limits of human performance.

The fact that diet manipulation on the one hand led to a maintenance of energy and $\mathrm{CHO}$ balance but on the other hand did not lead to a maintenance of nitrogen balance whenever protein intake was less than 1.5 g. kg- ${ }^{-1}$ day- ${ }^{-1}$ further provides evidence that the daily protein requirements of athletes involved in heavy sustained exercise are higher than the RDA value for normally active people and will be in the range of 1.5 to $1.8 \mathrm{~g} . \mathrm{kg}-1$ (Chapter III and IV). However the present data do not elucidate whether a possible adaptation to a 'relative' low protein intake occurs when exhausting exercise is repeated over a prolonged period of time. Such an adaptation was observed, as a result of training, when non exhaustive exercise was performed (Gontzea, 1975).

Measures to increase $\mathrm{CHO}$ intake are beneficial for performance. The relation of quantitative $\mathrm{CHO}$ intake to the amount of $\mathrm{CHO}$ stored and physical performance capacity has been proven in a large number of studies.

In the present work it was shown that performance was significantly increased by the addition of a $\mathrm{CHO}$ rich liquid to an aiready $\mathrm{CHO}$ rich conventional diet (Chapter V). It was further demonstrated that additional $\mathrm{CHO}$ intake leads to protein sparing and enhances recovery of the glycogen stores in the first $24 \mathrm{~h}$ after exercise. 
An increased consumption of mono- and di-saccharides in the daily diet has been a matter of discussion during the last 20 years as being a risk factor for the development of cardiovascular disease and of insulin resistance with subsequent diabetes (Davidson, 1965). The advice given to athletes to ingest $\mathrm{CHO}$ concentrated liquids in addition to the normal diet or as a substitute for normal food during exercise may therefore appear conflicting.

There are however a number of reasons to suggest that the supplementation of $\mathrm{CHO}$ beverages in the exercising athlete is not harmful in this respect. It is observed that a high $\mathrm{CHO}$ intake during exercise, especially mono- and di-saccharides, does not lead to a large increase in plasma insulin (chapter V1). From this observation and from the studies that showed that exogenous $\mathrm{CHO}$ is readily oxidized during exercise it is hypothesized that a high $\mathrm{CHO}$ intake during exercise is not harmful with respect to the development of insulin resistance.

Extra $\mathrm{CHO}$ intake at rest, if desired, should be limited to supplementation at the end of a normal meal in order to realize a smooth gastric emptying and to avoid large fluctuations in plasma insulin.

High plasma insulin levels after intake of $\mathrm{CHO}$ solutions at rest, in the fasting state, as well as a decreased physical performance whenever exercise is started at the moment of hyperinsulinemia, have been observed in several studies. However, the situation as well as the nutritional status in which the athletes were tested in these studies differed with respect to the situation in sports practice. (Chapter VI). The present work provides evidence that the ingestion of $\mathrm{CHO}$ containing liquids in the fed state during warming-up has no harmful effect on the blood glucose level nor on subjective fatigue during exercise. In contrast, blood glucose can be maintained at levels significantly above control values when ingestion is done properly. With respect to dietary counseling of athletes it should therefore be stressed that $\mathrm{CHO}$ containing beverages should only be ingested at the end of warming-up whenever this is followed by exercise or 5-3 min prior to the start, when warming-up is not possible.

Fructose as an alternative $\mathrm{CHO}$ source has been suggested as being of advantage because of its insulin independency. The argument is that fructose does not trigger insulin secretion and thus allows maximal lipolytic activity while at the same time supplying $\mathrm{CHO}$. In the present work however it was shown that supplementation with a $\mathrm{CHO}$ rich liquid, $50 \%$ of which consisted of free fructose, resulted in a significantly increased $\mathrm{CHO}$ metabolism and decreased fat metabolism (Chapter III). Moreover, the subjects receiving this dietary supplement had the largest protein degradation as measured from nitrogen excretion. These results, supported by the recent work of Tappy et al (1986), contradict the hypothesis of enhanced fat metabolism after fructose intake compared to glucose intake.

To what extent food and fluid intake during exercise leads to the development 
of abdominal problems is not entirely clear (Chapter VII). It is generally accepted that exercising with a full stomach leads to gastric distress. The advice given therefore is that the last meal should be taken at least $3 \mathrm{~h}$ prior to exercise. However with respect to the abdiominal problems occurring during exercise this may be too short because it has been observed that a normal meal has not passed the stomach within 5-7 $\mathrm{h}$ depending on its composition. The finding that homogenization of a meal causes a marked reduction in gastric emptying time and that liquid meals poor in dietary fiber and fat have a high emptying rate is of importance with respect to the ingestion of liquid meals prior to exercise or during exercise.

It thas been observed that gastric emptying and food absorption in the gut is not changed with exercise intensities up to $70 \% \mathrm{VO}_{2}$ max. However most of the studies have been done during cycling exercise and data from running experiments are lacking. It has been suggested by coaches that the occurrence of abdominal complaints and diahrrea in runners may be related to poor absorption. However, the observation that this occurs mainly in runners and not in cyclists suggests that the type of movement may be an important factor in the etiology of gastro-intestinal disturbances. It can be hypothesized that changes in gastro-intestinal motility due to increased reflex activity of the intestinal wall, caused by the pounding actions during running, may trigger the occurrence of intestinal cramps and that ischemic necrosis due to severe dehydration may cause the observed bloody diahrrea in the runner. Until now no controlled studies dealing with this problem are available, which indicates a need for the initiation of research in this field.

The results of the work presented here deal mainly with dietary problems related to energy consumption and energy exchange. Although the role of micronutrients has briefly been discussed in Chapter I, it cannot be concluded from the data presented to what extent micronutrients may have played a metabolic role in the exercise situations described, nor what the daily requirements under these circumstances are.

In conclusion the most important observations in the present work can be summarized as follows :

- elite athletes have changed eating patterns and consume $30-40 \%$ of total energy intake as small in-between meals consisting mainly of energy dense foodstuffs.

- with increasing energy expenditures there is an increased selection of foods and liquids that are high in energy, sweet, and convenient.

- there is an energy threshold of approximately $20 \mathrm{MJ}$ per day, above which athletes are unable to consume enough normal food in order to maintain energy balance. 
- this threshold occurs mainly through a decreased appetite and a limited tolerance of the stomach to a large food intake under exercise circumstances.

- for the degree of exercise intensity described, the normally recommended CHO intake of $60 \mathrm{en \%}$ is not sufficient to maintain "CHO balance".

- the supplementation of a CHO containing beverage in addition to the normal meals and during exercise is shown to be an effective measure to maintain energy - and "CHO balance" at higher energy expenditure levels.

- muscle glycogen supercompensation can be obtained within 24 h.after exhausting exercise by the supplementation of a CHO beverage to the normal diet.

- under the exercise circumstances described a protein requirement of $>1.5 \mathrm{~g} \cdot \mathrm{kg}^{-1} \cdot$ day $^{-1}$ is required to maintain nitrogen balance.

- when energy balance is negative, $1.7 \mathrm{~g}$ of protein . $\mathrm{kg}^{-1} . \mathrm{day}-1$ is insufficient to meet the needs.

- an increased $\mathrm{CHO}$ intake induces protein sparing.

- despite a high $\mathrm{CHO}$ intake during exercise and the resulting significantly increased blood glucose levels, lipolysis is stimulated by the execution of exhausting exercise.

- from the data gathered and the literature presented it is tempting to speculate that fructose ingestion during exercise causes some change in intermediate metabolism leading to a stimulation of $\mathrm{CHO}$ metabolism and inhibition of fat oxidation.

It is suggested that for future research in the field of nutrition and exercise the study of elite athletes should be conducted under controlled practical situations.

There is a need to gather data about the daily requirements of nutrients for this specific population. However, the participation of these highly gifted men and women in research will probably be one of the most limiting factors for the attainment of data

\section{REFERENCES:}

1. Davidson, P.C. and M.J. Albrinik. Insulin resistance in hyperglyceridemia Metabolism 14: 1059-1070, 1965.

2. Gontzea, J, R. Sutsescu, and S. Dimitranche. The influence of adaptation to physical effort on nitrogen balance in man. Nutrition Reviews 11:231, 1975.

3. Tappy, L., L.P Randin, J.P. Fellber, et al. Comparison of thermogenic effect of fructose and glucose in normal humans.

Am. لJ. Physiol. 250: E718-E7.24, 1986. 


\section{HOOFDSTUK 8 Samenvatting en konklusies}

"You are what you eat" en "eat to win" zijn populaire uitspraken afkomstig uit de wereld van de topsport welke gedurende de laatste 20 jaar een flinke invloed hebben gehad op de naar fitheid strevende mens. De voeding is een belangrijk aspekt bij het presteren geworden nu atleten met betrekking tot trainingsvolume en -intensiteit hun limiet hebben bereikt. Dit heeft bij trainers, coaches en inspanningsfysiologen geleid tot een hernieuwde interesse in de rol van voeding op het lichamelijk presteren en welzijn.

Het verstrekken van uniforme voedingsrichtlijnen is om een aantal redenen echter vaak moeilijk.

Op de eerste plaats bestaat er geen algemeen aanvaarde voedingsaanbeveling voor atleten die aan zware lichameljike training onderhevig zijn. Daarentegen hebben de meeste landen erkende tabellen met dagelijkse aanbevolen voedingskwantiteiten voor verschillende leeftijdsgroepen, sexe en niveaus van lichamelijke inspanning. De aanbevelingen voor mensen met zware lichamelijke arbeid zijn meestal verkregen uit onderzoekingen welke uitgevoerd zijn bij mijnwerkers en havenarbeiders. Informatie over de behoeften van atleten, die met betrekking tot de relatieve arbeidsintensiteit verschillen van mijnwerkers en havenarbeiders ontbreekt.

Een andere reden is het verschil in, en soms de strijdigheid tussen, de vele resultaten die verkregen zijn uit onderzoekingen naar de invloed van specifieke voedingsstoffen op de stofwisseling en het prestatievermogen. Alhoewel dergelijke verschillen vaak verklaard kunnen worden door de grote variatie in leeftijd, trainingsstatus, duur, intensiteit en type van de inspanning alsmede de hoeveelheid voedingsstoffen welke ingenomen is, is generalisatie op grond van deze resultaten moeilijk.

Een derde reden is het gebrek aan informatie uit goed gecontroleerd onderzoek omtrent de oorzaken van maagdarmproblemen bij lichamelijke inspanning.

Deze situatie leidt tot een diversiteit van opinies, vaak gebaseerd op subjectieve ervaring en/of foutieve interpretaties van de beschikbare gegevens en onderzoekingen.

In het voorliggende werk is een poging ondernomen om de voedingsproblemen, welke inherent zijn aan lichamelijke inspanning te analyseren. 
De twee belangrijkste doelen waren daarbij:

1. Het verzamelen van informatie over de voedingsgewoonten en -problemen bij goed getrainde atleten in hun dagellijkse situatie.

2. Het uitvoeren van experimenten, waarbij het effekt van voedingsmanipulatie op voedings en metabole parameters kan worden bestudeerd in laboratoriumomstandigheden welke de praktijksituatie zoveel mogelijk benaderen.

De beschikbare resultaten uit de literatuur tonen aan dat atleten andere eetgewoonten hebben en een toegenomen aantal tussenmaaltijden gebruiken op dagen dat er zeer intensief getraind wordt en de tijd voor rust en herstel beperkt is. Omdat voor dergelijke tussenmaaltijden veelal vette en zoete voedingsmiddelen gekozen worden, met een laag gehalte aan micronutriënten, is een achteruitgang van de "nutrient density" ( de aanwezigheid van vitaminen, minerallen en sporenelementen in relatie tot het energiegehalte), met het risiko van marginale micro-nutriënten inneming aanwezig, terwijl anderzijds de vetkonsumptie hoger is dan wenselijk (zie hoofdstuk I).

Het is daarom aan te bevelen om sportmensen te adviseren over de dagelijkse keuze van de juiste voedingsmiddelen. Een voorwaarde voor zo"n keuze is echter de beschikbaarheid van de betreffende voedingsmiddelen in de onmiddellijke omgeving. Daarom moeten in het bijzonder de sportkantines en de trainingscentra erop toe zien dat er een gevarieerde keuze mogelijkheid bestaat voor $\mathrm{KH}$ - en voedingsvezelrijke voedingsmiddelen zoals volkoren produkten, vers fruit en groenten.

Naast dit probleem toont de praktijk dat een adekwate energie inneming door middel van normale voedingsmiddelen onmogelijk kan worden gedurende dagen waarop het energieverbruik meer dan $20 \mathrm{MJ}$ (5000 kcal) bedraagt en de sporter blootstaat aan lichamelijke uitputting. De resultaten van het voorliggende onderzoek (hoofdstuk II) bewijzen dat een hoog koolhydraatgehalte van de voeding op zich geen garantie is voor een voldoende inneming van $\mathrm{KH}$ en energie gedurende dagen met zware langdurige inspanning. De toevoeging van voeibare energiekonsentraten aan het normale voedsel tijdens het verrichten van langdurige lichamelijke inspanning is in dit geval adekwaat gebleken met betrekking tot het handhaven van de energiebalans (hoofdstuk III).

De waarneming dat atleten die een $\mathrm{KH}$-rijke voeding konsumeren, samengesteld uit normale voedingsmiddelen, met daarbij een gemid- 
delde eiwitinneming van $1.7 \mathrm{~g} \mathrm{~kg}^{-1} . \mathrm{dag}^{-1}$, niet in staat waren om hur stikstofbalans te handhaven, roept vragen op over de juistheid var een extrapolatie van de aanbeveling voor eiwit, verkregen uit onder. zoekingen bij de "normale"bevolking, naar atleten die lichamelijks arbeid verrichten tot aan de grenzen van het menselijke vermogen.

Het gegeven dat $\mathrm{KH}$ suppletie enerzijds leidt tot het handhaven van $\mathrm{d}$ energie- en "KH"-balans, doch anderzijds niet tot het handhaven var de stikstofbalans, indien de dagelijkse eiwitinneming minder is dar 1.5 g.kg-1.dag-1, bewijst eveneens dat de dagelijkse eiwitbehoefte van intensief trainende atleten hoger is dan de aanbevoler hoeveelheid voor normaal aktieve mensen ( hoofdstuk III en IV).

De hier vermelde gegevens wijzen er echter niet op of er mogelijl een aanpassing aan een "relatief lage" eiwit inneming optreedt indie herhaald uitputtende arbeid wordt verricht gedurende een langert periode. Een dergelijke adaptatie ten gevolge van training wer waargenomen tijdens het verrichten van submaximale, niet uitput tende, arbeid (Gontzea, 1975).

De toegenomen konsumptie van mono- en di-sacchariden in de dage lijkse voeding is als risikofaktor voor de ontwikkeling van hart- el vaatziekten en van diabetes gedurende de laatste 20 jaar ondenwer van diskussie geweest (Davidson, 1965). Het advies aan sporters on $\mathrm{KH}$-oplossingen in te nemen tijdens de inspanning in plaats van $d$ normale voeding of als toevoeging aan de normale maaltijden met he doel om de absolute $\mathrm{KH}$ inneming te vergroten, kan daarom strijdi lijken. $\mathrm{Er}$ is echter een aantal redenen aan te voeren waarom dit i bepaalde omstandigheden niet zo is. Zo leidt de inneming van veel $\mathrm{Kr}$ tijdens inspanning niet tot een sterke verhoging van de plasmi insulinespiegel. Naar aanleiding van deze waarneming en van $d i$ onderzoekingen die aantonen dat de hoeveelheid $\mathrm{KH}$ die tijden inspanning wordt ingenomen, wordt geoxideerd, kan de hypothes worden gesteld dat een grote $\mathrm{KH}$-inneming tijdens het verrichten va zware lichamelijke inspanning geen nadelige gevolgen hoeft $t$ hebben .

De samenhang tussen KH-konsumptie enerzijds en de grootte van d $\mathrm{KH}$-voorraad in het lichaam en het lichamelijk prestatievermogen an derzijds is in een reeks van onderzoekingen aangetoond. In he voorliggende onderzoek wordt aangetoond dat het prestatievermoge signifikant verbeterde na de toevoeging van een KH-rijke vloeistc aan een reeds $\mathrm{KH}$-rijke voeding bestaande uit normale voedings middelen (hoofdstuk $\mathrm{V}$ ). Tevens wordt aangetoond dat de additionel $\mathrm{KH}$-inneming bij het verrichten van langdurige inspanning ee eiwitsparend effekt heeft (hoofdstuk IV) en dat het herstel van $d$ 
glycogeenvoorraad gedurende 24 uur na de inspanning is versneld. Fruktose is de laatste tijd, vanwege zijn "insuline onafhankelijkheid", aanbevolen als alternatieve $\mathrm{KH}$ bron voor sporters. Het argument is dat fruktose de secretie van insuline niet stimuleert, waardoor een maximale lipolytische aktiviteit mogelijk is, terwijl tegelijkertijd koolhydraat wordt toegevoerd. In het voorliggende werk wordt echter aangetoond dat suppletie van een $\mathrm{KH}$-oplossing, welke voor $50 \%$ uit vrij fruktose bestaat, resulteert in een sterk toegenomen $\mathrm{KH}$ - en een afgenomen vetmetabolisme (hoofdstuk III).

De proefpersonen die deze voedingsmanipulatie ondergingen, blijken tevens de grootste eiwitafbraak te hebben, gemeten aan de hand van de totale stikstofuitscheiding. Deze resultaten, welke ondersteund worden door het recente werk van Tappy et al (1986), spreken de hypothese over een toegenomen vetverbranding na fruktose-, in vergelijking tot na glucoseinneming ,tegen.

In verschillende onderzoekingen is een hoge plasma insuline spiegel na de inneming van $\mathrm{KH}$-oplossingen in nuchtere toestand tijdens rust waargenomen, en daaraan gekoppeld een afname van het fysieke prestatievermogen, indien de prestatie wordt begonnen op het moment dat de insuline spiegel hoog is. De situatie en de voedingstoestand waarin de atleten in deze onderzoekingen getest werden verschilt echter van die waarin de sporter zich in de praktijk bevindt (hoofdstuk VI).

De in dit proefschrift gepubliceerde resultaten tonen aan dat de inneming van $\mathrm{KH}$ - oplossingen na een ontbijt en tijdens een warmingup geen nadelig effekt heeft op de bloedglucosespiegel of op de subjektieve vermoeidheid. Het blijkt daarentegen dat de bloedglucosespiegel signifikant verhoogd blijft ten opzichte van de kontrole waarden indien de inneming op de juiste wijze geschiedt. Met betrekking tot het voedingsadvies aan de sporter zou daarom benadrukt moeten worden dat de inneming van $\mathrm{KH}$-oplossingen alleen zou moeten plaatsvinden aan het einde van de warming-up indien deze direkt wordt gevolgd door de wedstrijd of ten hoogste 3-5 minuten voor de start indien een warming-up niet mogelijk is.

In welke mate de inneming van voedsel en vocht tijdens de wedstrijd leidt tot het ontstaan van buikklachten is niet geheel duidelijk (hoofdstuk VII). Het is algemeen aanvaard dat het sporten met een volle maag kan leiden tot buikklachten. Derhalve wordt het advies gegeven om de laatste maaltijd tenminste 3 uur voor de inspanning te nuttigen. Met betrekking tot de buikklachten welke tjjdens de inspanning op kunnen treden, kan dit echter te kort zijn omdat de maaglediging van een normale maaltijd, afhankelijk van de samen- 
stelling, langer dan 5 uur kan duren. De konstatering dat homogenisering van een maaltijd leidt tot een duidelijke vermindering van de verblijftijd in de maag en dat vloeibare maaltijden met een laag gehalte aan voedingsvezel en vet een snelle maaglediging ten gevolge hebben, is een bijzonder belangrijk aspekt met betrekking tot de voedselkonsumptie tijdens langdurige arbeid. Sportbegeleiders hebben wel gesuggereerd dat het optreden van buikklachten en diarree bij hardlopers samenhangt met een slechte absorptie van het ingenomen voedsel. Er zijn echter observaties dat de maaglediging en voedingsstoffenabsorptie in de darm niet verandert bij arbeidsintensiteiten tot $70 \% \mathrm{VO}_{2}$ max. Bijna alle beschikbare onderzoekingen zijn uitgevoerd tijdens fietsbelasting en gegevens van loopexperimenten zijn niet voorhanden. Het gegeven dat de klachten vrijwel alleen optreden bij hardlopers en nauwelijks bij wielrenners, wijst erop dat de manier van voortbewegen een belangrijke ontstaansfaktor kan zijn. De hypothese kan gesteld worden dat veranderingen in maagdarmmotiliteit ten gevolge van een toegenomen reflexaktiviteit van de darmwand, die wordt veroorzaakt door de schokkende bewegingen tijdens het hardlopen, het ontstaam van darmkrampen veroorzaakt, terwijl ischaemische necrose ten gevolge van ernstige dehydratie de oorzaak kan zijn van de bloedige diarree welke bij hardlopers is waargenomen.

Tot op heden zijn er echter geen gegevens van gekontroleerd onderzoek over dit probleem beschikbaar.

\section{konklusies}

Aan de hand van de hier verzamelde gegevens en literatuur kan gesteld worden dat op dagen van langdurige inspanning, voor wat de voedselkonsumptie betreft, een drempelwaarde bestaat van ongeveer $20 \mathrm{MJ}$. Daarboven is voedselinneming moeilijk dan wel onmogelijk. De verminderde eetlust ten gevolge van intensieve duurinspanning en de veelal door vast voedsel veroorzaakte overlast onder deze omstandigheden zijn daarbij waarschijnlijk de belangrijkste faktoren.

Voor inspanningen van de beschreven intensiteit is de normaal aanbevolen inneming van $60 \mathrm{en \%} \mathrm{KH}$ in de vorm van gewone voedingsmiddelen niet voldoende om de "KH-" en energiebalans te handhaven. Indien $\mathrm{KH}$ oplossingen worden gesuppleerd wordt de "KH-" en energiebalans gehandhaafd en neemt het prestatie vermogen toe.

Bij een dergelijke inspanning bedraagt de minimale eiwitbehoefte van de sporter vermoedelijk 1.5 tot 1.8 gram per kilogram 
lichaamsgewicht per dag hetgeen hoger is dan de gebruikelijke

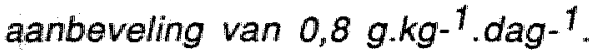

Bij langdurige uitputtende inspanning treedt, ondanks de inneming van geconcentreerde $\mathrm{KH}$ oplossingen, een versterkte lipolyse op.

Door middel van supplementering met $\mathrm{KH}$ concentraten kan binnen 24 uur een supercompensatie van het glycogeengehalte van spierweefsel worden bereikt.

Door de verkregen resultaten wordt de suggestie gewekt dat de inneming van fruktose bij lichamelijke inspanning leidt tot een stimulering van de $\mathrm{KH}$ stofwisseling en een remming van de vetstofwisseling.

In het algemeen kan worden gekonkludeerd dat toekomstig onderzoek op het gebied van de voeding van topsporters moet plaatsvinden onder gekontroleerde doch voor de sportpraktijk relevante omstandigheden.

Het verzamelen van informatie over de dagelijkse behoefte aan voedingsstoffen van topsporters is zeer gewenst. De bereidheid van deze zeer getalenteerde mannen en vrouwen om deel te nemen aan wetenschappelijk onderzoek zal echter een van de meest beperkende faktoren zijn voor het verkrijgen van de gewenste gegevens.

\section{REFERENTIES}

1. Davidson, P.C. and M.J. Albrink Metabolism 14: 1059, 1965

2. Gontzea, J., R. Sutsescu and S. Dimitranche.

The influence of adaptation to physical effort on nitrogen balance in man.

Nutritions Reviews 11: 231, 1975.

3. Tappy, L., L.P. Randin, J.P. Felber, et al.

Comparison of thermogenic effect of fructose and glucose in normal humans.

Am. J. Physiol. 250: E718-E724, 1986. 



\section{NAWOORD}

\section{Een alternatieve route}

De weg die ik bewandeld heb om uiteindelijk dit werk te schrijven was geen gewone weg. Het was een toeristische route door het land van de sport, de lichamelijke opvoeding en uiteindelijk de wetenschap.lk heb geboft dat ilk onder weg zoveel gezien heb en dat ik zoveel vrienden ontmoette die wisten aan te geven welke route voor mij waarschijnlijk de meest boeiende zou zijn.Als aktief wedstrijdschaatser geinteresseerd geraakt in trainingsmethoden en het funktioneren van het menselijk lichaam, volgde ik de opleiding voor bondstrainer, direkt gevolgd door de cursus sportmassage. Op de T-splitsing waar ik toen arriveerde stond een bord richting fysiotherapie en een bord richting lichamelijke opvoeding; het was de laatste richting waar de heer Klauke mij bij het trainersexamen op wees: "voor jou een veel mooiere weg"!

Geprikkell door nieuwsgierigheid belandde ik op de Academie voor Lichameijke Opvoeding te Amsterdam waar mijn belangstelling voor de achtergronden van het menselijk bewegen definitief vorm kreeg. Ik ontdekte dat een snelle manier van leren en tevens studiefinanciering het schrijven van artikelen was en het was de "grote jachtakte" van Hein Ouwersloot die het mij mogelijk maakte om boeiende zaken te beschrijven wanneer de" rest in het water lag". De wind blies in mijn rug toen Niels Lommen een proefwerk als "Chateau neut du

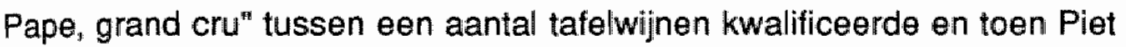
Alkema mij stimuleerde om mijn scriptie over hardrijden op de schaats te publiceren, mijn eerste boekje. Na het behalen van het eindexamen in 1977 bleek al gauw dat het er in de wereld van de lichamelijke opvoeding helemaal niet $z 0$ rooskleurig voorstond. Een afnemend aantal leerlingen, grotere schoolklassen en een overschot aan leraren noopten mij tot het inslaan van een andere weg. leidend naar een funktie bij de Koninklijke Nederlandse Atletiek Unie.

Trainingsleer en sportbegeleiding waren vanaf dat moment niet langer meer hobbyelementen. Na een periode van bijzondere belangstelling voor de training en belastbaarheid van jeugdigen en boeiende diskussies met Ham Kemper en Jos Geisel ging mijn interesse in de richting van de energiehuishouding bij lichamelijke inspanning. De rol van de voeding kwam daarbij naar voren en het was in dat verband dat ik in St Etienne voor het eerst Wim Saris ontmoette, een groentje op het gebied van de sport dacht ik toen, niet wetend dat hij later hoogleraar en tevens een van mijn begeleiders zou worden. Gestuurd door de stimulerende invloed van Hans Keizer volgde de deelname aan een studiedag aan de Universiteit van Limburg met als onderwerp voeding en topsport. Mijn rol van discussieleider wekte de belangstelling van Wander Nederland waar ik korte tijd later een funktie op de wetenschappelijke afdeling zou aanvaarden met als belangrijkste werkgebied voeding bij inspanning. Het was die funktie die mij in de gelegenheid stelde om 
kongressen te bezoeken waar mijn interesse in de rol van de voeding bij inspanning definitief gestalle kreeg. Het was de ontmoeting met Lars Hermansen, Dave Costill en Jack Wilmore die leidde tot de Litspraak dat de wetenschap wellicht een interessante toekomst voor mij verborg. De wens om een andere, meer wetenschappelijke weg te bewandelen werd definitief toen ik mij, gesteund door Rob Binkhorst, Foppe ten Hoor, Lars Hermansen en Wim Saris, aan de Vrije Universiteit van Brussel aanmeldde voor een doktoraatstudie.De bemiddeling van Marcel Hebbelinck leidde tot een licentiaat equivalentie en de bemiddeling van Hartwig Kämpf en Hans Widmer resulteerde in een research grant van Wander Bern. De keuze voor onderzoek viel op Maastricht . Ik verhuisde naar het land van het Bourgondische leven.

Dat ik nu in 1988 in Maastricht kan promoveren dank ik aan een nieuwe promotie regeling, een positief aspekt van het bewind Deetman.

Er is te weinig ruimte om alle andere vrienden die ik onderweg heb ontmoet en die mij hebben gesteund in het telkens weer kiezen van de weg die de grootste uitdaging leek te zijn, te vermelden. Het waren er vele en ik ben ze niet vergeten!

Bijzondere dank ben ik verschuldigd aan Jo Moonen voor zijn hulp bij het zoeken naar proefpersonen die genegen waren om twee keer zeven dagen in ons labotatorium te verblijven en daarbij te fietsen totdat volledige uitputting in zou treden. Mijn proefpersonen heb ik bewonderd voor hun doorzettings vermogen en voor de tranen die soms kwamen als de benen echt niet meer wilden. Voorts dank aan mijn collega's, zonder wie de uitvoering van een project als beschreven in dit proefschrift nooit mogelijk zou zijn geweest. Jolanda, zonder de preciese voedingskontrole en het immense rekenwerk dat daaraan verbonden was zou het werk nooit zijn geworden wat het nu is. Richard, we hebben vaak gelachen over de analyses in de wielrennerspoep en in de -urine. Het feit dat je daar geen dag je neus voor hebt opgehaald, betekent niet dat die voortdurend verstopt zat maar heeft mijn bewondering voor je inzet gewekt ! Trudy, een week lang in een kamertje zonder jouw verzorging zou het einde van het experiment hebben betekend. Een betere moeder hadden de jongens zich tijdens hun verblijf niet kunnen wensen. Paul, een computerleek temidden van een computergestuurd semi-automatsch systeem is als een orkest zonder dirigent. Ik ben je dank verschuldigd voor al die keren dat ik de melodie niet meer wist. Hans, Harm en Fons bedankt voor de assistentie bij het nemen van de spierbiopten; Peter en Gerrit voor het wegwijs maken binnen het inspanningslab; Wil, Peter en Hans voor de biochemische analyses en Ger voor de daarop volgende discussies.

Ed, hoe speel je het telkens weer klaar om "cool" te blijven terwijl alles om ons afbrandt? Beseffend dat het in dit proefschrift beschreven materiaal nog niet de helft is van alles wat wij verzameld hebben, heb ik er vaak aan gedacht wat er allemaal zou zijn mis gegaan zonder jouw laboratoriumexpertise en je grenze- 
loze inzet. Nancy, bedankt voor al je adviezen bij de data- en scriptwerwerking en voor je energieke inzet bij de vervolgstudies. Truus, Mary, Marjon en Rea bedankt voor het vele en uitstekende administratieve werk en voor de inzet tijdens de altijd ongelegen optredende overuren, zonder welke dit proefschrift nu stellig nog niet klaar zou zijn geweest.

Dit proefschrift dankt zijn inhoud mede aan de stimulerende discussies die ilk kon hebben met Lars Hermansen, Herman Adlercreutz, Jack Wilmore, Jacques Poortmans, Eric Newsholme, Per Henric Galbo "Pete Lemon, Peter Soeters en Rob Binkhorst. Zij waren allen betrokken bij de discussie over de pilotstudie en hadden tijd voor mij beschikbaar op het moment dat ik een boel moest leren. "Scientific faults, if you survive them, make you love science more!" Foppe en Wim, ik heb er heel wat gemaakt en ik ben steeds meer gaan houden van de wetenschap die mij zo boeit! Ik realiseer mij dat de ontspannen manier waarop jullie mij hebben begeleid en ook hebben geholpen op tijden dat $\mathrm{ik}$ het beslist niet gemakkelijk had, ertoe heeft geleid dat ik dit proefschrift in de geplande drie en een half jaar op tafel heb gekregen. Ik heb in die periode van jullie altijd weer kritische vragen en stimulerende discussies ontzettend veel geleerd.

Foppe, het duitse woord "Studienvater" is waarschijnlijk het meest treffende dat ik voor je kan bedenken. Ik heb veel aan je "vaderschap" te danken. Wim, je was toch minder "groen" dan ik in St Etienne dacht! Ik hoop nog lang van je kennis te kunnen profiteren.

Het werken aan dit proefschrift was slechts mogelijk door het beperken van de beschikbare tijd voor de mensen en de dingen die mij lief zijn. Ik heb ongetwijfeld mijn beste vrienden in de afgelopen drie jaar tekort gedaan. Ik ben blij te weten dat ik ze hierdoor niet heb verloren.

Lieve Ingmar en Kim, van de weinige uurtjes die wij samen kunnen delen hebben jullie er de laatste tijd zelfs nog wat af moeten staan. Ik vind het fijn dat jullie geduldig wilden wachten op momenten dat samen spelen veel leuker zou zijn geweest. Die uurtjes halen we in !

Lieve Nancy, net verhuisd naar Groot Haasdal zijn er dagen geweest dat ik werkend aan mijn klus meer een kamerplantje voor je was dan een gezellige huisgenoot. Ik heb je steun en je geduld enorm gewaardeerd. Betere tijden liggen voor ons. 
De auteur van dit proefschrift werd geboren op 8 september 1950 te Amsterdam. Na het behalen van van het HBS diploma aan het Alberdinck Thijm college te Hilversum werd de militiaire dienstplicht vervuld. Vanaf 1973 werd de studie lichamelijke opvoeding gevolgd aan de Akademie woor Lichamelijke Opvoeding te Arnsterdam, alwaar in 1977 het diploma werd werkiregen.

In de periode 1977-1980 was de auteur werkzaam als hoofd wan de afdeling opleidingen bij de Koniniklijke Nederlandse Atletiek Unie te Utrecht en was lid van de projektgroep topsport van de Nederlandse Sport Federatie.

In 1978 werd deelgenomen aan de International course on kinanthropometric techniques" aan de vrije universiteit van Brussel. Van 1980-1983 vervulde de auteur de funktle van hoofd van de wetenschappelijke afdeling bij Wander Nederland bw. te Uden. Sinds november 1983 verrichtte de auteur wetenschappelijk onderzoek op het gebied van voeding en inspanning aan de Universiteit van Limburg te Maastricht onder leiding van Prof. Dr. Ir. W. H. M. Saris en Prot. Dr. F. ten Hoor. 